\title{
A CONTINUOUS MODE DATA ACQUISITION TECHNIQUE FOR PROTON RECOIL PROPORTIONAL COUNTER NEUTRON SPECTROMETERS
}

by

E. F. Bennett
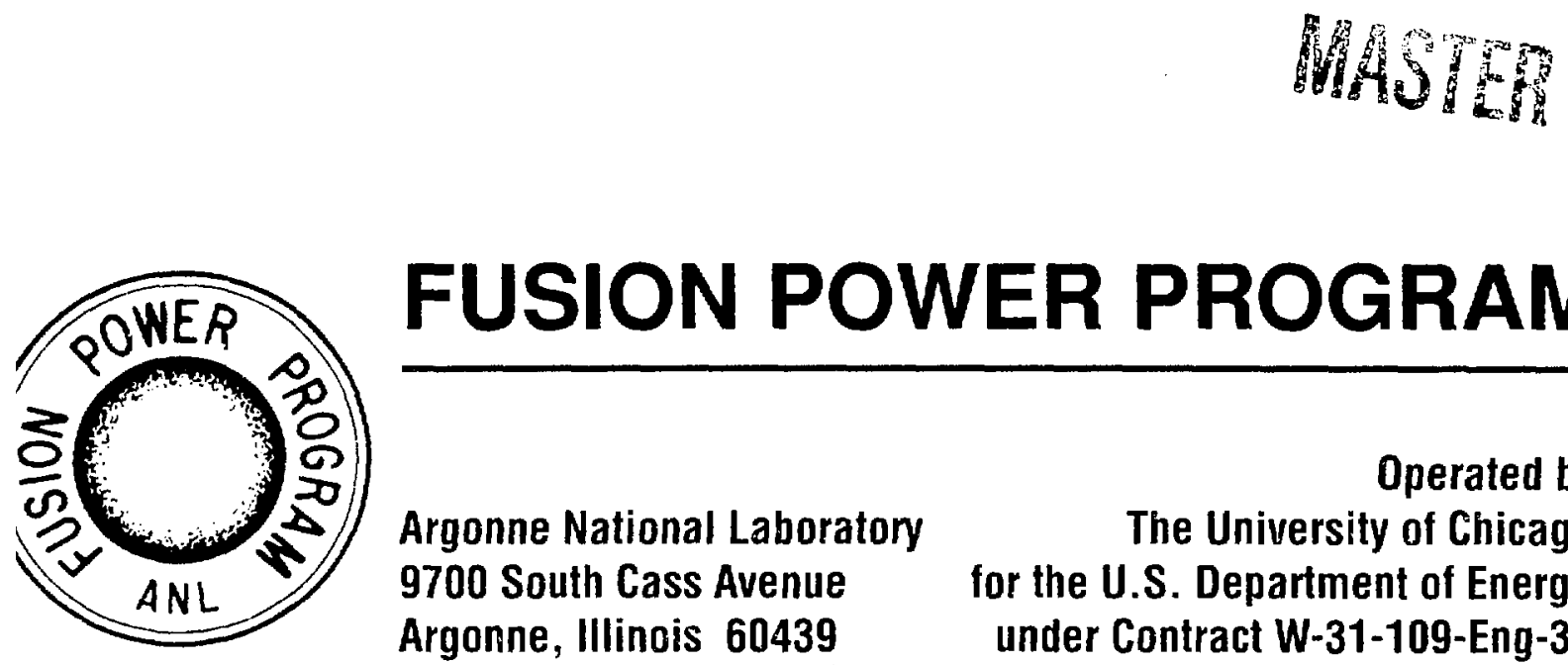

\section{FUSION POWER PROGRAM \\ Operated by}

Argonne National Laboratory 9700 South Cass Avenue Argonne, Illinois 60439 The University of Chicago for the U.S. Department of Energy under Contract W-31-109-Eng-38 


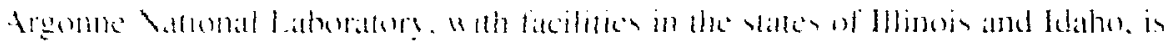

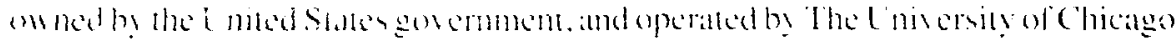
under the prosisiom ol a contrate with the Departmicrat of Energ!

\section{DiSCLAIMER}

This report wats prepared ats an account of work sponsored by an agency of the Inited States Government. Neither the Inited States Government nor any agenes thereof, nor any of their employees. makes any warranty, express or implied, or assumes any legal liability or responsibility for the accuracy. completeness, or usefulness of any information, apparatus, product or procens disclosed. or represents that its use would not infringe privately owned rights. Reference herein to any specific commercial product, process, or service by trade name. trademark. manufaturer, or otherwise, does not necesarrily constitute or imply its endorsement. recommendation. or favoring by the L nited States Government or any agency thereof. The views and opinions of authors expressed herein do not necessarily state or reflect those of the Cnited States Government or any agency thereof.

This report has been reproduced from the best available copy

$$
\text { Available from the }
$$

National Technicai Information Service

NTIS Eneryy Distribution Center

P.O. Box 1300

Oak Ridge. TN 37831

Price: Printed Copy A017

Microfiche AOI 


\section{ARGONNE NATIONAL LABORATORY \\ 9700 South Cass Avenue \\ Argonne, Illinois 60439-4801}

A CONTINUOUS MODE DATA ACQUISITION TECHNIQUE FOR PROTON RECOIL PROPORTIONAL COUNTER NEUTRON SPECTROMETERS

by

E.F. Bennett

March 1989

\section{MASTER:}

Work supported by

Office of Fusion Energy

U.S. Department of Energy

Under Contract W-31-109-Eng-38 


\section{$\underline{\text { Page }}$}

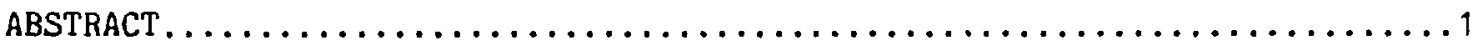

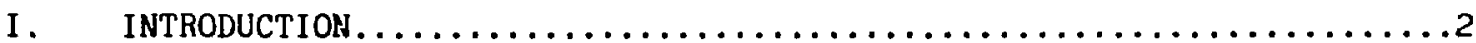

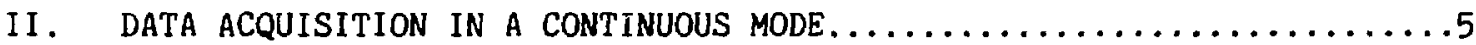

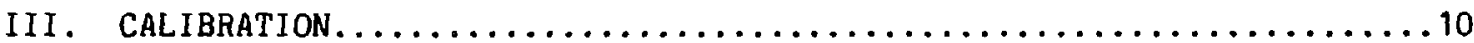

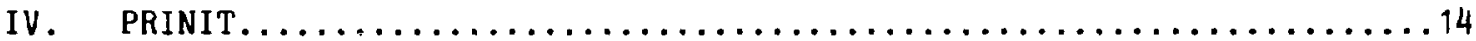

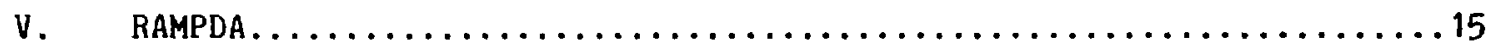

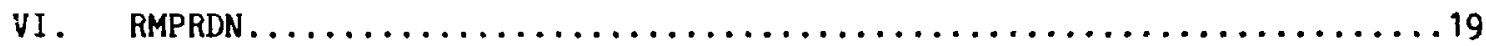

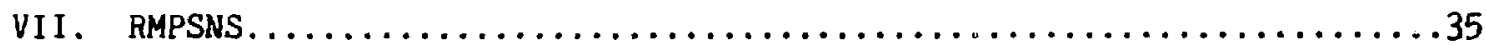

VIII . CONCLUSIONS ...............................49

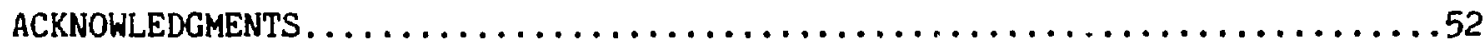

REFERENCES.......................................

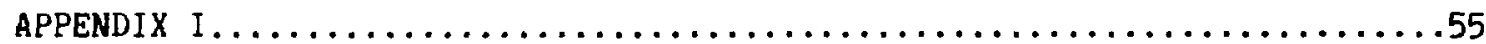

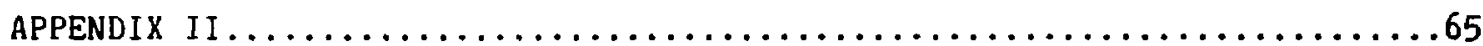

APPENDIX III $\ldots \ldots \ldots \ldots \ldots \ldots \ldots \ldots \ldots \ldots \ldots \ldots \ldots \ldots \ldots \ldots \ldots \ldots \ldots \ldots$

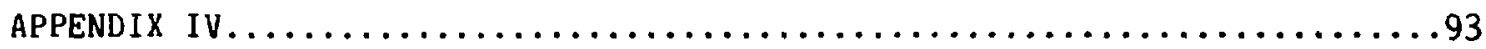

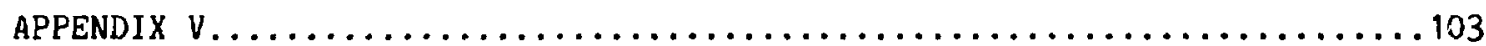

APPENDIX VI $\ldots \ldots \ldots \ldots \ldots \ldots \ldots \ldots \ldots \ldots \ldots \ldots \ldots \ldots \ldots \ldots \ldots \ldots \ldots \ldots \ldots$ 


\section{LIST OF FIGURES}

Figure No.

Caption

$\underline{\text { Page }}$

1

Block diagram of the data acquisition system

32 channel $x / y$ spectra in a mixed gamma/neutron

field with random test pulses included

Log(A) vs voltage calibration curve for the hydrogen counter together with results of a four coefficient least squares polynomial $\mathfrak{f i t}$

32 channel $x / y$ spectrum in a mixed radiation field

for the hydrogen counter

32 channel $x / y$ spectrum in a mixed radiation field

for the hydrogen counter

32 channel $x / y$ spectrum in a mixed radiation field

for the hydrogen counter

32 channel $x / y$ spectrum in a mixed radiation field

for the hydrogen counter

32 channel $x / y$ spectrum in a mixed radiation field

for the hydrogen counter

32 channel $x / y$ spectrum in pure co-60 gamma field

32 channel $x / y$ spectrum in pure Co-60 gamma field for the hydrogen counter

32 channel $x / y$ spectrum in mixed radiation field for the hydrogen/krypton counter

32 channel $x / y$ spectrum in mixed radiation field for the hydrogen/krypton counter

32 channel $x / y$ spectrum in pure co-60 gamma field for 


\section{LIST OF FIGURES (Continued)}

Figure No.

18

19

20

21

22

23

24

25

26
Caption

Page

White amplitude calibration spectrum

40

Smoothed test pulser spectrum

41

Test-pulser-normalized proton recoil spectrum

42

Smoothed ratio of white ionization to white amplitude calibration spectrum

Calibration-normalized proton recoil spectrum

44

46

correction for track truncation to hydrogen

counter data

Proton recoil spectrum for both counters; a

correction made for track truncation to

hydrogen counter data

Proton spectra from counters having different

48

stopping powers

Neutron spectrum at the JANUS facility showing

50 


\section{A CONTINUOUS MODE DATA ACQUISITION TECHNIQUE FOR \\ PROTON RECOIL PROPORTIONAL COUNTER NEUTRON SPECTROMETERS}

by

E. F. Bennett

\section{ABSTRACT}

The existing proton recoil proportional counter measurement technique Lised at FNS for joint FNS-ANL fusion blanket neutron spectroscopy requires that numerous piece-wise (but overlapping) measurements be carried out at a sequence of fixed counter voltages. The composite results of all of these independent measurements are required to construct a single neutron spectrum. This approach has been found to be both inefficient and subject to systematic errors. An altornative approach, in which data is acquired continuously using a slow time modulation of the high voltage bias supply, is here described. The electronics requirements are consistent with the basic detector/amplifier systems now operable at FNS. Some additional hardware including a programmable high voltage bias supply and a random amplitude test pulse generator are necessary. A description of the electronics and data acquisition hardware for these measurements will be provided at a later date. In this report we emphasize the numerical procedures involved to acquire and reduce data, and provide an illustrative example using one of the hardest neutron spectra readily available for this work at ANL (the JANUS facility). 


\section{INTRODUCTION}

Proportional counters may be used for measurements of ionization down to, and including, single electrons. This, together with use of hydrogencontaining gas as part of the filling, has resulted in extensive use of proportional counters as neutron spectrometers and dosimeters. Electron multiplication at the fine-wire anode of a proportional counter varies approximately exponentially with applied voltage. It would seem, therefore, that it should be sufficient to increase the voltage on the counter until those events of least initial ionization develop a pulse height well in excess of preamplifier noise. All events of interest could then be analyzed with a pulse height analyser of adequate channel capacity. Considerations of preamplifier noise together with non-linearity (through space charge saturation) of the electron avalanche mechanism in the counter contrive to make this simple mode of operation impractical for those applications reguiring a very large range of energy of events. For example, in order to amplify the ionization equivalent to that created in stopping a $1 \mathrm{keV}$ proton in the counting gas to a level well in excess of noise, a gas multiplication of about 1000 is required. Events at the high-ionization limit would be subject to the same gas multiplication, and the very large accumulation of charge in the resulting anode avalanche would become space charge limited; the relationship between pulse height, as measured, and ionization, as produced initially in the gas, would cease to be linear. The space charge saturation problem can perhaps be appreciated in another context. Consider the use of a parallel plate device for ionization detection. Electron-ion pairs are separated and collected over an area determined by the range of the initiating event together with whatever diffusion broadening occurs during transit of the free-electron cloud to the positive electrode. The proportional counter, by contrast, will focus the initial electron cloud inward along radially symmetric electric field lines to the anode, which is typically only about $1 / 1000$ of the cathode diameter. Due to this inherent focusing effect, the spatial density of charge at the counter anode is higher by perhaps 1000 relative to the spatial density of charge collected by a parallel plate detector. At these charge density levels, space charge saturation effects occur for the proportional counter which would be non-existent in parallel plate geometry. 
As a practical matter, therefore, it is desireable to minimize the total charge collection for the proportional counter in order to retain linearity between pulse height and initial ionization. Broad range energy coverage, under these restrictions, is then achieved by changes in voltage such that limits are placed upon the total charge collection (initial charge times multiplication) for events of interest. Data acquisition may proceed over a finite number of discrete voltage steps where the gain of the pulse amplifier is fixed at a conservatively high value to avoid non-linearity (but to still retain sufficiently low noise levels). This procedure leads to a piece-wise determination of the spectrum; the full result is a montage of individual results covering only a limited range of the spectrum at each voltage setting. Each piece of the spectrum must be normalized for source fluence, live time, etc. The amount of redundant data is large, there are normalization uncertainties, and a substantial amount of manipulation is required to produce a single composite final result.

In order to circumvent the above-mentioned difficulties for proportional counter data acquisition, we have tested a different approach in which data acquisition is accomplished by an arbitrary (but periodic) time modulation of the high voltage bias. For each event the value of the counter voltage is read together with the amplitude of the pulse produced. The voltage value, together with a calibration table which permits the gas multiplication to be derived for any voltage, allows the absolute energy of any event to be derived on an event-by-event basis. Since the voltage is read in as data, together with values for the pulse amplitude, any modulation of the voltage is acceptable as long as the range of the modulation is sufficiently great to include all of the energy region of interest. Restrictions may be placed upon any analyzed event to assure that the total ionization collected is within limits imposed by space charge and amplifier noise.

Having removed the restriction that pieces of the spectrum are each to be accumulated at fixed voltages, we can make use of any periodic voltage modulation profile (i.e. linear ramp, sine wave etc.). A single measurement need not be terminated until a suitable accumulation of data over the entire energy region of interest has been made, irregardless of the modulation. The modulation period will ordinarily be chosen to be rather long, of the order of several minutes or so. This implies that measurements are feasible only when 
substantial source instabilities over intervals of this magnitude do not occur. The modulation technique does retain an inherent inefficiency mechanism since events are selected subject to restrictions on total ionization collected. This is an unavoidable penalty where space-charge saturation of the multiplication process is of concern. The counter will record a substantially higher total detection rate than the rate at which events of acceptable magnitude are processed. On the other hand, continuousmode operation is relatively more efficient than fixed-voltage operation since considerable overlap of data is required for fixed-voltage operation and there is a substantial time penalty associated with repeated termination and restart of acquisition as required for the fixed-voltage mode.

The entire data acquisition system including amplifiers, analog-digital converters, test pulser and programmable high voltage supply has been fabricated from IC components in a light-weight, low-volume package with interface to a PC. The electronics will be described elsewhere. Operation of the system is equivalent to that exhibited by the more conventional spectrometers; the detector is placed in the radiation field, acquisition is enabled for a time sufficient to gain acceptable counting statistics, and the full range of data is available at the termination of the run.

In the following, details of the operation of the acquisition system, together with codes and examples of the application of the procedures for neutron spectroscopy will be described. Hardware for implimenting the acquisition technique will be reported at a later date.

The procedures described here involve the use of a number of relatively short routines run sequentially; those routines which perform data acquisition also include an appropriate machine language counterpart. It is probably desirable not to combine these code sections together at this time even though this would substantially reduce the total code length. As outlined here, each section performs, for the most part, some operation that can be described more-or-less independently of other operations. Extensive built-in options for editing data are included in the codes. These options could largely be eliminated in a compact procedure containing only the essentials.

The basic acquisition procedure described here is, in any event, now obsolete. 32 bit processors operating at $16 \mathrm{MHz}$ and higher are now widely available at low cost. Use of this newer PC equipment is highly advantageous 
for this work. Larger arrays, with an attendant increase in resolution and a simplification of the acquisition code, will become possible using the newer hardware.

\section{DATA ACQUISITION IN A COATINUOUS MODE}

A block diagram depicting the basic data acquisition system is depicted in Fig. 1. The arangement shown is for positive high voltage applied to the counter anode with a high voltage blocking capacitor between anode and preamplifier. Negative high voltage applied directly to the cathode is superior since the blocking capacitor can be dispensed with. In most applications for small sized counters where space is limited the positively biased ancde is more convenient since independent electrical insulation of the cathode is not required.

The preamplifier is the conventional "charge sensitive" type. Test pulses are fed directly to the input FET gate through a small-value capacitance (1pF).

High voltage is generated using a $D C / D C$ converter with programmable input. A high voltage divider resistance is attached to the high voltage output of the converter. The divider output is proportional to high voltage but does not exceed a value of about 10 volts maximum.

Pulses from the preamplifier drive a pair of analog amplifiers in parallel. The " $y$ " amplifier is an integrating amplifier with good low frequency response. Irregardless of the tine profile of the counter induction response to an ionizing event, the $y$ amplifier will deliver a peak pulse amplitude proportional to the value of total ionization. By contrast, the "x" amplifier has limited low frequency response and therefore tends to "differentiate" the induction profile. The differentiated pulse contains information useful for the identification of the origin of the pulse; pulses of the same energy ( $y$ pulse height) can originate from different underlying ionization phenomena (see Ref. 1 for example).

All three analog amplitudes ( $y, x$ and $v$ ) are presented to a multiplexer, digitized to 4096 channels maximum, and read into data registers of the PC. An event analysis is initiated only if the peak value of the $y$ pulse falls within the acceptance range of a pair of level discriminators. Within the 


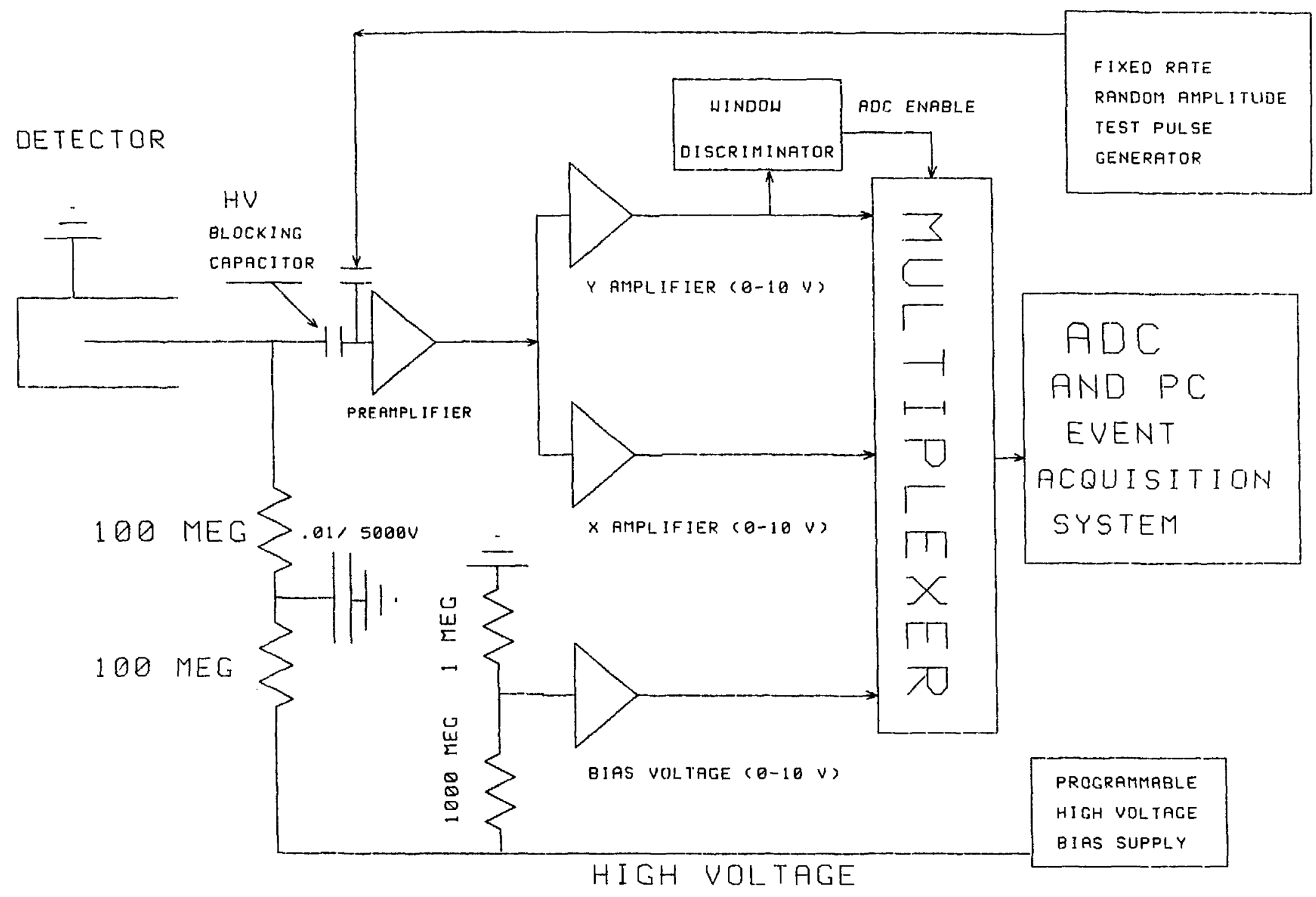

FIG.1 BLOCK DIAGRAM OF THE DATA ACQUISITION SYSTEM. 
acquisition program, the ratio of the $x$ amplifier pulse to the $y$ amplifier pulse is formed, and this ratio (scaled to 32 channels maximum) is stored in memory together with the appropriate energy of the event. Event energy is determined from the $y$ amplifier pulse together with the value of gas multiplication at the voltage for the event. The gas multiplication is taken from a calibration table in which multiplication is expressed as a function of voltage. The stored result then consists of a two-dimensional array; one dimension of which is energy (actually, log of energy) and the other is the corresponding $x / y$ value. Test pulses are fed to the preamplifier and are processed in exactly the same manner as ionization data. The rise time of the test pulser is adjusted, however, to exceed that of any pulse arising from an ionizing event. Test pulses are, in consequence, recognized as that region of the $x / y$ spectrum of greatest amplitude.

Fig. 2 contains an example of an $x / y$ spectrum at a single energy value for a hydrogen filled proportional counter exposed to a mixed neutron and gamma radiation field. Three distinct regions of the spectrum are apparent. The region at the highest channel number is from test pulses and is easily distinguished from events of lower $x / y$ amplitude. The lowest (and least well defined) region is an electron loss distribution from gamma interactions! in the counter walls. The central spectrum is from proton recoil events. Although the shape of the gamma and neutron spectra changes with changing energy, the test pulse line has fixed width and location. Following termination of a measurement, events in each category are integrated for each energy to provide independent spectra for test pulses, for proton recoils, and for gammas.

The test pulser provides a fixed rate of random amplitude pulses input to the preamplifier; these test pulses are processed in the same manner as are pulses whose origin is from ionizing events. It is the use of the test pulse distribution that allows the appropriate normalization to be made to the proton recoil distribution irregardless of the way in which counter voltage is varied during the course of the measurement.

Data acquisition and analysis are done using several codes which will be considered in detail together with data from a neutron spectrum measurement at the JANUS facility (see Ref. 2). The first code, designated PRINIT (Appendix I), is intended to provide results useful in setting up the system. The 

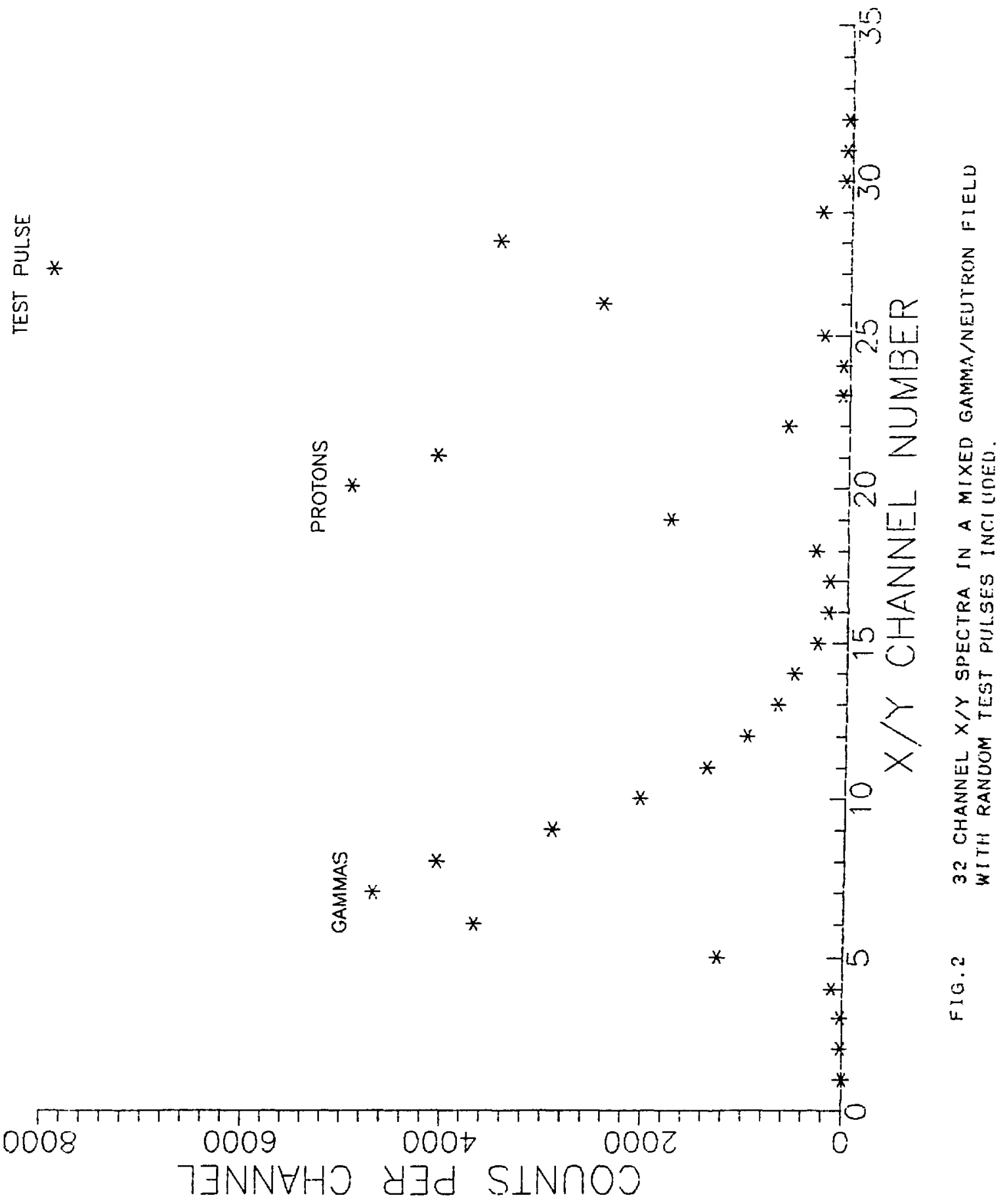
machine subroutine PRMINP called by PRINIT contains the instructions for input of the actual data used. The code RAMPDA (Appendix II) is the data acquisition procedure; the actual acquisition is done within the machine callable routine RAMPIN. An option exists within RAMPDA in which only the test pulse spectrum is acquired in the absence of applied counter voltage. This option needs be run only once for a given system setup configuration. The test pulse calibration result is applied to the final analysis of all runs using identical parameter sets, which includes the type of voltage modulation and the voltage extremes. The code RMPRDN (Appendix III) contains all of the procedures necessary to provide the individual spectra for test pulses and for proton recoils and gammas from the raw data as determined from RAMPDA. In addition to the raw data generated by RAMPDA, a background gamma spectrum is also required for the analysis of raw data. It will seldom be convenient to provide a background gamma spectrum of precisely the same nature as that which exists during data acquisition in a mixed neutron/gamma field of interest. We have found that an adequate approximation to the gamma field existing during measurements can be obtained by use of pure sources alone (Co$60, \mathrm{Cs}-137)$ placed in proximity to the counter. Results using the pure sources are adequate to allow data reduction to be carried out with little sensitivity to the true spectrum of the gamma source for most practical situations.

RMPSNS (Appendix VI) is the last of the procedures and converts measured spectra as produced from RMPRDN to neutron spectra. RMPSNS contains a subsitantial amount of internal edit of sequential steps and these will be followed in detail using actual data to illustrate the procedure.

Before entering a detailed discussion of each of the acquisition and reduction procedures, the calibration for the detector will be described. The proportional counter is not an absolute energy detector and a full calibration curve is required from which the energy at any value of pulse height can be inferred if the corresponding detector bias voltage is known.

Implimentation of the ramp acquisition procedure has only been carried out using a PC-XT (16 bit, $4.77 \mathrm{MHz}$ ). Pulse processing times for this system are long and significant dead time losses can occur for acquisition rates of only a few thousand counts per second or so. The use of only 16 bits for machine register operations limits array size as well as the accuracy of data. Software formatting for double precision operations would entail 
substantial, and unacceptable, increases in event processing times. These restrictions are eliminated using the newer 32 bit processors having clock frequencies of $16 \mathrm{MHz}$ or more. The numerical procedures as outlined here are specific for the old machines however, and would require re-programming to operate on the newer PC's.

\section{CALIBRATION}

There is no universal prescription for predicting the counter gas multiplication value $A$ for all voltages within the range of interest for proportional counters. Gas multiplication depends upon gas species and pressure as well as upon voltage and the dimensions of the anode and cathode. Multiplication is also subject to space-charge saturation, which is sensitive to the spatial extension if the initiating event. When calibration measurements are carried out using ionizing events of substantial track length, space-charge saturation is minimized. Even if the absolute gas multiplication were derivable from gas and counter parameters, the complexities of the basic counter induction effect and of the filter characteristics of the analog amplifiers together with uncertainty in $W$, the energy loss per ion pair for the gas, and uncertainties in the absolute value of the preamplifier feedback capacitor would require at least one calibration against a known source of ionization. The quantity here referred to as " $A$ " is not, therefore, to be taken as the true absolute electron multiplication, but rather as a quantity proportional to multiplication but with substantial uncertainty in the factor of proportionality. From the calibration of relative $A$ vs. voltage and an absolute value for the energy scale at some particular voltages the energy corresponding to any value of $y$ amplifier pulse height may be derived. The gain of the analog pulse amplifiers does not vary during data acquisition; only the counter bias voltage is modulated to allow the measurement to include the full range of energies of interest.

Although calibration data for proportional counters will be sensitive to detector details, it has been universally observed that the $\log$ of $A$ is a smoothly varying function of voltage; and not greatly different from linear with voltage for most applications. A low order polynomial $f$ it of $\log (A)$ vs. voltage will always provide an excellent fit over the range of voltages of practical interest. For calibration at the higher energies, we have made use 
of mono-ionizing events from the exoergic reaction He-3(n,p)t (764.5 keV) induced by thermal neutrons on counters containing a low partial pressure of He-3 in the filling gas. Only a very small partial pressure of He-3 is required due to the large thermal neutron cross section of He-3. Only those counters showing good resolution (as indicated by a narrow line width for the He-3 related pulse height spectrum) are acceptable for use as neutron spectrometers. An absolute calibration at a much lower energy can be obtained by observing the neutron spectrum produced by a counter surrounded by iron and exposed to fast neutrons. The scattering resonance in iron at $28 \mathrm{keV}$ is very prominent in an iron environment and serves to provide a suitable absolute reference. In order to provide low energy calibration data of a relative nature, we have used the observed counter response to gamma sources (Co-60 for example) as a function of voltage. The mean ionization produced is low and this allows data to be derived over the lower energy region from about 1 kev to about $50 \mathrm{keV}$ for hydrogen-filled counters at typical values for gas pressure. Although the pulse amplitude spectrum in response to gammas is broad, it is not difficult to establish some index of the distribution such as peak channel value.

Measurement results contained in this report were taken with a pair of counters; the first counter contained essentially hydrogen and will be referred to as the "hydrogen" counter while the second counter contained a $50 / 50$ mixture of hydrogen and krypton (for improved stopping power) and is referred to as the "hydrogen/krypton" counter. Total pressure for the hydrogen counter was about 6 atmospheres, and pressure for the hydrogen/krypton counter was about 9 atmospheres. The anode wire had a diameter of $1 \mathrm{mil}$ and the cathode diameter was $3 / 4$ inch. Fig. 3 contains a Joint calibration for the hydrogen counter using the He- $3(n, p) t$ reaction for the higher energies (lower values of $A$ ) together with a Co-60 gamma source for the lower energies (higher values for A). The low energy data is made absolute by normalizing measured neutron spectra to the $28 \mathrm{keV}$ iron resonance. In the determination of the relative $A$ vs. voltage for either high or low energy data, changes in amplifier gain are made commensurate with changes in voltage (multiplication) in order to maintain the pulse amplitude spectrum within range of the data acquisition electronics. 


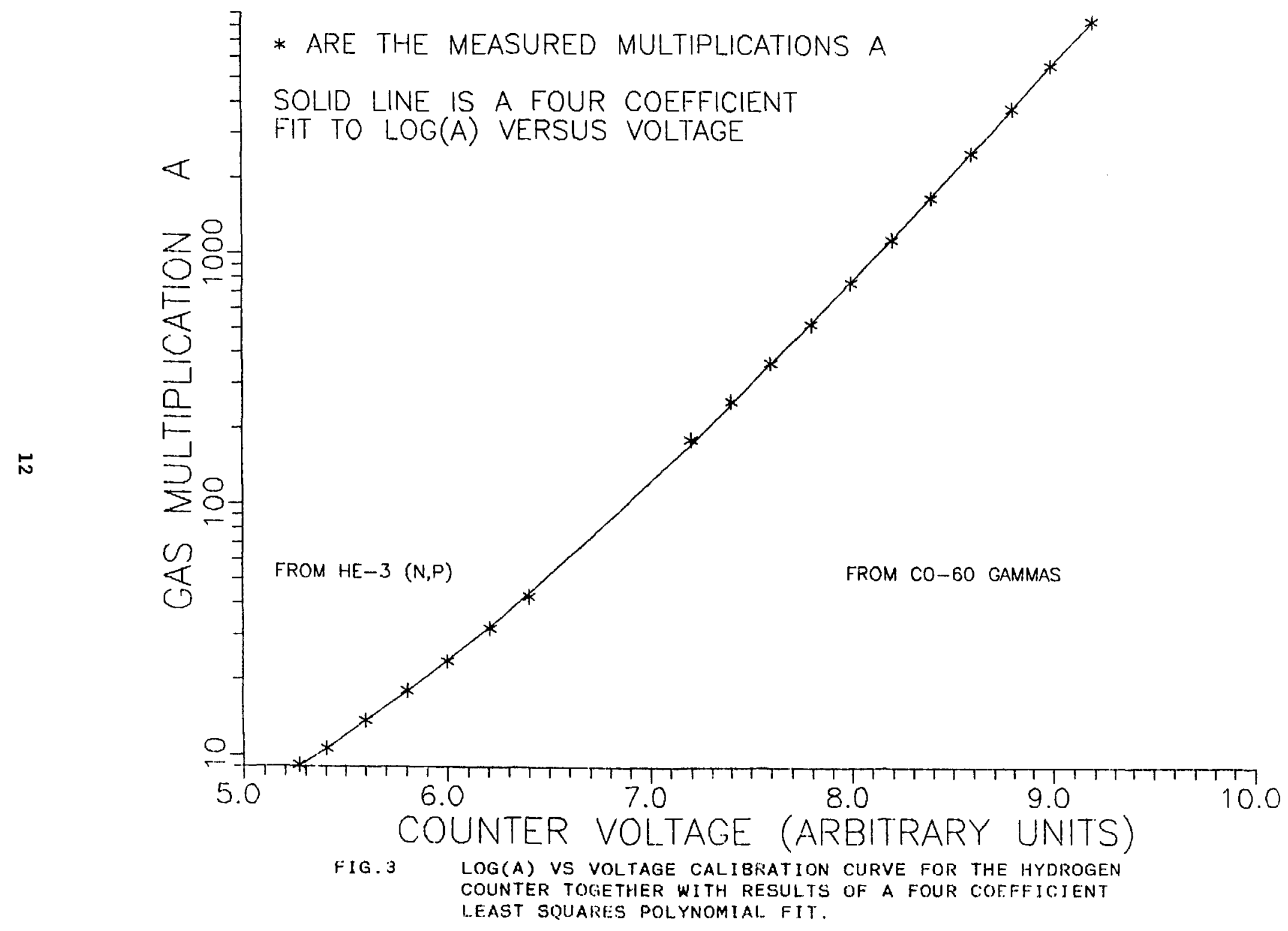


The peak channel value for the He-3(n,p)t reaction cannot be relied upon at arbitrarily high voltage due to space-charge saturation distortion. Neither is it possible to exiend the information from gamma data to arbitrarily low voltages since this data will ultimately be limited by amplifier noise. By observing the shape of the He-3(n,p)t line as voltage increases, $a$ point will be reached at an $A$ of about 50 where observable distortion of the line shape will occur. Any additional calibration data above this value of $A$ will be suspect. Since the extent of initial ionization for calibration data using a gamma source is low, this data can be extended to correspondingly higher values of A without distortion. As a consequence of these restrictions on acceptable values of $A$ during calibration, there will be an intermediate region of the calibration curve (for the hydrogen counter) where no calibration data exists. Since $\log (A)$ is a smoothly varying function of voltage, however, this region will be adequately represented using a low order polynomial fit which includes measured results at both extremes. In Fig. 3 a four coefficient least squares polynomial fit of $\log (A)$ vs. $V$ is shown together with measured datum points covering the extremes of low and high A values. A calibration done in this manner is highly accurate at the absolute reference points but is less reliable elsewhere. Additional calibration data taken using accelerator neutrons and also additional scattering resonance structur: (other than $\mathrm{Fe}$ ) induced in neutron spectra (author's unpublished notes) indicates that the overall calibration accuracy is not biased by more than about $5 \%$ for any value of A using results of a low order polynomial fitting scheme applied to experimentally derived values for relative $A$.

It is usually necessary to measure neutron spectra with a pair of counters; hydrogen for the lower energies and another counter with higher stopping power for the higher energies. For the higher stopping power counter it suffices only to use the $\operatorname{He} 3(n, p) t$ reaction line, which is located conveniently near mid-range of the measurement region of interest from about $100 \mathrm{keV}$ to about $2 \mathrm{MeV}$, for calibration. For either counter type, the product of the energy of the event corresponding to full scale pulse amplitude of the $y$ (energy) amplifier and the gas multiplication is held to values less than about $10 \mathrm{MeV}$. It is this restriction which minimizes the extent to which space-charge saturation effects distort data. 
The calibration procedure described here and based upon only two absolute energy points is entirely arbitrary. Access to an accelerator, and observation of $n-p$ scattering spectra for different energies is desirable although this procedure is difficult to apply below about $50 \mathrm{keV}$. Numerous neutron scattering resonances in light elements may be found in the energy region above $1 \mathrm{keV}$. These can be used for additional calibration results through observation of the neutron spectrum produced when the counter is surrounded by the scattering material and subjected to fast neutron irradiation. Calibration results will improve in accuracy in proportion to the availability of additional data from use of a greater number of absolute energy points.

\section{PRINIT}

The initialization utility PRINIT is listed in Appendix I together with its machine I/O routine PRMINP. The Fortran Main Program PRINIT calls the machine subroutine PRMINP according to options selected from an initial menu. Consider PRMINP first. This procedure contains the callable subroutines A1PX, A1PY, DSHV, A21P, and SETUP. All input operations from the $A D C$ are through a standard 8255-A interface (Ref. 3). The full data word is held jointly in ports labelled " $A$ " and " $B$ ". The " $C$ " port is a handshaking port, and is used to indicate that a data event has been processed and is ready to read in, and also to generate reset logic for the $A D C$.

SETUP is only called once to program the interface and to locate the origin of data arrays in the Fortran Main Program.

A1PX and A1PY are used for single channel pulse height analysis modes for either the $x$ or $y$ amplifier alone. It is useful to operate in this mode for calibration or for linearizing the ADC etc.

DSHV is a routine only used for reading the high voltage level. Values for voltage are read in 256 times consecutively and the mean value and deviation about the mean are listed. This routine is useful in linearizing the $A D C$ for voltage data and in checking $A D C$ performance.

A21P is a special two parameter analysis mode which allows an $x / y$ pulse amplitude distribution to be rscorded for any range of the corresponding $y$ amplifier pulses. It is useful to operate in this mode for checking system 
linearity and performance and for observing the response of the system to the random amplitude test pulser. Termination of any of the acquisition options leaves the data from that procedure in the array $M 1 P$, and this array may then be displayed on the PC monitor or results may be selectively printed. The plotting routines make use of the GRAFMATICS (fief. 4) software package; a version compatible with both the Fortran used and the monitor type is required. Data produced in the routine may be saved on disc. An option exists to read data to allow stored results to be returned for additional plotting or listing if desired.

\section{RAMPDA}

The procedure RAMDA (Appendix 11), using the machine routine RAMPIN.ASM, is the data acquisition program for neutron spectroscopy using the voltage modulation technique described here. After receiving the calibration data and the acceptable voltage range, minimum and maximum voltage values are determined. In the proportional mode, counter gas multiplication must exceed 5 or so to prevent contamination of data by non-multiplying regions of the detector such as the field-definition tubes at each axial extremity. The upper limit of 10000 or so corresponds to events of too low an energy to be of use.

The machine program RAMFIN contains only the three subroutines SETUP, ANA and TPLSR. Again, as was the case for PRINIT, SETUP is only used to initialize the $82551 / 0$ port and to locate the origin of data arrays in the Fortran Main Program. ANA is the subroutine in which the basic data acquisition is done while TPLSR is a test pulser calibration mode used only in the absence of data pulses.

Counter calibration data is required initially. From the calibration procedure an expansion of $\log (A)$ vs. voltage (Fig. 3) exists and this information $(\mathrm{CO}, \mathrm{C} 1, \mathrm{C} 2, \mathrm{C} 3)$ is read in. Also required is the voltage range for the modulation, VBOT to VTOP, together with the corresponding $A D C$ equivalent (modulo 4096) for each limit NBOT, NTOP.

Three tables denoted by IGAIN(3000), LOGTB(4096) and INLGTB(3548) are then filled out prior to commencing event acquisition. The table IGAIN consists of values of $\log$ of the inverse multiplication as derived from calibration data. These $\log (1 / A)$ values are related to the maximum gain value 
GMAX determined from the maximum allowable voltage value VTOP. The table is only filled out for the range UTOP to UBOT; events outside this range are screened out in the machine acquisition procedure. Within the voltage acceptance window VBOT to VTOP, the voltage associated with any event can be quickly derived in a single addressing operation using the IGAIN table, which is only generated once prior to commencing data acquisition. It would be possible to generate these $\log (1 / A)$ values for each event from the calibration polynomial expansion data directly but this would require use of math routines and would lead to very slow acquisition and large system dead time, especially for the $4.77 \mathrm{MHz}$ PC on which all of this work is based.

In addition to the IGAIN table (to determine the $\log (1 / A)$ for the event from the decoded voltage) the table LOGTB(I) is generated which allows a scaled and normalized value for the $\log$ of the $x$ or $y$ amplifier pulse height to be determined by a single addressing operation. Also, a table INLGTB(I) is generated which is the inverse of the $\log$ table and allows an argument to be derived from the value of the log, again using a single addressing operation. Use of tables for derivation of values for $\log$ and anti-log is fast but accuracy is limited if the processor is only 16 bits.

The basic acquisition approach, using these tables is as follows:

From the observed $A D C$ conversion for the $x$ and $y$ pulses, $10 g$ values for $\log (x)$ and $\log (y)$ are looked up in the LOGTB table. The difference $\log (x)-$ $\log (y)=\log (x / y)$ is formed and this result is converted to a normalized (32 channel) value for $x / y$ using the inverse log table INLGTB. Biasing and scaling is required for all values to retain accuracy using only 16 bit operations. The $\log$ of the inverse multiplication $\log (1 / \mathrm{A})$ (including biasing and scaling) is derived by lookup in the IGAIN table. This is added to $\log (y)$ forming $\log (y)+\log (1 / A)=\log (y / A)$ for the event. $\log (y / A)$, apart from an additive constant, is just the $\log$ of the energy of the event, and it is this quantity that is used in establishing the two-parameter data array for the event spectrum. The true modulation range is set by an external analog programming adjustment and may be somewhat different from the input range VBOT to VTOP. This will not matter however; data that lie outside of the VBOT to VTOP interval will be discarded and the efficiency of the system reduced correspondingly. 
Only 16 bit single precision arithmetic is available using the PC-XT system. Double precision is available by programming but this would result in a drastic slowing of the data acquisition process and is not an acceptable option. It is with some difficulty that the acquisition procedure can be carried out within the 16 bit limit; a considerable amount of scaling and manipulation of table limits is required. ADC conversion of all data is modulo 4096.

The acceptance range of the $y$ amplifier is set not only by the voltage when the event occured but by the requirement that any event analyzed be within the range 896 to 4096 . 4096 is the maximum conversion count of the $A D C$; any event exceeding this value will be rejected. Channel 896 is a rather arbitrary low channel limit below which an event is rejected. Amplifer noise begins to significantly effect resolution if the low channel limit is set at a value below 896. In consequence of the finite range of $y$ pulse amplitudes accepted, all spectra will exhibit a decreasing amplitude at both low and high energies irregardless of the voltage modulation profile. This does not matter however; the calibration procedure will correct for this since the random amplitude test pulses are subject to the same acceptance constraints as is the data. At some values of high and low energy extremes, statistics will become unacceptably poor and it is this consideration which will define the range of useable data from the measurements.

The Fortiran program RAMPDA menu allows entry to either the subroutine ANA or TPLSR. Within ANA, data acquisition using the machine program RAMPIN.ASM is carried out, and the two-parameter data array $\operatorname{IDAT}(32,512)$ is generated until adequate statistics have been accumulated. For each of the $\log (\mathrm{y} / \mathrm{A})$ channels ( 1 to 512 ) an associated $x / y$ spectrum ( 1 to 32 channels) of the kind shown in Fig. 2 is stored. After termination of the acquisition process, an option exists to display the 32 channel $x / y$ spectrum for any $\log (y / A)$ value. All of the relevant data for the run are then stored on disc.

The utility routine TPLSR, which may be opted for from RAMPDA, is only run with the high voltage removed from the detector (but using the same voltage modulation parameters as is done in the acquisition mode). There are no ionizing events recorded in this test pulse calibration mode since there is no detector voltage. Results are required using this calibration mode for data analysis but only one calibration result suffices for all runs done using 
the same set of parameters.

Use of the TPLSR calibration mode requires some clarification. We require an acquisition program that provides the true spectrum of the unknown source, with live time normalization, independent of the time variation of the proportional counter high voltage bias supply. Consider an idealized situation in which a source of ionization of random amplitude (white) exists in the detector and can be counted, without dead-time loss, together with the unknown ionization distribution to be measured. Also assume that the two types of ionizing events are distinguishable. For any voltage modulation, the white ionization spectrum serves directiy as a normalization spectrum for the unknown; the ratio of the two results at each energy becomes the absolute data spectrum.

There is no straightforward method for introducing a white ionization spectrum into the detector for calibration purposes however. It is relatively easy, on the other hand, to introduce a white test puiser amplitude spectrum in a pseudo-random fashion at least. This can be implimented using a linear function generator with a high repetition rate to provide the test pulser reference voltage. Periodic test pulse generation may be used rather than pulses which occur randomnly in time; the sources of ionizing events in the data spectrum are assumed to occur at random however.

The machine routine TPLSR returns a pair of numbers for each test pulse analyzed. The first of these is essentially the log of energy (apart from shifting and scaling required to accomodate 16 bjt arithmetic and the 4096 channel $A D C)$. The second number is the $\log$ of the relative gas multiplication and is immediately converted to the gas multiplication $A$. Two arrays are formed using these data. The first (denoted by WHAMP in the code in Appendix II) becomes the test pulse spectrum for a white amplitude test pulse distribution while the second array (denoted by WHION) is derived from WHAMP through use of the appropriate gas multiplication value and corresponds to the test pulse spectrum for an equivalent white distribution of ionization. By running the calibration procedure in the absence of counter voltage, and with all other parameters identical, we provide a calibration which includes the effects of all parameter settings such as the acceptance limits on the $y$ amplifier pulse height. The ratio of these two spectra are needed to provide the normalization required to convert measured spectra to absolute values (the 
measured spectra will always contain the random test pulse spectrum together with the spectrum of the unknown source).

Neutron spectrum measurements were made with the system using linear (ramp) modulation, sine wave modulation, and for fixed voltage values covering only a piece of the energy range. All of these methods, after appropriate test pulser normalization, provided results in agreement with each other. The ramp (linear) modulation is perhaps preferable to the sine wave in regards overall variation in statistical precision. Sine modulation tends to emphasize data at the extremes $\hat{0} \hat{i}$ energy at the expense of mid-range results. It is probably better to use the linear modulation which emphasizes mid-range at the expense of limiting values.

\section{RMPRD}

The RMPRDN procedure (Appendix III) is used to reduce the raw data as generated by RAMPDA. Raw data exists as a two dimensional array consisting of a 32 channel $x / y$ spectrum for each value of energy (Fig. 2). It is the purpose of RMPRDN to resolve this two dimensional array into distinct one dimensional spectra for proton recoils, for test pulses, and for background. The one dimensional arrays are saved for conversion to absclute proton recoil spectra and subsequently to neutron spectra; these operations are handled within the procedure RMPSNS, which is the last of the numerical procedures treated here.

In advition to the two-dimensional data array we require, as additional input, the constants GMAX and FSEXA derived during calibration. GMAX is the greatest value of gas multiplication allowed in the measurement and is derived within the data acquisition procedure RAMPDA from input values for the range of voltage modulation together with the calioration result relating multiplication to voltage. FSEXA, which is also derived from calibration data, is the product of multiplication and energy corresponding to the $y$ pulse height that induces full scale ADC conversion. Pulse amplitude analysis for the $y$ (energy) amplifier is restricted to events in excess of an arbitrary value denoted by LVL after ADC conversion. y amplifier events below LVL are considered to be too close to noise levels to be retained. From GMAX and FSEXA, the absolute $\log$ (energy) value can be derived for any channel in excess of a value NYMIN set during table construction at the commencement of the data 
acquisition procedure in RAMPDA.

To illustrate the RMPRDN procedure, consider Figs. 4-8 which show the 32 channel $x / y$ pulse height distributions for a selection of energies ranging from below $1 \mathrm{KeV}$ to a maximum of about $100 \mathrm{KeV}$ for the hydrogen counter. Figs. 9-10 are $x / y$ spectra of a pure Co-60 gamma source for a range of identical values of energy. Notice that the right-most distribution, from test pulses only, is always well resolved and has a narrow, and unchanging, line width. It requires only a very simple algorithm to recognize this region of the $x / y$ spectrum and to integrate this data region on an energy by energy basis.

The central peak, from proton recoils, is not as simple to resolve uniquely since the shape changes continuously with energy. At the lowest energy (Fig. 4) considerable overlap between the gamma component and the neutron component can be seen, while at the higher energies (Fig. 8) where gamma events are absent, considerable broadening of the proton recoil component occurs due to an increase in range of the recoil proton to values in excess of a few millimeters. At the higher energies the proton component has broadened to include all of the region of $x / y$ below the test pulser. The numerical procedures used to set the various integration limits for each energy value are somewhat arbitrary. Use of gamma background subtraction is required, and this leads to an improved result for proton integration especially for the lower energy values where gamma and proton $x / y$ spectra tend to show increased overlap. The line width of the proton region of the $x / y$ spectrum provides a means of estimating the energy limits above which there is an insignificant gamma background contribution. As energy increases, a point is reached beyond which the spatial extent of tracks increases rather rapidly. This may be observed from the effect upon the width of the proton data line. For additional increases in energy, the proton recoils include all of the region of the $x / y$ spectrum below the test pulse data peak, which is essentially unchanging in shape or location as energy changes.

Initially, after a determination is made of acceptable energy channel limits for the data, the proton peak width is derived as a function of increasing channel number. A channel, denoted by $\mathrm{N} 15$, is found where the proton peak has broadened by a factor of 1.5 from its average at lower channels. Above $N 15$ there is relatively little gamma background in the 


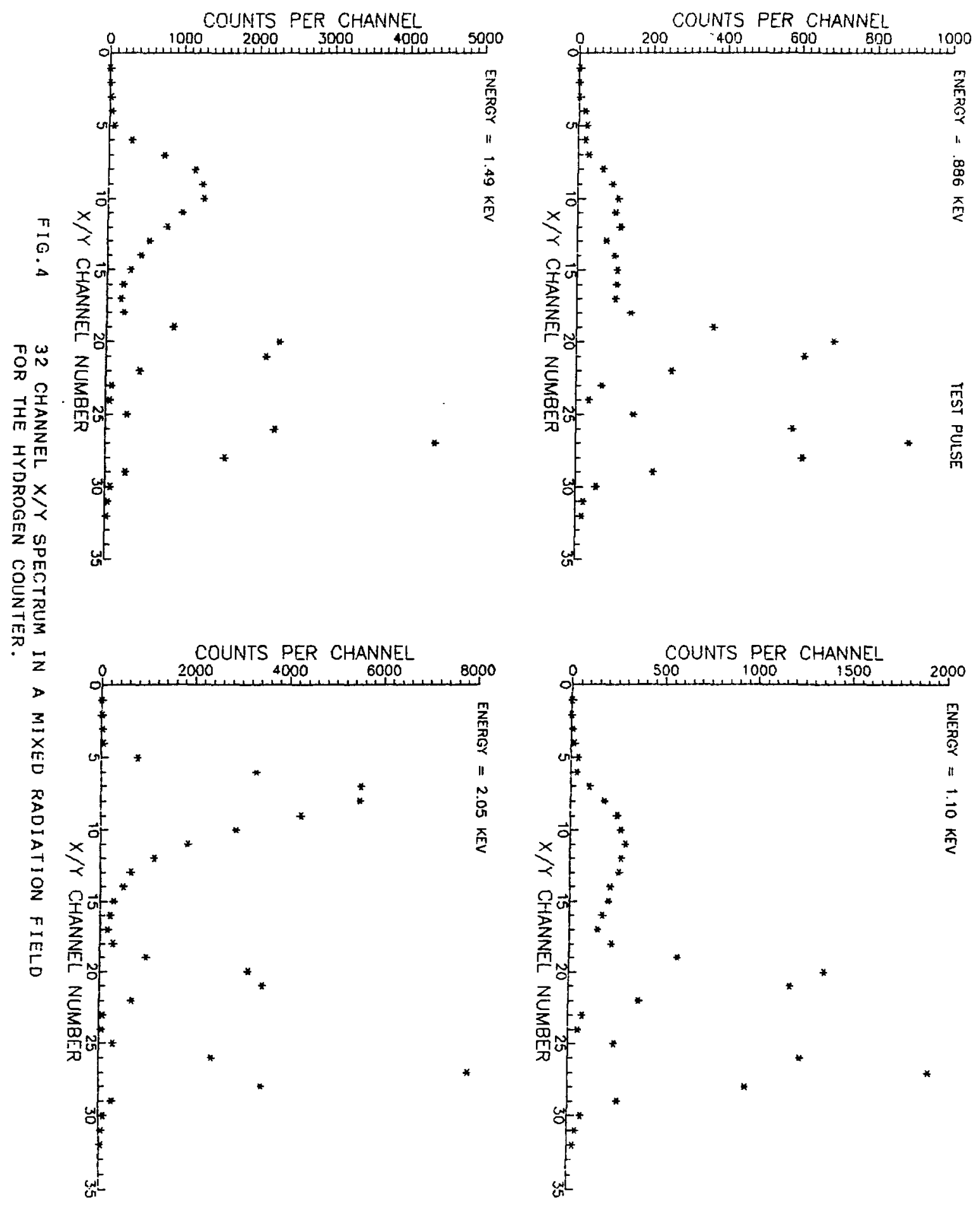




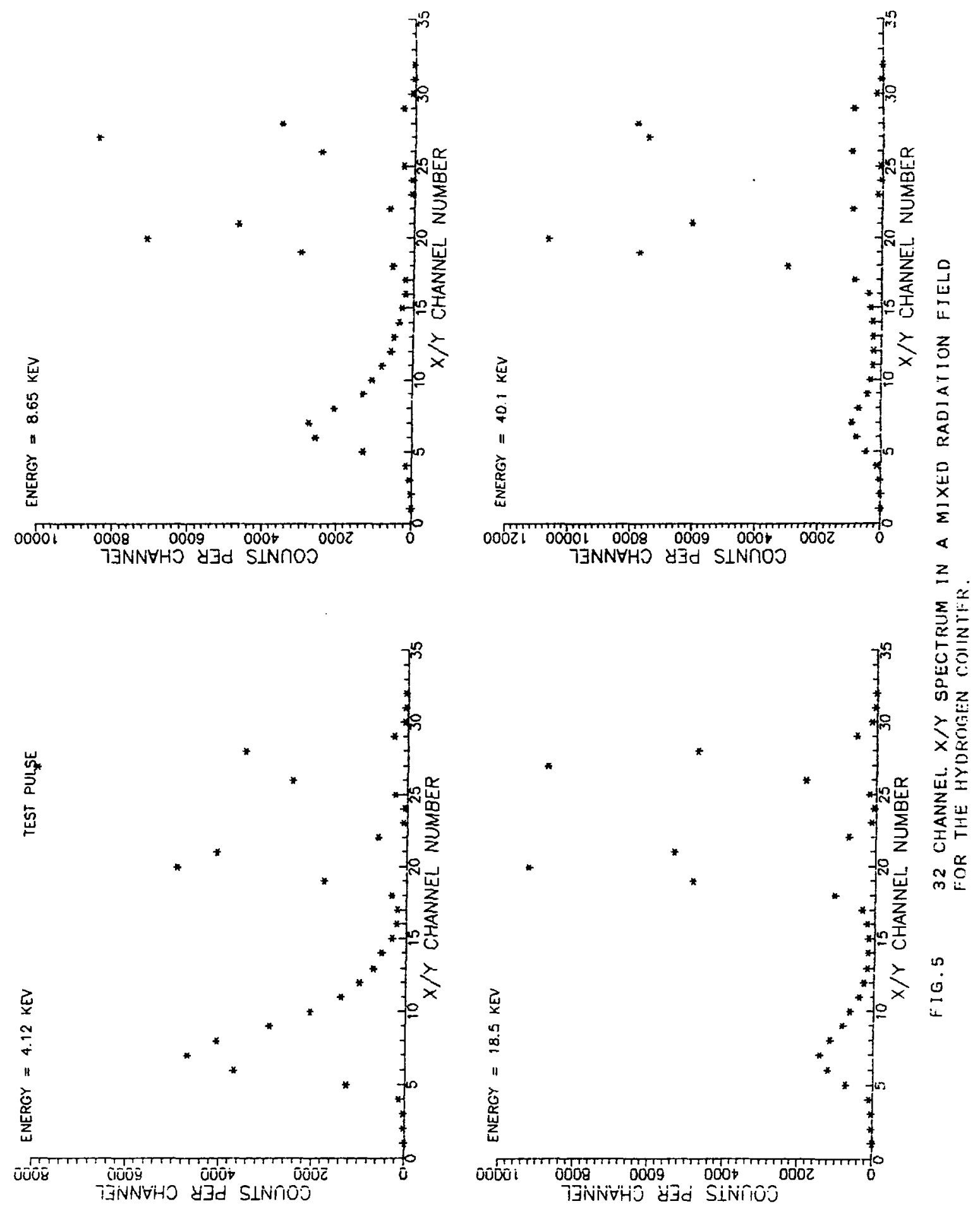




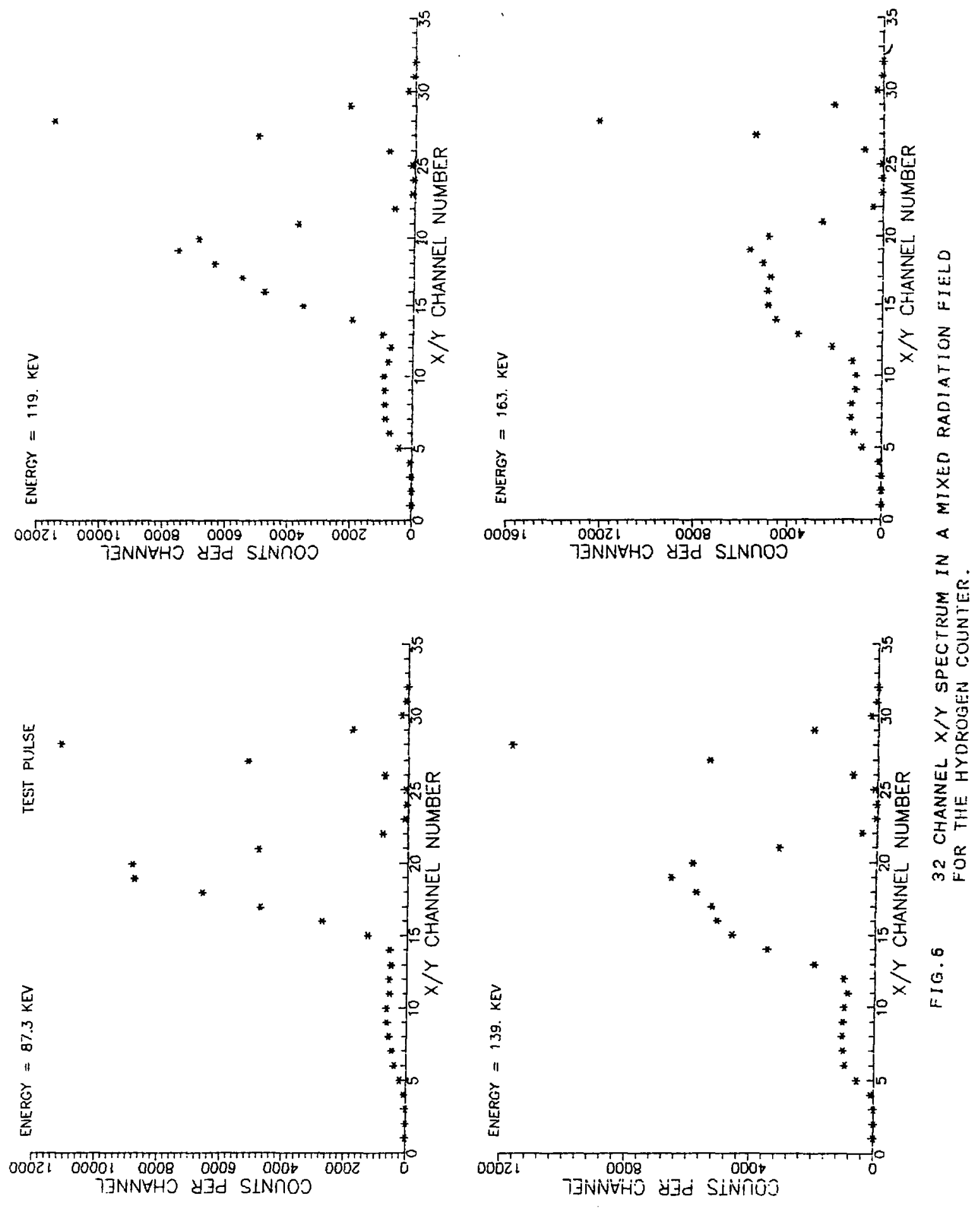




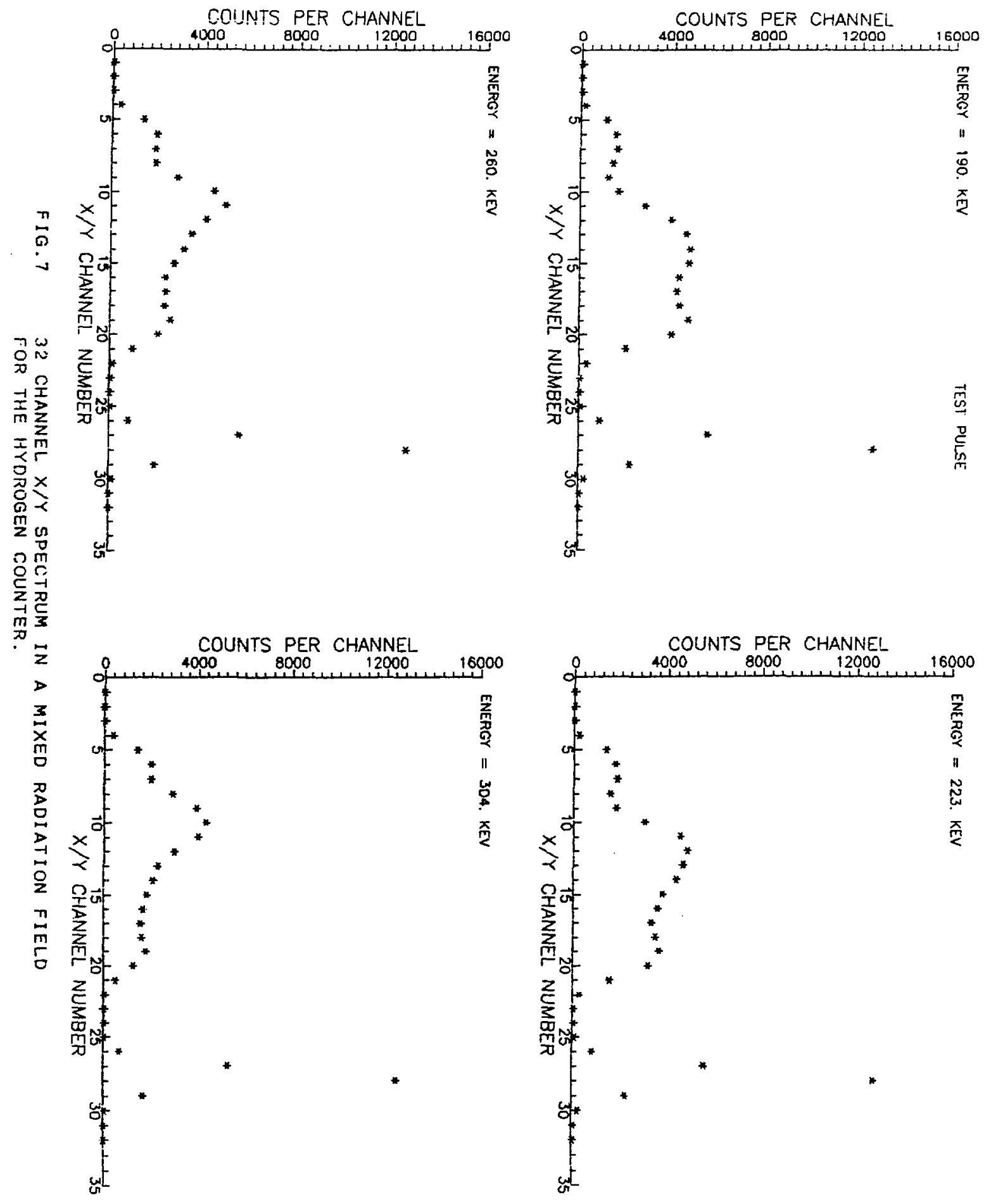




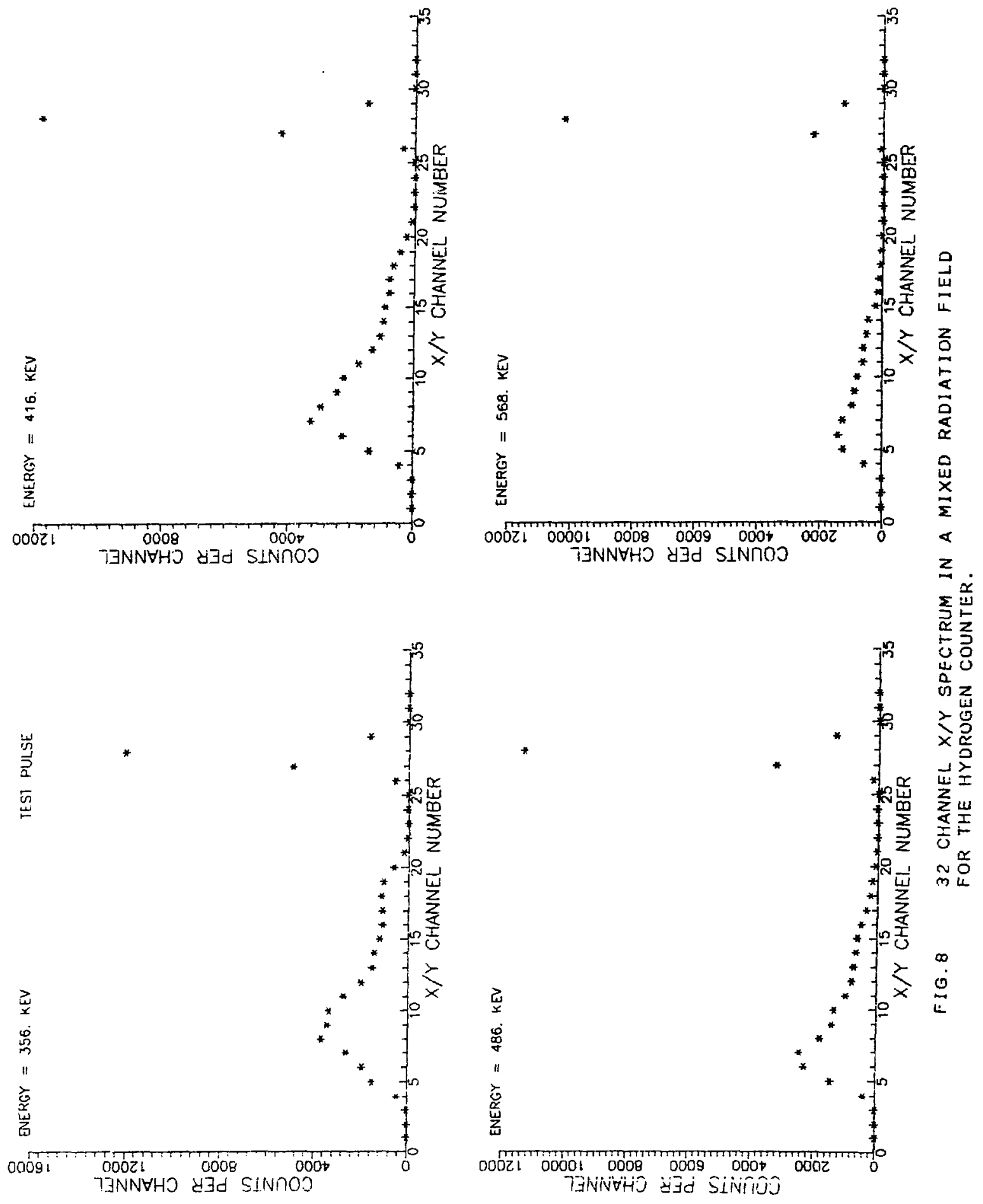



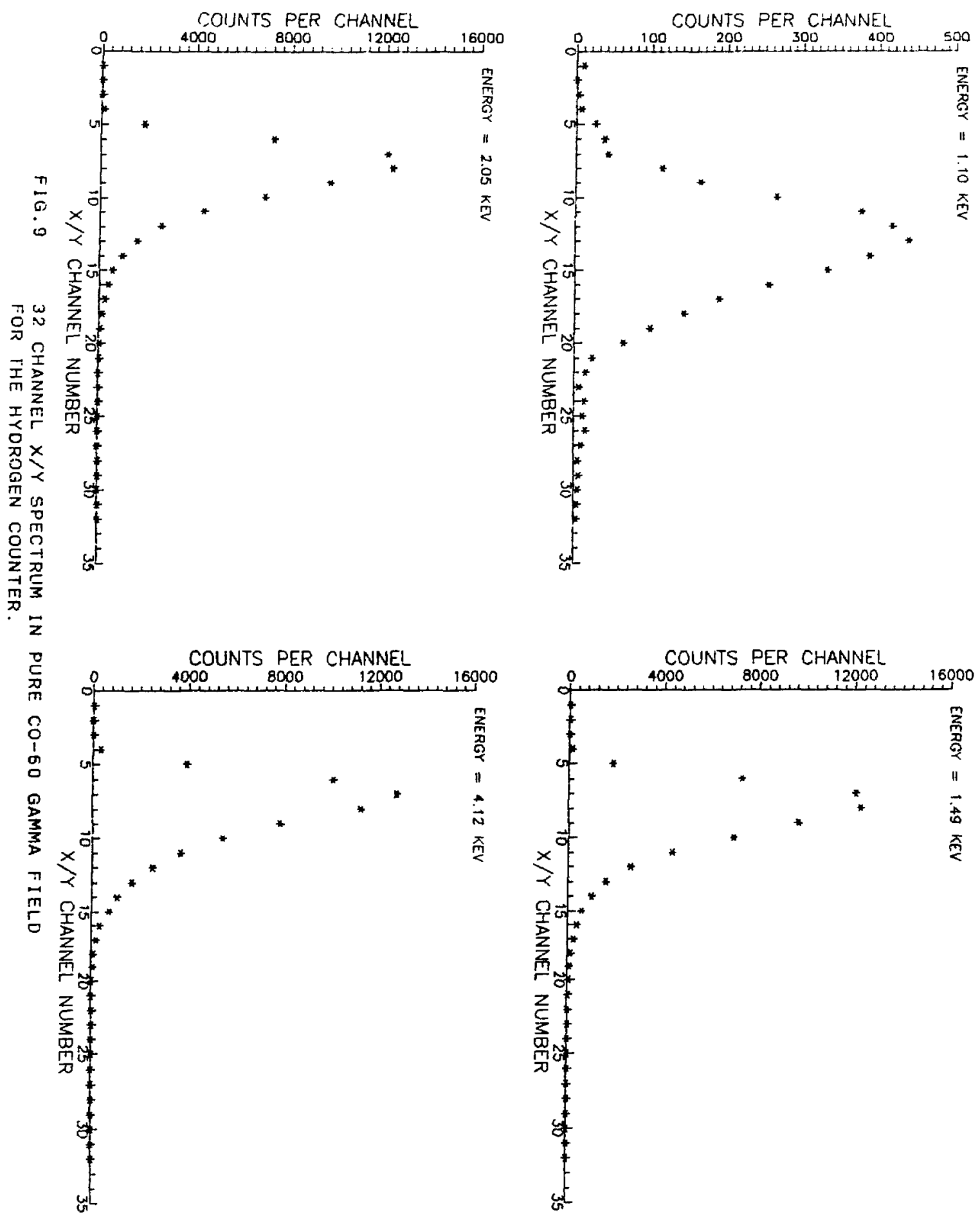


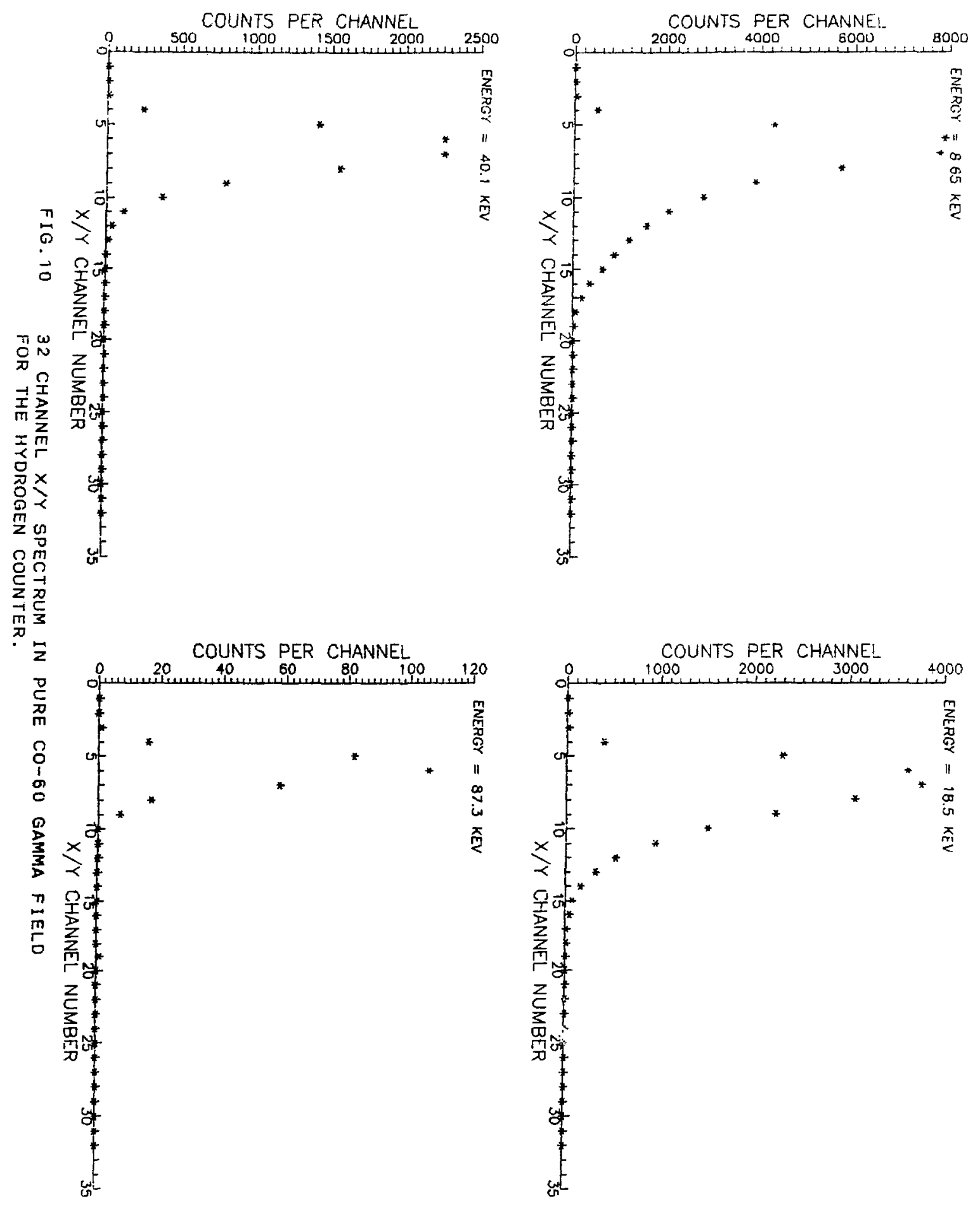


data. The ratio of gamma events in a pure-gamma background spectrum to that in the mixed gamma/neutron field is derived over the lower energy region where this ratio is not very energy dependent. At higher energies, the increasing proton recoil track length will cause degradation of the events of recoil origin into lower $x / y$ channels where they will be included with the region containing gamma counts. This will distort the ratio of gammas in the mixed field data to gammas in the pure gamma field and indicates a limit to the use of this ratio in a gamma subtraction procedure. Having arrived at an energy channel dependent ratio of background gammas to data gammas, this ratio is then used for all energies to correct data for background. The initial data reduction consists of the subtraction of gamma background using measured gamma background data.

An option in the data reduction procedure may be utilized which allows a correction to be made for events which distort the spectrum through wall-andend effects. Consider Figs. 6-7, which contain plots of $x / y$ spectra for the hydrogen counter at energies in the vicinity of $100 \mathrm{keV}$. Gamma events are absent from the $x / y$ plots at these energies, but a rather distinctive residual profile remains. A region of the spectrum below about channel 10 can be recognized which is a consequence of wall-and-end distortion arising from scattering by the most energetic region of the neutron spectrum. This walland-end distorted data can be expected to exhibit a shape distribution (in $x / y$ space) not greatly different from the distribution exhibited by gammas since both kinds of events involve quite long ionizing track lengths. The scattered proton recoil has entered either walls or ends of the counter; the energy loss of the recoil prior to leaving the effective counting region is comparable to recoils of a much lower energy. Using an averaged $x / y$ distribution for pure gammas, a subtraction of the region at low $x / y$ values for the mixed field data can be carried out. After this is done, some typical residuals are shown in Fig. 11. Compare $x / y$ spectra for comparable energies shown in Fig. 11 to data at the same energies in Figs. 6-7 before the correction is made. Removal of the wall-and-end component amounts to perhaps a $10 \%$ correction in the region from $100 \mathrm{keV}$ to $200 \mathrm{keV}$; below $100 \mathrm{KeV}$ the correction rapidly becomes insignificant since the rate of normal recoils far e*ceeds rates for truncated events even in the rather hard JANUS spectrum used here for illustration. Above about $200 \mathrm{keV}$, the correction is meaningless since all proton recoils have assumed a significant track extension. It is not intended to use data 


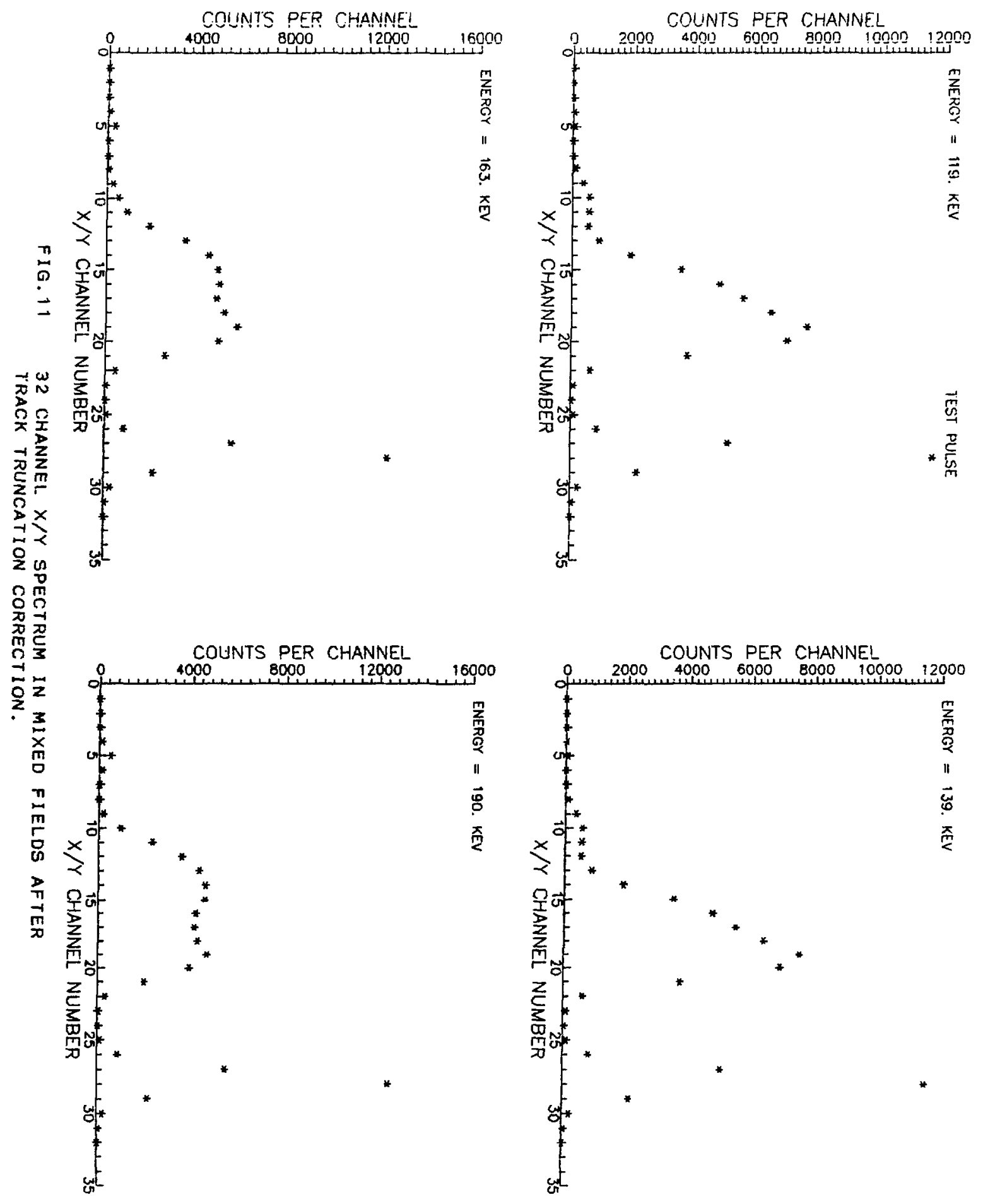


from the hydrogen counter for energies higher than about $200 \mathrm{keV}$. The counter with increased stopping power is used to extend the data to higher energies and to provide a region of overlap with results using the low density hydrogen counter.

Having corrected the raw data for gamma background, and for wall-and-end truncation effects near $100 \mathrm{keV}$, it remains to integrate each $x / y$ spectrum over appropriate channel limits that correspond to proton recoils, test pulser, and residual gamma background. This is done using least squares fitting to provide smoothing of channel limits which define the various data regions. Normalization of the proton count at each energy to the test pulser count at the same energy accomplishes the live time correction since test pulse and data events are acquired in an identical manner by the pulse analysis electronics.

Appendix IV contains a full output edit of data from the analysis of a single measurement of the JANUS neutron spectrum using the hydrogen counter. The various quantities listed are:

\section{1) Total Points and Start Point}

These are defined by the requirement that data not be retained too close to the extremes of energy where statistics are poor.

\section{2) Initial Averge Proton Line Width}

Over the lower energies, the width of the proton recoil line in the 32 channel $x / y$ spectrum is nearly fixed. As energy increses, line width broadens. At the point where the proton line width has increased by $50 \%$, gamma background can be assumed to be absent.

\section{3) N15 Channel}

Energy channel where proton line width has increased by $50 \%$.

4) NBRK Channel

Energy channel above which the proton region has deteriorated to the point that it occupies the entire low- $x / y$ region of the spectrum.

5) .9WMAX Channel

Channel at which ratio of gamma component in background to gamma component in data becomes less than .9 of the maximum value the ratio assumes. 
6) Column $J$ varies from 1 to the total number of energy points.

7) DVAL are the channel boundaries that separate gammas from protons.

8) EDVAL are the smoothed values for DVAL.

9) TVAL are the channel values which separate proton recoll region from test pulse region.

10) ETVAL are smoothed values for TVAL.

11) LINE is the proton recoil line width.

12) RATIO is the ratio of gamma background counts in pure background to counts in mixed field data.

13) GAMMAS are the residual of integrated counts corresponding to the garma region in the background-subtracted data.

14) PRTS are the integrated proton recoil spectra.

15) TIME are the integrated test pulse spectra.

Figs. 12 and 13 contain 32 channel spectra for a few specific energy values for the hydrogen/krypton counter in the JANUS mixed radiation field, and Fig. 14 contains some pure gamma background data. The higher stopping power of this gas mixture compared with hydrogen alone allows data to be acquired at correspondingly higher values of energy. There is very little gamma background above about $400 \mathrm{keV}$. The listing of analysis output for this counter data in the JANUS neutron spectrum is provided in Appendix $V$. Note that the GAMMAS column contains a scattering of positive and negative numbers. The quantity listed is a residual, after ganma background subtraction has been made, of counts ever the $x / y$ spectrum assigned to events of gamma origin. The presence of values of either sign is, consequently, not prohibited. Perfect subtraction would imply a null value for this quantity for all channels. It should be noted that proton peak integration extends only over a region of the $x / y$ spectrum containing predominantly proton recoil data with relatively little contribution from gammas. The GAMMAS column in Appendices IV and $V$ is not, therefore, any indication of the remaining contamination by gammas of the proton count; this residual will be very much less than any of the numbers listed in the GAMMAS column. 

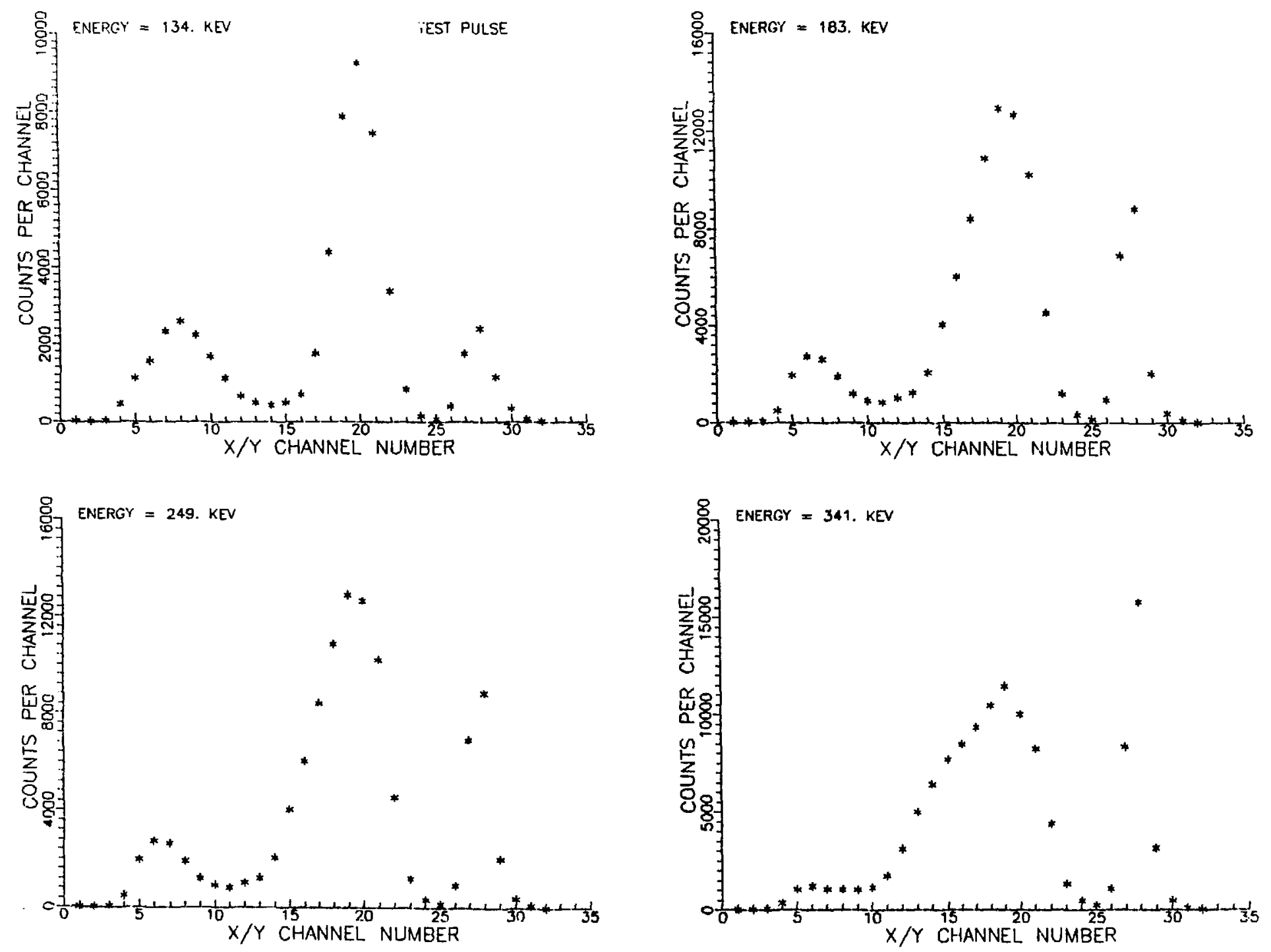

FIG. 1232 CHANNEL $X / Y$ SPECTRUM IN MIXEO RADIATION FIELD FOR THE HYDROGEN/KRYPTON COUNTER. 

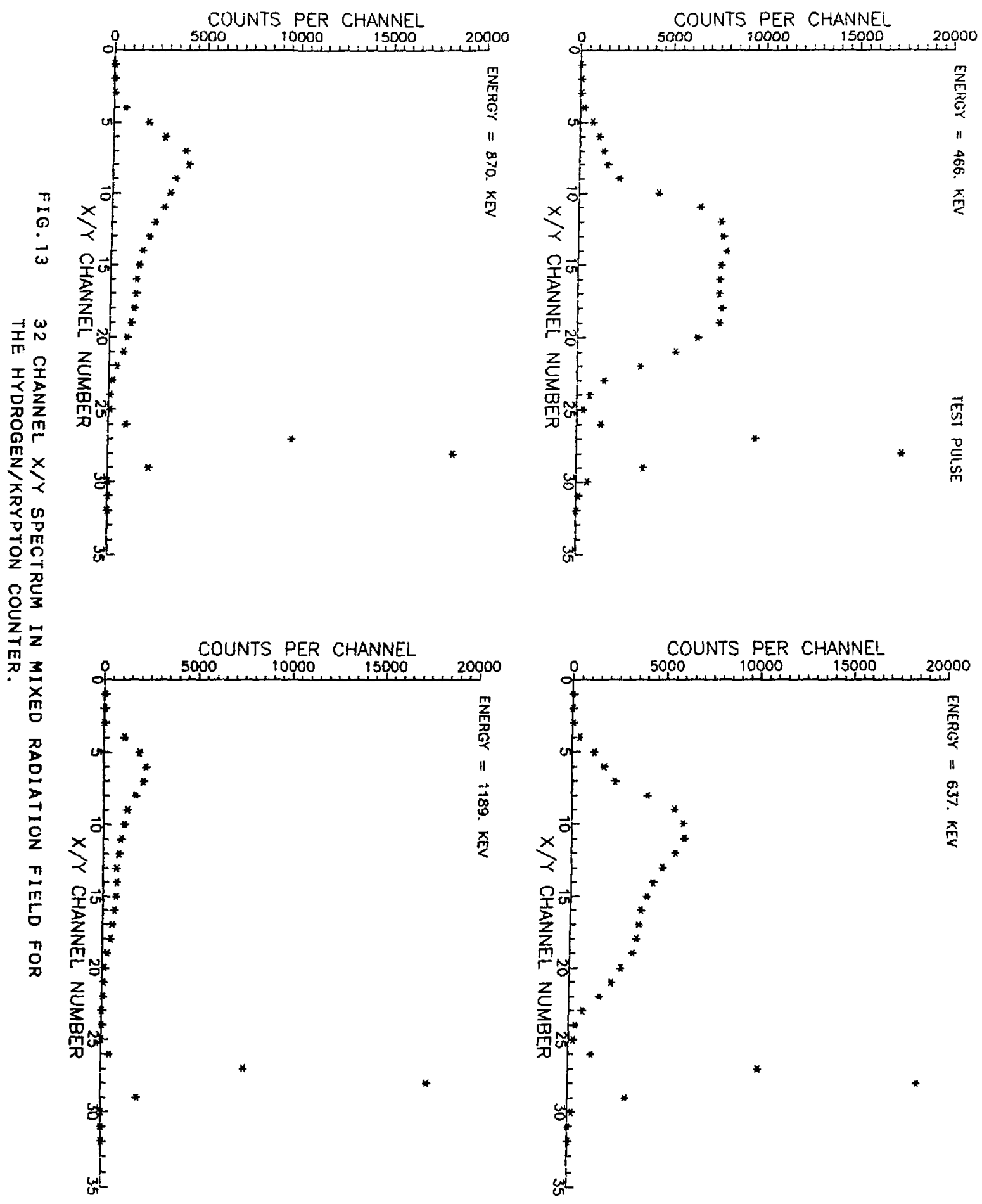

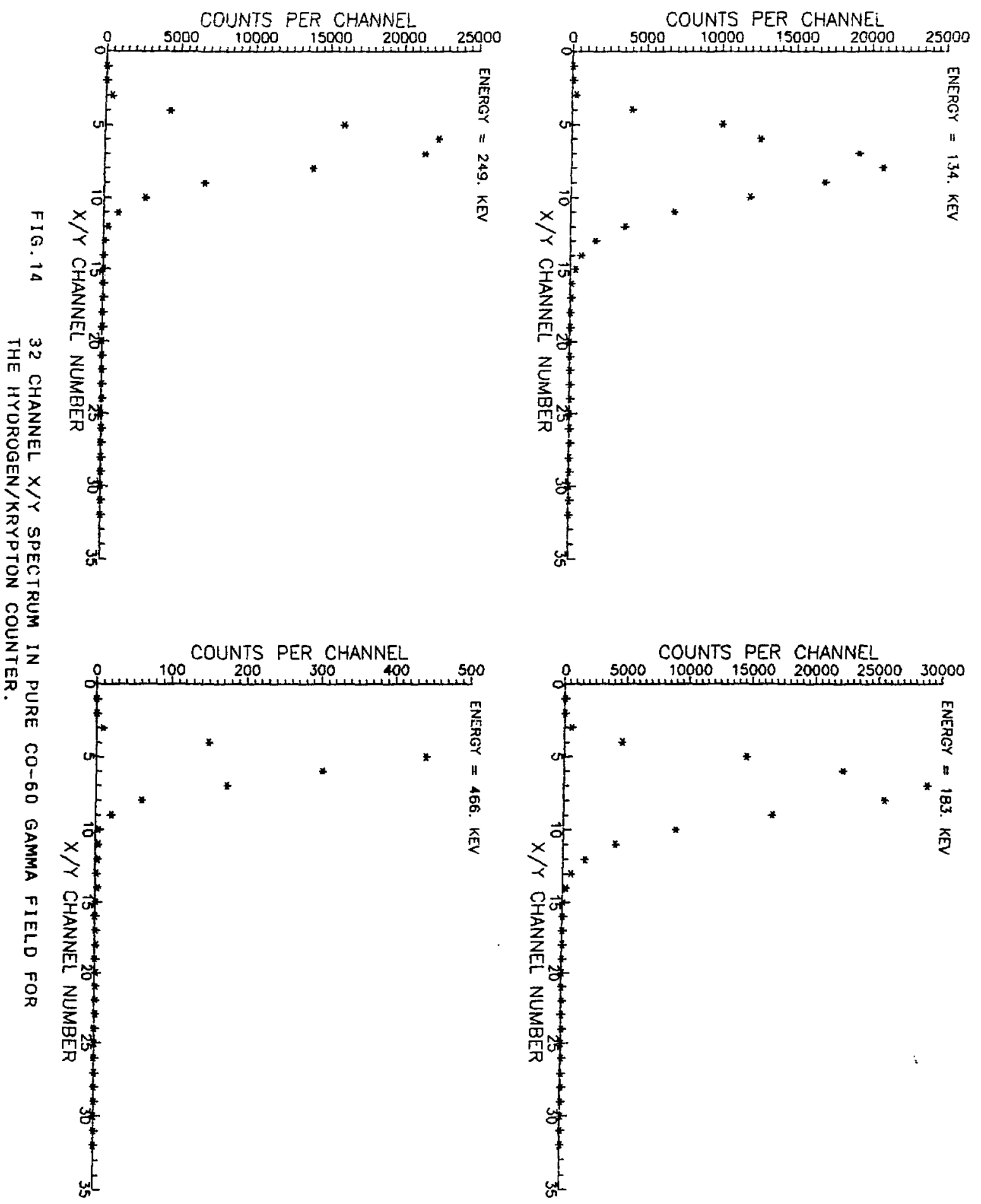


\section{RMPSWS}

The final numerical procedure required, RMPSNS as listed in Appendix VI, is needed to convert the measured distribution of proton recoil events, RAPS, to an absolutely normalized proton recoil spectrum. Use is made of the test pulser spectrum (denoted by TIME) recorded simultaneously with proton recoil data and the test pulse calibration spectra (WHION and WHAMP) recorded in the TPLSR procedure within RAMPDA in the absence of ionizing events. Normalization of the proton count by the test pulse count at each energy accomplishes live time correction. Normalization by the ratio of WHION to WHAMP accomplishes conversion to a white ionization reference spectrum.

In addition to data passed through from the RAMPDA procedure, we require a value for the absolute test pulser rate CPS, and for HATM, the number of hydrogen atoms in the effective counter volume. CPS is the absolute rate at which test pulses are recorded, not the rate of test pulse generation. The difference is in consequence of the fact that no pulses are recorded if test pulse amplitude is not within the $y$ amplifier acceptance window between LVL and 4096. This rate is best determined by a separate run using the TPLSR mode of RAMPDA (Appendix II) at any fixed voltage within table limits; the number for CPS provided in the TPLSR mode at full modulation may be incorrect (on the low side) if a swing in voltage is permitted with extremities that lie outside of the range of the tables constructed at the beginning of RAMPDA.

After all required data are input, the RMPSNS procedure determines absolute values for energy at each point (ENERGY(I)). The ionization created per unit proton energy loss becomes complicated at energies below $1 \mathrm{keV}$; use of a quantity WCTOFF set at $0.3 \mathrm{keV}$ (Ref. 5) is an approximate correction for this effect which will have little impact upon energy scale except at the lowest energies.

RMPSNS contains an option to edit data at each step. Figs. 15 and 16 contain plots of the proton recoil spectrum (RAPS) and of the corresponding test pulse spectrum (TIME) respectively for a measurement using the hydrogen counter in the JANUS facility. A characteristic feature of all of these spectra will be the readily observed break points at high and low energy that signal the energy values where amplifier channel limits are encountered. Events become less frequent above and below these limits since there are increasingly fewer combinations of amplifier pulse height channel and gas 


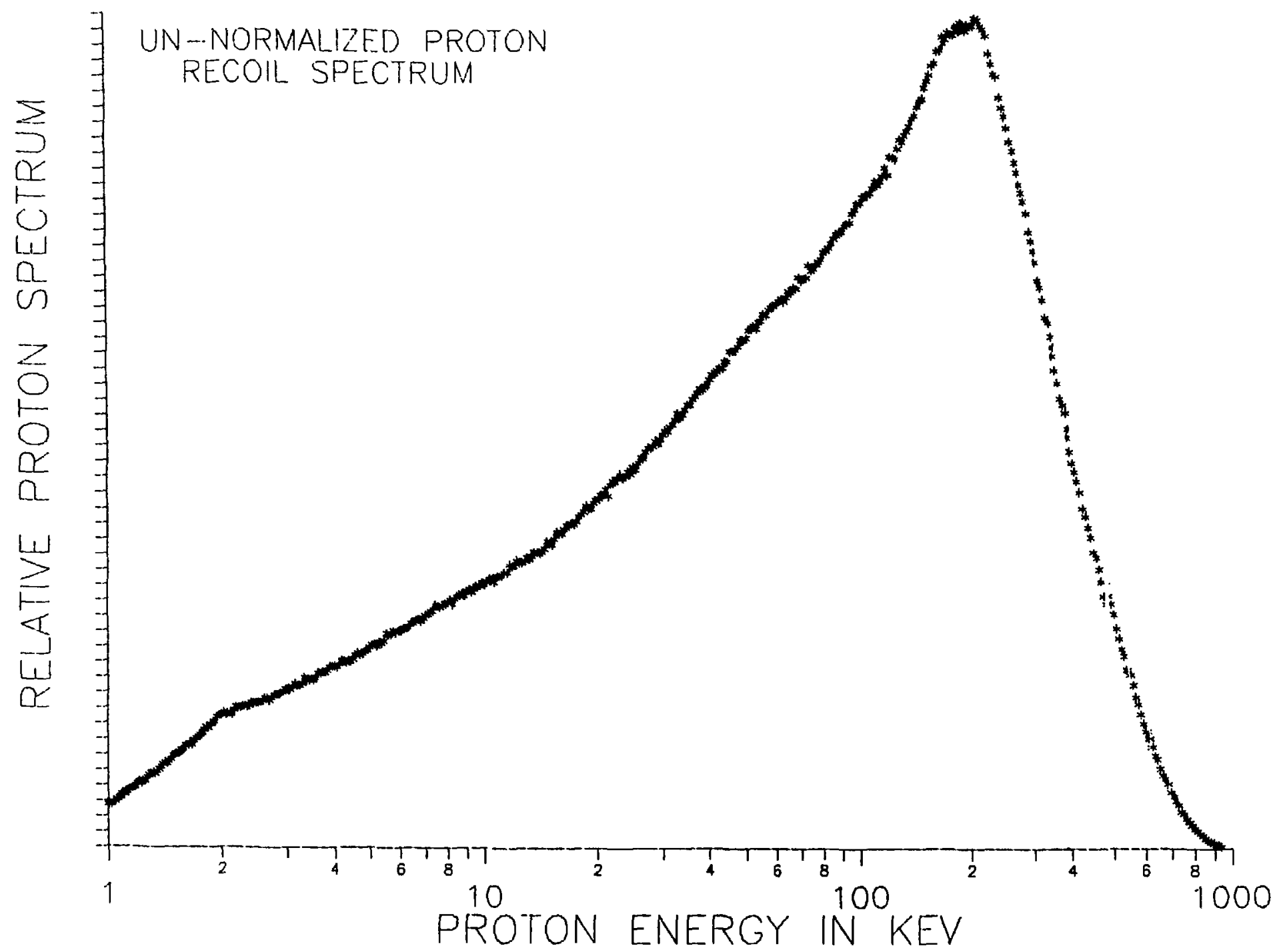

FIG. 15

PROTON RECOIL SPECTRUM BEFORE NORMALIZATION FOR THE HYOROGEN COUNTER. 


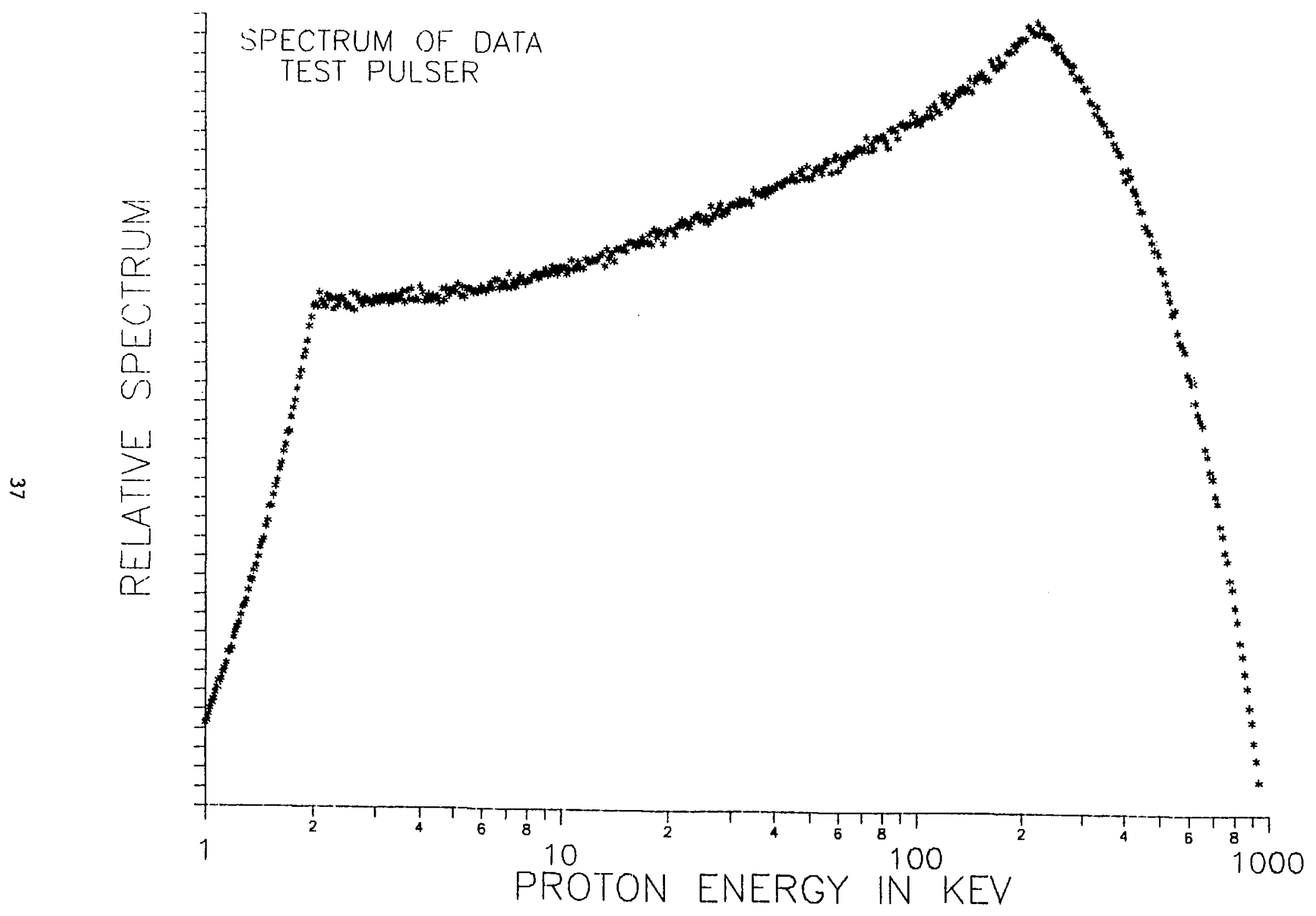

FIG.16 RANDOM TEST PULSE SPECTRUM FOR THE HYDROGEN COUNTER. 
multiplication that can lead to events of these limiting magnitudes.

Figs. 17 and 18 are plots of the calibration spectra WHION and WHAMP that represent the response of the system to event spectra that are uniform in ionization and in test pulse amplitude respectively. The WHION result is weighted by an arbitrary channel-dependent scaling factor to maintain an amplitude range appropriate for plotting. WHION, as input, increases in amplitude over several decades as energy decreases.

Fig. 19 is a plot of TIME after a smoothing has been done. There is no detail in the test pulse spectrum (the high and low break points are an artifact of the discrete limits upon the acceptance range of $y$ amplifier pulses). Since this spectrum is featureless and slowly varying, a smoothing operation can be applied to reduce the statistical uncertainty in the distribution as measured.

Fig. 20 is a plot of the proton recoil distribution normalized to the smoothed test pulse distribution. This normalization accomplishes the live time correction. Statistics in the plotted distribution are entirely in consequence of counting statistics in the RAPS spectrum.

Fig. 20 is the proton spectrum per unit test pulse amplitude spectrum. We desire the proton spectrum per unit "white" test pulse spectrum, which will simulate a normalization to a "white" ionization spectrum response. The conversion is through the ratio of white ionization to white amplitude shown in Fig. 21. This ratio involves only test pulse calibration data and is, therefore, featureless. Smoothing may, consequently, be carried out to reduce the statistical error in the ionization-to-amplitude calibration ratio.

Normalizing the spectrum of Fig. 20 to that of Fig. 21 provides the final result, which is plotted in Fig. 22 as the calibration normalized proton recoil spectrum. All normalization procedures (apart from the hydrogen atom content of the detector) have been applied and Fig. 22 is the measured result to be processed further into a neutron spectrum if desired. An arbitrary energy-dependent scaling factor has been retained to provide a range of the spectrum amplitude consistent with a linear ordinate scale for plotting purposes only. The true proton recoil spectrum increases monotonically with decreasing energy. Note that all of the high-low break channel effects are now absent; the normalization procedures using the random test pulse data has 


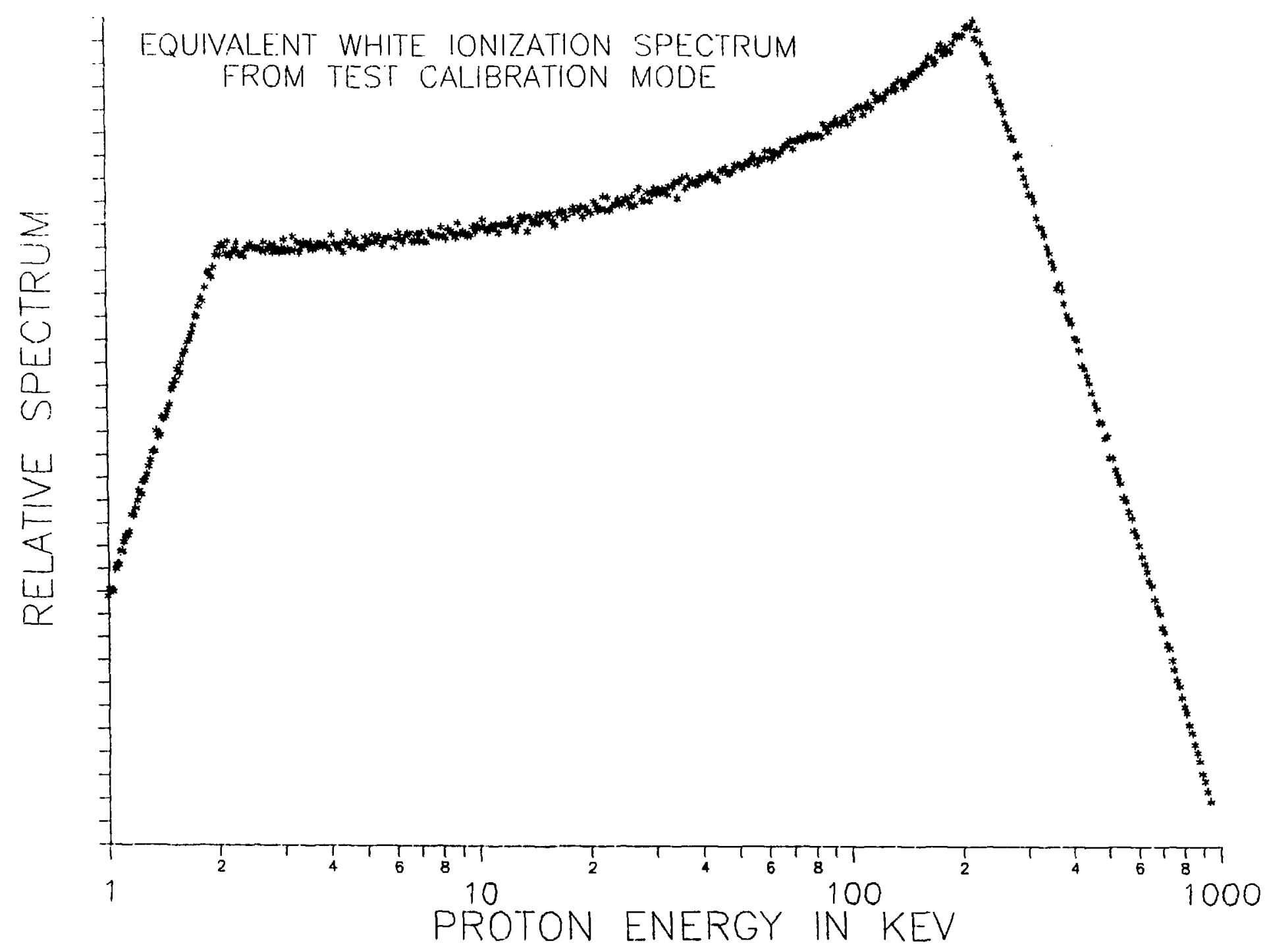

FIG. 17 WHITE IONIZATION CALIBRATION SPECTRUM. 


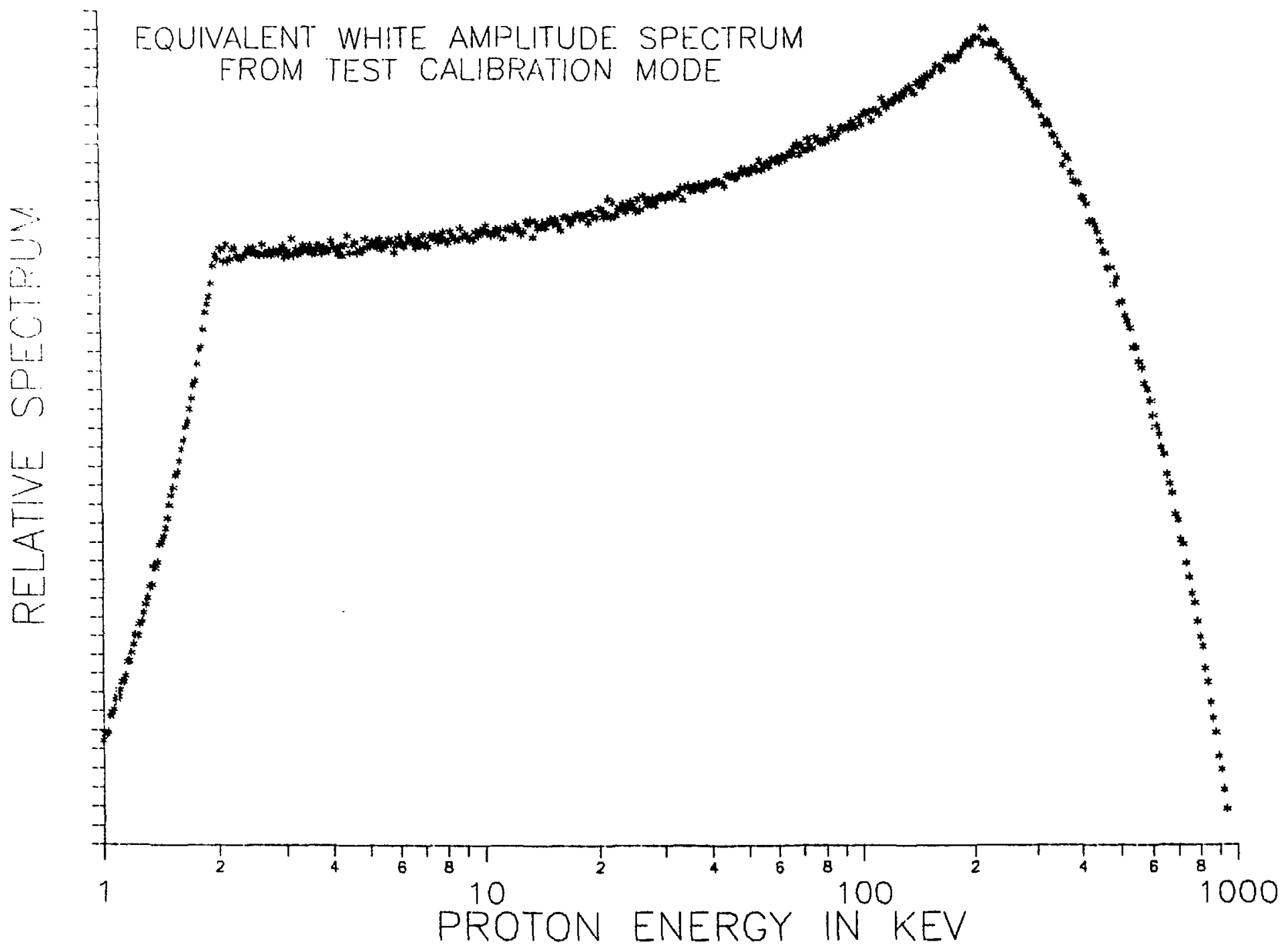

FIG.18 WHITE AMPLITUDE CALIBRATION SPECTRUM. 


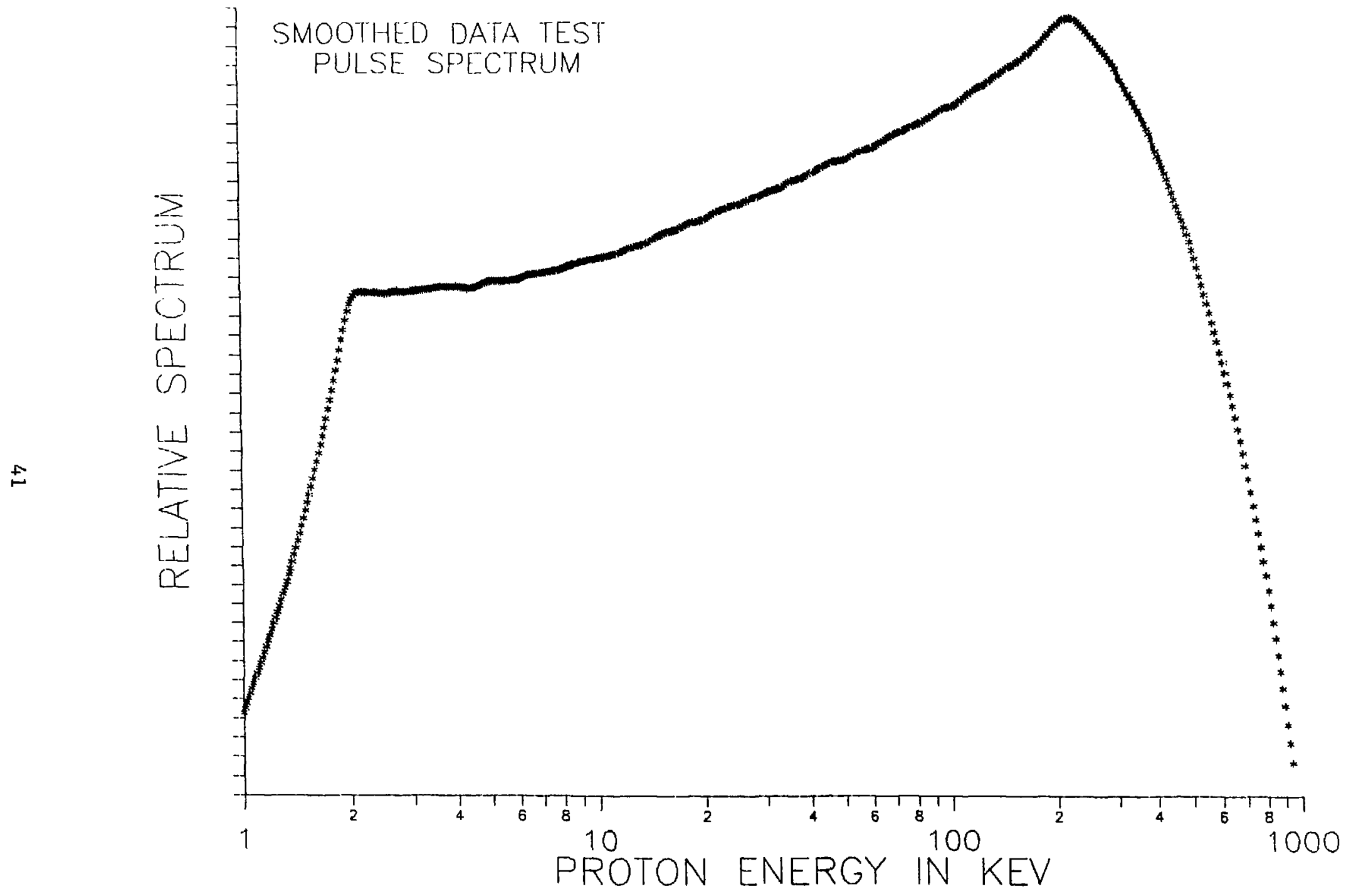

FIG.19 SMOOTHED TEST PULSER SPECTRUM 


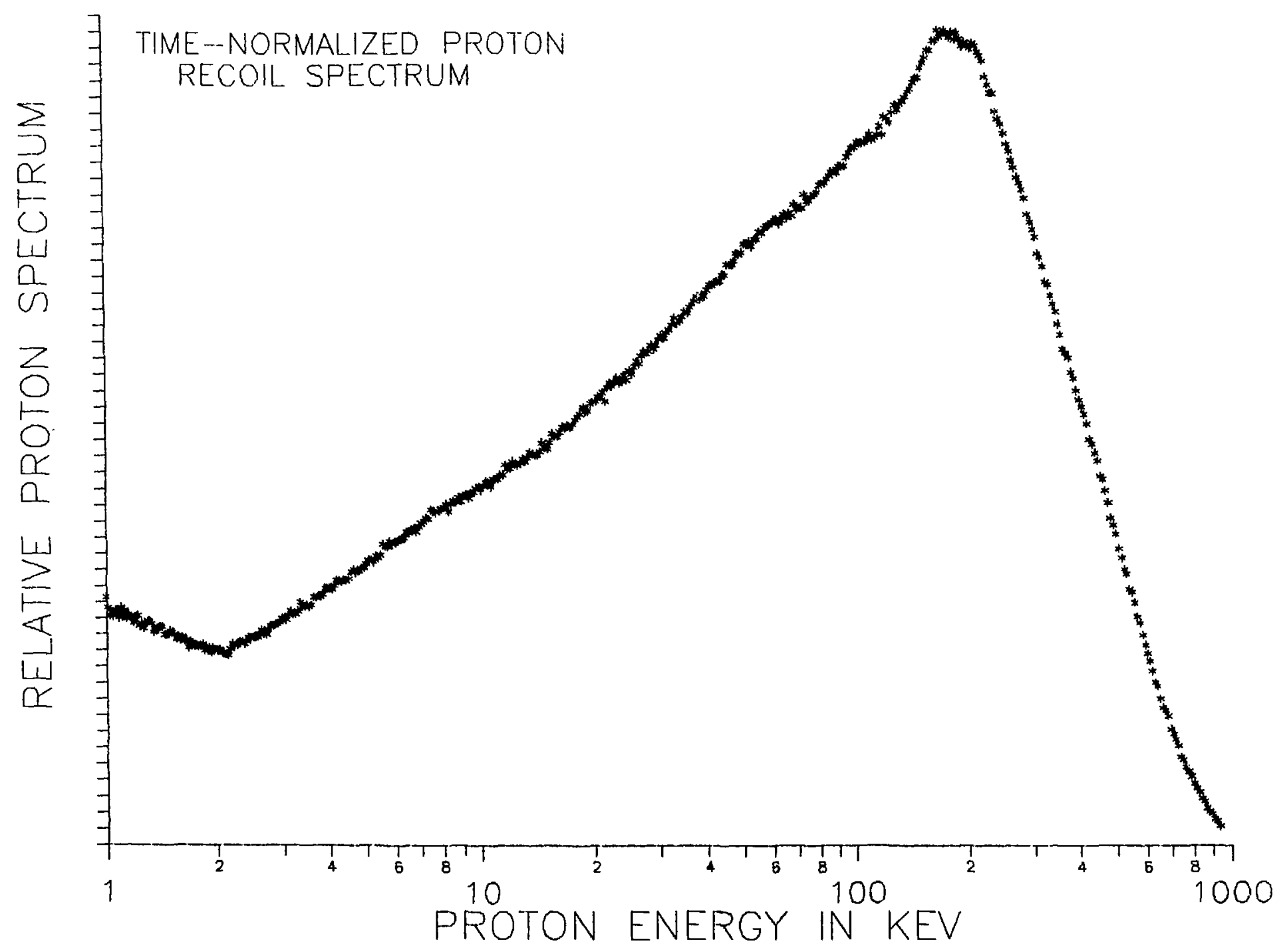

FIG.20 TEST-PULSER-NORMALIZED PROTON RECOIL SPECTRUM. 


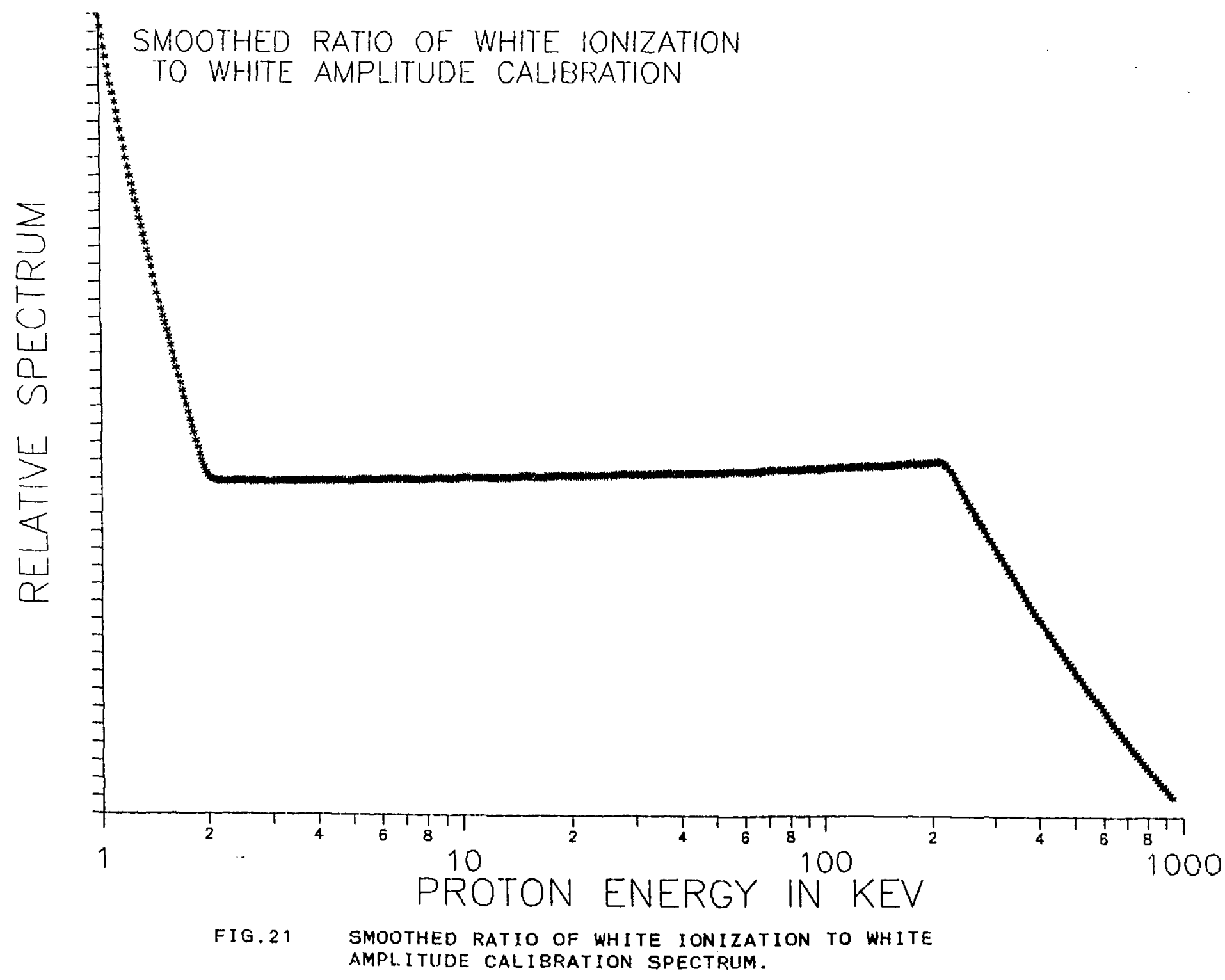




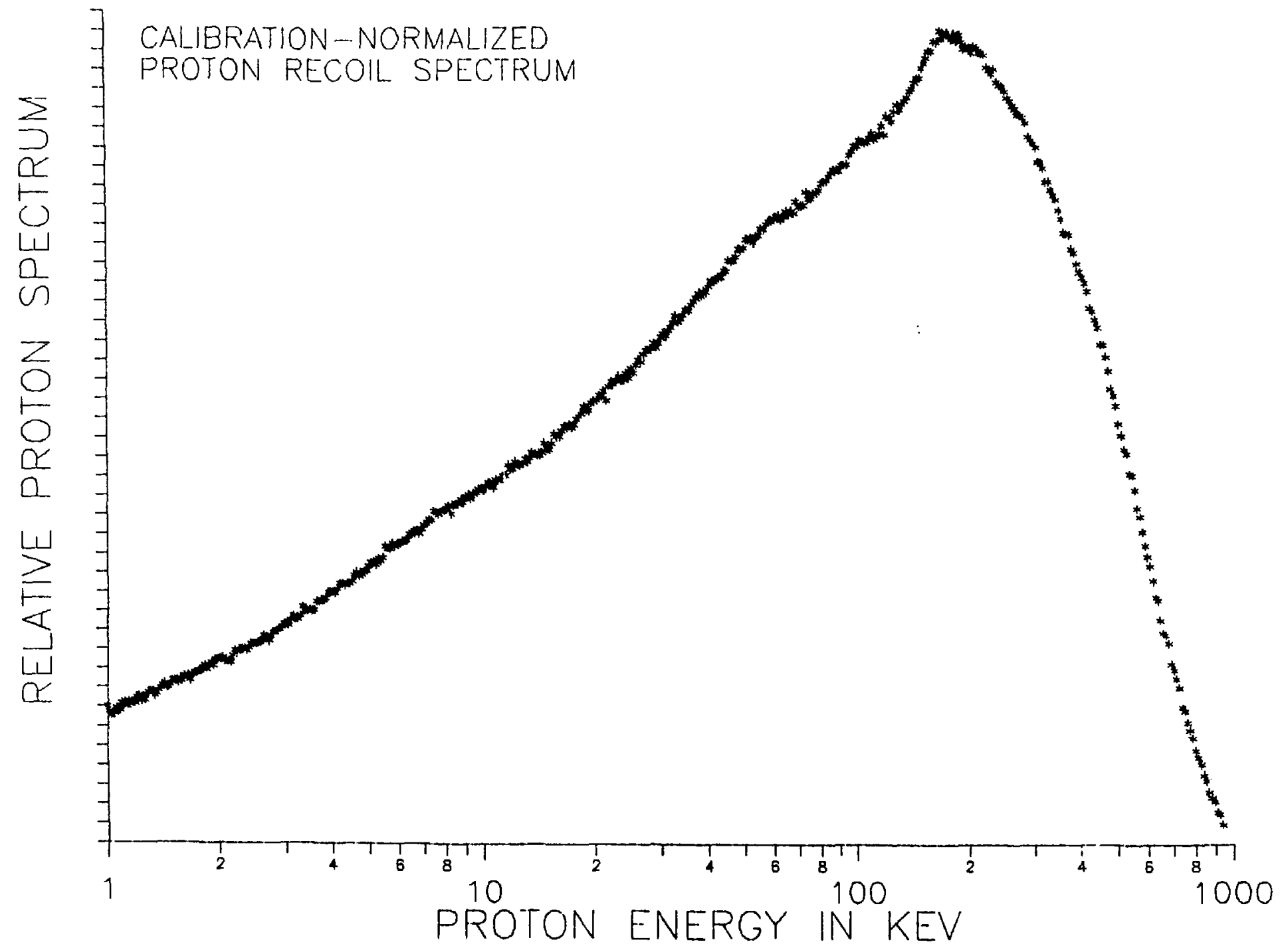

FIG.22 CALIBRATION-NORMALIZEO PROTON RECOIL SPECTRUM. 
removed these features and the final result only reflects statistics together with the true variation of proton recoil spectrum with energy.

Following completion of the normalization operations, the proton recoil spectrum is converted to a neutron spectrum using the same procedure found in Ref. 1 for example. The density of points in the neutron spectrum is reduced to be consistent with a lethargy spacing of about .05 , which is sufficient for plotting, and both the proton recoil spectrum and the neutron spectrum are saved for plotting using the GRAPHER (Ref. 6) plotting routines.

Figs. 23 and 24 contain plots of the JANUS proton recoil spectrum utilizing results from both the hydrogen counter and the hydrogen/krypton counter. Detailed plots of the intermediate analysis for the hydrogen/krypton data are not included since they are very similar in appearance to those shown in Figs. 15-22 for the hydrogen data.

The hydrogen counter data in Fig. 23 does not contain the correction for the wall-and-end truncation component discussed in Section VI which has a significant impact only above about $100 \mathrm{keV}$. The proton recoil spectrum is $10 \%$ or so above that for the higher stopping hydrogen/krypton counter in this energy region if the wall-and-end truncation component is retained for the hydrogen counter data. Fig. 24 contains the proton spectrum for both counters after the track truncation correction has been made. A significant improvement in agreement in the overlap region from $100 \mathrm{keV}$ to $200 \mathrm{keV}$ is seen if this correction is applied. Above about $200 \mathrm{keV}$, data for the hydrogen counter becomes increasingly subject to error as recoil tracks lengthen and the analysis procedures used in the RMPRDN code of Section VI break down entirely. The data analysis routines used here are unreliable for the hydrogen counter above about $200 \mathrm{keV}$; only counters with substantially improved stopping power can be used in this energy regime. One can, however, find a region of overlap at around 100 to $200 \mathrm{keV}$ where proton spectra for both counters are in substantial agreement.

An additional measurement in the JANUS facility was carried out using a counter filled with a $50 / 50$ mixture of hydrogen and argon. Proton-recoil spectra using each of the counters (hydrogen, hydrogen/argon, hydrogen/ krypton) are shown in Fig. 25 (no correction to the hydrogen counter data for wall-and-end effects were made). Results show that the proton recoil spectrum is not too greatly altered between the argon and krypton results for energies 


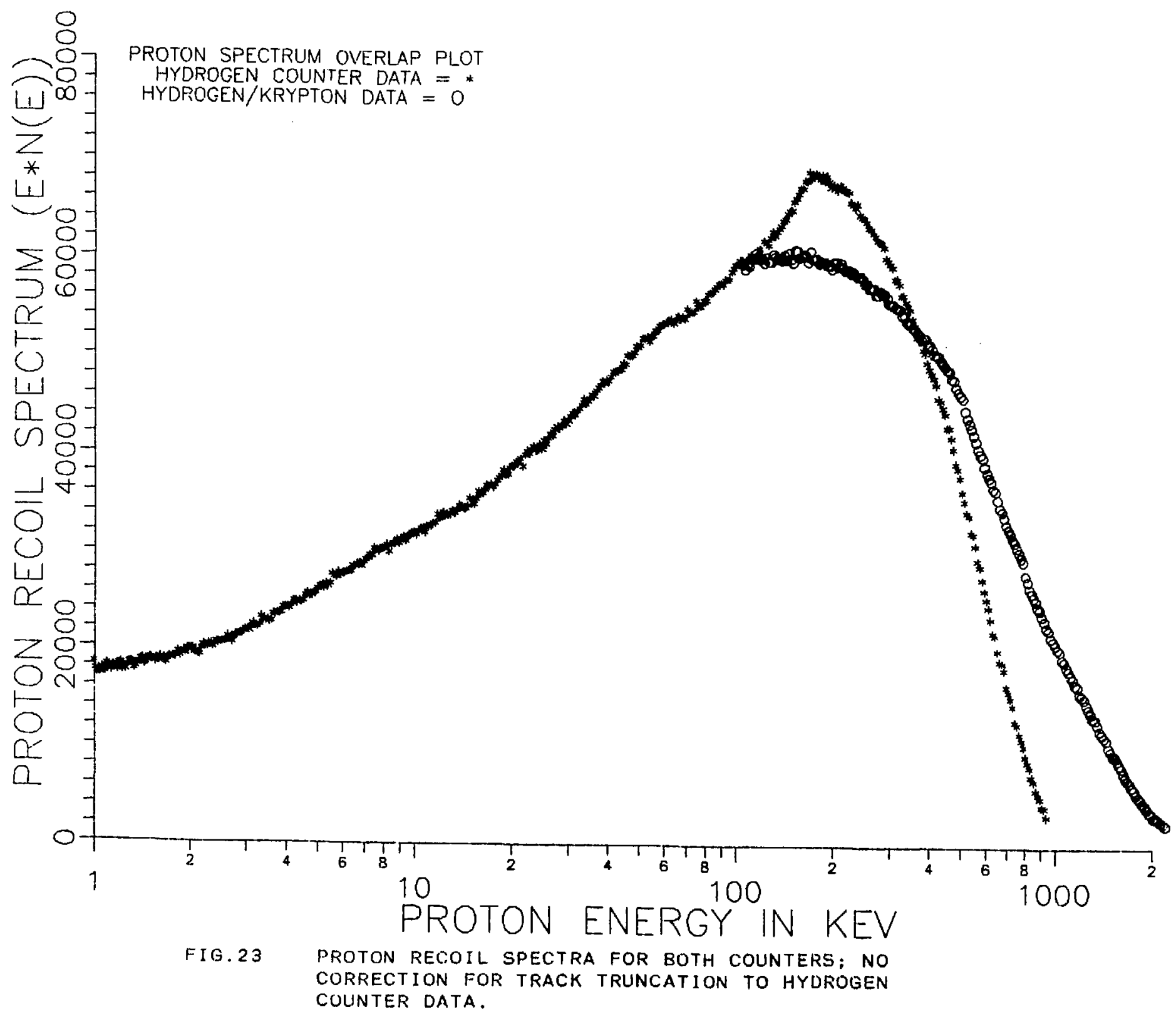




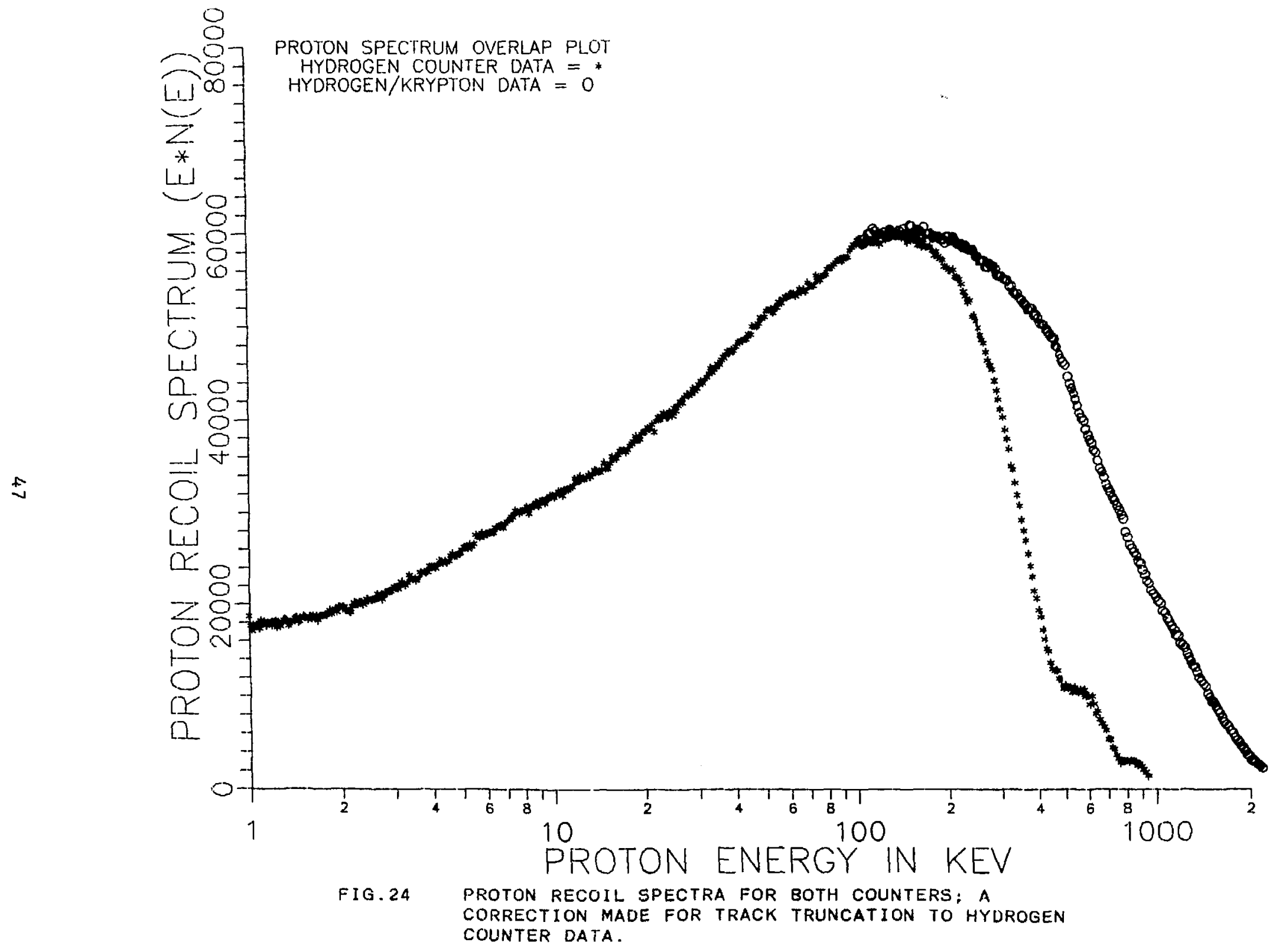




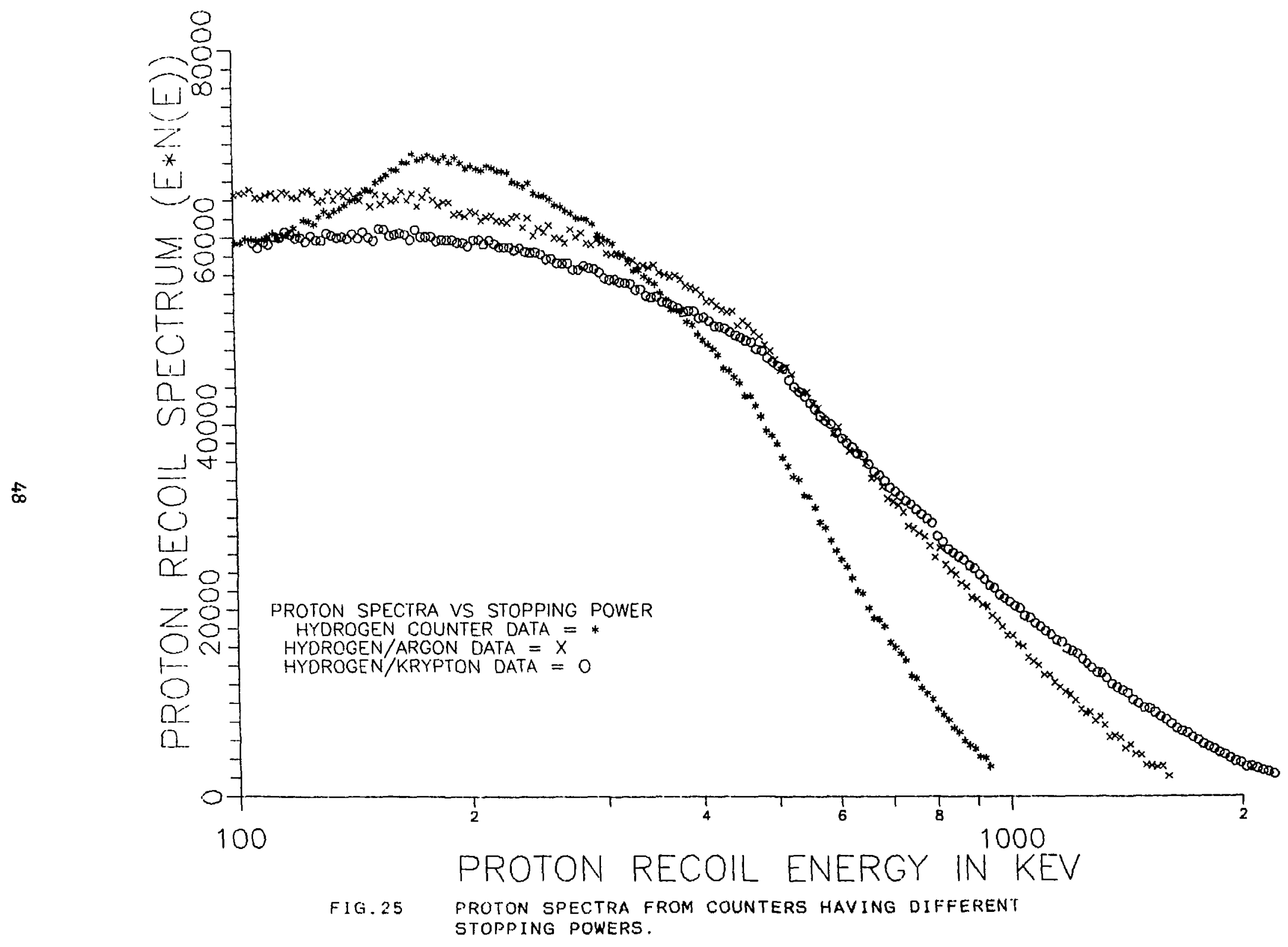


below about $1 \mathrm{MeV}$. The indication is that further increases in stopping power beyond hydrogen/krypton are only likely to result in substantial improvements in the spectrum at energies above about $1 \mathrm{MeV}$.

Fig. 26 contains the neutron spectrum using the joint hydrogen and hydrogen/krypton data taken in the irradiation room of the JANUS facility. The hydrogen counter data (Fig. 24) is used below $200 \mathrm{keV}$, the hydrogen/ krypton counter data is used above about $100 \mathrm{keV}$. Statistical (rms) error bars are also shown. The spectrum is very hard; this was a primary design objective for the facility. Additional information relating to the neutron spectrum at JANUS can be found in Ref. 2 .

\section{CONCLUSIONS}

The continuous acquisition mode neutron spectroscopy technique for proton recoil proportional counters offers several advantages by contrast with the conventional approach utilizing discrete voltage steps. Operation of the acquisition system is 'conventional'; the system is turned on and runs unattended for a time required to obtain adequate counting statistics. At the termination of the run all data over the full energy range is available for analysis. There are no restrictions on the voltage modulation profile. Use of a random amplitude test pulser is essential and test pulses are acquired together with data. A separate run with the test pulser in the absence of data serves to calibrate the pulse processing system completely and to provide a normalization for dead time losses. Pulse pileup and overload distortion are readily observable in their effects upon test pulse line widths for any energy.

The continuous mode data acquisition is also more efficient than are procedures using discrete voltages since considerable overlap of data from adjacent voltage settings is required if voltages are discrete. Also, efficiency is improved by avoiding the interruption of acquisition to check, store, and re-initialize acquisition as is required when using discrete voltages.

The basic period for the modulation will ordinarily be chosen rather long; several minutes or so. If the source intensity varies significantly over time intervals of several minutes, the continuous modulation procedure would become unsatisfactory and should not be considered. 


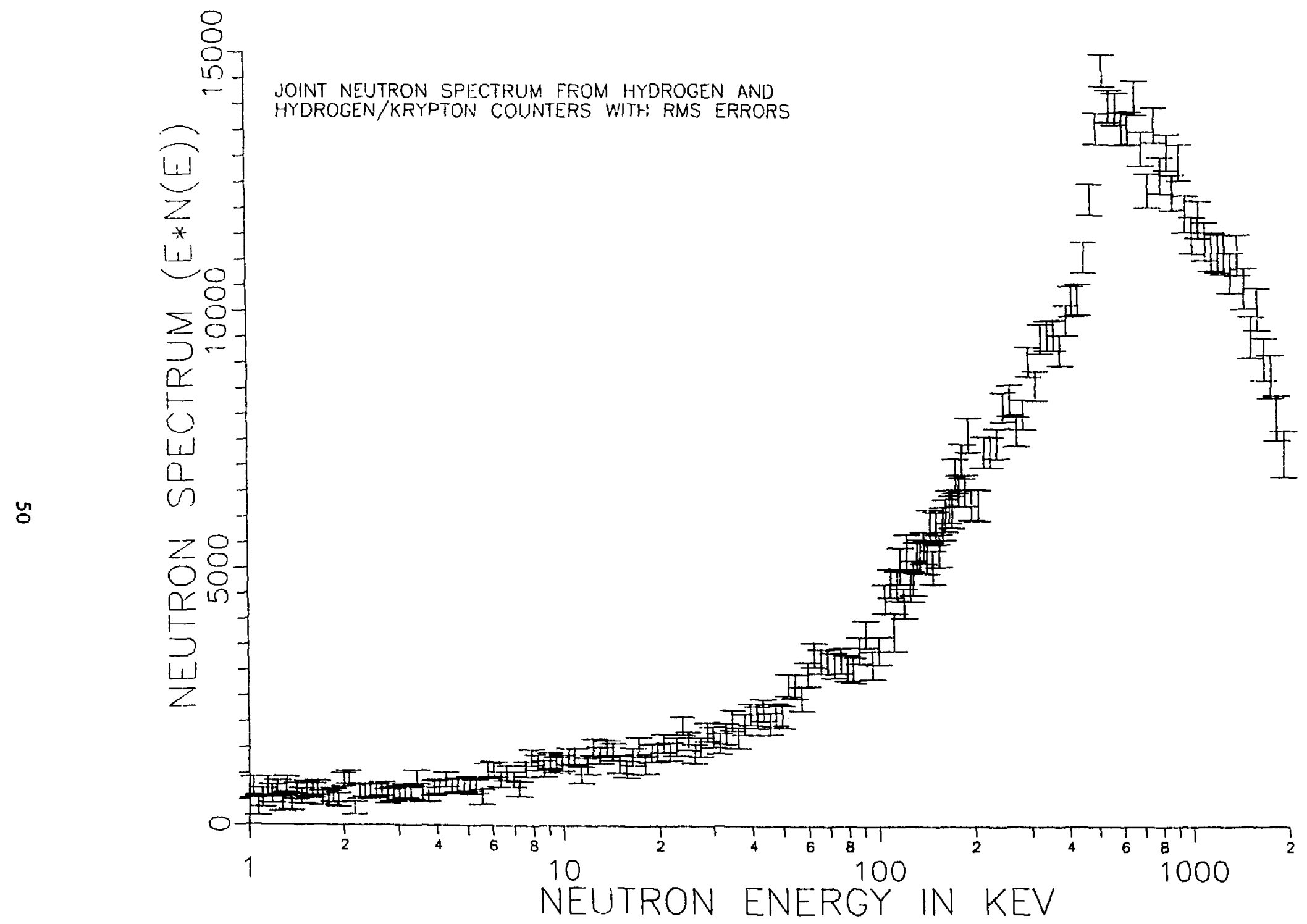

FIG. 26 NEUTRON SPECTRUM AT THE JANUS FACILITY SHOWING STATISTICAL ERRORS. 
It appears, rather unfortunately, that a pair of counters that provide overlapping data will be required to obtain good-quality measurements over the full energy region from about $1 \mathrm{keV}$ to about $2 \mathrm{MeV}$. Hydrogen gas is certainly preferable for use at energies below about $200 \mathrm{keV}$. Admixing hydrogen with heavy noble gases will extend the upper energy response well beyond that attainable with hydrogen alone. These noble gas counters will acquire sensitivity to soft photons however, and measurements at the lower energies will become difficult to perform since discrimination against this type of background may be poor. If one can tolerate a somewhat more limited result, a $50 / 50$ mixture of hydrogen and argon may be acceptable and single counter data from about $10 \mathrm{keV}$ to about $1 \mathrm{MeV}$ can be obtained if a careful calibration for the counter is carried out over this energy region. For many practical applications, including fast-neutron dosimetry in degraded fission spectra, it may suffice to only obtain recoil proton data in this more restricted energy region. 


\section{ACKNOWLEDGMENTS}

We wish to acknowledge the participation of T. J. Yule in carrying out the development program outlined here. 


\section{REFERENCES}

(1) T. J. Yule and E. F. Bennett, "Techniques and Analyses of Fast Reactor Neutron Spectroscopy With Proton-Recoil Proportional Counters" ANL-7763 (1971).

(2) E. F. Bennett and T. $\therefore$. Yule, "A Neutron Spectrum Measurement at the JANUS Facility Using Proton-Recoil Proportional Counters" Radiation Research 50, No.2 (1972).

(3) PC-MATE BASE BOARD, TECMAR INC., 6225 Cochran Road, Solon, Ohio.

(4) GRAFMPIC, MICROCOMPATIBLES INC., 301 Prelude Dr., Silver Springs, Md.

(5) E. F. Bennett, "Proportional Counter Proton-Recoil Spectrometer With Gamma Discrimination" Rev. Sci. Inst. 35, 1153 (1962).

(6) GRAPHER, GOLDEN SOFTWARE INC., 807 14th St., P.0. Box 281, Golden Colorado. 
APPENDIX I

LISTING OF THE CODES PRINIT.FOR AND PRMINP.ASM USED FOR SETUP AND TESTING 
LISTING OF THE CODES PRINIT.FOR AND PRMINP. ASM USED FOR SETUP AND TESTING.

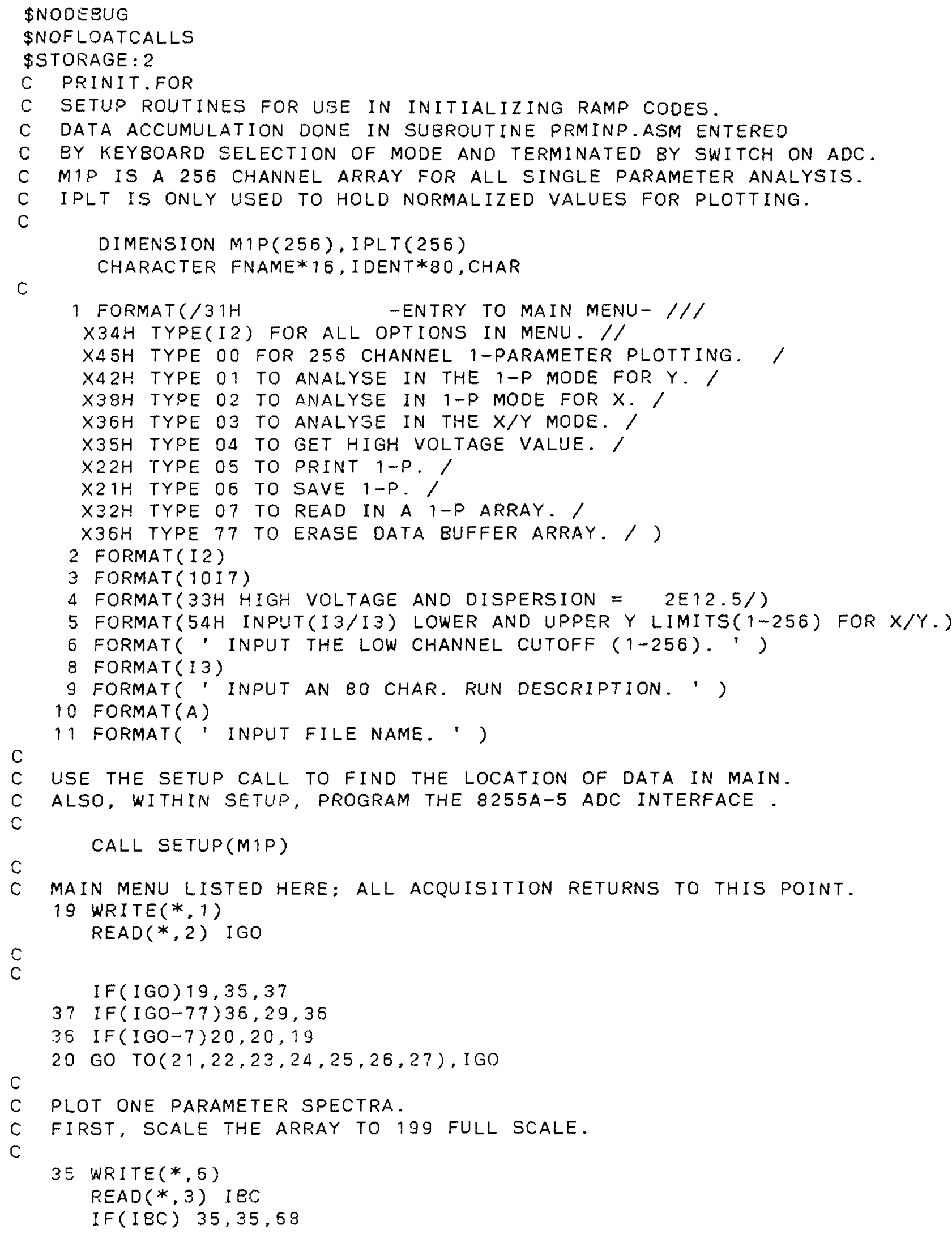




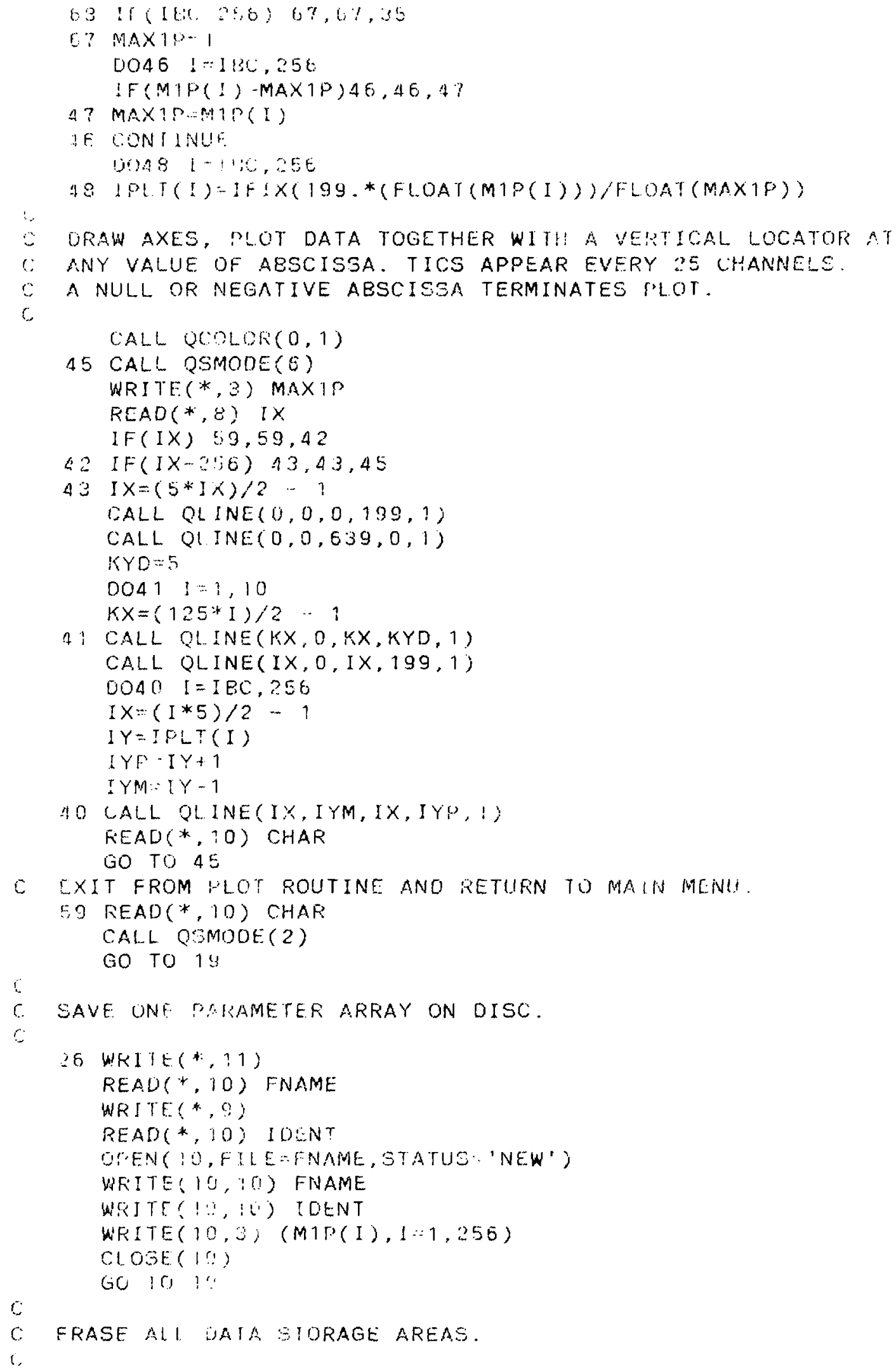




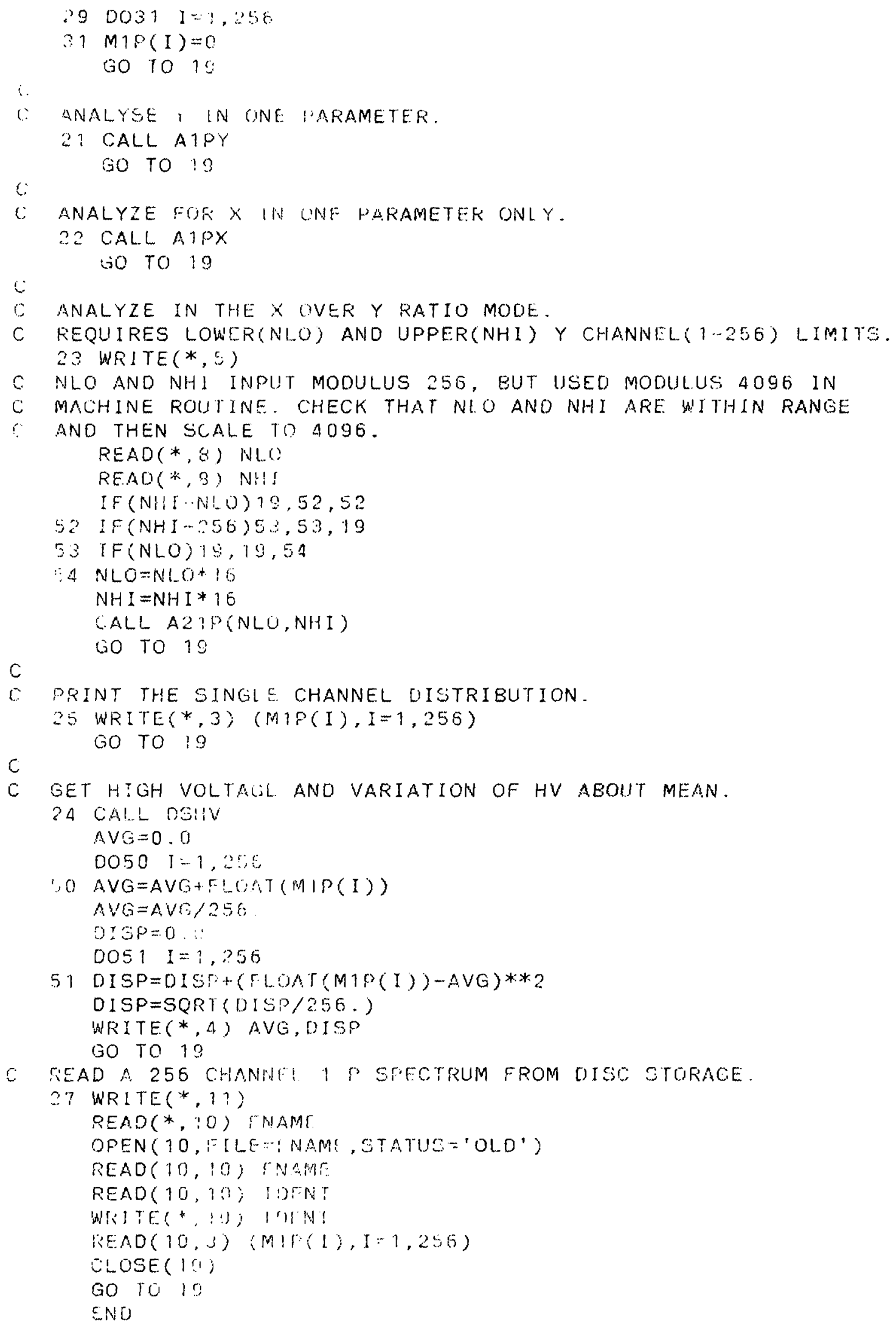


PAGE $\quad 132$

TITLE PRMINP.ASM

; SETUF TOUITINE FOR RAMP PROCEDURE.

PRMINP IS A UTILITY PROGRAM FOR PUISE AMPLITUDE ANALYSIS

LISING HIGH VOLTAGE BIAS MODULATION.

INPUT IS FROM A 4096 ADC THROUGH AN 8255A-5 INTERFACE IN COMPAQ.

PRMINP ANALYSES SEQUENTIALLY ALL THREE INPUT VARIABLES.

PRMINP CONTAINS THE FOLLOWING PUBL IC ROUTINES:

1) A1PX... ANALYSE THE X ADC IN 1 PARAMETER

2) AIPY... ANALYSE THE Y ADC IN 1 PARAMETEK.

3 DSHV... DETERMINE HIGH VOLTAGE VALUE.

4) A21P... ANALYSE IN THE IP MODE OF $2 P$.

5) SETUP... LOCATE THE arRaYS IN MAIN, program InTERface.

SATA NEEDED FOR QUAD TECHMAR 8255 INTERFACE.

; EASE ADDRESS AND RELATIVE LOCATION OF PORTS.

; ALSO LOCATION OF THE EXIT BIT INDICATING RUN TERMINATION.

;

EASE EQU 240 ;8255A $\cdots 5$ BASE ADDRESS FOR UNIT \#O.

$P P$ EQU 0 ;CONTROL PORT ADDRESS

PA EQU 3 ;A PORT AOURESS.

PP. EQU 2 ;B PORT ADDRESS.

PC EQU 1 ;C PORT ADDRESS.

EXE EQU 100000008 ;TOP BIT OF B BYTE FOR EXIT.

;

DATA SEGMENT 'DATA'

M1F DW(O) ; THE ONE PARAMETER SPECTRA ( $X, Y, X / Y$ ) RESIOF HERE.

NI.O OW(O) :LOWER Y CHANNEL $(1-4096)$ BOUNO FOR $X / Y$.

NHII DW(O) ;UPPER Y CHANNEL $(1-4096)$ BUUND FOR $X / Y$.

DATA ENDS

XIROLIP GROLIP TOATA

CONE SEGMENT 'CODE'

ACSOUME CS:CODE, DS:DGROUP, SS:DGROUP

SETUT IG USEO TO LOCATE THE ADDRESSE OF DATA ARRAY FROM MAIN. ALSO, PROGRAMMING OF THE $8255 A-5$ IS CARRIED OUT IN SETUP.

SETUP FONC FAR

PUELIC SETUP

PUSH EF

MOV EF,SP

MOV BX, [EOH] ;ADDRESS OF IP ARRAY.

MOV MIP, BX

WWOKAM THE Q255 T/O FORT.

MOV AL, OBGH ;MODE 1, OPTION ?.

OUT BASE+PP,AI.

POF $\quad$ EP

RET 4

; EACK TO MAIN. 
EXIT FROM ALL ACQUISITION ROUTINES IS ACCOMPLISHED BY RAISING

DATA BIT 16 (TOP BIT OF MOST SIGNIFICANT BYTE IN PORT B).

THIS BIT IS ATTACHED DIRECTLY TO A SWITCH ON THE ADC.

;........A $1 \mathrm{PX}$

A $1 \mathrm{PX}$

PROC

ANALYSE

PUBLIC

FAR

MOV

A $1 P X$

$S I, M 1 P$

;PUT STARTING 1P ADDRESS IN SI.

RSET REQUIRED INITIALLY AND WHEN DATA IS NOT WITHIN AN ACCEPTABLE RANGE. RESET IS ACCOMPLISHED BY TOGGLING BIT 7 OF THE C PORT UP AND THEN DOWN.

IN SINGLE PARAMETER MODES, CONVERSION IS 4096 FULL SCALE BUT ARRAY IS SAVED ONLY TO EXTENT OF 256 CHANNELS.

$\begin{array}{lll}\text { MOV } & \text { AL, OFH } & \text {;LOAD BIT HIGH. } \\ \text { OUT } & \text { BASE+PP,AL } & \text {;SET BIT HIGH. } \\ \text { IN } & \text { AL, BASE+PA } & \text {;INPUT A PORT AND CLEAR. } \\ \text { IN } & \text { AL, BASE+PB } & \text {;INPUT B PORT AND CLEAR. } \\ \text { MOV } & \text { AL, OEH } & \text {;LOAD BIT } 7 \text { LOW. } \\ \text { OUT } & \text { BASE+PP,AL } & \text {;SET BIT } 7 \text { LOW AND RESET. }\end{array}$

; READ IN Y AS A DUMMY PROCEDURE TO INITIATE CONVERSION OF $x$.

STRTIX: IN AL, BASE+PC ;GET C PORT DATA.

TEST AL, 02 :TEST BIT 2 HIGH.

JE STRTIX

; LOOP TILL DATA READY.

IN AL, BASE+PA :INPUT LOW BYTE OF DATA FROM PORT A.

IN AL, BASE+PB ;INPUT HIGH BYTE FROM PORT $B$.

; REPEAT THE INPUT PROCEDURE TO ACQUIRE $X$.
STRT 2X: IN
TEST
$A L, B A S E+P C$
; GET C PORT DATA.
JE
$A L, 02$
; TEST BIT 2 HIGH.
STRT $2 X$
; LOOP TILL DATA READY.
IN AL, BASE+PA
INNUT LOW BYTE OF DATA FROM PORT A.
MOV
$D L, A L$
IN $\quad A L, B A S E+P B$
MOV $D H, A L$
; AND PUT INTO DL.
: INPUT HIGH BYTE FROM PORT B.
; FULL WORD IN DX.

; ONE MORE TIME TO CLEAR HV AND RE-ENABLE.

STRT $3 X:$ IN AL, BASE+PC

TEST AL,O2

JE STRT $3 X$

IN $A L, B A S E+P A$

IN $A L, B A S E+P B$

;

$\begin{array}{ll}\text { TEST } & \text { DH, EXE } \\ \text { JNE } & \text { RET IX } \\ \text { INC } & D X \\ \text { INC } & \text { DX } \\ \text { CMP } & \text { DX, 4096 } \\ \text { JNS } & \text { STRT } 1 \times \\ \text { SAR } & D X, 1 \\ \text { SAR } & D X, 1\end{array}$

; TEST EXIT BIT.

;IF EXIT BIT SET, RETURN TO MAIN.

; TOP VALID $X=4096$.

;START OVER IF PULSE IS TOO LARGE.

SAR DX, 1

DX, 1

:SCALE FROM 4096 TO 256 (2 BYTES). 


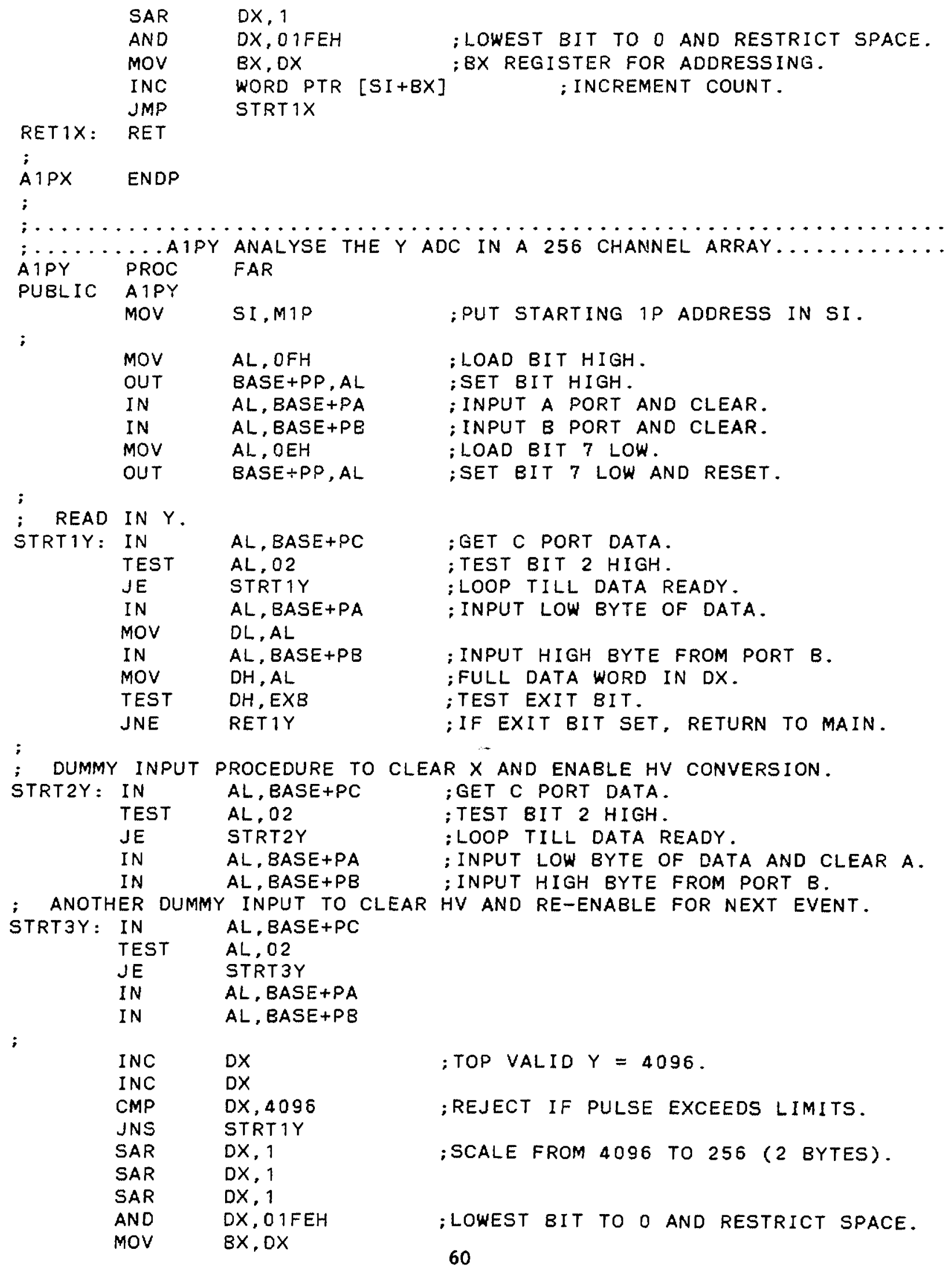




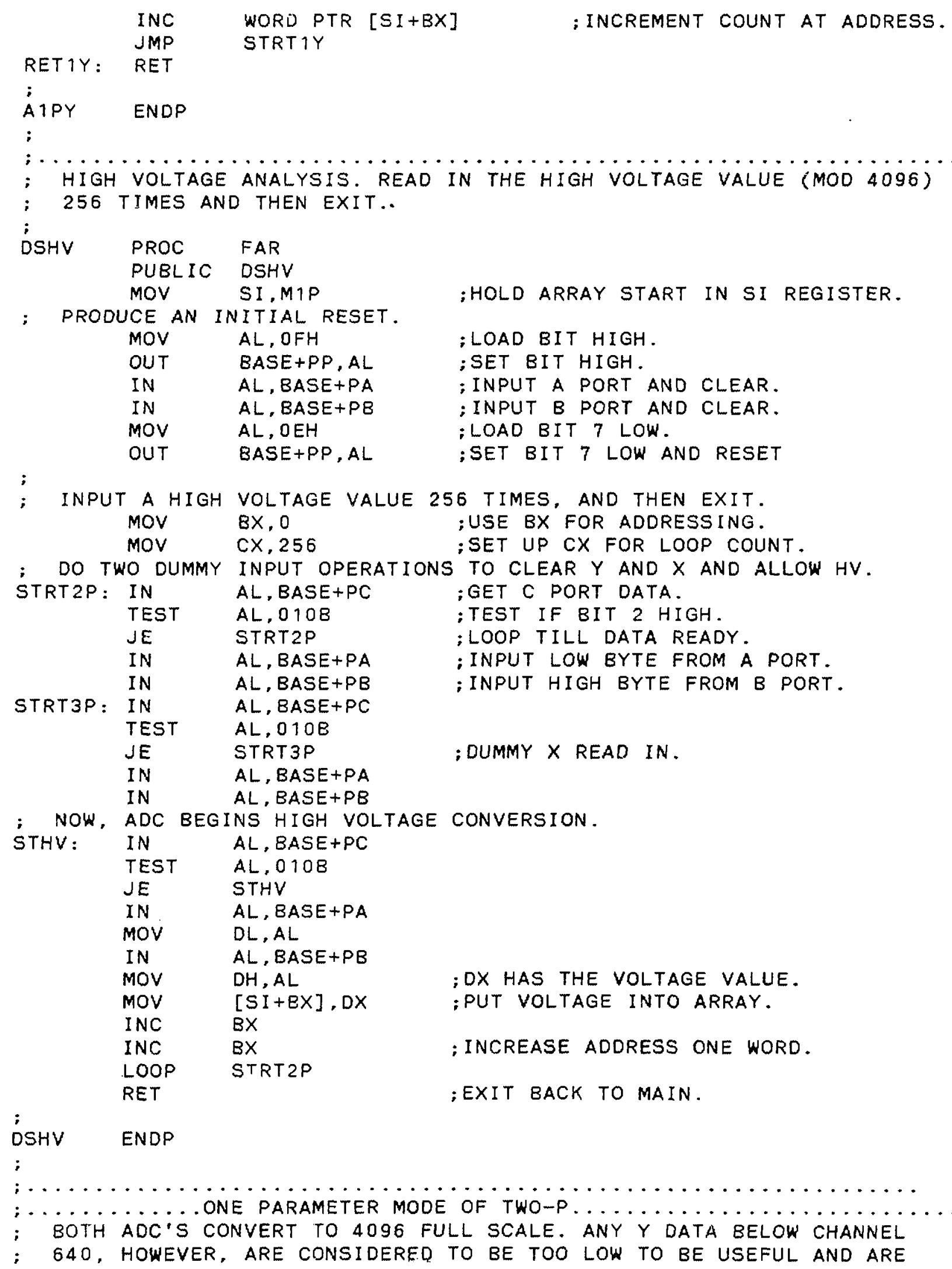




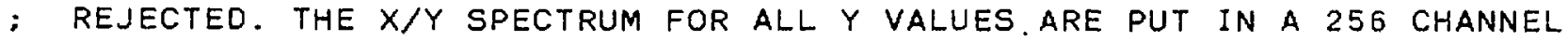
; ARRAY.

;

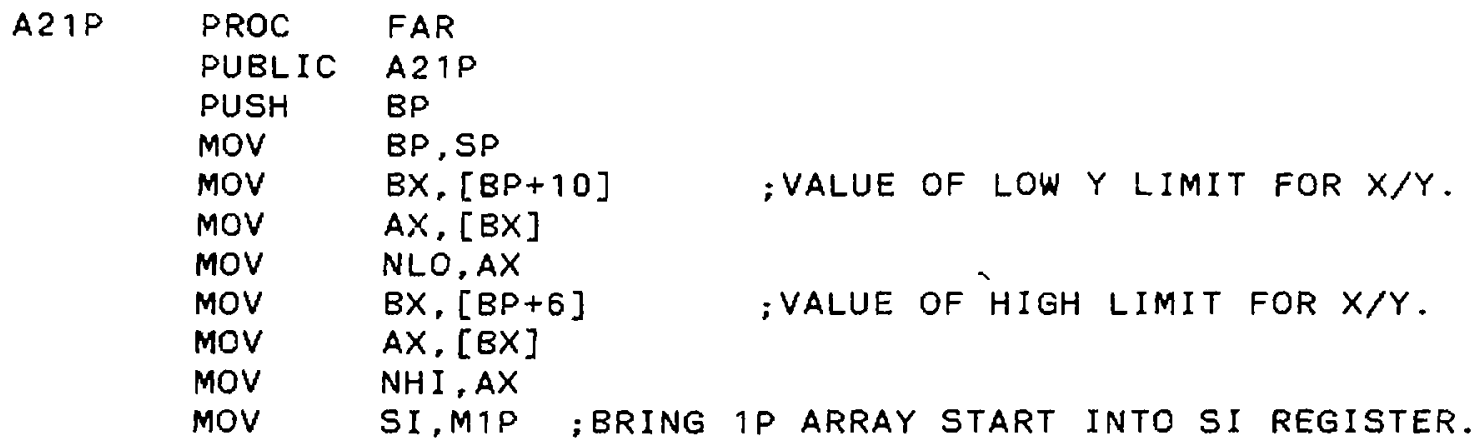
; PRODUCE AN INITIAL RESET OR RESET FOLLOWING BAD DATA.
RS21P: MOV
$A L, O F H$
OUT BASE+PP, AL
IN AL, BASE+PA
IN AL, BASE+PB
MOV AL, OEH
OUT BASE+PP,AL
; LOAD BIT HIGH.
; SET BIT HIGH.
; INPUT A PORT AND CLEAR.
; INPUT B PORT AND CLEAR.
; LOAD BIT 7 LOW.
;SET BIT 7 LOW AND RESET.
ST21P: IN
TEST
$A L, B A S E+P C$
; GET C PORT DATA.
$J E$
$A L, 010 B$
; TEST IF BIT 2 HIGH.
; LOOP TILL DATA READY.
IN AL, BASE+PA
; INPUT LOW BYTE FROM A PORT.
MOV
$D L, A L$
;SAVE IN DX REGISTER
IN AL, BASE+PB
; INPUT HIGH BYTE FROM B PORT.

AT THIS POINT, ADC BEGINS $X$ CONVERSION.

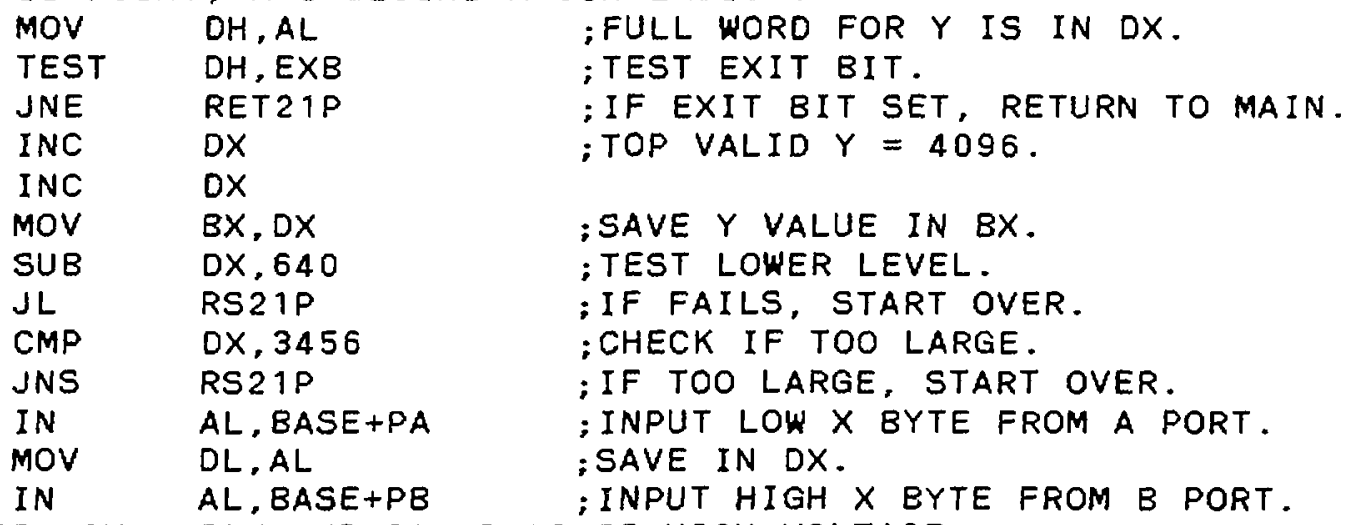

; ADC IS NOW RESET AND CAN PROCESS HIGH VOLTAGE.

MOV DH,AL ;FORM WORO IN DX FOR $X$ DATA.

; CHECK TO SEE THAT NLO $Y Y \angle N H I$ BEFORE PROCEEDING.

$\begin{array}{lll}\text { INC } & \text { OX } & \text {; TOP VALID } X=4096 . \\ \text { INC } & \text { DX } & \text {;TEST Y AGAINST NLO. } \\ \text { CMP } & \text { BX,NLO } & \text {;IF Y LESS, RE-START. } \\ \text { JS } & \text { RS21P } & \text {;TEST Y AGAINST NHI. } \\ \text { CMP } & \text { BX,NHI } & \text {;IF Y GREATER, RE-START. } \\ \text { JNS } & \text { RS21P } & \text {;DON T LET X EXCEED OR EQUAL Y. } \\ \text { CMP } & \text { BX, DX } & \text {;IF IT IS, START OVER ON NEW DATA. } \\ \text { JLE } & \text { ST21P } & \text {;MULTIPLY } X \text { BY } 512 . \\ \text { ROL } & \text { DX, } 1 & \end{array}$




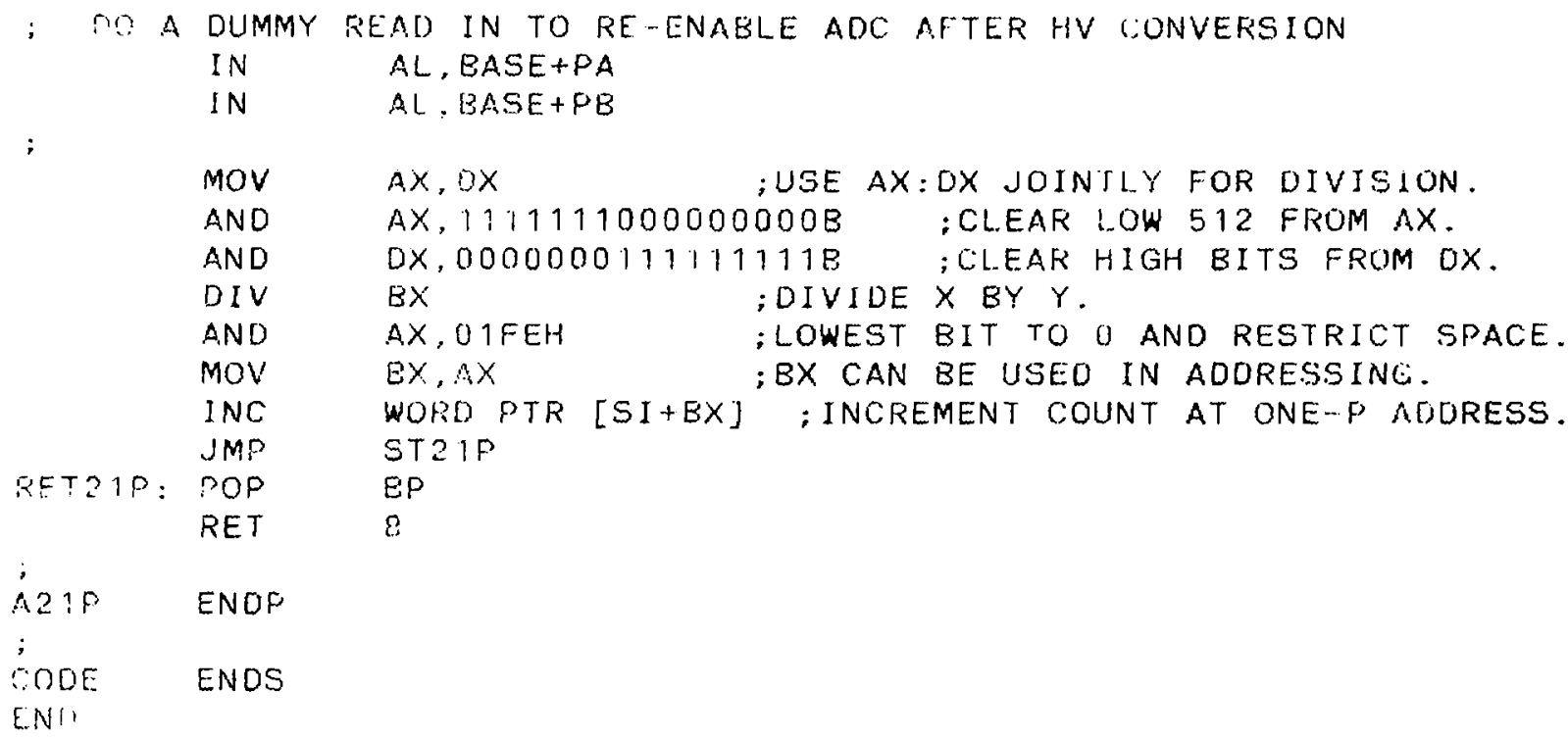


APPENDIX II

LISTING OF THE CODES RAMPDA.FOR AND RAMPIN.ASM FOR DATA ACQUISITION 
LISTING OF THE CODES RAMPDA.FOR AND RAMPIN. ASM FOR OATA ACQUISITION.

\section{\$NODEBUG}

\$NOFLOATCALLS

\$STORAGE: 2

C RAMPOA.FOR

C RAMP VOLTAGE MODULATION ACQUISITION FOR RECOIL PROTON COUNTERS.

C RECOIL PROTON ACQUISITION DONE IN MACHINE ROUTINE RAMPIN. ASM.

C RAMPIN HAS ANA FOR PROTON RECOIL ACQUISITION AND TPLSR FOR

C TEST PULSE CALIBRATION.

C

C DO NOT INCREASE ARRAY DIMENSIONS OR PROGRAM MAY EXCEED ONE PAGE. DIMENSION IGAIN(3000), LOGTB(4096), INLGTB(3548), IDAT( 32,512$),$ $X I D U M(512)$, WHION $(512)$, WHAMP ( 512$)$

C

C

EQUIVALENCE (WHAMP( 1$), \operatorname{IDAT}(1,1)),($ WHION $(1), \operatorname{IDAT}(1,50))$

INTEGER*4 MAX, I DUM, NSEC

CHARACTER FNAME* 16, IDENT*72, OPTION*6, DELETE*E

gGaIN IS THE LOG OF THE GAS GAIN FOR ANY VALUE OF VOLTAGE. GGAIN IS PROVIDED EY CALIBRATION PROCEDURES WHICH PRODUCE A FOUR COEFFICIENT FIT TO LOG(A) VS VOLTAGE.

GGAIN (VOLTS $)=C 0+$ VOLTS* $(C 1+$ VOLTS* $(C 2+$ VOLTS*Ca $)$

1 FORMAT ( $8 F 8.0)$

2 FORMAT (6E12.5)

3 FORMAT( 'INPUT(I 3 ) NEGATIVE TO CALIBRATE, POS TO RUN." )

4 FORMAT( ' FOUR COEFFICIENTS FOR THE LOGA(V) VS V FIT. ')

5 FORMAT ( 16 I5)

6 FORMAT( ' INPUT A FILE NAME FOR THE BASIC CALIBRATION DATA. ')

7 FORMAT( ' VOLTAGE LIMITS AND CORRESPONDING ADC COUNTS.' $)$

8 FORMAT ( 12 I 6$)$

9 FORMAT(/45H TURN ON PRINTER TO SAVE GAS GAIN TABLE EDIT. )

$10^{\circ}$ FORMAT $/ / / 10 X, 24 H$ EDIT OF DATA AND TABLES //

$\times 52 H$ THE FOUR CONSTANTS WHICH PARAMETERIIE LOGA VS $V$ ARE /

X4E14.7/41H THE ALLOWED GAS GAIN RANGE (GMIN, GMAX) $=2 \mathrm{H} 12.5 /$

$\times 33 H$ THE ADC LOW BIAS CHANNEL FOR $Y=I 7 / /)$

11 FORMAT (39H THE RAMP VOLTAGE UPPER LIMIT IS VTOP = F8.3/

$\times 39 H$ THE RAMP VOLTAGE LOWER LIMIT IS VBOT $=F 8.3 /$

XA $7 \mathrm{H}$ THE ADC NUMBER CORRESPONDING TO VTOP IS NTOP $=I 6 ;$

$X 4$ ?H THE AOC NUMBER CORRESPONDING TO VBOT IS NBOT $=I 6 / / 1)$

12 FORMAT ( $8 E 10.4$ )

13 FORMAT( ' INPUT DISC NAME FOR TEST CALIBRATION SPECTRIMM ')

14 FORMAT (4E14.7)

15 FORMAT (I3)

16 FORMAT (5OH INPUT(I3) THE LOG ENERGY CHANNEL(1-512) TO PRINT. / $\times 6 O H$ NULL INPUT TO SAVE. NEGATIVE INPUT TO CONTINUE ACQUISITION. $)$

17 FORMAT (//4OH TWO PARAMETER LOG $(Y / A)$ VS $X / Y$ SPECTRUM. $/$

$\times 28 H$ THE VOLTAGE RAMP LIMITS ARE $2 F 8,3 /$

$\times 39 H$ THE CORRESPONDING ADC COUNT VALUES ARE 2 I6/

$\times 51 \mathrm{H}$ THE FOUR COEFFICIENTS IN LOG(A) VS $V$ EXPANSION ARE $/ 4 E 14.7 /$

$\times 24 H$ THE Y PULSE ADC BIAS IS I $7 /$

$\times 3 O H$ THE GAS GAIN RANGE IS BETWEEN $2 E 12.5 / 1$

$\times 30 \mathrm{H} I / 64$ IS THE A.ESOLUTE VALUE OF /

XQSH LOG(Y/A) FOR ANY DATA CHANNEL I FROM 1 TO $4096 . / 1)$

18 FORMAT ( $32 \mathrm{H}$ TOTAL COUNT OVER ALL CHANNELS $=E 12.5 /$ ) 
20 FORMAT ( $9 H$ CHANNE! $=$ I $4 / 11 \mathrm{H}$ MAX COUNT $=16)$

21 FORMAT ( $/ 41$ H LIST OF ENERGY SPECTRUM SUMMED OVER $X / Y$. / )

22 FORMAT( 1018$)$

23 FORMAT(A)

24 FORMAT(' INPUT DISK FILE NAME, )

25 FORMAT(') INPUT 72 CHARACTER FILE DESCRIPTOR ')

26 FORMAT (44H INPUT "DELETE" TO AVOID SAVING FILE ON DISC)

27 FORMAT(' INPUT(I8) RUN TIME IN SECONDS' )

28 FORMAT $(32 H$ TEST PULSER COUNTS PER SECOND $=E 12.5 /$

C

C

C

C

C

C

C

C

C

C

C

C

$\mathrm{C}$

C

C

$\mathrm{C}$

50 WRITE $(*, 6)$

READ (*,23) FNAME

OPEN $\left(10, F I L E=F N A M E, F O R M={ }^{\prime}\right.$ FORMATTEO', STATUS $={ }^{\circ}$ OLD' $\left.{ }^{\prime}\right)$

C READ AN IDENTIFIER FOR THE BASIC DATA.

READ (10,23) IDENT

WRITE $(*, 23)$ I DENT

C READ VOLTAGE LIMITS AND CORRESPONDING ADC COUNT VALUES.

$\operatorname{READ}(10.2)$ VBOT, VTOP

$\operatorname{READ}(10,5)$ NEOT, NTOP

WR I TE $(*, 7)$

WRITE $(*, 2)$ VBOT, VTOP

WRITE $(*, 5)$ NBOT, NTOP

$C$ INPUT THE 4 POLYFIT COEFFICIENTS WHICH EXPRESS LOGA(A) $V S$. $V$. READ $(10,14)$ CO,C1,C2,C3

CLOSE (10)

WRITE $(*, 4)$

WRITE(*,14) $\mathrm{CO}, \mathrm{C} 1, \mathrm{C} 2, \mathrm{C} 3$

C

C

C

C

C

C

C

DETERMINE THE GAS GAIN LIMITS FROM VBOT AND VTOP.

IF MINIMUM GAS GAIN, GMIN, IS NOT AT LEAST 5 OR SO.

NO PROPORTIONAL MODE WILL EXIST. IF MAXIMUM GAS

GAIN, GMAX, EXCEEDS ABOUT 10000, EVENTS COUNTED WILL BE TOO LOW IN ENERGY TO EE OF INTEREST.

GMAX $=\operatorname{EXP}(G G A I N(V T O P))$

GMIN $=\operatorname{EXP}($ GGAIN (VBOT $))$

WRITE(*,2) GMIN, GMAX 
pause ' are the limits of gas gain acceptaele? '

C

71 RANGE $=4096 . * A L O G((4096 . * G M A X) /(896 . * G M I N))$

$$
\text { IF (RANGE-32767.) } 72,82,82
$$

82 PAUSE ' VOLTAGE RANGE EXCESSIVE FOR 16 BITS.' GO TO 50

C

C

C

C

C

$\mathrm{C}$

C

$\mathrm{C}$

C

C EDIT THE GAS GAIN TABLE AND PARAMETERS.

WRITE $(*, 9)$

PAUSE

WRITE $(*, 10)$ CO, C1,C2,C3, GMIN, GMAX, LVL

WRITE $(*, 11)$ VTOP, VBOT, NTOP, NBOT

CAN NOW PROCEED TO FILL OUT ALL TABLES REQUIRED.

$72 K N A=N T O P-N B O T+1$

$$
\text { IF }(K N A-1) 93,43.63
$$

93 PAUSE ' GAS GAIN TABLE COUNT ERROR ' GO TO 50

63 IF (KNA-3000)91,91,92

92 PAUSE ' MORE THAN 3000 IN GAIN TABLE : GO TO 50

91 DENOM=FLOAT (NTOP-NBOT) GO TO 59

43 DENOM $=1.0$ VALUE GMAX.

59 GMXLG=ALOG (GMAX)

DO4O I=1, KNA

$U=V B O T+(V T O P-V B O T) * F L O A T(I-1) / D E N O M$

$40 \operatorname{IGAIN}(I)=\operatorname{IFIX}(4096 . *(\operatorname{GMXLG-GGAIN(U)))}$ CHANNEL NUMBER RANGING FROM 1 TO 4096 CHANNELS. LVL IS THE ADC

54 LVL $=898$

DO4 $1 \quad I=1,4096$

$41 \operatorname{LOGTB}(I)=\operatorname{IFIX}(4096 . * A L O G(F L O A T(I) / F L O A T(L V L)))$ PULSE AMPLITUDE EVENT FROM FALLING OUT OF THE RANGE 1 TO 3548. LINTA =IFIX(1024.*ALOG (32.))

DOA $2 I=1$, LINTA

$42 \operatorname{INLGTB}(I)=I F I X(\operatorname{EXP}(F L O A T(I) / 1024)$.

DETERMine log gas gain table. gains are Relative to the maXimum

GENERATE A TABLE OF VALUES FOR 409S*LOG(I/LVL) WHERE I IS THE $X$ OR $Y$

GENERATE A TABLE OF VALUES OF ADDRESSES CORRESPONDING TO $X / Y$ VALUES FROM 1 TO 31 FROM GIVEN VALUES FOR 1024*LOG $(32 * X / Y)$. THE TABLE LENGTH IS LINTA (LINTA=3548). RESTRICTIONS UPON $X$ AND Y WILL PREVENT ANY 


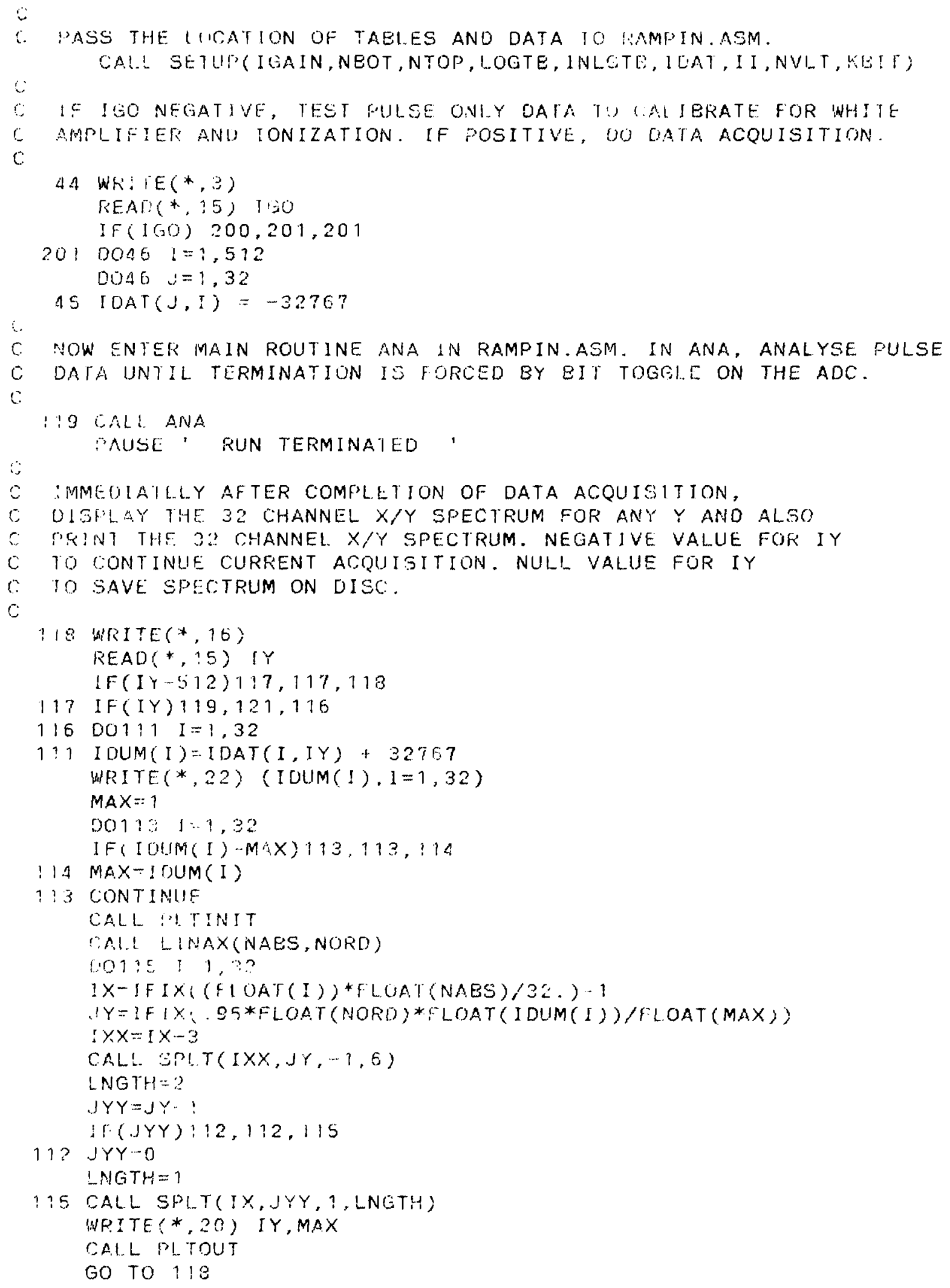


C. ADD UP THE X/Y FOR ALL Y ANO PRINT REQULT FOLLONING LISTING

$r$ OF THE RELEVANT INPUT PARAMETERS.

C GMAX IS THE MAXIMUN GAS GAIN OF 10000 ALLOWEO. LVL IS THE ADC BIAS.

:

21 PAUSE ' PRINTER ON TO sAVE OUTPUT DATA EOIT '

WRITE $(*, 17)$ VEOT, VTOP, NBOT, NTOP,CO,C1,C2,C3,LVL,GMIN, GMAX

WRITE(*, :1)

$A L L=0.0$

Do64 $I=1,512$

$\operatorname{MAX}=0$

$0062 J=1,32$

62 MAX $=$ MAX + IDAT (S.I $)+32767$

$A L L=A L L+F L O A T(M A X)$

64 I DUM(I) $=$ MAX

WRITE(*,13) AL.L

WRITE $(*, 22)$ (IOUM $(I), I=1,512$ )

c

c

SAVE THE UNFORMATTEO MAIN DATA ARRAY ON OISC.

WRITE $(*, 2 E)$

READ(*,23) OPTION

IF (OPTION.EQ. 'DELETE') GO TO 44

WRITE (*,2.4)

REAO(*,23) MAME

WRITE(*,25)

READ (*,23) TOEN!

WRITE(*,27)

READ(*,22) NSEC

OFEN (10,FIL : FNAME, FORM='UNFORMATTED', STATUS='NEW')

WRITE(10) TNAME

WRITE(10) IDENT

WRITE (10) NSEC

WRITE (10) LVL

WRITE(10) GMAX

WRITE $(10)$ IOAT

CLOSE (10)

GO TO 41

c.

C OALIBRATION MOOE IISING TEST PUILSER ONLY. DETERMINE THE RESPONSE

C TO AN EQUIVALENT WHITE IONIZATION SPECTRUM (WHION) AND ALSO TO

C $\therefore$ WHITE AMPLIFIER SPECTRUM (WHAMP). FOR THE WHITE IONIZATION

C SPECTRUM, MUST REDUCE THE PROBAEILITY EY A TO ACCOUNT FOR THE

C EQUIVALENT SCALE-UP OF THE FULSE AMPLITUDE BY A.

C:

OLEAR ARRAYS AND COMMENCE, TERMINATE IF KBIT NON ZERO.

200 DO203 $I=1,512$

WHAMP (I) $=0 \quad 0$

203 WHION $(1) \div 0.0$

SEAD SEQUENRES OF II $=51: L O G(Y / A)$, NVL T=4OO6LOG(GMAX/A), KEIT.

THE TPLSR KOUTINE I 3 FOUND IN MACHINE UTILITY RAMPIN.ASM.

207 CAIL TPLSR

WA TERO FOR KI: T CAISES TERMINATION.

IF (KEIT) $206,200,305$

$\because O S$ AMUL $=$ GMAX*EX:' ( -1 UAT (NVLT)/4096.)

$I I=I I+1$ 


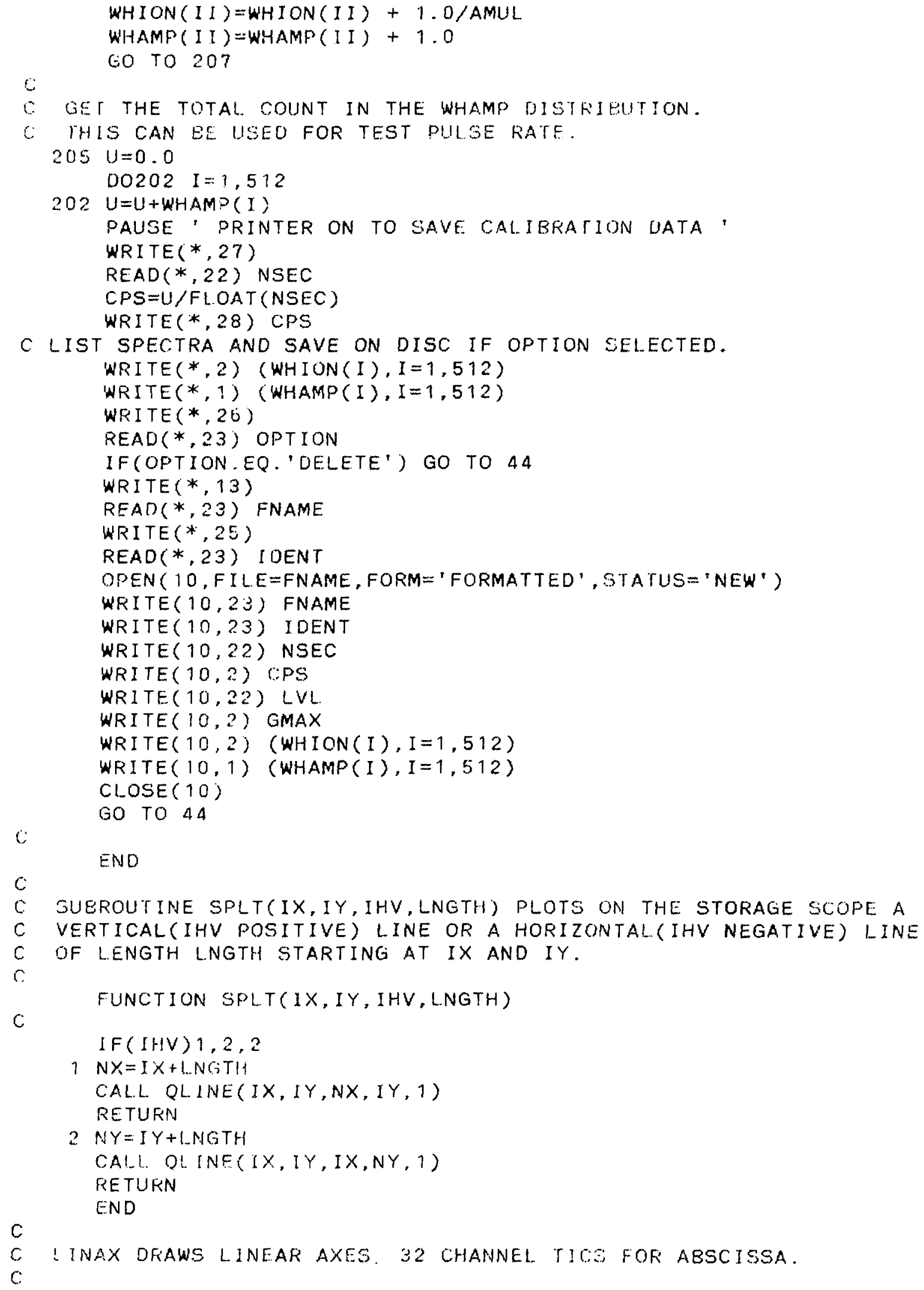




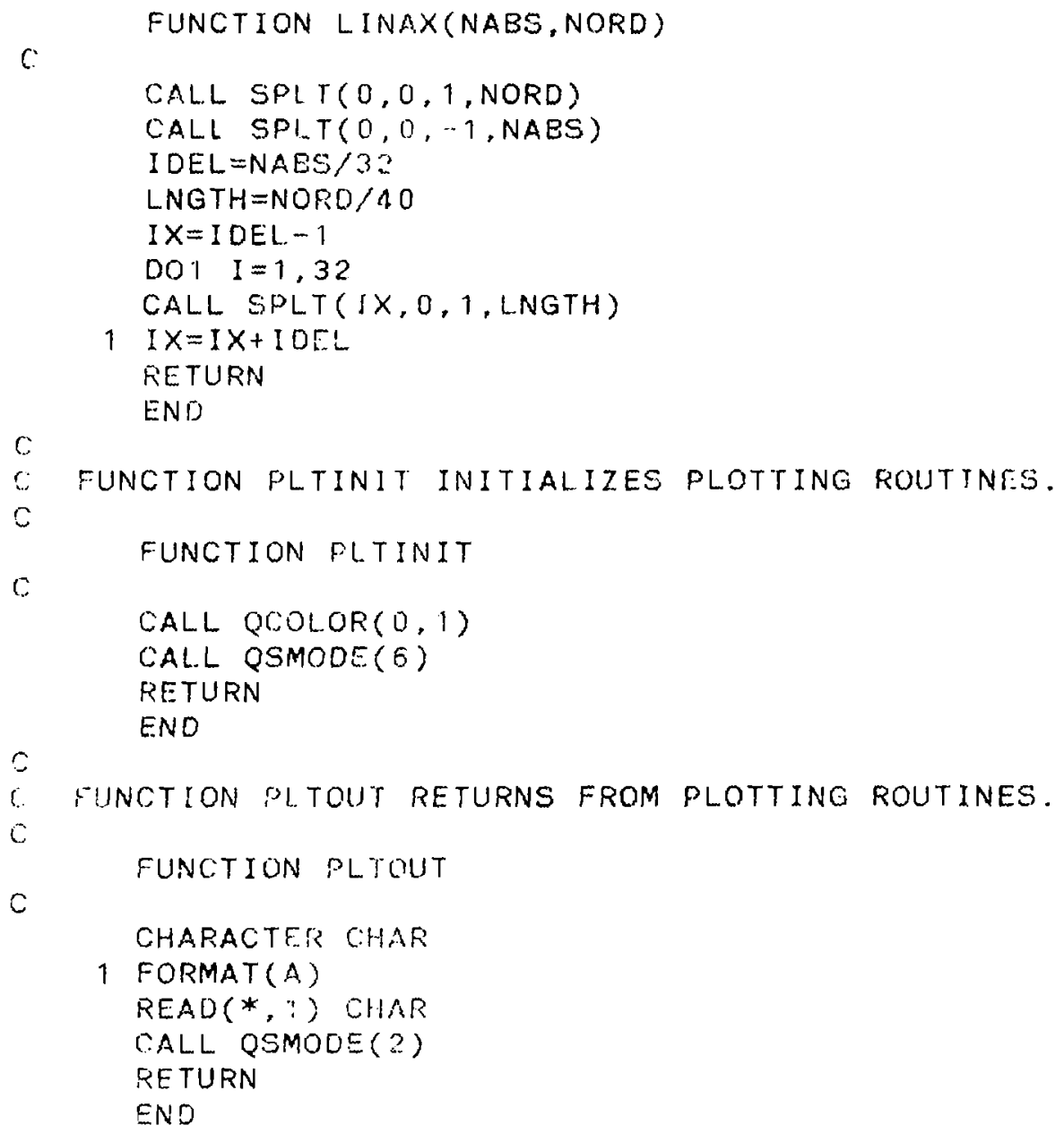


PAGE, 132

TITLE RAMPIN. ASM

RAMPIN IS A UTILITY FOR PULSE AMPLITUDE ACQUISITION BASED UPOP A RAMP VARIATION OF THE COUNTER EIAS VOLTAGE TIME DEPENDEMCE. COMPUTATIONS ARE ORGANIZED AROUND A 16 EIT WORD AND NO USE IS MADE OF EXTENDED MATH FUNCTIONS.

INPUT ADC CONVERSION FOR $X$ AND $Y$ PUISE HEIGHT ANO FOR VOLTAGE ARE FROM O TO 4095 CHANNELS ( 12 BITS).

2 IS ADDEO TO ALL CONVERSIONS TO PRODUCE 4097 CHANNELS FULL SCALE. THIS ADDITION OF 2 IS INTENDED TO AVOIO ADC MISSING BIT EFFECT. LINEARITY, AS DETERMINEO IN PRINIT, IS MAINTAINED AS 1 TO $40 S 6$.

RAMPIN. ASM CONTAINS THE FORTRAN CALLAELE ROUTINES SETUP, ANA, AND TPLSR.

SETUP IS IS A UTILITY TO LOCATE ARRAYS IN MAIN. ARGUMENTS OF SETUP ARE-

1... IGAIN; ADDRESS OF TABLE OF GAS GAIN VS VOLTAGE.

2....NBOT; STARTING(LOWEST) VALUE OF VOLTAGE IN TABLE.

3.... NTOP; ENDING(HIGHEST) VALUE OF VOLTAGE IN TABLE.

4... LOGTE; ADDRESS OF 4096 CHANNEL TAELE OF LOG CHANNEL.

$5 . .$. INLGTB; ADDRESS OF INVERSE LOG TABLE.

6... IDAT; ADDRESS OF $2-P X / Y$ EY LOG(Y/A) DATA ARRAY.

T....II; JOINT 512 LOGY/A ADDRESS.

$8 \ldots$...NVLT; 4096 LOG (AMAX/A) FOR EVENT

9....KEIT; SET TO UNITY WHEN END-OF-RAMS DETECTED.

; DATA REQUIRED FOR QUAD TECHMAR INTERFACE.

-NEED BASE ADDRESS AND LOCATION OF PORTS RELATIVE TO EASE.

;

BASE EQU 240 :EASE ADURESS FOR UNIT HO.

$P F$ EQU 0 ;CONTROL FORT ADDRESS.

$P A$ EQU 3 ;A PORT ADDRESS.

$P B \quad$ EQU 2 ;E PORT ADDRESS.

PC EQU 1 ;C PORT ADDRESS.

EXP EQU $10000000 E$;TOP BIT OF 8 BYTE FOR EXIT TEST.

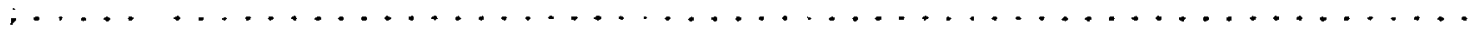

;

DGROUP GROUP DATA

CODE SEGMENT 'CODE'

ASSUME CS:CODE,DS:DGROUP,SS: DGROUP

; SETUO ROUTINE LOCATES ADORESSES OF DATA IN MAIN PROGRAM.

; A!SO, WITHIN SETUF, PROGRAM THE 8255-A DATA INPUT PORT.

SERUP PROC FAR

PUBLIC SETUP

PUSH BP

MOV BP,SP

MOV BX, [BP+3E] ;ADDRESS OI CAS GAIN TABLE.

MOV IGAIN, B:

;ADDRESS OI CAS GAIN TABLE.
;PLACE IN IGAIN.

MOV $\quad E X,[B P+34]$

MOV $A X,[B X]$

MOV NBOT,AX

; ADDRESS OF GAIN TABLE LOW LIMIT. : PLACE ADDRESS CONTENT IN NBOT. 


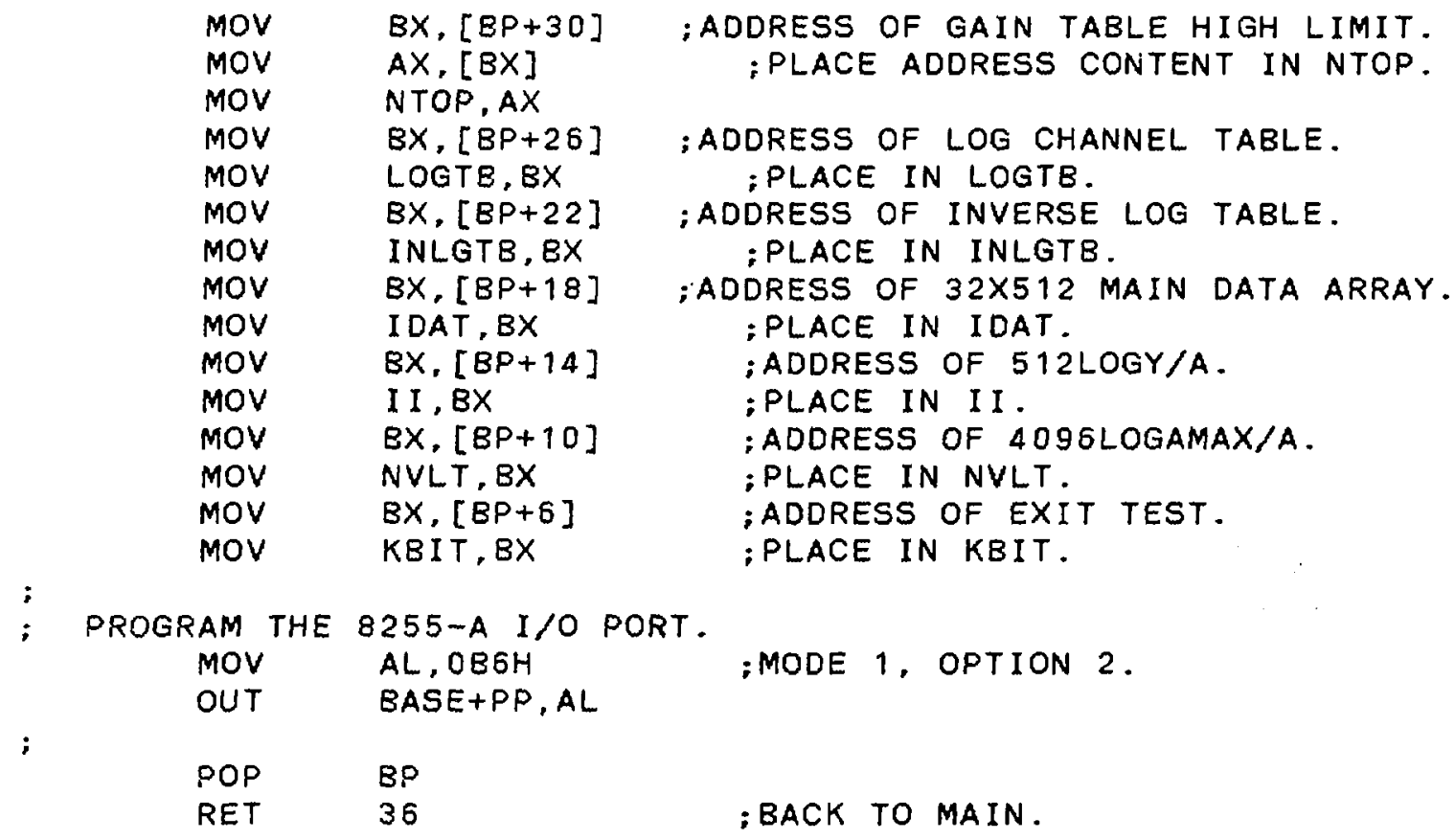

; SETUP ENDP

THREE PARAMETER ANALYSIS.

ADC CONVERTS $Y, X$, AND HV TO 4096 FULL SCALE. CHECK TO SEE IF $Y$ IS BELOW THE 896 CHANNEL DISCRIMINATION LIMIT (FOR MAXIMUM CHANNEL NUMBER OF 4096). MAKE SURE $X$ IS LESS THAN $Y$. ALSO TEST TO VERIFY THAT HIGH VOLTAGE IS WITHIN TABLE LIMIT SETTINGS.

IF ALL DATA OK, PROCEED TO FORM JOINT $X / Y$ AND LOG(Y/A) ADDRESS.

FIRST PRODUCE A RESET. THIS BIT TOGGLE SEQUENCE UNLOCKS THE ADC REGARDLESS OF STATUS AND ALLOWS ANALYSIS TO COMMENCE.
MOV $A L, O F H$
OUT BASE+PP, AL ; LOAD RESET BIT HIGH.
IN $A L, B A S E+P A$ ; SET BIT HIGH.
IN $A L, B A S E+P B$
MOV AL, OEH - INPUT A PORT AND CLEAR.
OUT BASE+PP, AL - INPUT B PORT AND CLEAR. ; LOAD BIT 7 LOW.
JMP STRT
;SET 7 LOW AND RESET.

BACK: RET ;RETURN TO MAIN PROGRAM IF BIT SET.

RSET MAY BE USED TO FORCE A RESET WHENEVER OFF-NORMAL DATA IS ENCOUNTERED FOR THE Y CHANNEL (RSETY) OR FOR THE $\times$ CHANNEL (RSETX). 


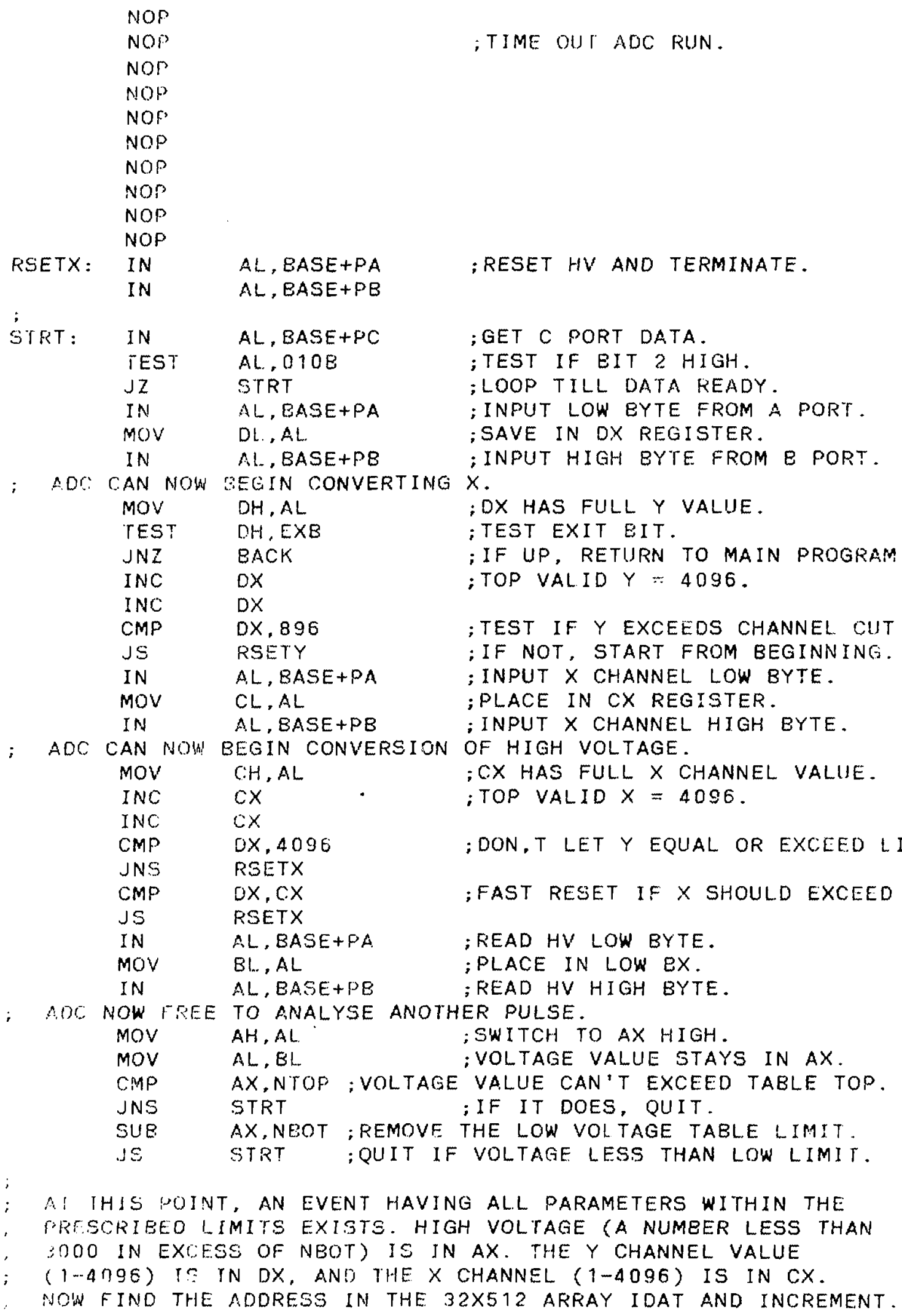




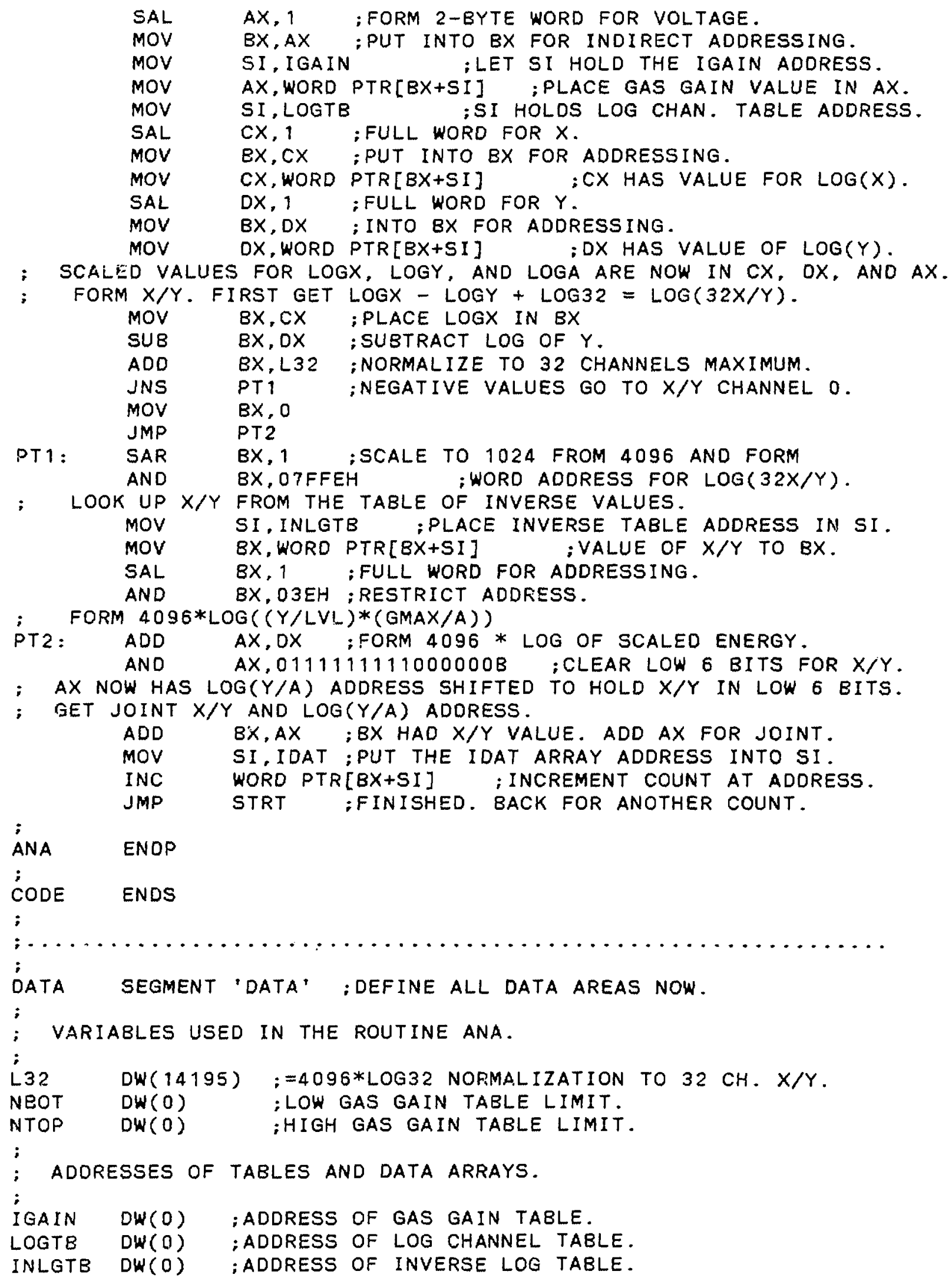




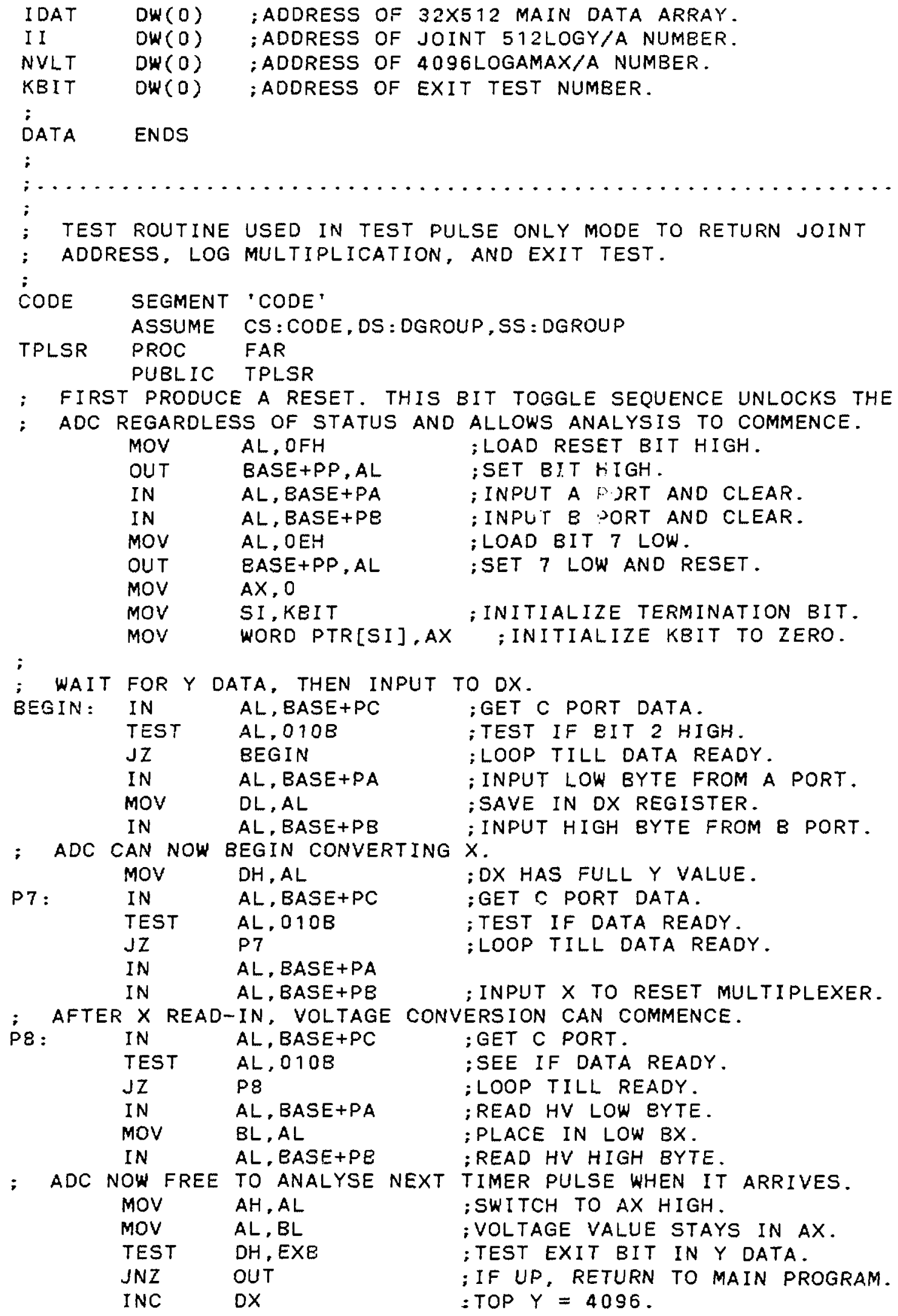




\begin{tabular}{|c|c|c|}
\hline INC & $D X$ & \\
\hline CMP & $D X, 896$ & ; Y MUST $=$ OR EXCEED CHANNEL CUT OFF. \\
\hline 」S & BEGIN & ; IF NOT, START FROM BEGINNING. \\
\hline CMP & $D X, 4096$ & ;DONT LET Y EQUAL OR EXCEED 4096. \\
\hline JNS & BEGIN & ; IF HAPPENS, START OVER. \\
\hline CMP & $A X, N T O P$ & ; VOLTAGE VALUE CAN'T = OR EXCEED TABLE TOF \\
\hline $\begin{array}{l}\text { JNS } \\
\text { SUB }\end{array}$ & $\begin{array}{l}\text { BEGIN } \\
A X, N B O T\end{array}$ & $\begin{array}{l}\text {; IF IT DOES, QUIT. } \\
\text {;REMOVE THE LOW VOLTAGE TABLE LIMIT. }\end{array}$ \\
\hline JS & BEGIN & : QUIT IF VOLTAGE LESS THAN LOW LIMIT. \\
\hline
\end{tabular}

AT THIS POINT, AN EVENT HAVING ALL PARAMETERS WITHIN THE PRESCRIBED LIMITS EXISTS. HIGH VOLTAGE (A NUMBER LESS THAN 3000 IN EXCESS OF NBOT) IS IN AX. Y IS IN DX.

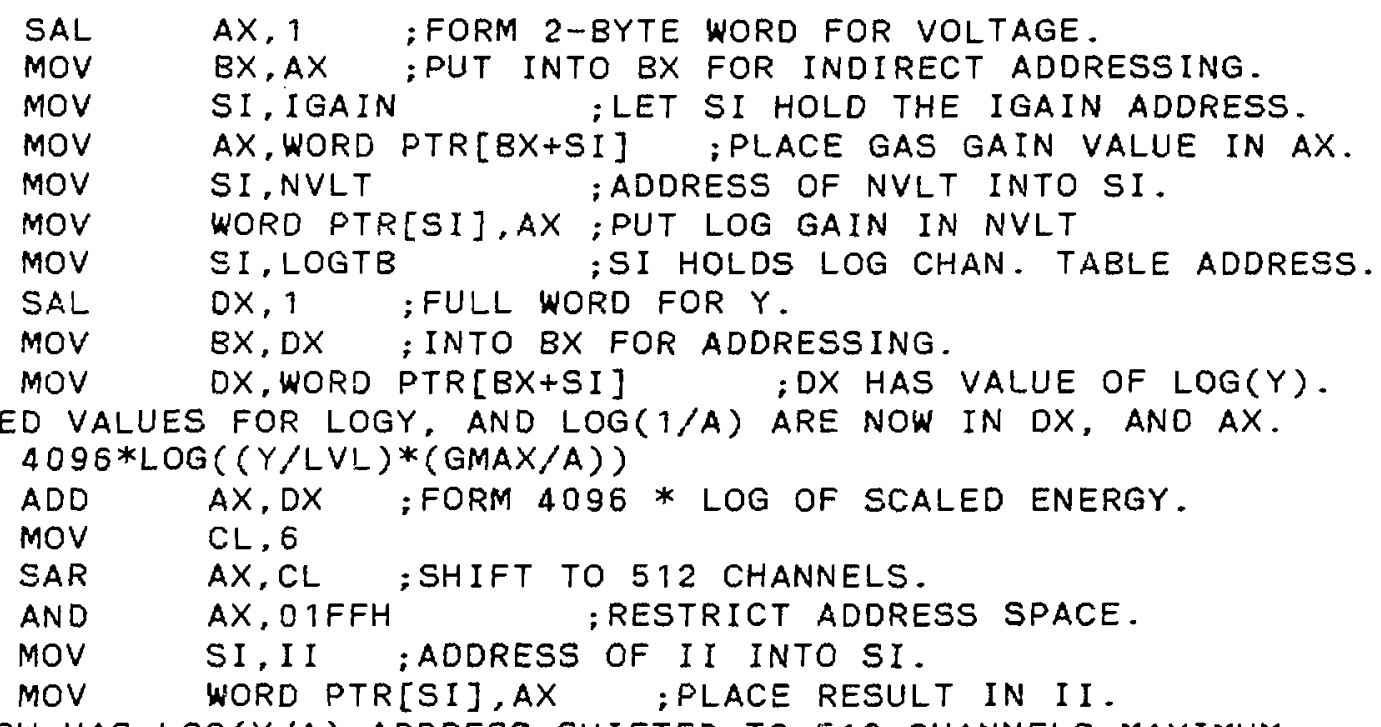

; I I NOW HAS LOG(Y/A) ADDRESS SHIFTED TO 512 CHANNELS MAXIMUM.

; NVLT HAS THE 4096. LOG(GMAX/A) VALUE.
RET ;FINISHED. BACK FOR ANOTHER COUNT.
OUT: MOV AX, 1 ;SET TERMINATION BIT.
MOV SI,KBIT ;ADDRESS OF BIT TO SI.
MOV WORD PTR[SI], AX ;SET KBIT NON ZERO TO INDICATE FINISH. RET ;BACK TO MAIN.

$\begin{array}{ll}\dot{T} & \\ \dot{\text { COLSLR }} & \text { ENDP } \\ \dot{\text { END }} & \end{array}$


APPENDIX III

LISTING OF THE CODE RMPRDN.FOR USED FOR DATA REDUCTION 
LISTING OF THE CODE RMPRDN.FOR USED FOR DATA REDUCTION.

\$NODEBUG

\$NOFLOATCALLS

\$LARGE

\$STORAGE : 2

C RMPRDN.FOR

C PROTON PEAK INTEGRATION FOR PROTON-RECOIL COUNTER SPECTRA.

C RMPRON IS FOR RAMP-VOLTAGE MODE DATA ONLY.

C

DIMENSION IDAT $(32,512)$, NDAT $(32,512)$, TVAL(512), ETVAL (512),

XTPLSE(512),WIDE(512), PRTS(512), DVAL (512), EDVAL (512), GAMS(512),

XDATI $(32,511)$, DATN $(32,511), D(32), \operatorname{RATEO}(512), \operatorname{GMS}(32)$

COMMON Y(512),X(512),B( 9$), W(512)$

C

DOUBLE PRECISION E, EVLV,DPI

INTEGER*4 NSEC, NNSEC

CHARACTER FNAME* 16, PNAME*16, IDENT*72, JDENT*72

C

C

ESTABLISH THE LOG OF ENERGY ELOG AT ANY CHANNEL

$E L O G(I)=F L O A T(I+N Y M I N-1) / 64$ + CAL

WHERE CAL = ALOG( (LVL/GMAX)*FSEXA/4096.).

? FORMAT(47H INPUT A 10 CHAR. FILE NAME FOR 2-P DATA ARRAY. )

2 FORMAT(A)

3 FORMAT (I 3$)$

4 FORMAT(5OH INPUT POS TO SAVE ON DISC, OR NEG TO DELETE SAVE.)

5 FORMAT (6E12.5)

6 FORMAT( 33 H INPUT(I 3$)$ THE Y CHANNEL(1-NCHY). )

7 FORMAT $(16 H$ PROTON VALLEY $=I 3,14 H$ TEST VALLEY $=13 /$

$\times 14 \mathrm{H}$ PROTON PEAK $=13,12 \mathrm{H}$ TEST PEAK $=13 /$

$\times 34 H$ CHECK SPECTRUM BEFORE PROCEEDING. )

8 FORMAT (/45H-

X49H ALL OPTIONS REACHED BY INPUTTING (I3) 1 TO 4 ). 1

X48H 1 ...PRINT RAW DATA BETWEEN ANY CHANNEL LIMITS.

$X 49 H \quad 2 \ldots D I S P L A Y$ AND PRINT 32-CHANNEL $X / Y$ FOR ANY $Y$.

$\times 42 \mathrm{H} \quad 3$... CARRY OUT GAMMA BACKGROUND ANALYSIS.

X49H 4 ... COMPLETE ANALYSIS AND OUTPUT FINAL RESULTS. 1 )

9 FORMAT ( $/ / / 18 \times, 27 H L I S T I N G$ OF ANALYSIS RESULTS $/ /)$

10 FORMAT (I 8,4F6. 1,2F6.2,3E11.4)

11 FORMAT $/ / 19 H \quad J, 5 H$ DVAL, $7 H$ EDVAL, 5H TVAL,7H ETVAL,6H LINE. X 8 RATIO, 9H GAMMAS , 11H PRTS ,9H TIME /)

12 FORMAT ( $49 H$ CAN'T FIND CONSISTENT SET OF DATA PEAKS/VALLEYS. 1 )

13 FORMAT ( $8 F 8.0)$

1.4 FORMAT $(32 \mathrm{H}$ INITIAL AVG PROTON LINE WIDTH $=$ F7.2/

X51H CHANNEL WHERE LINE BROADENS TO 1.5 TIMES INITIAL = I5/)

15 FORMAT ( 16 I 5 )

16 FORMAT (43H INPUT A FILE NAME FOR THE PROTON SPECTRUM.)

17 FORMAT ( $31 \mathrm{H}$ TOTAL POINTS AND START POINT $=2$ I5)

18 FORMAT ( $10 \mathrm{~F} 8.0)$

19 FORMAT( $52 H$ INPUT A FILE NAME FOR THE GAMMA BACKGROUND SPECTRUM )

20 FORMAT ( 2 I 8 )

21 FORMAT $(/ 41 \mathrm{H}$ $\times 46 \mathrm{H}$

$\times 36 \mathrm{H}$

$\times 29 H$

$\times 32 \mathrm{H}$

TOTAL POIFTS AND START POINT $=2 I 5 /$

INITIAL AVERAGE PROTON LINE WIDTH $=F 7.2 \%$

N15 AND NBRK CHANNELS ARE 2 I5/

.90 WMAX CHANNEL $=I 5 /$

RUN TIME IN SECONDS $=$ I $8 /$ ) 
22 FORMAT ( 43 Y Y CHANNEL WHERE GAMMA RATIO $=.90$ OF MAX $=$ I5)

23 FORMAT $(5 O H$ Y CHANNEL WHERE $X / Y$ PROTON CUT-OFF CHANNEL IS $1=I 5)$

24 FORMAT ( $43 H$ INPUT A.DAT FILE NAME FOR $32 \times / Y$ SPECTRUM)

26 FORMAT( $35 H$ THE ENERGY FOR THE X/Y SPECTRUM IS E12.5)

25 FORMAT(53H INPUT(I3/I3) LOW AND HIGH Y LIMITS FOR DATA LISTING./)

27 FORMAT(53H INPUT NEGATIVE CHAN. NULL ABOVE AND SAVE FOR GRAPHER)

28 FORMAT(45H INPUT THE ENERGY SCALE FACTOR FSEXA (E12.5). )

29 FORMAT( $36 H$ THE Y (OR LOG(E)) CHANNEL NUMBER IS I5)

30 FORMAT (44H INPUT NEGATIVE TO DELETE LOW $X / Y$ CORRECTION )

C

32 FORMAT $(/ 33 H X / Y$ DISTRIBUTION FOR $Y$ CHANNEL = I 3 )

C NCHY, THE NUMBER OF Y (ENERGY) CHANNELS, IS LESS THAN 512.

C THIS RESTRICTS A FLOATING POINT ARRAY TO LESS THAN 1 PAGE.

C THE NUMBER OF $X / Y$ CHNNELS IS FIXED AT 32.

NCHY $=511$

NYMIN $=1$

LTOT $=\mathrm{NCHY}$

C NABS AND NORD ARE $X$ AND Y POINT COUNT FOR PLOTTING ROUTINES. NABS $=720$

NORD $=348$

GO TO 203

$c$

C MAIN MENU. OPTIONS SELECTED HERE.

200 WRITE $(*, 8)$

$\operatorname{READ}(*, 3)$ I GO

IF (IGO) $200,200,201$

201 IF (IGO-4)202,202,200

202 GO TO $(204,205,206,199)$, IGO

C

C INPUT A 32 XNCHY CHANNEL DATA ARRAY FROM DISC.

C CONVERT TO FLOATING POINT.

C

203 MITE $(*, 1)$

READ (*,2) FNAME

OPEN $(10$, FILE=FNAME, FORM = 'UNFORMATTED', STATUS= 'OLD')

READ (10) FNAME

WRITE $(*, 2)$ FNAME

READ ( 10) IDENT

WRITE $(*, 2)$ IDENT

READ ( 10$)$ NSEC

READ (10) LVL

READ (10) GMAX

READ (10) IDAT

CLOSE (10)

$00208 \mathrm{I}=1, \mathrm{NCHY}$

DO208 $J=1,32$

$208 \operatorname{DATI}(\mathrm{J}, \mathrm{I})=\operatorname{FLOAT}(\operatorname{IDAT}(\mathrm{J}, \mathrm{I}))+32767$.

WCTOFF $=.3$

WRITE $(*, 28)$

READ (*,5) FSEXA

$C A L=A L O G((F L O A T(L V L) / G M A X) * F S E X A / 4096$.

GO TO 200

C

C ONLY PRINT THE RAW DATA BETWEEN Y CHANNEL LIMITS AS INPUT.

C 


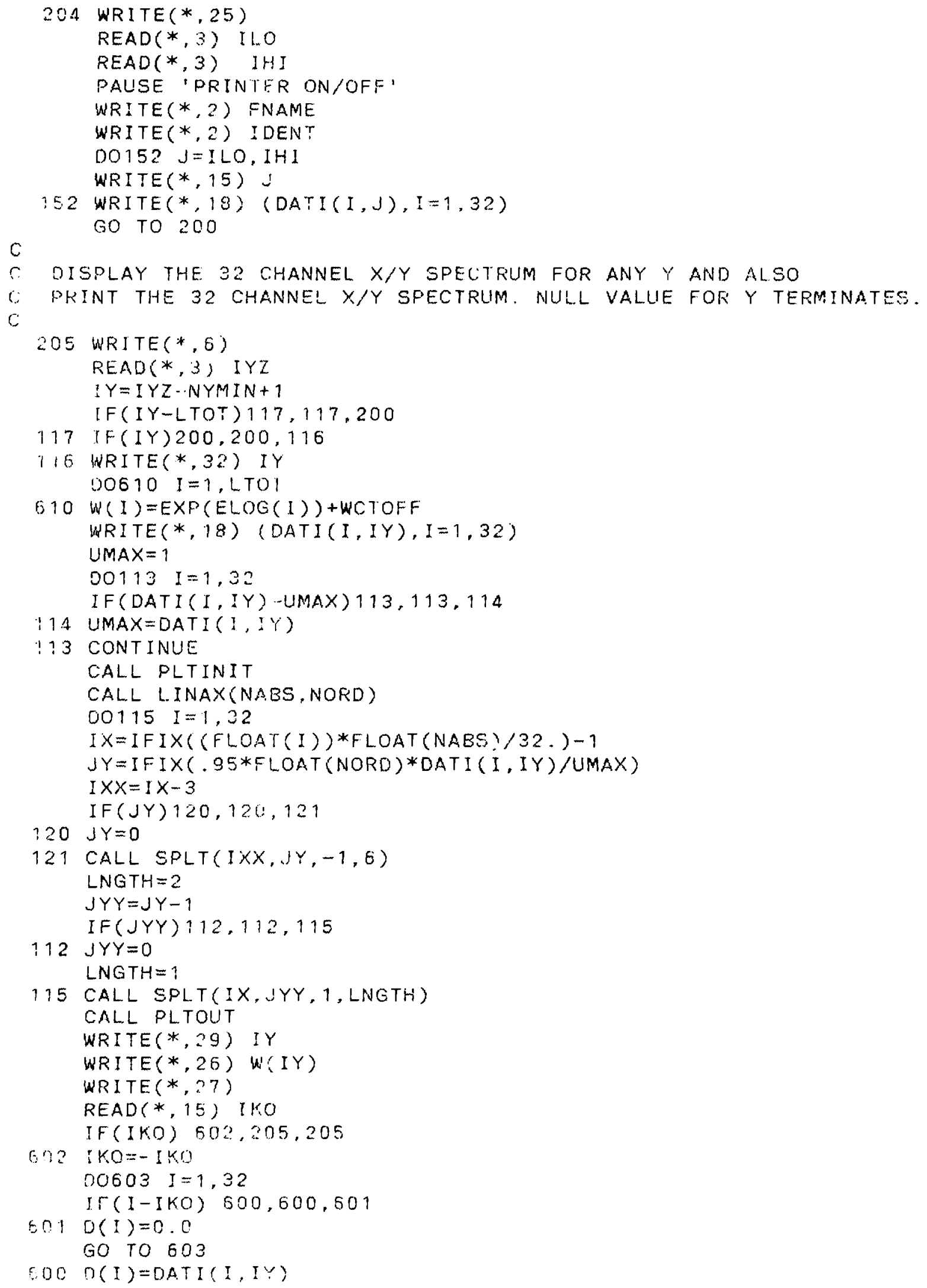


603 CONTINUE

WRITE $(*, 24)$

READ(*,2) FNAME

OPEN $\left(10, F I L E=F N A M E, F O R M=\right.$ 'FORMATTED', STATUS $\left.={ }^{\prime} N E W W^{\prime}\right)$

DO605 I $=1,32$

$X I=F L O A T(I)$

605 WRITE $(10,5) \times I, D(I)$

CLOSE (10)

GO TO 205

$\mathrm{C}$

C ANALYSE FOR DATA AND LIVE TIME USING BACKGROUND SUBTRACTION.

C COLLAPSE TO A SINGLE 32-CHANNEL SPECTRUM D(I), LOCATE THE

C VALLEY CHANNELS BEFORE PROTON PEAK (NVDAT) AND BEFORE LIVE

C TIME PEAK (NVTEST).

C

206 UMAX $=0.0$

$D 0128 \quad I=1,32$

UDUM $=0.0$

DO $129 \mathrm{~J}=1, \mathrm{NCHY}$

129 UDUM=UDUM+DATI $(I, J)$

I $F$ (UDUM-UMAX) $128,128,127$

127 UMAX $=$ UDUM

$128 \quad D(I)=U D U M$

C DERIVE THE TEST PULSER PEAK CHANNEL JTPK, AND THE TEST VALLEY JTVAL.

DLTA $=0.025 *$ UMAXX

$I=32$

$83 \mathrm{IF}(\mathrm{D}(\mathrm{I}-1)-D(\mathrm{I})+D L T A) 80.81 .81$

$81 \mathrm{I}=\mathrm{I}-1$

$I F(I-1) 82.82,83$

82 WRITE(*,12)

GO TO 200

$80 \mathrm{JTPK}=\mathrm{I}$

$86 \operatorname{IF}(D(I-1)-D(I)) 84,84,85$

$84 I=I-1$

I F $(I-1) 82,82,86$

85 JTVAL $=I$

C DERIVE THE PROTON PEAK JDPK AND ASSUME PROTON-GAMMA VALLEY

C NVDAT IS 5 CHANNELS BELOW THIS.

$I=I-1$

$89 I F(D(I-1)-D(I)) 88,88,87$

$87 I=I-1$

$\operatorname{IF}(I-1) 82,82,89$

88 JDPK $=I$

NVDAT $=J D P K-5$

C NVTST BETTER VALUE FOR PROTON-TEST PULSE VALLEy VALUe.

NVTST = IFIX(HILO $(0, J D P K, J T P K, D))$

C

C PLOT THE COLLAPSED $X / Y$ SPECTRUM AND SHOW VALLEY CHANNELS.

CALL PLTINIT

CALL LINAX(NABS, NORD)

DO165 $I=1,32$

IX $=I F I X((F L O A T(I)) * F L O A T(N A B S) / 32)-$.

$J Y=I F I X(.95 * F L O A T(N O R D) * D(I) / U M A X)$

I $X X=I X-3$

CALL SPLT(IXX, JY, -1,6) 


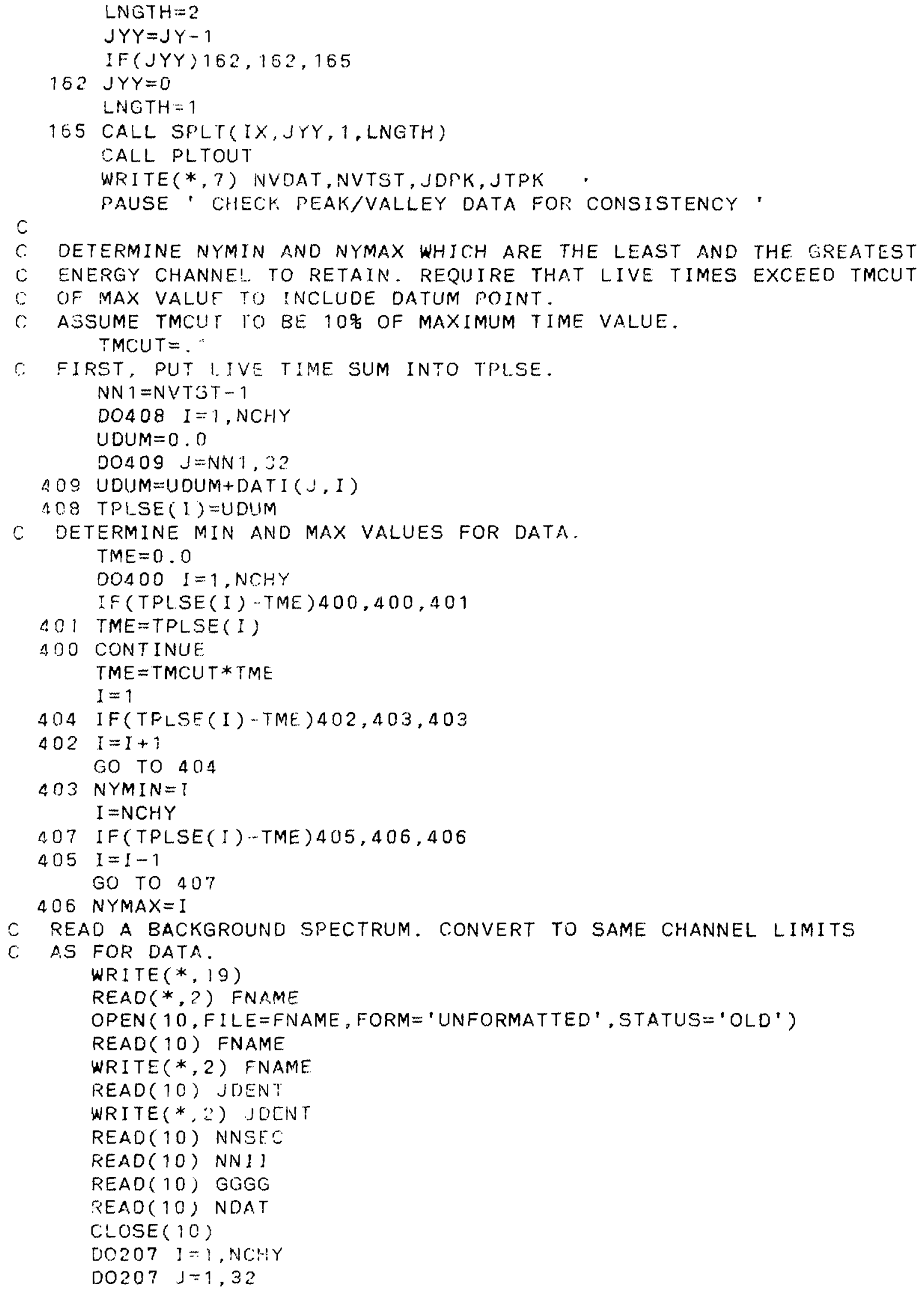




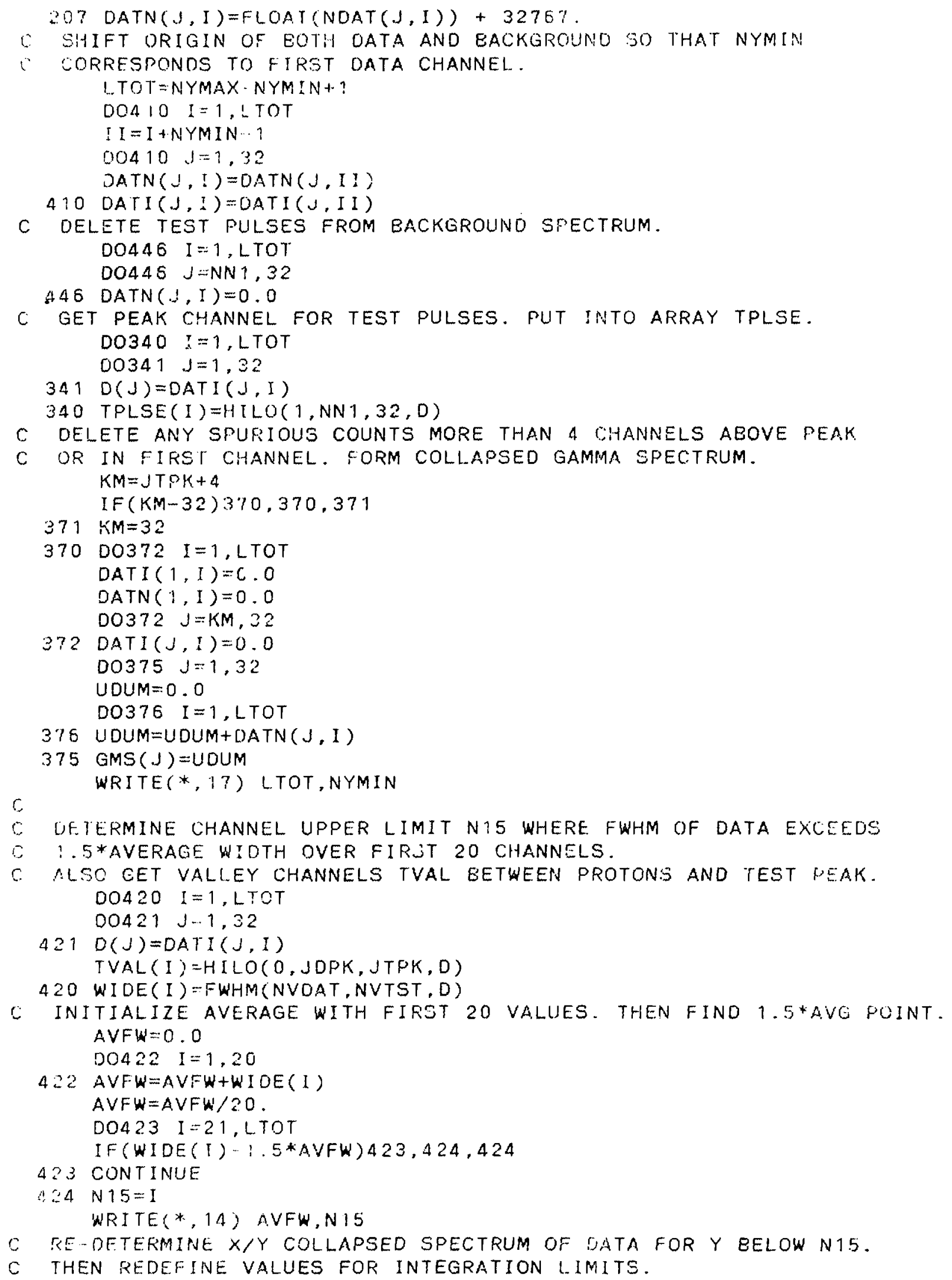


$00412 J=1,32$

UDUM $=0.0$

$D 0413 \quad I=1, N 15$

413 UDUM=UOUM+DATI $(J, I)$

$412 \quad D(J)=U D U M$

JDPK=IFIX(HILO $(1, N V D A T, N V T S T, D))$

$J T P K=I F I X(H I L O(1, N V T S T, 32, D))$

NVTST $=$ IFIX $(H I L O(0, J D P K, J T P K, D))$

NVDAT $=J D P K-I F I X(1.5 * F W H M(N V D A T, N V T S T, D)+.5)$

C FORM THE RATIO OF GAMMA COMPONENT IN PURE GAMMA RUN TO GAMMA

C COMPONENT IN DATA UP TO THE N!S CHANNEL NUMBER. FIT THIS

C RATIO AND USE TO CORRECT DATA ON A CHANNEL-BY CHANNEL BASIS. DOS30 I $=1, N 15$

$S M 1=0.0$

$S M 2=0.0$

$X(I)=F L O A T(I)$

$W(I)=1.0$

DO53 $1 J=1$, NVDAT

$S M 1=S M 1+O A T I(J, I)$

$531 S M 2=S M 2+D A T N(J, I)$

$530 Y(I)=S M 2 / S M 1$

$M F I T=9$

CALL LSQPOL (MFIT, NI5)

C LET $W(I)=$ RATEO BE THE EVALUATED RATIO OF PURE GAMMAS TO dATA gAMMAS.

$D 0532 \quad I=1, N 15$

$D P I=F L O A T(I)$

EVLV $=0.0$

D0533 $J=1$, MF IT

$533 \quad E V L V=E V L V+B(J) * D P I * *(J-1)$

$532 W(I)=E V L V$

C W(I) WILL DECREASE AT HIGH I VALUES DUE TO DEGRADATION OF THE PROTON

C DATA INTO GAMMA INTEGRATION WINDOW. FIND MAXIMUM FOR W(I) AND THEN

C FIND THE CHANNEL KGL FOR WHICH W(I) IS LESS THAN 90\% OF MAXIMUM.

C USE W AT KGL FOR ALL CHANNELS ABOVE KGL.

$I=N 15-10$

WMAX $=0.0$

427 IF (W(I)-WMAX) $425,425,426$

426 WMAX $=W(I)$

$I=I-1$

IF $(I-1) 425,425,427$

425 WMAX $=.90 *$ WMAX

$I=N 15-10$

430 IF (W(I )-WMAX) $429,428,428$

$429 I=I-1$

IF $(I-1) 428,428,430$

$428 K G L=I$

WRITE(*,22) KGL

C SUBTRACT THE BACKGROUND USING THE FITTED RATIO BELOW KGL

C AND THE RATIO AT KGL ABOVE KGL.

WASM $=W(K G L)$

DO5 $38 \quad I=1$, LTOT

IF (I-KGL) $535,536,536$

536 WEI GHT $=$ WASM

RATEO (I ) =WASM

GO TO 537 


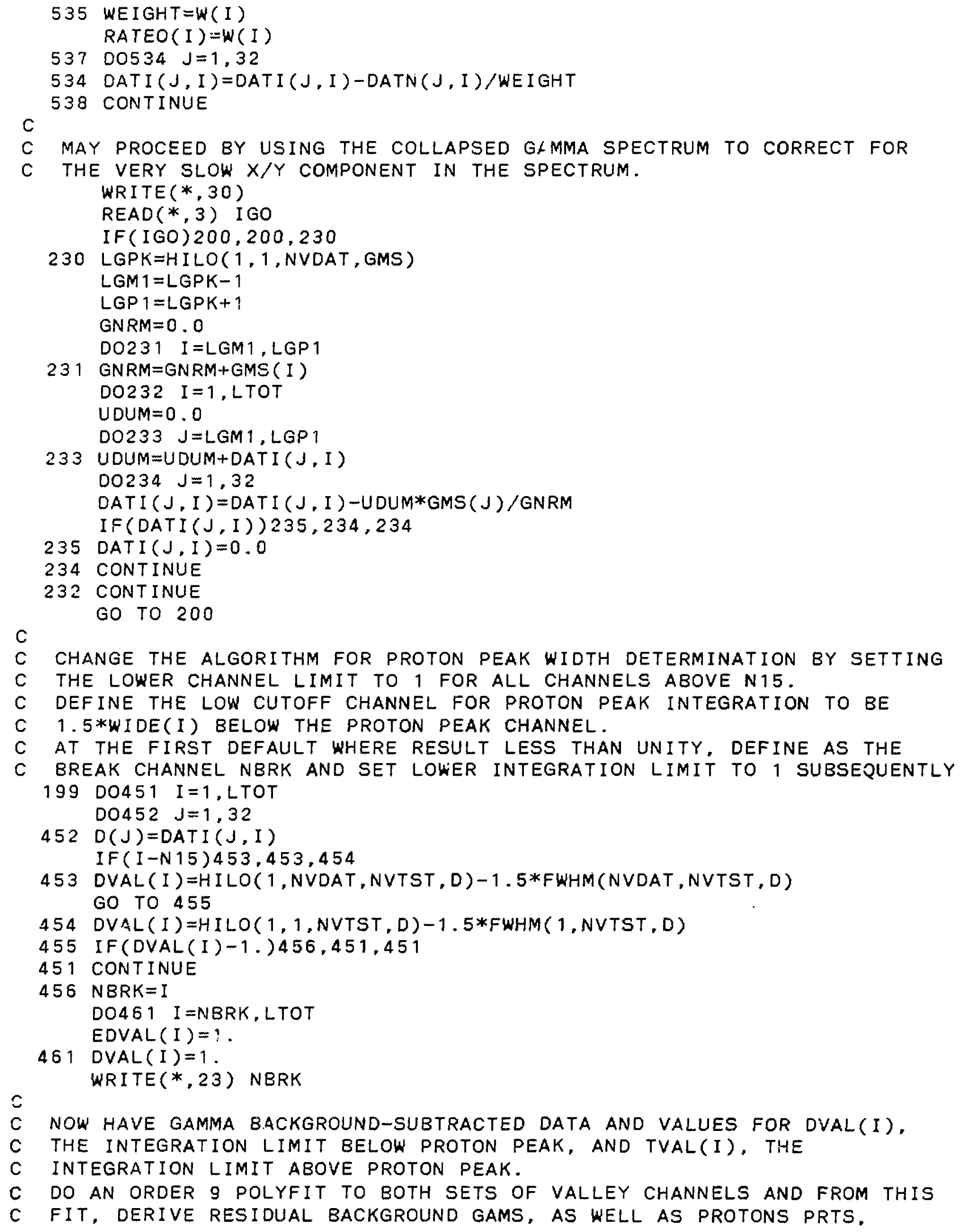


C AND THE TEST FULSE DISTRIEUTION TPLSE,

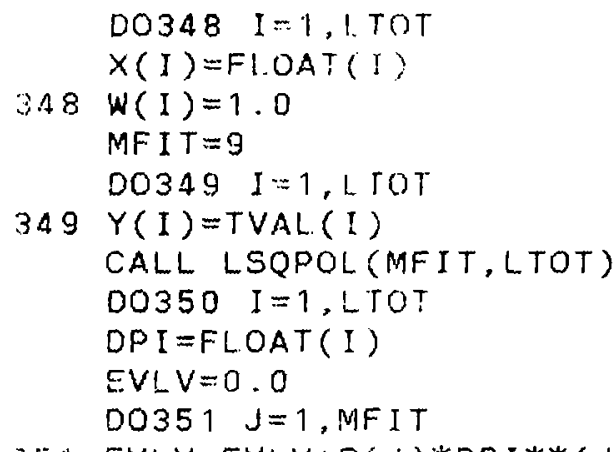

$351 E V L V=E V L V+B(J) * D P I * *(J-1)$

350 ETVAL(I) $=E V L V$

DO352 I $=1$, NBRK

$352 \quad Y(I)=O V A L(I)$

CALL LSQPOL (MFIT, NERK)

DO353 $I=1, N B R K$

DPT $=F L O A T$ (I)

$E V L V=0.0$

DO354 J:: 1 , MFIT

354 EVLV $=E V L V+B(J) * D P I * *(J-1)$

EDVAL (I) $=E V L V$

IF(EDVAL (I) - 1. ) 356,353,353

356 EDVAL(I) $=$ ?

353 CONTINUE

c

C USING THE FitTED CHANNEL VALUES, DERIVE A SPECTRUM FOR LIVE TIME

C ANO PROTON RECOILS AND ALSO THE RESIDUAL BACKGROUND GAMS.

DO251 I=1, LTOT

DC252 $J=1,32$

252 D $(J)=$ OATI $(J, I)$

$E V 1=E D V A L(I)$

$E V 2=E T V A L(I)$

NVI $=I F I X(E \vee 1)$

$N \vee 2=I F I X(E \vee 2)$

DIF1=EVI-FLOAT (NVI)

$C 1 H=(1 .-D I F 1) * D(N V 1)$

DIF2 $=E V 2-F L O A T$ (NV2)

$C 2 H=(1 .-D I F 2) * D(N \vee 2)$

$C 2 L=D I F 2 * D(N \vee 2)$

$N V 2 P 1=N V 2+1$

SUM $1=C 2 H$

DO254 J $=N \vee 2 P 1,32$

254 SUM $1=S U M 1+D(J)$

TPLSE(I) = SUM 1

$N \vee 1 P 1=N \vee 1+1$

$N V 2 M 1=N V 2-1$

SUM $1=C 1 H+C_{2}:$

DO255 J=NV1P1, NV2M1

255 SUM $1=5 U M 1+O(J)$

SUM2 $=D I F 1 * D(N V 1)$

$N \vee 1 M 1=N \vee 1-1$

DO256 J $J$, NVIM? 


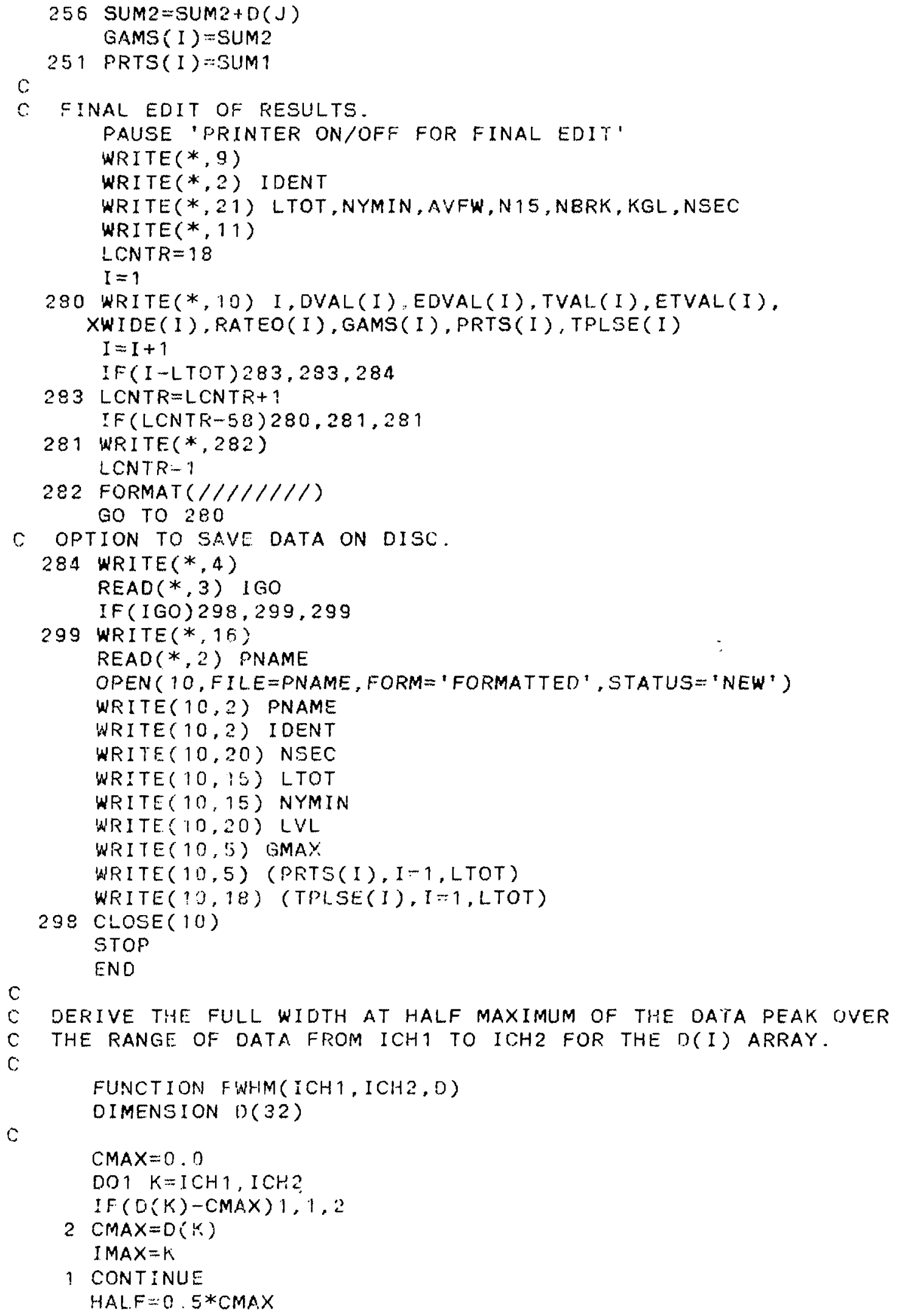




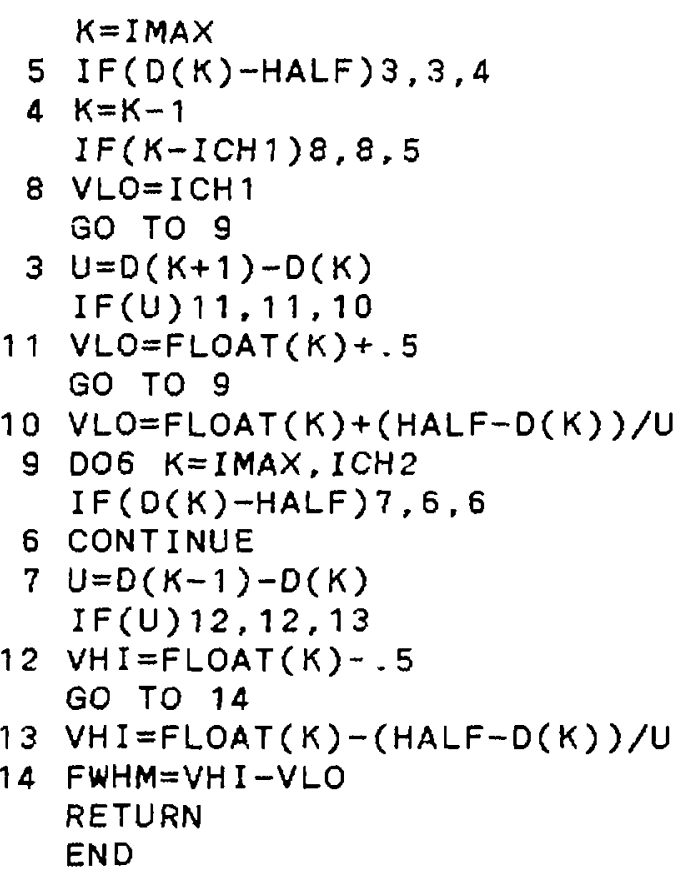

C FUNCTION HILO (LH, ILO, IHI, D) FETURNS MAXIMUM (LH=1) OR MINIMUM(LH=O)

C COUNT CHANNEL NUMBER OF THE ARRAY D(I) IN THE INTERVAL ILO TO IHI.

C

C FUNCTION HILO(LH, ILO, IHI, D)

DIMENSION D(32)

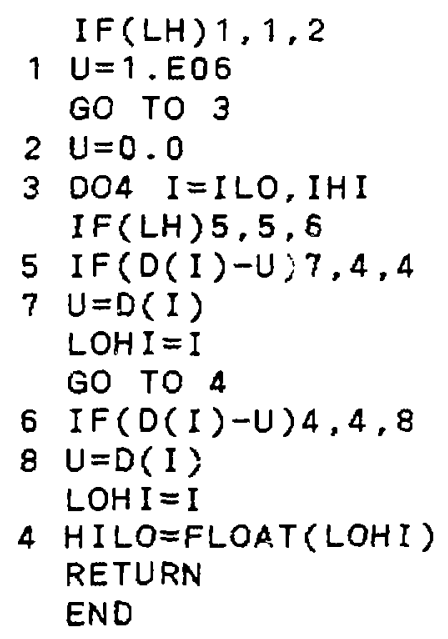

c

C

C

SUBROUTINE SPLT(IX, IY, IHV, LNGTH) PLOTS ON THE STORAGE SCOPE A VERTICAL (IHV POSITIVE) LINE OR A HORIZONTAL(IHV NEGATIVE) LINE C OF LENGTH LNGTH STARTING AT IX AND IY.

C

C SUEROUTINE SPLT(IX, IY, IHV, LNGTH)

\footnotetext{
I $F($ IHV $) 1,2,2$

$1 N X=I X+L N G T H$

CALL QLINE(IX, IY,NX, IY, 1)
} 


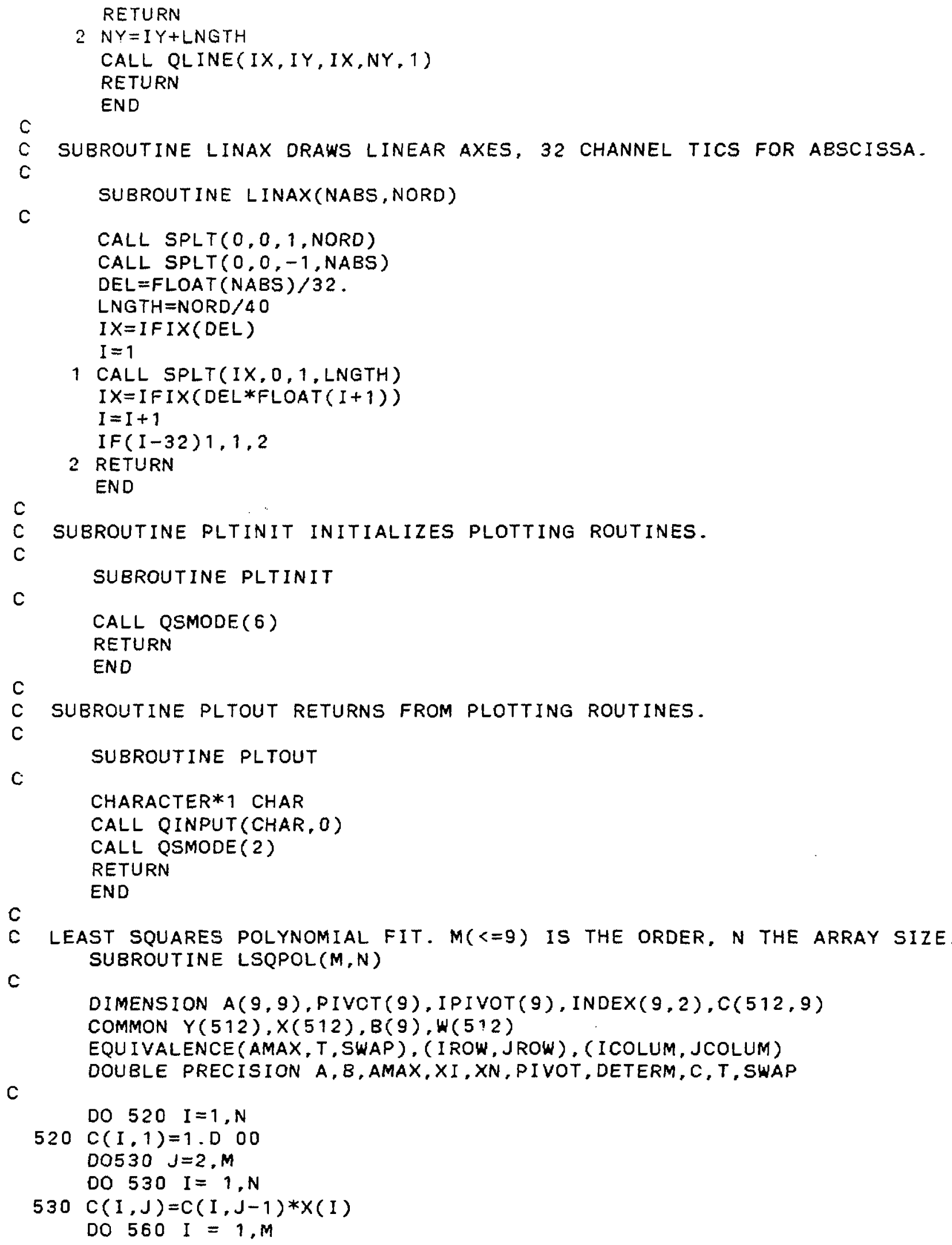




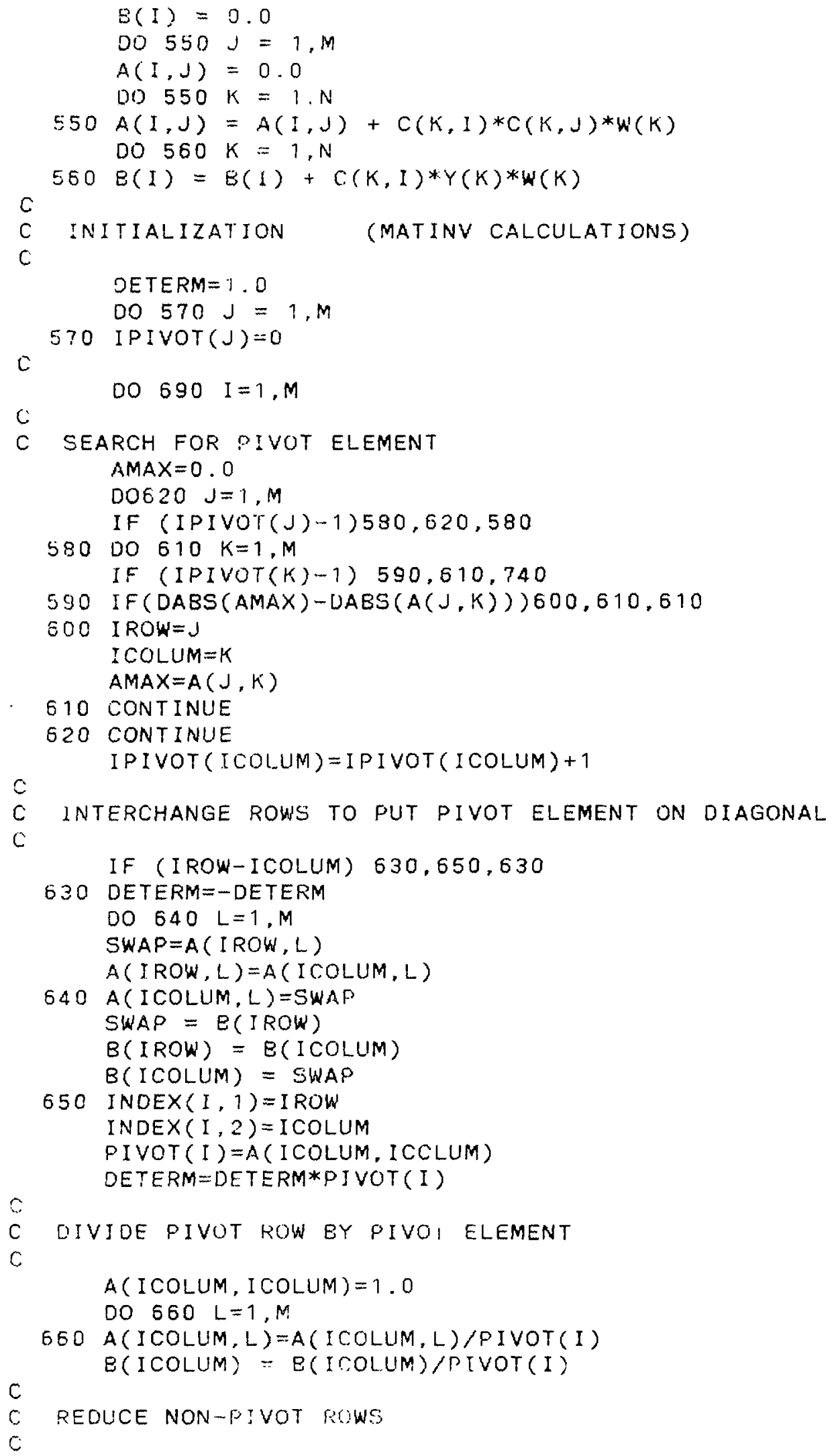




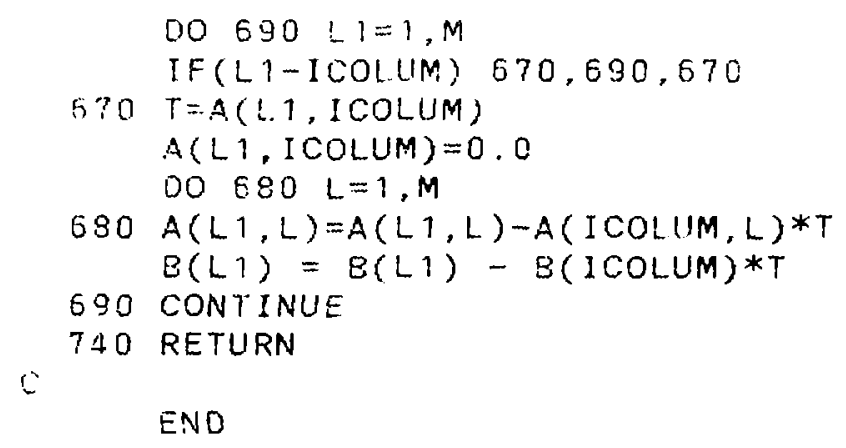


APPENDIX IV

LISTING OF THE RMPRDN OUTPUT DATA FOR THE HYDROGEN COUNTER IN THE JANUS NEUTRON SPECTRUM 


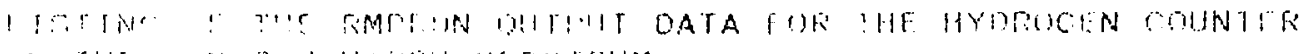

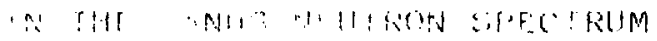

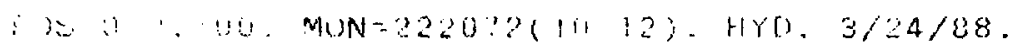

TUTAL POLNIS AND ETART POINT : $475 \quad 28$ INITIA! AVEKAOE WROTON LINE WIOTH = 2.70 N15 AND NERK GHANNELS ARE 321376 .$O O$ WMAX $U$ IANNEL $=220$

RUN TIME IN $3 E C O N O S=19190$

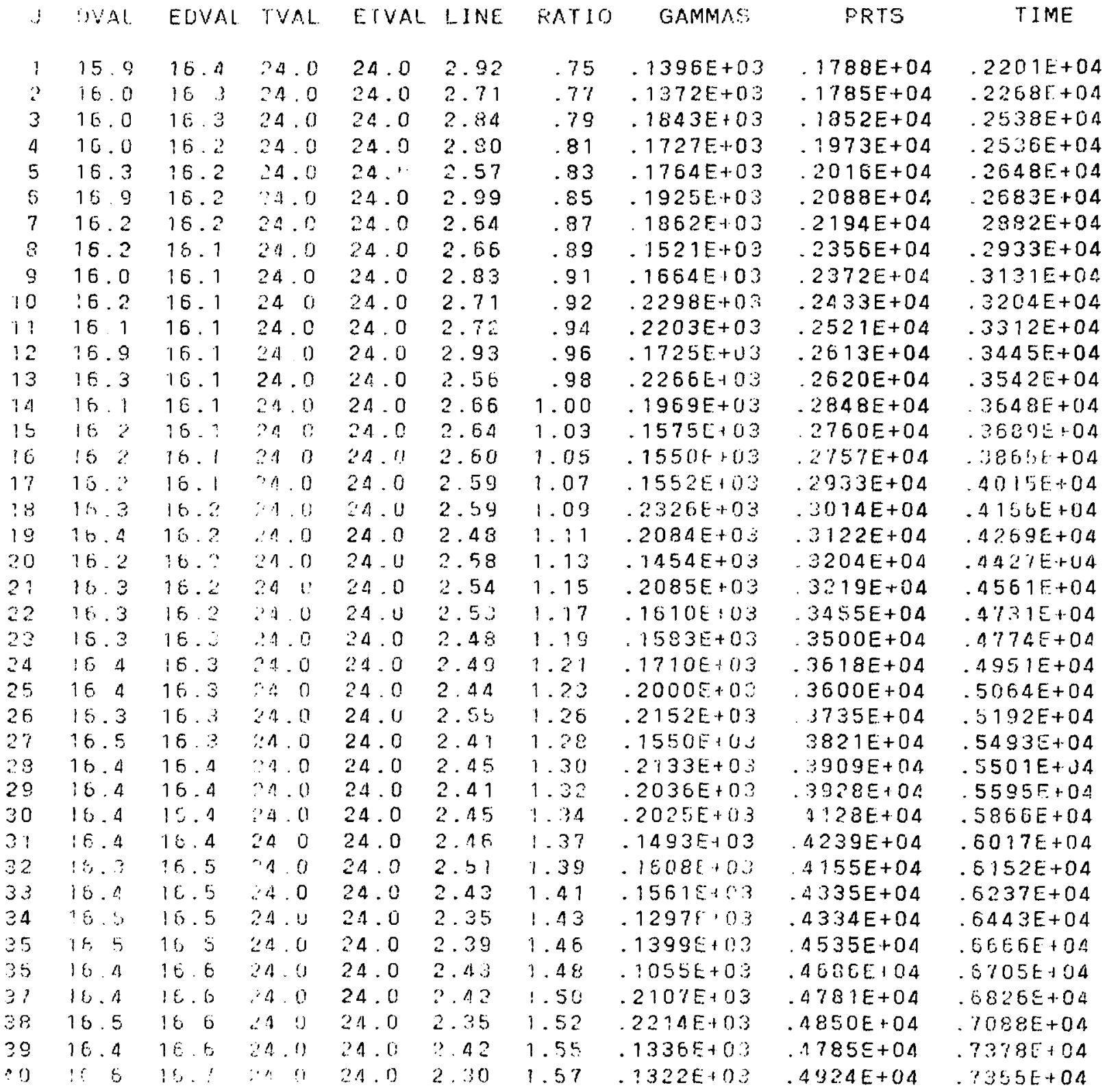




\begin{tabular}{|c|c|c|c|c|c|c|c|c|c|}
\hline 41 & 16.5 & 16.7 & 24.0 & 24.0 & 2.39 & 1.59 & $.1011 \mathrm{E}+03$ & $.5070 E+04$ & $.7609 E+04$ \\
\hline 42 & 16.5 & 16.7 & 24.0 & 24.0 & 2.37 & 1.61 & $.1674 E+03$ & $5209 E+04$ & $.7740 E+04$ \\
\hline 43 & 16.5 & 16.7 & 24.0 & 24.0 & 2.37 & 1.64 & $.1684 E+03$ & $.5371 E+04$ & $.7978 E+04$ \\
\hline 44 & 16.5 & 16.7 & 24.0 & 24.0 & 2.34 & 1.66 & $.2124 E+03$ & $.5490 E+04$ & $.8221 E+04$ \\
\hline 45 & 16.4 & 16.8 & 24.0 & 24.0 & 2.40 & 1.68 & $.1310 E+03$ & $.5409 E+04$ & $.8368 E+04$ \\
\hline 46 & 16.5 & 16.8 & 24.0 & 24.0 & 2.35 & 1.70 & $.1503 E+03$ & $.5539 E+04$ & $.8450 E+04$ \\
\hline 47 & 16.5 & 16.8 & 24.0 & 24.0 & 2.36 & 1.73 & $.1412 E+03$ & $.5691 E+04$ & $.8764 E+04$ \\
\hline 48 & 16.4 & 16.8 & 24.0 & 24.0 & 2.40 & 1.75 & $.1122 E+03$ & $.5914 E \div 04$ & $.8927 E+04$ \\
\hline 49 & 16.5 & 16.8 & 24.0 & 24.0 & 2.35 & 1.77 & $.1312 E+03$ & $.6000 E+04$ & $.9277 E+04$ \\
\hline 50 & 16.6 & 16.8 & 24.0 & 24.0 & 2.32 & 1.79 & $.9147 E+02$ & $.6053 E+04$ & $.9302 E+04$ \\
\hline 51 & 16.6 & 16.9 & 24.0 & 24.0 & 2.26 & 1.81 & $.3559 E+03$ & $.6091 E+04$ & $.9580 E+04$ \\
\hline 52 & 16.6 & 16.9 & 24.0 & 24.0 & 2.30 & 1.84 & $.1267 E+03$ & $.6293 E+04$ & $.9822 E+04$ \\
\hline 53 & 16.6 & 16.9 & 24.0 & 24.0 & 2.29 & 1.86 & $.1647 E+03$ & $.6305 E+04$ & $.9965 E+04$ \\
\hline 54 & 16.5 & 16.9 & 24.0 & 24.0 & 2.33 & 1.88 & $.1067 E+03$ & $6549 E+04$ & $.1025 E+05$ \\
\hline 55 & 16.6 & 16.9 & 24.0 & 24.0 & 2.30 & 1.90 & $.1347 E+03$ & $.6555 E+04$ & $.1042 E+05$ \\
\hline 56 & 16.6 & 16.9 & 24.0 & 24.0 & 2.28 & 1.92 & $.1733 E+03$ & $.6731 E+04$ & $.1071 E+05$ \\
\hline 57 & 16.5 & 16.9 & 24.0 & 24.0 & 2.34 & 1.95 & $.1587 E+03$ & $.6629 E+04$ & $.1088 E+05$ \\
\hline 58 & 16.5 & 16.9 & 24.0 & 24.0 & 2.34 & 1.97 & $.1918 E+03$ & $.6897 E+04$ & $.1120 E+05$ \\
\hline 59 & 17.5 & 16.9 & 24.0 & 24.0 & 2.33 & 1.99 & $.9448 E+02$ & $.7027 E+04$ & $.1124 E+05$ \\
\hline 60 & 16.5 & 16.9 & 24.0 & 24.0 & 2.32 & 2.01 & $.1804 E+03$ & $.7105 E+04$ & $.1160 E+05$ \\
\hline 61 & 16.5 & 16.9 & 24.0 & 24.0 & 2.35 & 2.03 & $.1474 E+03$ & $.7263 E+04$ & $.1184 E+05$ \\
\hline 62 & 16.6 & 17.0 & 24.0 & 24.0 & 2.30 & 2.05 & $.1403 E+03$ & $.7350 E+04$ & $.1203 E+05$ \\
\hline 63 & 17.5 & 17.0 & 24.0 & 24.0 & 2.34 & 2.07 & $.1489 E+03$ & $52 E+04$ & $.1234 E+05$ \\
\hline 64 & 16.5 & 17.0 & 24.0 & 24.0 & 2.34 & 2.09 & $.1951 E+03$ & $.7764 E+04$ & $.1265 E+05$ \\
\hline 65 & 17.5 & 17.0 & 24.0 & 24.0 & 2.34 & 2.11 & $.2361 E+03$ & $.7682 E+04$ & $.1281 E+05$ \\
\hline 66 & 17.5 & 17.0 & 24.0 & 24.0 & 2.33 & 2.13 & $.1334 E+03$ & $.7915 E+04$ & $.1316 E+05$ \\
\hline 67 & 17.5 & 17.0 & 24.0 & 24.0 & 2.32 & 2.15 & $.2402 E+03$ & $.8114 E+04$ & $.1332 E+05$ \\
\hline 68 & 17.6 & 17.0 & 24.0 & 24.0 & 2.30 & 2.17 & $.1773 E+03$ & $.8071 E+04$ & $.1358 E+05$ \\
\hline 69 & 17.6 & 17.0 & 24.0 & $24: 0$ & 2.30 & 2.19 & $.1374 E+03$ & $.8406 E+04$ & $.1396 E+05$ \\
\hline $70^{\circ}$ & 17.6 & 17.0 & 24.0 & 24.0 & 2.28 & 2.21 & $.2376 E+03$ & $.8499 E+04$ & $.1419 E+05$ \\
\hline 71 & 17.6 & 17.0 & 24.0 & 24.0 & 2.28 & 2.23 & $.1569 E+03$ & $.8583 E+04$ & $.1448 E+05$ \\
\hline 72 & 17.6 & 17.0 & 24.0 & 24.0 & 2.29 & 2.25 & $.1677 E+03$ & $.8668 E+04$ & $.1453 E+05$ \\
\hline 73 & 17.6 & 17.0 & 24.0 & 24.0 & 2.28 & 2.27 & $.2116 E+03$ & $.8566 E+04$ & $.1447 E+05$ \\
\hline 74 & 17.5 & 17.0 & 24.0 & 24.0 & 2.32 & 2.29 & $.1094 E+03$ & $.8638 E+04$ & $.1484 E+05$ \\
\hline 75 & 17.6 & 17.0 & 24.0 & 24.0 & 2.29 & 2.30 & $.2254 E+03$ & $.8588 E+04$ & $.1463 E+05$ \\
\hline 76 & 17.6 & 17.0 & 24.0 & 24.0 & 2.29 & 2.32 & $.2062 E+03$ & $.8560 E+04$ & $.1457 E+05$ \\
\hline 77 & 17.6 & 17.0 & 4.0 & 24.0 & 2.30 & 2.34 & $.4212 E+03$ & $8841 E+04$ & $1447 E+05$ \\
\hline 78 & 17.6 & 16.9 & 24.0 & 24.0 & 2.31 & 2.36 & $.5208 E+03$ & $.9075 E+04$ & $.1477 E+05$ \\
\hline 79 & 17.6 & 16.9 & 24.0 & 24.0 & 2.28 & 2.37 & $2 E+03$ & $.8995 E+04$ & $.1465 E+05$ \\
\hline 80 & .6 & 16.9 & 24.0 & 24.0 & 2.29 & 2.39 & $E+03$ & $7 E+04$ & $.1468 E+05$ \\
\hline 81 & 17.6 & 16.9 & 4.0 & 24.0 & 2.29 & 2.41 & $E+03$ & $6 E+04$ & $.1441 \mathrm{E}+05$ \\
\hline 82 & 16.6 & 16.9 & 24.0 & 24.0 & 2.23 & 2.42 & $0 E+03$ & $.9170 E+04$ & $.1471 E+05$ \\
\hline 83 & 17.5 & 16.9 & 24.0 & 24.0 & 2.33 & 2.44 & $2 E+03$ & $.9060 E+04$ & $.1450 E+05$ \\
\hline 84 & 17.5 & 16.9 & 24.0 & 24.0 & 2.35 & 2.46 & $E+03$ & $3 E+04$ & $.1466 E+05$ \\
\hline 85 & 16.5 & 16.9 & 24.0 & 24.0 & 2.31 & 2.47 & $2 E+03$ & $.9358 E+04$ & $.1473 E+05$ \\
\hline 86 & 16.6 & .9 & 24.0 & 24.0 & 2.29 & 2.49 & $1 E+04$ & $.9326 E+04$ & $.1461 E+05$ \\
\hline 87 & 16.5 & 16.9 & 24.0 & 24.0 & 2.32 & 2.50 & $2 E+04$ & $.9347 E+04$ & $.1447 E+05$ \\
\hline 88 & 16.5 & 16.9 & 24.0 & 24.0 & 2.31 & 2.52 & $.1263 E+04$ & $.9374 E+04$ & $.1452 E+05$ \\
\hline 89 & 16.6 & 16.9 & 24.0 & 24.0 & 2.30 & 2.53 & $.1343 E+04$ & $.9397 E+04$ & $.1444 \mathrm{E}+05$ \\
\hline 90 & 16.6 & 16.9 & 24.0 & 24.0 & 2.29 & 2.54 & $.1436 \mathrm{E}+04$ & $.9494 E+04$ & $.1432 E+05$ \\
\hline 91 & 16.6 & 16.9 & 24.0 & 24.0 & 2.30 & 2.56 & $.1580 E+04$ & $.9719 E+04$ & $.1440 E+05$ \\
\hline 92 & 16.6 & 16.9 & 24.0 & 24.0 & 2.29 & 2.57 & $1650 E+04$ & $.9676 E+04$ & $.1480 E+05$ \\
\hline 93 & 16.6 & 16.9 & 24.0 & 24.0 & 2.29 & 2.58 & $.1838 E+04$ & $.9511 E+04$ & $.1468 E+05$ \\
\hline 94 & 16.6 & 16.9 & 24.0 & 24.0 & 2.29 & 2.60 & $.1579 E+04$ & $.9730 E+04$ & $.1461 E+05$ \\
\hline 95 & 16.6 & 16.8 & 24.0 & 24.0 & 2.26 & 2.61 & $.735 E+04$ & $.9882 E+04$ & $.14535+05$ \\
\hline 96 & 16.5 & 16.8 & 24.0 & 24.0 & 2.32 & 2.62 & $.1666 E+04$ & $.9896 E+04$ & $.1470 E+05$ \\
\hline 97 & 16.6 & 16.8 & 24.0 & 24.0 & 2.30 & 2.63 & $1603 E+04$ & $9961 E+04$ & $.1466 E+05$ \\
\hline
\end{tabular}




\begin{tabular}{|c|c|c|c|c|c|c|c|c|c|}
\hline 98 & 16.5 & 16.8 & 24.0 & 24.0 & 2.31 & 2.64 & $.1697 E+04$ & $.1001 E+05$ & $.1483 E+05$ \\
\hline 99 & 16.6 & 16.8 & 24.0 & 24.0 & 2.30 & 2.66 & $.1875 E+04$ & $.1009 E+05$ & $.1455 E+05$ \\
\hline 100 & & .8 & 24.0 & 24.0 & 2.30 & 2.67 & $.1809 E+04$ & $6 E+05$ & $.1463 E+05$ \\
\hline 101 & 16.5 & 16.8 & 24.0 & 24.0 & 2.26 & 2.68 & $.1408 E+04$ & $.1026 \mathrm{E}+05$ & $.1473 E+05$ \\
\hline 102 & 16.6 & 16.8 & 24.0 & 24.0 & 2.28 & 2.69 & $.2147 E+04$ & $.1019 \mathrm{E}+05$ & $.1460 E+05$ \\
\hline 103 & 16.6 & 16.8 & 24.0 & 24.0 & 2.27 & 2.70 & $.2144 E+04$ & $.1042 \mathrm{E}+05$ & $.1460 E+05$ \\
\hline 104 & 16.6 & 16.8 & 24.0 & 24.0 & 2.24 & 2.71 & $.1987 E+04$ & $.1061 E+05$ & $.1474 E+05$ \\
\hline 105 & 16.6 & 16.8 & 24.0 & 24.0 & 2.27 & 2.72 & $.1534 E+04$ & $.1048 E+05$ & $.1466 E+05$ \\
\hline 106 & 16.6 & 16.8 & 24.0 & 24.0 & 2.25 & 2.72 & $.1674 E+04$ & $.1047 E+05$ & $.1475 E+05$ \\
\hline 107 & 16.6 & 16.8 & 24.0 & 24.0 & 2.25 & 2.73 & $.1341 E+04$ & $.1062 E+05$ & $.1458 E+05$ \\
\hline 108 & 16.6 & 16.8 & 24.0 & 24.0 & 2.25 & 2.74 & $.1612 E+04$ & $.1102 E+05$ & $.1471 E+05$ \\
\hline 109 & 16.6 & 16.7 & 24.0 & 24.0 & 2.25 & 2.75 & $.1339 E+04$ & $.1085 E+05$ & $.1464 E+05$ \\
\hline 110 & 16.6 & 16.7 & 24.0 & 24.0 & 2.25 & 2.76 & $.1247 E+04$ & $.1085 E+05$ & $.1479 E+05$ \\
\hline 111 & 16.6 & 16.7 & 24.0 & 24.0 & 2.26 & 2.76 & $.1394 E+04$ & $.1094 E+05$ & $.1464 E+05$ \\
\hline 112 & 16.6 & 16.7 & 4.0 & 24.0 & 2.29 & 2.77 & $.9856 E+03$ & $.1085 E+05$ & $.1471 E+05$ \\
\hline 113 & 16.6 & 16.7 & 4.0 & 24.0 & 2.30 & 2.78 & $.1257 E+04$ & $.1093 E+05$ & $.1488 E+05$ \\
\hline 114 & 15.7 & 16.7 & 4.0 & 24.0 & 2.23 & 2.79 & $.9648 E+03$ & $.1131 E+05$ & $.1460 E+05$ \\
\hline 115 & 16.7 & 16.7 & 4.0. & 24.0 & 2.22 & 2.79 & $.9921 E+03$ & $.1128 E+05$ & $.1489 E+05$ \\
\hline 116 & 16.6 & 6.7 & 24.0 & 24.0 & 2.26 & 2.80 & $.8846 E+03$ & $.1138 E+05$ & $68 E+05$ \\
\hline 117 & 16.6 & 16.7 & 24.0 & 24.0 & 2.25 & 2.80 & $8 E+03$ & $.113 .7 E+0.5$ & $4 E+05$ \\
\hline 118 & 16.6 & 16.7 & 24.0 & 24.0 & 2.26 & 2.81 & $.9220 E+03$ & $.1143 E+05$ & $5 E+05$ \\
\hline 119 & 16.7 & 16.7 & 24.0 & 24.0 & 2.24 & 2.81 & $.7538 E+03$ & $.1171 \mathrm{E}+05$ & $.1468 E+05$ \\
\hline 120 & 16.6 & 16.7 & 24.0 & 24.0 & 2.25 & 2.82 & $.7547 E+03$ & $.1170 E+05$ & $4 E+05$ \\
\hline 121 & 16.7 & 16.7 & 24.0 & 24.0 & 2.22 & 2.82 & $.6551 E+03$ & $.1174 E+05$ & $.1501 E+05$ \\
\hline 122 & 16.6 & 16.7 & 24.0 & 24.0 & 2.26 & 2.83 & $.1001 E+04$ & $7 E+05$ & $.1485 E+05$ \\
\hline 123 & 16.6 & 16.7 & 24.0 & 24.0 & 2.24 & 2.83 & $.5846 E+03$ & $.1183 E+05$ & $.1462 E+05$ \\
\hline 124 & 16.6 & 16.7 & 24.0 & 24.0 & 2.24 & 2.84 & $.5719 E+03$ & $.1208 E+05$ & $.1471 E+05$ \\
\hline 125 & 16.6 & 16.7 & 24.0 & 24.0 & 2.25 & 2.84 & $9 E+03$ & $.1204 E+05$ & $.1479 E+05$ \\
\hline 126 & 16.7 & 16.7 & 24.0 & 24.0 & 2.23 & 2.84 & $2 E+03$ & $.1195 E+05$ & $4 E+05$ \\
\hline 127 & 16.7 & 16.7 & 24.0 & 24.0 & 2.23 & 2.85 & $.6452 E+03$ & $.1206 E+05$ & $.1477 E+05$ \\
\hline 128 & 16.7 & 16.7 & 24.0 & 24.0 & 2.18 & 2.85 & $.6481 E+03$ & $.1203 E+05$ & $.1470 E+05$ \\
\hline 129 & 16.7 & 16.7 & 24.0 & 24.0 & 2.17 & 2.85 & $.4534 E+03$ & $.1214 E+05$ & $.1475 E+05$ \\
\hline 130 & 16.7 & 16.7 & 24.0 & 24.0 & 2.20 & 2.85 & $.5903 E+03$ & $.1244 E+05$ & $.1460 E+05$ \\
\hline 131 & 16.7 & 16.7 & 24.0 & 24.0 & 2.20 & 2.85 & $.5093 E+03$ & $.1260 E+05$ & $.1495 E+05$ \\
\hline 132 & 16.6 & 16.7 & 24.0 & 24.0 & 2.24 & 2.88 & $.8099 E+03$ & $.1245 E+05$ & $.1465 E+05$ \\
\hline 133 & .8 & 16.7 & 24.0 & 24.0 & 2.16 & 2.86 & $.5765 E+03$ & $.1254 E+05$ & $.1496 E+05$ \\
\hline 134 & .7 & .7 & 24.0 & 24.0 & 2.22 & 2.86 & $.3950 E+03$ & $.1270 E+05$ & $.1479 E+05$ \\
\hline 35 & .7 & .7 & 24.0 & 24.0 & 2.19 & 2.86 & $.4989 E+03$ & $.1274 E+05$ & $.1486 E+05$ \\
\hline 136 & .7 & 16.7 & 24.0 & 24.0 & 2.21 & 2.86 & $.7260 E+03$ & $.1295 E+05$ & $.1435 E+05$ \\
\hline 137 & .7 & 0.7 & 24.0 & 24.0 & 2.20 & 2.86 & $.6716 E+03$ & $.1313 E+05$ & $.1490 E+05$ \\
\hline 3 & .7 & 5.7 & 1.0 & 4.0 & 2.20 & 2.86 & $E+03$ & $5 E+05$ & $8 E+05$ \\
\hline 3 & .7 & 16.7 & 1.0 & 4.0 & 2.20 & 2.86 & $E+03$ & $E+05$ & $9 E+05$ \\
\hline 140 & 16.7 & 16.7 & .0 & 4.0 & 2.18 & 2.86 & +03 & $E+05$ & $11 E+05$ \\
\hline 141 & 16.7 & 16.7 & .0 & 24.0 & 2.20 & 2.86 & $.6882 E+03$ & $.1322 E+05$ & $.1474 \mathrm{E}+05$ \\
\hline 42 & .7 & .7 & .0 & 24.0 & 2.17 & 2.86 & $E+04$ & $6 E+05$ & $14 E+05$ \\
\hline 19 & .7 & .7 & .0 & .0 & 2.22 & .86 & +04 & +05 & $7 E+05$ \\
\hline & .7 & .7 & .0 & .0 & 2.17 & 2.86 & +04 & +05 & $E+05$ \\
\hline 145 & 16.7 & 16.7 & 24.0 & 24.0 & 2.18 & 2.86 & $.8896 E+03$ & $.1376 E+05$ & $.1486 E+05$ \\
\hline 46 & .8 & .7 & 4.0 & 24.0 & 2.15 & 2.86 & $.7750 E+03$ & $1402 E+05$ & $1490 E+05$ \\
\hline 47 & .8 & .7 & 4.0 & 24.0 & 2.15 & 2.86 & $.1008 E+04$ & $.1389 E+05$ & $.1489 E+05$ \\
\hline 48 & 10.7 & 16.7 & 4.0 & 24.0 & 2.18 & 2.86 & $.1048 E+04$ & $.1403 E+05$ & $.1502 E+0.5$ \\
\hline 149 & 16.8 & 16.7 & 4.0 & 24.0 & 2.14 & 2.86 & $.1089 E+04$ & $1405 E+05$ & $1496 E+05$ \\
\hline 150 & 16.7 & 16.7 & 24.0 & 24.0 & 2.18 & 2.86 & $.1129 E+04$ & $.1417 E+05$ & $.1490 E+05$ \\
\hline 151 & .8 & .7 & 24.0 & 24.0 & 2.15 & 2.86 & $.9457 E+03$ & $.1423 E+05$ & $.1498 E+05$ \\
\hline 152 & 16.8 & 16.7 & 24.0 & 24.0 & 2.16 & 2.86 & $8464 E+03$ & $.1426 E+05$ & $.1511 E+05$ \\
\hline 153 & 16.7 & 16.7 & 24.0 & 24.0 & 2.17 & 2.85 & $.7037 E+03$ & $.1457 E+05$ & $.1499 E+05$ \\
\hline 154 & 16.7 & 16.7 & 24.0 & 24.0 & 2.22 & 2.85 & $.8256 E+03$ & $1456 E+05$ & $.1520 E+05$ \\
\hline
\end{tabular}




\begin{tabular}{|c|c|c|c|c|c|c|c|c|c|}
\hline 155 & 16.8 & 16.7 & 24.0 & 24.0 & 2.15 & 2.85 & $.7606 E+03$ & $.1473 E+05$ & $.1520 E+05$ \\
\hline 156 & 16.7 & 16.7 & 24.0 & 24.0 & 2.19 & 2.85 & $9711 E+03$ & $.1477 E+05$ & $.1499 E+05$ \\
\hline 157 & 16.7 & 16.7 & 24.0 & 24.0 & 2.17 & 2.85 & $.7170 E+03$ & $.1464 E+05$ & $.1505 E+05$ \\
\hline 158 & 16.7 & 16.7 & 24.0 & 24.0 & 2.17 & 2.84 & $.1001 E+04$ & $.1487 E+05$ & $.1515 E+05$ \\
\hline 159 & 16.8 & 16.7 & 24.0 & 24.0 & 2.16 & 2.84 & $.9110 E+03$ & $.1504 E+05$ & $.1500 E+05$ \\
\hline 150 & 16.8 & 16.7 & 24.0 & 24.0 & 2.16 & 2.84 & $.9989 E+03$ & $.1511 E+05$ & $.1536 E+05$ \\
\hline 161 & 16.7 & 16.7 & 24.0 & 24.0 & 2.19 & 2.84 & $.1309 E+04$ & $.1529 E+05$ & $.1502 E+05$ \\
\hline 162 & 16.7 & 16.7 & 24.0 & 24.0 & 2.18 & 2.83 & $.7317 E+03$ & $.1528 E+05$ & $.1517 E+05$ \\
\hline 163 & 16.7 & 16.7 & 24.0 & 24.0 & 2.18 & 2.83 & $.1082 E+04$ & $.1569 E+05$ & $.1504 E+05$ \\
\hline 164 & 16.8 & 15.7 & 24.0 & 24.0 & 2.16 & 2.83 & $.1055 E+04$ & $.1564 E+05$ & $.1514 E+05$ \\
\hline 65 & 16.7 & 6.7 & 24.0 & 24.0 & 2.18 & .83 & $.7702 E+03$ & $.1558 E+05$ & $.1530 E+05$ \\
\hline 166 & 16.8 & 16.7 & 24.0 & 24.0 & 2.12 & .82 & $.8910 E+03$ & $.1571 \mathrm{E}+05$ & $.1519 E+05$ \\
\hline 167 & 16.7 & 16.7 & 24.0 & 24.0 & 2.17 & 2.82 & $.6965 E+03$ & $.1578 E+05$ & $.1513 E+05$ \\
\hline 168 & 16.8 & 16.7 & 24.0 & 24.0 & 2.16 & 2.82 & $.8324 E+03$ & $.1587 E+05$ & $.1519 E+05$ \\
\hline 69 & 16.8 & 16.7 & 24.0 & 24.0 & 2.13 & 2.81 & $.9849 E+03$ & $.1606 E+05$ & $.1517 E+05$ \\
\hline 170 & 16.8 & 16.8 & 24.0 & 24.0 & 2.11 & 2.81 & $.1020 E+04$ & $.1573 E+05$ & $.1531 E+05$ \\
\hline 171 & 16.8 & 16.8 & 24.0 & 24.0 & 2.13 & 2.81 & $.1048 E+04$ & $.1612 E+05$ & $.1534 E+05$ \\
\hline 172 & 16.8 & 16.8 & 24.0 & 24.0 & 2.14 & 2.81 & $.9583 E+03$ & $.1627 E+05$ & $.1539 E+05$ \\
\hline 173 & 16.8 & 16.8 & 24.0 & 24.0 & 2.14 & 2.80 & $.7457 E+03$ & $.1625 E+05$ & $5 E+05$ \\
\hline 174 & 16.8 & 16.8 & 24.0 & 24.0 & 2.13 & 2.80 & $.9461 E+03$ & $.1649 E+05$ & $.1534 E+05$ \\
\hline 175 & 16.8 & 16.8 & 24.0 & 24.0 & 2.12 & 2.80 & $.9535 E+03$ & $.1633 E+05$ & $.1538 E+05$ \\
\hline 176 & 16.8 & 16.8 & 24.0 & 24.0 & 2.14 & 2.79 & $.7808 E+03$ & $.1660 E+05$ & $.1549 E+05$ \\
\hline 177 & 16.8 & 16.8 & 24.0 & 24.0 & 2.15 & 2.79 & $.7702 E+03$ & $.1670 E+05$ & $.1534 E+05$ \\
\hline 178 & 16.8 & 16.8 & 24.0 & 24.0 & 2.15 & 2.79 & $.7106 E+03$ & $.1654 E+05$ & $.1537 E+05$ \\
\hline 179 & 16.8 & 16.8 & 24.0 & 24.0 & 2.12 & 2.78 & $.7278 E+03$ & $.1682 E+05$ & $.1556 \mathrm{E}+05$ \\
\hline 180 & 16.7 & 16.8 & 24.0 & 24.0 & 2.19 & 2.78 & $.7890 E+03$ & $.1688 E+05$ & $.1548 E+05$ \\
\hline 181 & 16.8 & 16.8 & 24.0 & 24.0 & 2.14 & 2.78 & $.9289 E+03$ & $.1706 E+05$ & $.1536 \mathrm{E}+05$ \\
\hline 182 & 16.8 & 16.8 & 24.0 & 24.0 & 2.12 & 2.77 & $.7510 E+03$ & $.1711 E+05$ & $.1554 E+05$ \\
\hline 183 & 16.8 & 16.8 & 24.0 & 24.0 & 2.13 & 2.77 & $.7986 E+03$ & $.1701 E+05$ & $.1550 E+05$ \\
\hline 184 & 16.8 & 16.8 & 24.0 & 24.0 & 2.15 & 2.76 & $.9224 E+03$ & $.1723 E+05$ & $.1556 E+05$ \\
\hline 185 & 16.8 & 16.8 & 24.0 & 24.0 & 2.14 & 2.76 & $.4716 E+03$ & $.1740 E+05$ & $.1536 E+05$ \\
\hline 186 & 16.7 & 16.8 & 24.0 & 24.0 & 2.17 & 2.76 & $.7813 E+03$ & $.1741 E+05$ & $.1550 E+05$ \\
\hline 187 & 16.8 & 16.8 & 24.0 & 24.0 & 2.14 & 2.75 & $.6486 E+03$ & $.1723 E+05$ & $.1572 E+05$ \\
\hline 188 & 16.8 & 16.8 & 24.0 & 24.0 & 2.12 & 2.75 & $.8774 E+03$ & $.1759 E+05$ & $.1549 E+05$ \\
\hline 189 & 16.8 & 16.8 & 24.0 & 24.0 & 2.15 & 2.75 & $.7211 \mathrm{E}+03$ & $.1757 E+05$ & $.1554 E+05$ \\
\hline 190 & 16.8 & 16.8 & 24.0 & 24.0 & 2.16 & 2.74 & $.7548 E+03$ & $.1760 E+05$ & $.1567 E+05$ \\
\hline 191 & 16.8 & 15.8 & 24.0 & 24.0 & 2.12 & 2.74 & $.5967 E+03$ & $.1780 E+05$ & $.1551 E+05$ \\
\hline 192 & 16.7 & 16.8 & 24.0 & 24.0 & 2.17 & 2.73 & $.6148 E+03$ & $.1785 E+05$ & $.1552 E+05$ \\
\hline 193 & 16.8 & 16.8 & 24.0 & 24.0 & 2.14 & 2.73 & $.5917 E+03$ & $.1837 E+05$ & $.1577 E+05$ \\
\hline 94 & 16.8 & 16.8 & 24,0 & 24.0 & 2.14 & 2.73 & $.8345 E+03$ & $.1822 E+05$ & $.1570 E+05$ \\
\hline 95 & .8 & 16.8 & 24.0 & 24.0 & 2.10 & 2.72 & $E+03$ & $.1827 E+05$ & $77 E+05$ \\
\hline 96 & .8 & .8 & 24.0 & 24.0 & 2.14 & 2.72 & $E+03$ & $1862 E+05$ & $4 E+05$ \\
\hline 97 & .8 & 16.8 & 24.0 & 24.0 & 2.13 & 2.71 & $E+03$ & $.1850 E+05$ & $72 E+05$ \\
\hline 198 & .7 & .8 & 24.0 & 24.0 & 2.17 & 2.71 & $E+03$ & $.1850 E+05$ & $.1573 E+05$ \\
\hline 199 & .7 & 16.8 & 24.0 & 24.0 & 2.17 & 2.70 & $E+03$ & $.1860 E+05$ & $36 E+05$ \\
\hline חمת & .7 & .8 & 24.0 & 24.0 & 2.21 & 2.70 & $E+03$ & $1883 E+05$ & $.1589 E+05$ \\
\hline 201 & .8 & 16.8 & 24.0 & 24.0 & 2.15 & 2.69 & $D E+03$ & $.1871 E+05$ & $.1558 E+05$ \\
\hline 202 & .7 & 16.8 & 24.0 & 24.0 & 2.19 & 2.69 & $6972 E+03$ & $.1891 \mathrm{E}+05$ & $.1602 E+05$ \\
\hline 203 & 16.8 & 16.7 & 24.0 & 24.0 & 2.15 & 2.68 & $8259 E+03$ & $.1919 E+05$ & $.1577 E+05$ \\
\hline 204 & 16.8 & 16.7 & 24.0 & 24.0 & 2.15 & 2.68 & $6338 E+03$ & $.1914 E+05$ & $.1591 E+05$ \\
\hline 205 & 16.8 & 16.7 & 24.0 & 24.0 & 2.16 & 2.67 & $7662 E+03$ & $.1909 E+05$ & $.1571 E+05$ \\
\hline 206 & 16.7 & 6.7 & 24.0 & 24.0 & 2.17 & 2.67 & $.7577 E+03$ & $.1918 E+05$ & $.1603 E+05$ \\
\hline 207 & 16.7 & 6.7 & 24.0 & 24.0 & 2.18 & 2.66 & $.6873 E+03$ & $.1938 E+05$ & $.1601 E+05$ \\
\hline 208 & 16.7 & 16.7 & 24.0 & 24.0 & 2.18 & 2.66 & $6876 E+03$ & $.1987 E+05$ & $.1603 E+05$ \\
\hline 209 & 16.7 & 16.7 & 24.0 & 24.0 & 2.17 & 2.65 & $7094 E+03$ & $1966 E+05$ & $.1607 E+05$ \\
\hline 210 & 16.8 & 16.7 & 24.0 & 24.0 & 2.16 & 2.65 & $.7108 E+03$ & $.1965 E+05$ & $.1596 E+05$ \\
\hline $2 ! 1$ & 16.7 & 16.7 & 24.0 & 24.0 & 2.17 & 2.64 & $8069 E+03$ & $.2001 E+05$ & $.1621 E+05$ \\
\hline
\end{tabular}




\begin{tabular}{|c|c|c|c|c|c|}
\hline & 6.7 & 6.7 & 24.0 & 24.0 & \\
\hline 13 & 16.7 & 16.7 & 24.0 & 24.0 & 2.20 \\
\hline 14 & 6.6 & 6.7 & 24.0 & 24.0 & 2.24 \\
\hline 15 & 6.7 & 6.7 & 4.0 & 24.0 & 2.2 \\
\hline & .8 & & 4.0 & 24.0 & 1 \\
\hline 1 & 8 & .7 & 4.0 & 24.0 & 2.1 \\
\hline 1 & 6.7 & 6.7 & 24.0 & 24.0 & 2.18 \\
\hline 19 & 6.7 & 16.7 & 24.0 & 24.0 & 2. 19 \\
\hline 20 & .7 & 6.7 & 24.0 & 24.0 & 2.19 \\
\hline 21 & 6.7 & 16.7 & 24.0 & 24.0 & 2.20 \\
\hline 22 & .6 & 16.7 & 24.0 & 24.0 & 2.26 \\
\hline 23 & 6.7 & 16.7 & 24.0 & 24.0 & 2.21 \\
\hline 24 & .7 & 16.6 & 24.0 & 24.0 & 2.22 \\
\hline 2 & & 16.6 & 24.0 & 24.0 & 2.2 \\
\hline 226 & .6 & 16.6 & 24.0 & 24.0 & 2.27 \\
\hline 2 & .6 & 6.6 & 24.0 & 24.0 & .2 \\
\hline 28 & .6 & 6.6 & 4.0 & 4.0 & .2 \\
\hline 2 & .7 & 16.6 & 24.0 & 4.0 & .2 \\
\hline 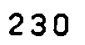 & .5 & .6 & 4.0 & 4.0 & .3 \\
\hline & .6 & 6.6 & 4.0 & 4.0 & .2 \\
\hline 32 & .6 & 6.6 & 4.0 & 4.0 & .2 \\
\hline 33 & & & 4.0 & 4.0 & .3 \\
\hline 24 & & 6 & 24.0 & 4.0 & 3 \\
\hline 35 & 5 & & 4.0 & 4.0 & .3 \\
\hline 36 & 5 & & $4 . .0$ & 4.0 & .3 \\
\hline & 6 & & 4.0 & 4.0 & .25 \\
\hline 20 & .4 & & 4.0 & 4.0 & .37 \\
\hline & 5 & & 4.0 & 4.0 & .33 \\
\hline & .4 & 5 & 4.0 & 4.0 & .40 \\
\hline & .5 & .5 & 4.0 & 4.0 & .33 \\
\hline ? & .5 & .5 & 4.0 & 4.0 & .36 \\
\hline & .4 & .5 & 4.0 & 4.0 & .39 \\
\hline & .4 & .5 & 4.0 & 4.0 & .38 \\
\hline & .4 & .5 & 4.0 & 24.0 & 2.40 \\
\hline & .4 & .5 & 4.0 & 4.0 & 2.39 \\
\hline & .4 & .4 & 4.0 & 4.0 & 2.41 \\
\hline & .4 & .4 & 4.0 & 4.0 & 2.42 \\
\hline 49 & .4 & .4 & 4.0 & 4.0 & 2.42 \\
\hline & .4 & .4 & 4.0 & 4.0 & 2.42 \\
\hline & .3 & .4 & 4.0 & 4.0 & .45 \\
\hline & .4 & .4 & 4.0 & 4.0 & .43 \\
\hline & .4 & 4 & 4.0 & 0 & 2.43 \\
\hline & .4 & .4 & 4.0 & 4. & 2.43 \\
\hline & 3 & & 4.0 & 4. & 2.49 \\
\hline & & & 4.0 & 4. & 2.46 \\
\hline & & 5.3 & 4.0 & 24.0 & 2.49 \\
\hline & .3 & .3 & 4.0 & 4.0 & 2.47 \\
\hline & .3 & .3 & 4.0 & 24.0 & 2.49 \\
\hline & .2 & 3 & 4.0 & 24.0 & 2.53 \\
\hline & .2 & & 4.0 & 24.0 & 2.55 \\
\hline & .3 & .3 & 4.0 & 24.0 & 2.50 \\
\hline & & & 4.0 & 24.0 & 2.54 \\
\hline & & & 9.0 & 24.0 & 2.57 \\
\hline & & & 24.0 & 24.0 & 2.57 \\
\hline & & & 24.0 & 24.0 & 2.57 \\
\hline & & & .0 & 24.0 & 2.58 \\
\hline & 16.1 & 16.2 & 24.0 & 24.0 & 2.83 \\
\hline
\end{tabular}

2.63

2. 63

2. 62

2. 62

2.61

2. 60

2. 59

2. 59

2. 58

2.58

2. 58

2.58

2.58

2. 58

2. 58

2. 58

2. 58

2.58

2.58

2.58

2. 58

2.58

2. 58

2.58

2.58

2.58

2.58

2.58

2.58

2. 58

2.58

2.58

2.58

2.58

2. 58

2. 58

2.58

2.58

2.58

2. 58

2. 58

2. 58

2. 58

2. 58

2. 58

2. 58

2.58

2. 58

2. 58

2. 58

2. 58

2. 58

2. 58

2. 58

2. 58

2. 58

2.58
$.7191 E+03$

$.8819 E+03$

$.8661 \mathrm{E}+03$

$.8926 E+03$

$.6697 \cdot E+03$

$1018 E+04$

$.8827 E+03$

$.7840 E+03$

$.7349 E+03$

$.8861 \mathrm{E}+03$

$.9100 E+03$

$.8906 E+03$

$.9970 E+03$

$.9822 E+03$

$.8966 E+03$

$.9113 E+03$

$.9331 E+03$

$.9679 E+03$

$.9080 E+03$

$.9260 \mathrm{E}+03$

$.1034 E+04$

$.9290 E+03$

$1032 E+04$

$.1117 E+04$

$.1071 E+04$

$.1170 E+04$

$.1139 \varepsilon+04$

$.1083 E+04$

$.1113 E+04$

$.1180 E+04$

$.1056 E+04$

. $1005 E+04$

$.1102 E+04$

$.1173 E+04$

$.1184 \mathrm{E}+04$

$.1105 E+04$

$.1309 E+04$

$.1246 E+04$

$.1303 E+04$

$.1145 E+04$

$.1249 E+04$

$.1409 E+04$

$.1487 \mathrm{E}+04$

$.1419 E+04$

$.1520 E+04$

$.1359 E+04$

$.1491 E+04$

$.1566 E+04$

$.1464 E+04$

$.1439 E+04$

$.1546 E+04$

$.1615 E+04$

$.1650 E+04$

$.1568 E+04$

$.1654 E+04$

$1656 E+04$

$1618 E+04$
$.2046 E+05$ $.2035 E+05$ $.2037 E+05$ $.2063 E+05$ $.2090 E+05$ $.2089 E+05$ $.2104 E+05$ $.2094 E+05$ $.2115 E+05$ $.2143 E+05$ $.2162 \mathrm{E}+05$ $.2178 E+05$ $.2216 E+05$ $.2195 E+05$ $.2196 E+05$ $.2235 E+05$ $2248 E+05$ $.2258 E+05$ $.2286 E+05$ $.2288 E+05$ $.2318 E+05$ $.2278 E+05$ $.2351 \mathrm{E}+05$ $.2378 E+05$ $.2366 \mathrm{E}+05$ $.2390 E+05$ $.2416 E+05$ $.2394 E+05$ $.2404 E+05$ $.2437 E+05$ $.2415 E+05$ $.2465 E+05$ $.2447 E+05$ $.2488 E+05$ $.2524 E+05$ $.2517 E+05$ $.2561 E+05$ $.2587 \mathrm{E}+05$ $.2581 E+05$ $.2596 E+05$ $.2631 \mathrm{E}+05$ $.2613 E+05$ $.2640 E+05$ $.2671 E+05$ $.2697 E+05$ . $2690 E+05$ $.2722 E+05$ . $2737 E+05$ $2765 E+05$ $.2808 E+05$ $.2782 E+05$ $.2803 E+05$ $.2830 E+05$ $.2863 E+05$ $.2861 \mathrm{E}+05$ $.2899 E+05$ $.2921 E+05$
$.1620 E+05$ $1619 E+05$ $1610 E+05$ $1621 E+05$ $1616 E+05$ $1633 E+05$ $.1620 E+05$ $1621 \mathrm{E}+05$ $.1643 E+05$ $.1616 E+05$ $.1656 \mathrm{E}+05$ $.1634 E+05$ $.1651 E+05$ $.1649 E+05$ $.1619 E+05$ $.1642 E+05$ $.1653 E+05$ $.1658 E+05$ $.1654 E+C 5$ $.1642 E+05$ $.1667 E+05$ $.1666 E+05$ $.1681 \mathrm{E}+05$ $.1670 E+05$ $.1674 \mathrm{E}+05$ $.1660 E+05$ $.1674 E+05$ $.1687 E+05$ $.1692 E+05$ $.1694 E+05$ $.1681 E+05$ $1678 E+05$ $.1689 E+05$ $1673 E+05$ $.1717 E+05$ $.1688 E+05$ $.1697 E+05$ $.1709 E+05$ $.1722 E+05$ $.1694 E+05$ $.1706 E+05$ $1701 \mathrm{E}+05$ $.1718 \mathrm{E}+05$ $.1722 E+05$ $1721 E+05$ $1719 E+05$ $1733 E+05$ $1723 E+05$ $1728 E+05$ $1727 E+05$ $1732 E+05$ $1722 E+05$ $1758 E+05$ $1748 E+05$ $.1752 E+05$ $.1747 E+05$ $.1759 E+05$ 


\begin{tabular}{|c|c|c|c|c|c|c|c|c|c|}
\hline 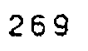 & 16.1 & 16.1 & 24.0 & 24.0 & 2.62 & 2.58 & $.1666 \mathrm{E}+04$ & $.2939 E+05$ & $.1744 E+05$ \\
\hline 70 & 16.0 & 16.1 & 24.0 & 24.0 & 2.65 & 2.58 & $.1643 E+04$ & $.2969 E+05$ & $.1764 E+05$ \\
\hline 71 & 16.0 & 16.1 & 24.0 & 24.0 & 2.66 & 2.58 & $1881 E+04$ & $.2959 E+05$ & $1757 E+05$ \\
\hline 272 & 16.1 & 16.1 & 24.0 & 24.0 & .62 & 2.58 & $.1899 E+04$ & $.2987 E+05$ & $.1763 E+05$ \\
\hline 273 & 16.0 & 16.1 & 24.0 & 24.0 & .65 & .58 & $.1804 E+04$ & $298 E E+05$ & $.1765 E+05$ \\
\hline 274 & 16.0 & 16.0 & 24.0 & 24.0 & .64 & .58 & $.1844 E+04$ & $.3024 E+05$ & $.1774 E+05$ \\
\hline 275 & 16.0 & 16.0 & 24.0 & 24.0 & .67 & .58 & $.1884 E+04$ & $.3061 E+05$ & $.1774 E+05$ \\
\hline 276 & 15.9 & 16.0 & 24.0 & 24.0 & .71 & 2.58 & $.1854 E+04$ & $.3065 E+05$ & $.1773 E+05$ \\
\hline 277 & .9 & 16.0 & 4.0 & 4.0 & 74 & 2.58 & $.1909 E+04$ & $.3082 E+05$ & $.1782 E+05$ \\
\hline 78 & .0 & 16.0 & 4.0 & 24.0 & .67 & 2.58 & $.1965 E+04$ & $.3098 E+05$ & $.1786 E+05$ \\
\hline 79 & .9 & & 4.0 & 4.0 & .73 & 2.58 & $.1970 E+04$ & $03 E+05$ & $.1785 E+05$ \\
\hline 280 & .9 & & .0 & 4.0 & .72 & 2.58 & $5 E+04$ & $.3145 E+05$ & $.1799 E+05$ \\
\hline 281 & .9 & & 4.0 & 4.0 & .72 & 2.58 & $.2090 E+04$ & $E+05$ & $6 E+0$ \\
\hline 32 & .9 & & 4.0 & 24.0 & 2.74 & 2.58 & $2058 E+04$ & $08 E+05$ & $5 E+$ \\
\hline 33 & .8 & & 4.0 & 24.0 & 2.80 & . & $2161 E+04$ & $12 E+05$ & $\bar{E}+$ \\
\hline 84 & .8 & & 4.0 & 24.0 & 2.81 & 2.5 & $2124 E+04$ & $E+05$ & 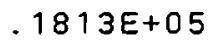 \\
\hline 285 & .8 & 8 & 4.0 & 24.0 & 2.83 & 2.58 & $2231 E+04$ & $3 E+05$ & $1791 \mathrm{E}+$ \\
\hline 286 & .7 & 7 & 24.0 & 24.0 & 2.83 & 2.58 & $.2020 E+04$ & $E+05$ & $.1821 \mathrm{E}+$ \\
\hline 287 & .7 & & 4.0 & 24.0 & 2.90 & 2.58 & $.2108 E+04$ & $E+05$ & $O E+05$ \\
\hline 38 & .7 & & 24.0 & 24.0 & 2.89 & 2.58 & $E+04$ & $E+05$ & $E+05$ \\
\hline 289 & .7 & & 24.0 & 24.0 & 2.89 & .58 & $E+04$ & $=+05$ & $3 E+05$ \\
\hline 90 & .6 & & 24.0 & 24.0 & 2.95 & .58 & $E+04$ & $E+05$ & $6 E+05$ \\
\hline 31 & .5 & & 4.0 & 24.0 & 3.02 & 2.58 & $=+04$ & $E+05$ & $E+05$ \\
\hline & .5 & & 4.0 & 24.0 & .00 & 58 & .21 & $=05$ & $5 E+05$ \\
\hline 3 & .5 & & 24.0 & 24.0 & 2.99 & 2.58 & $E+04$ & +05 & $3 E+05$ \\
\hline 294 & 15.5 & & 24.0 & 24.0 & 3.00 & 2.58 & $.2256 E+04$ & $E+05$ & $1840 E+05$ \\
\hline 295 & .5 & & 24.0 & 24.0 & .02 & 58 & $.2262 E+04$ & $\varepsilon+05$ & $.1835 E+05$ \\
\hline 96 & & & 24.0 & 24.0 & 5 & o & +04 & +05 & $6 E+05$ \\
\hline 7 & .4 & 1 & 24.0 & 24.0 & .06 & 58 & $.2204 E+04$ & +05 & $E+05$ \\
\hline 38 & .3 & 2 & 4.0 & 4.0 & .13 & 58 & $.2205 E+04$ & $E+05$ & $1 E+05$ \\
\hline 9 & 3 & & 1.0 & 4.0 & 11 & 58 & .2203 & +05 & $2 E+05$ \\
\hline O & .2 & & .0 & 4.0 & 17 & 58 & +04 & +05 & $E+05$ \\
\hline 1 & .1 & & .0 & 4.0 & 24 & 58 & .223 & +05 & $E+05$ \\
\hline 2 & .2 & & .0 & 4.0 & 19 & 58 & .227 & $E+05$ & $=05$ \\
\hline & .1 & & .0 & 4.0 & 29 & 58 & +04 & +05 & +05 \\
\hline & .0 & & .0 & 4.0 & 32 & 58 & +04 & +05 & $=05$ \\
\hline 5 & .1 & . & 4.0 & 4.0 & 26 & 58 & +04 & $E+05$ & $E+05$ \\
\hline & & & 4.0 & 4.0 & 42 & 58 & +04 & +05 & $E+05$ \\
\hline 07 & & & .0 & 1.0 & .44 & 58 & +04 & +05 & $E+05$ \\
\hline 0 & & & .0 & 1.0 & .46 & 58 & +04 & $E+05$ & $E+05$ \\
\hline 00 & .6 & & .0 & 4.0 & & & +04 & +05 & $E+05$ \\
\hline & & & 4.0 & 4.0 & 5 & & .22 & 05 & 05 \\
\hline & & & .0 & 4.0 & & & .22 & +05 & .05 \\
\hline & .5 & & .0 & 24.0 & 6 & & .2 & +05 & 05 \\
\hline & .5 & & .0 & 24.0 & 5 & & 4 & +05 & +05 \\
\hline & & & 4.0 & 24.0 & & & 4 & +05 & +05 \\
\hline & & & 24.0 & 24.0 & & & & +05 & $E+05$ \\
\hline & .3 & & 24.0 & 24.0 & 3.77 & 2. & $E+04$ & $E+05$ & $E+05$ \\
\hline & .2 & & 24.0 & 24.0 & 3.90 & 2. & $E+04$ & $9 E+05$ & $E+05$ \\
\hline 318 & .2 & & 24.0 & 24.0 & 3.89 & 2.58 & $2116 E+04$ & $E+05$ & $E+05$ \\
\hline 319 & .1 & & 24.0 & 24.0 & 3.96 & 2.58 & $2101 E+04$ & $.3839 E+05$ & $E+05$ \\
\hline 320 & .0 & & 24.0 & 24.0 & 3.97 & 2.58 & $1966 E+04$ & $3849 E+05$ & $1 E+05$ \\
\hline 361 & .9 & .6 & 24.0 & 24.0 & 4.08 & 2.58 & $.2034 E+04$ & $.3867 E+05$ & $7 E+05$ \\
\hline & .7 & 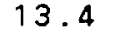 & 24.0 & 24.0 & 4.18 & 2.58 & $1984 E+04$ & $3897 E+05$ & $1920 E+05$ \\
\hline & .6 & 13.3 & 24.0 & 24.0 & 4.25 & 2.58 & $1942 E+04$ & $3924 E+05$ & $1914 E+05$ \\
\hline 64 & .6 & 13.2 & 24.0 & 24.0 & 4.30 & 2.58 & $1998 E+04$ & $3952 E+05$ & $1895 E+05$ \\
\hline 325 & 12.6 & 13.1 & 24.0 & 24.0 & 4.25 & 2.58 & $1914 E+04$ & $3969 \varepsilon+05$ & $.1930 E+05$ \\
\hline
\end{tabular}




\begin{tabular}{|c|c|c|c|c|c|c|c|c|c|}
\hline 326 & 13.5 & 13.0 & 24.0 & 24.0 & 4.36 & 2.58 & $.1904 E+04$ & $.3967 E+05$ & $.1933 E+05$ \\
\hline 327 & 12.5 & 12.9 & 24.0 & 24.0 & 4.34 & 2.58 & $.1810 E+04$ & $.4005 E+05$ & $.1925 E+05$ \\
\hline 28 & 12.3 & 12.8 & 24.0 & 24.0 & 4.50 & 2.58 & $.1734 E+04$ & $.4011 E+05$ & $.1927 E+05$ \\
\hline 29 & 12.3 & 12.6 & 24.0 & 24.0 & 4.49 & 2.58 & $.1746 E+04$ & $.4022 E+05$ & $.1936 E+05$ \\
\hline 30 & 2.2 & 12.5 & 24.0 & 24.0 & 4.57 & .58 & $.1795 E+04$ & $.4078 E+05$ & $1959 E+05$ \\
\hline 31 & 11.9 & 12.4 & 24.0 & 4.0 & .74 & .58 & $.1684 E+04$ & $.4103 E+05$ & $1933 E+05$ \\
\hline 32 & 11.9 & 12.2 & 24.0 & 24.0 & .72 & .58 & $.1529 E+04$ & $.4130 E+05$ & $.1944 E+05$ \\
\hline 33 & 12.0 & 12.1 & 24.0 & 24.0 & 4.71 & .58 & $.1473 E+04$ & $.4136 E+05$ & $.1932 E+05$ \\
\hline 334 & 11.6 & 12.0 & 24.0 & 24.0 & 4.95 & .58 & $.1467 E+04$ & $E+05$ & $.1942 E+05$ \\
\hline 35 & 11.5 & 11.8 & 24.0 & 24.0 & 5.04 & 2.58 & $.1401 E+04$ & $.4: 71 E+05$ & $.1950 E+05$ \\
\hline 36 & 11.5 & 11.7 & 24.0 & 24.0 & 6.01 & 2.58 & $.1239 E+04$ & $.4171 \mathrm{E}+05$ & $.1953 E+05$ \\
\hline 337 & 11.3 & 11.5 & 24.0 & 24.0 & 6.03 & 2.58 & $.1233 E+04$ & $.4181 E+05$ & $.1972 E+05$ \\
\hline 38 & 11.2 & 11.4 & 24.0 & 24.0 & 5.99 & 2.58 & $.1223 E+04$ & $.4209 E+05$ & $.1951 E+05$ \\
\hline 39 & 11.0 & 11.2 & 24.0 & 24.0 & 5.99 & 2.58 & $.1195 E+04$ & $.4243 E+05$ & $.1982 E+05$ \\
\hline 0 & 10.9 & 11.0 & 24.0 & 24.0 & 5.99 & 2.58 & $.1045 E+04$ & $.4214 E+05$ & $.1968 E+05$ \\
\hline 11 & 10.7 & 10.9 & 24.0 & 24.0 & 5.98 & 2.58 & $.9754 E+03$ & $.4233 E+05$ & $.1962 E+D E$ \\
\hline 2 & 10.6 & 10.7 & 24.0 & 24.0 & 5.95 & 2.58 & $.8854 E+03$ & $.4258 E+05$ & $.2006 E+05$ \\
\hline 343 & 10.4 & 10.5 & 24.0 & 24.0 & 5.98 & 2.58 & $.8156 E+03$ & $.430 \uparrow E+05$ & $.1991 E+05$ \\
\hline 344 & 10.1 & 10.3 & 24.0 & 24.0 & 5.92 & 2.58 & $.7538 E+03$ & $.4248 E+05$ & $.2009 E+05$ \\
\hline 345 & 9.9 & 10.2 & 24.0 & 24.0 & 6.01 & 2.58 & $.6466 E+03$ & $.4350 E+05$ & $.1979 E+05$ \\
\hline 346 & 9.9 & 10.0 & 24.0 & 24.0 & 5.96 & 2.58 & $.5476 E+03$ & $.4335 E+05$ & $.1994 E+05$ \\
\hline 7 & 9.6 & .8 & 24.0 & 24.0 & 5.97 & 2.58 & $.5077 E+03$ & $.4309 E+05$ & $.1996 E+05$ \\
\hline 8 & 9.5 & 9.6 & 4.0 & 24.0 & 5.94 & 2.58 & $.4967 E+03$ & $.4362 E+05$ & $.2007 E+05$ \\
\hline 9 & 9.4 & 9.4 & 4.0 & 24.0 & 5.96 & 2.58 & $.3949 E+03$ & $.4408 E+05$ & $.2019 E+05$ \\
\hline 0 & 9.2 & 9.2 & 4.0 & 24.0 & 5.94 & 2.58 & $.3905 E+03$ & $E+05$ & $.2014 E+05$ \\
\hline 1 & 9.0 & 9.0 & 4.0 & 24.0 & 5.98 & 2.58 & $.2388 E+03$ & +05 & $.2027 E+05$ \\
\hline 2 & 8.7 & 8.8 & 24.0 & 24.0 & 5.96 & 2.58 & $.3047[+03$ & $E+05$ & $.2017 E+05$ \\
\hline 3 & 8.5 & 8.6 & 24.0 & 24.0 & 5.94 & 2.58 & $30 E+03$ & $=+05$ & $2026 E+05$ \\
\hline & 8.3 & 8.4 & 24.0 & 24.0 & 5.98 & 2.58 & $.2876 E+03$ & +05 & $E+05$ \\
\hline 355 & 8.3 & 8.2 & 24.0 & 24.0 & 5.90 & 2.58 & $3021 E+03$ & $E+05$ & $.2016 E+05$ \\
\hline 356 & 8.1 & 8.0 & 24.0 & 24.0 & 5.90 & 2.58 & $.2835 E+03$ & $E+0.5$ & $.2041 E+05$ \\
\hline 35 & 8.0 & 7.8 & 24.0 & 24.0 & 5.88 & 2.58 & $3207 E+03$ & +05 & $E+05$ \\
\hline & 7.8 & 7.5 & 24.0 & 24.0 & 5.89 & 2.58 & $3 E+03$ & $E+05$ & $2053 E+05$ \\
\hline 359 & 7.4 & 7.3 & 24.0 & 24.0 & 5.92 & 2.58 & $5 E+03$ & $E+05$ & $E+05$ \\
\hline 360 & 7.3 & 7.1 & 24.0 & 24.0 & 5.90 & 2.58 & $E+03$ & $E+05$ & $7 E+05$ \\
\hline 361 & 7.1 & 6.9 & 24.0 & 24.0 & 5.90 & 2.58 & $E+03$ & +05 & $5 E+05$ \\
\hline 62 & 6.8 & 6.6 & 24.0 & 24.0 & 5.90 & 2.58 & $E+03$ & $E+05$ & $7 E+05$ \\
\hline 3 & 6.6 & 6.4 & 24.0 & 24.0 & 5.89 & 2.58 & $\mathrm{DE}+03$ & $E+05$ & $6 E+05$ \\
\hline 364 & 6.2 & 6.2 & 24.0 & 24.0 & 5.94 & 2.58 & $.4477 E+03$ & $E+05$ & $.2085 E+05$ \\
\hline 365 & 6.2 & 5.9 & 24.0 & 24.0 & 5.86 & 2.58 & $.3505 E+03$ & $E+05$ & $.2076 E+C 5$ \\
\hline 366 & 5.9 & 5.7 & 24.0 & 24.0 & 5.88 & 2.58 & $3 E+03$ & $E+05$ & $.2105 E+05$ \\
\hline 367 & 5.6 & 5.5 & 24.0 & 24.0 & 5.85 & 2.58 & $2561 E+03$ & $E+05$ & $2084 E+05$ \\
\hline 368 & 5.4 & 5.2 & 24.0 & 24.0 & 5.84 & 2.58 & $.2027 E+03$ & $E+05$ & $2086 E+05$ \\
\hline & & 5.0 & 24.0 & 24.0 & 5.88 & 2.58 & $3 E+03$ & +05 & $2 E+05$ \\
\hline 37 & 4.9 & 4.7 & 24.0 & 24.0 & 5.86 & 2.58 & $E+02$ & $E+05$ & $2120 E+05$ \\
\hline & 4.9 & 4.5 & 24.0 & 23.9 & 82 & & +02 & +05 & $7 \varepsilon+05$ \\
\hline & 4.4 & 4.3 & 24.0 & & & & +02 & & $E+05$ \\
\hline 373 & 4.3 & 4.0 & 24.0 & 23.9 & 5.82 & 2.58 & $1082 E+02$ & $E+05$ & $.2139 E+05$ \\
\hline & 4.0 & 3.8 & 24.0 & 23.9 & 5.82 & 2.58 & $.6592 E+01$ & $.4462 E+05$ & $.2128 E+05$ \\
\hline . & 4.0 & 3.5 & 24.0 & 23.9 & 5.79 & 2.58 & $.2513 E+00$ & $.4471 E+05$ & $.2140 E+05$ \\
\hline & 1.0 & $3 \cdot 3$ & 24.0 & 23.9 & 5.79 & 2.58 & $.2364 E+00$ & $4434 E+05$ & $.2152 E+05$ \\
\hline 377 & 1.0 & 1.0 & 24.0 & 23.9 & 5.84 & 2.58 & $.0000 E+00$ & $.4442 E+05$ & $.2151 \mathrm{E}+05$ \\
\hline 378 & 1.0 & 1.0 & 24.0 & 23.9 & 5.77 & 2.58 & $.0000 E+00$ & $.4432 E+05$ & $.2153 E+05$ \\
\hline 379 & 1.0 & 1.0 & 24.0 & 23.9 & 5.80 & 2.58 & $.0000 E+00$ & $4438 E+05$ & $.2185 E+05$ \\
\hline 380 & 1.0 & 1.0 & 24.0 & 23.9 & 5.76 & 2.58 & $.0000 E+00$ & $.4454 E+05$ & $2181 E+05$ \\
\hline 381 & 1.0 & 1.0 & 24.0 & 23.9 & 5.69 & 2.58 & $.0000 E+00$ & $.4393 E+05$ & $2170 E+05$ \\
\hline 382 & 1.0 & 1.0 & 24.0 & 23.9 & 5.71 & 2.58 & $.0000 E+00$ & $.4383 E+05$ & $.2165 E+05$ \\
\hline
\end{tabular}




\begin{tabular}{|c|c|c|c|c|c|c|c|c|c|}
\hline 83 & 1.0 & 1.0 & 24.0 & 23.9 & 5.79 & 2.58 & $.0000 E+00$ & $.4357 E+05$ & $.2196 E+05$ \\
\hline & 1.0 & 1.0 & 24.0 & 3.9 & 5.72 & 2.58 & $.0000 E+00$ & $.4286 E+05$ & $.2168 E+05$ \\
\hline 5 & 1.0 & 1.0 & 4.0 & 3.8 & 5.69 & 2.58 & $.0000 E+00$ & $.4195 E+05$ & $.2183 E+05$ \\
\hline 36 & 1.0 & 1.0 & 24.0 & 23.8 & 5.71 & 2.58 & $.0000 E+00$ & $.4121 E+05$ & $.2162 E+05$ \\
\hline $8 ?$ & .0 & 1.0 & 24.0 & 23.8 & 5.65 & 2.58 & $.0000 E+00$ & $.4034 E+05$ & $.2162 E+05$ \\
\hline 88 & 1.0 & 1.0 & 24.0 & 23.8 & 5.68 & 2.58 & $.0000 E+00$ & $.4016 E+05$ & $.2159 E+05$ \\
\hline 89 & 1.0 & 1.0 & 24.0 & 23.8 & 5.69 & 2.58 & $.0000 E+00$ & $.3839 E+05$ & $.2156 \varepsilon+05$ \\
\hline 90 & 1.0 & 1.0 & 24.0 & 23.8 & 5.65 & 2.53 & $.0000 E+00$ & $.3812 E+05$ & $.2133 E+05$ \\
\hline 91 & 1.0 & 1.0 & 24.0 & 23.8 & 5.66 & 2.58 & $.0000 E+00$ & $.3728 E+05$ & $.2127 E+05$ \\
\hline 92 & 1.0 & 1.0 & 23.0 & 23.8 & 5.59 & 2.58 & $O E+Q O$ & $.3642 E+05$ & $38 E+05$ \\
\hline 33 & 1.0 & 1.0 & 24.0 & 23.8 & .64 & 2.58 & $O E+0 O$ & $47 E+05$ & $E+05$ \\
\hline 34 & $1: 0$ & 1.0 & 24.0 & 23.8 & .63 & 2.58 & $.0000 E+00$ & $.3477 E+05$ & $E+05$ \\
\hline 95 & 1.0 & 1.0 & 24.0 & 23.7 & .57 & 2.58 & $.0000 E+00$ & $.3416 E+05$ & $.2100 E+05$ \\
\hline 396 & 1.0 & 1.0 & 24.0 & 23.7 & 5.60 & 2.58 & $.0000 E+00$ & $.3315 E+05$ & $.2099 E+05$ \\
\hline 397 & 1.0 & 1.0 & 23.0 & 23.7 & 5.50 & 2.58 & $10 \varepsilon+00$ & $.3218 E+05$ & $E+05$ \\
\hline 8 & 1.0 & 1.0 & 23.0 & 23.7 & 5.58 & 2.58 & $E+00$ & $.3146 E+05$ & $E+05$ \\
\hline 399 & 1.0 & 1.0 & 24.0 & 23.7 & 5.53 & 2.58 & $O E+00$ & $.3084 E+05$ & $.2088 \varepsilon+05$ \\
\hline 400 & 1.0 & 1.0 & 23.0 & 23.7 & 5.56 & 2.58 & $O E+00$ & $.2966 E+05$ & $.2054 E+05$ \\
\hline 401 & 1.0 & 1.0 & 23.0 & 23.7 & 5.46 & 2.58 & $E+00$ & $.2863 E+05$ & $E+05$ \\
\hline 402 & 1.0 & 1.0 & 24.0 & 23.6 & .48 & 2.58 & $O E+00$ & $.2767 E+05$ & $E+05$ \\
\hline 403 & 1.0 & 1.0 & 24.0 & 23.6 & 5.45 & 2.58 & $O E+00$ & $.2666 E+05$ & $E+05$ \\
\hline 404 & 1.0 & 1.0 & 24.0 & 23.6 & 5.39 & 2.58 & OE+OO & $.2580 E+05$ & $.2026 E+05$ \\
\hline 405 & 1.0 & 1.0 & 23.0 & 23.6 & .39 & 2.58 & $.0000 E+00$ & $.2466 E+05$ & $.2029 E+05$ \\
\hline 406 & 1.0 & 1.0 & 23.0 & 23.6 & 31 & 2.58 & $.0000 E+00$ & $.2374 E+05$ & $E+05$ \\
\hline 407 & 1.0 & 1.0 & 24.0 & 23.6 & 5.37 & 2.58 & $.0000 E+00$ & $.2274 E+05$ & $E+05$ \\
\hline 408 & 1.0 & 1.0 & 23.0 & 23.5 & .31 & 2.58 & $.0000 E+00$ & $.2139 E+0.5$ & $.1965 E+05$ \\
\hline 409 & .0 & .0 & 3.0 & 3.5 & 29 & 2.58 & $.0000 E+00$ & $.2091 E+05$ & $E+05$ \\
\hline 410 & .0 & .0 & 3.0 & 23.5 & .14 & 2.58 & $.0000 E+00$ & $.1980 E+05$ & $E+05$ \\
\hline 411 & .0 & .0 & 24.0 & 23.5 & 22 & 2.58. & $.0000 E+00$ & $.1878 E+05$ & $E+05$ \\
\hline 41 & .0 & .0 & 23.0 & 23.5 & .09 & $2.58^{\circ}$ & $E+00$ & $.1787 E+05$ & $E+05$ \\
\hline 413 & 0 & .0 & 24.0 & 23.4 & 5.06 & 2.58 & $.0000 E+00$ & $.1676 E+05$ & $=05$ \\
\hline & 0 & .0 & 24.0 & 23.4 & 4.91 & 2.58 & $.0000 E+00$ & $.1588 E+05$ & $=05$ \\
\hline 19 & & 1.0 & 24.0 & 23.4 & 4.97 & 2.58 & $0 \varepsilon+00$ & $.1508 E+05$ & $E+05$ \\
\hline 115 & & 1.0 & 23.0 & 23.4 & 4.80 & 2.58 & $O E+00$ & $.1407 E+05$ & $E+05$ \\
\hline & & & 24.0 & 23.4 & 4.67 & 2.58 & $E+00$ & $.1313 E+05$ & $E+05$ \\
\hline 18 & 0 & & 23.0 & 23.3 & 4.68 & 2.58. & $O E+0 O$ & $.1230 E+05$ & $E+05$ \\
\hline & & & 23.0 & 23.3 & 4.52 & 2.58 & $E+00$ & $O E+05$ & $E+05$ \\
\hline 90 & & 0 & 23.0 & 23.3 & 4.46 & 2.58 & $E+00$ & $3 E+05$ & $E+05$ \\
\hline & & & 3.0 & 23.3 & 4.36 & 2.58 & $=+00$ & $8 E+04$ & +05 \\
\hline 422 & 1.0 & 1.0 & 23.0 & 23.2 & 3.94 & 2.58 & $E+00$ & $.9415 E+04$ & $E+05$ \\
\hline 423 & 1.0 & 1.0 & 24.0 & 23.2 & 3.95 & 2.58 & $E+00$ & $.8570 E+04$ & $E+05$ \\
\hline 424 & 1.0 & 1.0 & 23.0 & 23.2 & 3.92 & 2.58 & $=\div 00$ & $.79 \bumpeq 3 E+04$ & $E+05$ \\
\hline 425 & 1.0 & 1.0 & 23.0 & 23.2 & 3.69 & 2.58 & +00 & $.7291 E+04$ & $E+05$ \\
\hline 426 & 1.0 & 1.0 & 23.0 & 23.1 & 3.30 & 2.58 & $E+00$ & $7034 E+04$ & $E+05$ \\
\hline 427 & 1.0 & 1.0 & 23.0 & 23.1 & 3.17 & 2.58 & $E+00$ & $.6329 E+04$ & $E+05$ \\
\hline 428 & 1.0 & $? .0$ & 23.0 & 23.1 & 2.82 & 2.58 & $E+00$ & $5913 E+04$ & $.1714 E+05$ \\
\hline 429 & 1.0 & 1.0 & 24.0 & 23.0 & 2.88 & 2.58 & $E+00$ & $.5716 \varepsilon+04$ & $O E+05$ \\
\hline 430 & 1.0 & 1.0 & 24.0 & 23.0 & 2.66 & 2.58 & $D E+00$ & $5635 E+04$ & $.1665 E+05$ \\
\hline 431 & 1.0 & 1.0 & 23.0 & 23.0 & 2.51 & 2.58 & $.0000 E+00$ & $.5139 E+04$ & $.1658 E+05$ \\
\hline 432 & 1.0 & 1.0 & 24.0 & 23.0 & 2.38 & 2.58 & $D E+00$ & $5035 E+04$ & $.1635 E+05$ \\
\hline 433 & 1.0 & 1.0 & 22.0 & 22.9 & 2.25 & 2.58 & $.0000 E+00$ & $4605 E+04$ & $.1614 E+05$ \\
\hline 434 & 1.0 & 1.0 & 22.0 & 22.9 & 2.00 & 2.58 & $.0000 E+00$ & $4419 E+04$ & $.1603 E+05$ \\
\hline 435 & 1.0 & 1.0 & 23.0 & 22.9 & 1.76 & 2.58 & $.0000 E+00$ & $4477 E+04$ & $1566 E+05$ \\
\hline 436 & 1.0 & 1.0 & 23.0 & 22.8 & 1.57 & 2.58 & $.0000 E+00$ & $4242 E+04$ & $1558 E+05$ \\
\hline 437 & 1.0 & 1.0 & 22.0 & 22.8 & 1.61 & 2.58 & $.0000 E+00$ & $4193 E+04$ & $1529 E+05$ \\
\hline 438 & 1.0 & 1.0 & 23.0 & 22.8 & 1.45 & 2.58 & $.0000 E+00$ & $3918 E+04$ & $1505 E+05$ \\
\hline 439 & 1.0 & 1.0 & 23.0 & 22.7 & 1.36 & 2.58 & $.0000 \varepsilon+00$ & $.4012 E+04$ & $1485 E+05$ \\
\hline
\end{tabular}




\begin{tabular}{|c|c|c|c|c|c|c|c|c|c|}
\hline 440 & 1.0 & 1.0 & 23.0 & 22.7 & 1.72 & 2.58 & $.0000 E+00$ & $.3806 E+04$ & $.1449 E+05$ \\
\hline 441 & 1.0 & 1.0 & 22.0 & 22.6 & 1.50 & 2.58 & $.0000 E+00$ & $.3673 E+04$ & $.1460 E+05$ \\
\hline 442 & 1.0 & 1.0 & 22.0 & 22.6 & 1.51 & 2.58 & $.0000 E+00$ & $.3675 E+04$ & $.1401 E+05$ \\
\hline 443 & 1.0 & 1.0 & 23.0 & 22.6 & 2.19 & 2.58 & $.0000 E+00$ & $.3457 E+04$ & $.1376 E+05$ \\
\hline 444 & 1.0 & 1.0 & 22.0 & 22.5 & 1.83 & 2.58 & $.0000 E+00$ & $.3478 E+04$ & $.1366 E+05$ \\
\hline 445 & 1.0 & 1.0 & 22.0 & 22.5 & 1.28 & 2.58 & $.0000 E+00$ & $.3160 E+04$ & $.1352 E+05$ \\
\hline 446 & 1.0 & 1.0 & 22.0 & 22.4 & 2.24 & 2.58 & $.0000 E+00$ & $.3096 E+04$ & $.1293 E+05$ \\
\hline 447 & 1.0 & 1.0 & 22.0 & 22.4 & 1.74 & 2.58 & $.0000 E+00$ & $2729 E+04$ & $1286 E+05$ \\
\hline 448 & 1.0 & 1.0 & 2.0 & 22.4 & 2.15 & 2.58 & $.0000 E+00$ & $.2902 E+04$ & $.1271 E+05$ \\
\hline 449 & 1.0 & 1.0 & 3.0 & 22.3 & 2.15 & 2.58 & $.0000 E+00$ & $.2582 E+04$ & $.1220 E+05$ \\
\hline 450 & 1.0 & 1.0 & 22.0 & 22.3 & 1.54 & 2.58 & $.0000 E+00$ & $.2220 E+04$ & $.1190 E+05$ \\
\hline 451 & 1.0 & 1.0 & 22.0 & $22 . ?$ & $2.38^{\circ}$ & 2.58 & $O E+0 O$ & $.2230 E+04$ & $4 E+05$ \\
\hline 452 & 1.0 & 1.0 & 21.0 & 22.2 & 2.19 & 2.58 & $E+00$ & $E+04$ & $1 E+05$ \\
\hline 453 & 1.0 & 1.0 & 24.0 & 22.1 & .87 & 2.58 & $E+00$ & $E+04$ & $1 E+05$ \\
\hline 454 & 1.0 & 1.0 & 22.0 & 22.1 & 1.50 & 2.58 & $D E+00$ & $O E+04$ & $0 E+05$ \\
\hline 455 & 1.0 & 1.0 & 22.0 & 22.0 & 2.28 & 2.58 & $.0000 E+00$ & $.1462 E+04$ & $.1042 \mathrm{E}+05$ \\
\hline 456 & 1.0 & 1.0 & 22.0 & 22.0 & 2.13 & 2.58 & $O E+O O$ & $.1195 E+04$ & $4 E+05$ \\
\hline 457 & 1.0 & 1.0 & 22.0 & 21.9 & 2.59 & 2.58 & $.0000 E+00$ & $.1136 E+04$ & $.9797 E+04$ \\
\hline 458 & 1.0 & 1.0 & 23.0 & 21.9 & 1.50 & 2.58 & $.0000 E+00$ & $.9137 E+03$ & $.9609 E+04$ \\
\hline 459 & 1.0 & 1.0 & 22.0 & 21.8 & 2.67 & 2.58 & $.0000 E+00$ & $.8394 E+03$ & $.9009 E+04$ \\
\hline 460 & 1.0 & 1.0 & 22.0 & 21.8 & .75 & 2.58 & $.0000 E+00$ & $1 E+03$ & $5 E+04$ \\
\hline 461 & 1.0 & 1.0 & 22.0 & 21.7 & 1.50 & 2.58 & $.0000 E+00$ & $.5783 E+03$ & $.8337 E+04$ \\
\hline 462 & 1.0 & 1.0 & 21.0 & 21.7 & 1.39 & 2.58 & $.0000 E+00$ & $.4759 E+03$ & $.8105 E+04$ \\
\hline 463 & 1.0 & 1.0 & 22.0 & 21.6 & 4.25 & 2.58 & $E+00$ & $.4854 E+03$ & $E+04$ \\
\hline 464 & 1.0 & 1.0 & 22.0 & 21.5 & $3.50^{\circ}$ & 2.58 & $E+00$ & $E+03$ & $E+04$ \\
\hline 465 & 1.0 & 1.0 & 22.0 & 21.5 & .83 & 2.58 & $E+00$ & $E+03$ & $E+04$ \\
\hline 466 & 1.0 & 1.0 & 20.0 & 21.4 & 1.63 & 2.58 & $E+00$ & $.3809 E+03$ & $O E+04$ \\
\hline 467 & 1.0 & 1.0 & 21.0 & 21.4 & .67 & 2.58 & $D E+00$ & $.3767 E+03$ & $2 E+04$ \\
\hline 468 & 1.0 & 1.0 & 22.0 & 21.3 & 2.63 & 2.58 & $.0000 E+00$ & $.3410 E+03$ & $E+04$ \\
\hline 469 & 1.0 & 1.0 & 21.0 & 21.2 & .71 & 2.58 & .00 & $E+03$ & $7 E+04$ \\
\hline 470 & 1.0 & 1.0 & 22.0 & 21.2 & .75 & 2.58 & $.0000 E+00$ & $.2377 E+03$ & $.4804 E+04$ \\
\hline 471 & 1.0 & 1.0 & 22.0 & 21.1 & 1.29 & 2.58 & $O E+0 O$ & $.2319 E+03$ & $.4286 E+04$ \\
\hline 472 & 1.0 & 1.0 & 20.0 & 21.0 & .50 & 2.58 & $.0000 E+00$ & $.1831 E+03$ & $.3915 E+04$ \\
\hline 473 & 1.0 & 1.0 & 20.0 & 21.0 & 4.00 & 2.58 & $.0000 E+00$ & $.1392 E+03$ & $.3386 E+04$ \\
\hline $474^{\circ}$ & 1.0 & 1.0 & 22.0 & 20.9 & 3.00 & 2.58 & $.0000 E+00$ & $.1018 E+03$ & $.2927 E+04$ \\
\hline 475 & 1.0 & 1.0 & 20.0 & 20.8 & 1.00 & 2.58 & $.0000 E+00$ & $.6403 E+02$ & $.2365 E+04$ \\
\hline
\end{tabular}


APPENDIX V

LISTING OF THE RMPRDN OUTPUT DATA FOR THE HYDROGEN/KRYPTON COUNTER

IN THE JANUS NEUTRON SPECTRUM 
LISTING OF THE RMPRDN OUTPUT DATA FOR THE HYDROGEN/KRYPTON COUNTER IN THE JANUS NEUTRON SPECTRUM.

HYD/KR AT $0,0,100.3 H R, 34$ MIN. ATTN REMOVED(DOWN). $3 / 30 / 88$.

TOTAL POINTS AND START POINT $=19525$

INITIAL AVERAGE PROTON LINE WIDTH $=3.57$

N15 AND NBRK CHANNELS ARE $56 \quad 94$

.90 WMAX CHANNEL $=46$

RUN TIME IN SECONDS $=12840$

\begin{tabular}{|c|c|c|c|c|c|c|c|c|}
\hline DVAL & EDVAL & TVAL & ETVAL & LINE & R.AT & GAMMAS & RTS & IME \\
\hline 14.7 & 14.6 & 25.0 & 25.0 & 3.51 & 7.39 & $-.9584 E+02$ & $.2200 E+05$ & $.3422 E+04$ \\
\hline 14.8 & 14.7 & 25.0 & 25.0 & 3.49 & 7.38 & $-.1379 E+03$ & $.2258 E+05$ & $.3546 E+04$ \\
\hline 14.8 & 14.8 & 25.0 & 25.0 & 3.47 & 7.37 & $.2375 E+03$ & $2362 E+05$ & $.3728 E+04$ \\
\hline 4.7 & 4.8 & 5.0 & 5.0 & 3.51 & 7.37 & $-.7095 E+01$ & $2434 E+05$ & $E+04$ \\
\hline 4.7 & 14.8 & 25.0 & 25.0 & 3.51 & 7.36 & $-.2743 E+03$ & $2557 E+05$ & +04 \\
\hline 4.7 & 4.8 & 250 & 0 & 3.56 & 7.36 & $-.6349 E+02$ & $2645 E+05$ & $E+04$ \\
\hline 4.7 & 14.8 & 25.0 & 25.0 & 3.53 & 7.36 & $-.4494 E+01$ & $.2762 E+05$ & $.4391 E+04$ \\
\hline 14.7 & 14.7 & 25.0 & 25.0 & 3.53 & 7.36 & $.1946 E+02$ & $.2846 E+05$ & $.4579 E+04$ \\
\hline 14. & 14.7 & $25: 0$ & & 3.56 & 7.36 & $-.2348 E+03$ & $.2925 E+05$ & $.4810 E+04$ \\
\hline 14.8 & 14.7 & 25.0 & & 3.47 & 7.36 & -.264 & $.3027 E+05$ & $.5041 E+04$ \\
\hline 14.6 & 14.6 & & & 3.61 & 7.37 & $.2160 E+02$ & $.3103 E+05$ & $.5266 E+04$ \\
\hline 14.6 & 14.6 & & & 3.60 & 7.37 & $E+02$ & $.3229 E+05$ & $.5372 E+04$ \\
\hline 14.6 & 14.5 & & & 3.57 & 7.37 & -.13 & $.3303 E+05$ & $.5620 E+04$ \\
\hline 14.5 & & & & 3.64 & & -.17 & $E+05$ & $.5916 E+04$ \\
\hline 14.5 & & & & 3.64 & & -.92 & .354 & $.6035 E+04$ \\
\hline 14.6 & & & & 3.63 & 7.38 & $-.2510 E+03$ & .3622 & $.6162 E+04$ \\
\hline 14.6 & 14.4 & 25 & & 3.62 & 7.38 & $-.5919 E+02$ & .3712 & $.6588 E+04$ \\
\hline 14.5 & 14.4 & 25 & 0 & 3. & 7.38 & -.478 & .380 & .679 \\
\hline 14.4 & 4.4 & 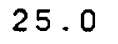 & & 3.76 & 7.38 & -.457 & .3886 & $E+04$ \\
\hline 14.5 & 14.4 & 25 & & 3.65 & 7.38 & -.327 & .4015 & $E+04$ \\
\hline 14.3 & 14. & 2 & & 3.80 & 7.38 & -.267 & .407 & $E+04$ \\
\hline 14.4 & 1 & & & .74 & 7.38 & -.240 & 4215 & .761 \\
\hline 14.3 & 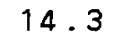 & & & .80 & 7.37 & -.495 & 427 & $E+04$ \\
\hline 14.2 & 14 & 25 & & 3.84 & 7.36 & -.469 & $4347 E+05$ & $E+04$ \\
\hline 2 & 11 & & & 3.88 & 7.36 & -.244 & 4537 & +04 \\
\hline & 1 & & & 3. & 7.35 & -.18 & 463 & +04 \\
\hline & 1 & & & 3. & 7.34 & -.28 & 5 & $E+04$ \\
\hline & 1 & & & & 7.33 & -.22 & 48 & $=04$ \\
\hline & & & & 3. & 7.32 & -.657 & .492 & +04 \\
\hline & 1 & & & 4. & 7.30 & -.60 & .50 & +04 \\
\hline & 1 & & & 4. & 7.29 & -.65 & .5 & +05 \\
\hline & 1 & & & 4 . & 7.27 & -.614 & 5 & .1028 \\
\hline & & & & & 7.26 & -.556 & & $.1058 E+05$ \\
\hline 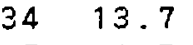 & 1 & & 25 & 4.20 & 7.24 & -.980 & $.5430 E+05$ & $.1100 E+05$ \\
\hline .7 & 13.7 & 25 & 25.0 & 4.23 & 7.22 & $-.9331 E+03$ & $.5534 E+05$ & $.1135 E+05$ \\
\hline 5 & 13. & 25 . & 25.0 & 4.33 & 7.20 & $-.7697 \mathrm{E}+03$ & $.5591 E+05$ & $.1153 E+05$ \\
\hline & 13. & 25.0 & 25.0 & 4.28 & 7.18 & $-.7963 E+03$ & $.5713 E+05$ & $.1191 E+05$ \\
\hline 13.5 & 13.4 & 25.0 & 25.0 & 4.33 & 7.15 & $-.1003 E+04$ & $.5810 E+05$ & $.1221 E+05$ \\
\hline 13.4 & 13. & 25 . & & 4.38 & 7.12 & $-.1415 E+04$ & $.5914 E+05$ & $.1238 E+05$ \\
\hline 13.3 & 13.1 & 25.0 & 25.0 & 4.49 & 7.09 & $-.1467 E+04$ & $.5996 E+05$ & $.1296 E+05$ \\
\hline
\end{tabular}




\begin{tabular}{|c|c|c|c|c|c|c|c|c|c|}
\hline 41 & 13.4 & 13.0 & 25.0 & 25.0 & 4.42 & 7.05 & $-.1476 E+04$ & $.6105 E+05$ & $.1329 E+05$ \\
\hline 42 & 13.2 & 12.9 & 25.0 & 25.0 & 4.55 & 7.00 & $-.1707 E+04$ & $.6172 E+05$ & $.1356 E+05$ \\
\hline 43 & 13.0 & 12.8 & 25.0 & 25.0 & 4.64 & 6.95 & $-.1901 E+04$ & $.6343 E+05$ & $.1382 E+05$ \\
\hline 44 & 12.9 & 12.6 & 5.0 & 5.0 & 4.70 & 6.89 & $-.1787 E+04$ & $.6446 E+05$ & $30 E+05$ \\
\hline 45 & 12.9 & 12.5 & 25.0 & 5.0 & 4.74 & 6.82 & $-.2008 E+04$ & $.6490 E+05$ & $.1448 E+05$ \\
\hline 46 & 12.8 & 12.3 & 25.0 & 5.0 & 4.82 & 6.74 & $-.2259 E+04$ & $.6639 E+05$ & $.1511 E+05$ \\
\hline 47 & 11.7 & 12.2 & 25.0 & 25.0 & 4.85 & 6.74 & $-.2171 E+04$ & $.6701 E+05$ & $.1525 E+0$ \\
\hline 48 & 11.5 & 12.1 & 25.0 & 25.0 & 4.97 & 6.74 & $-.2117 E+04$ & $.6773 E+05$ & $E+0$ \\
\hline 49 & 11.5 & 11.9 & 25.0 & 25.0 & 4.97 & 6.74 & $-.2277 E+04$ & $.6895 E+05$ & $B E+0$ \\
\hline 50 & 11.5 & 11.8 & 25.0 & .0 & 5.01 & 6.74 & $-.2068 E+04$ & $.7012 E+05$ & $.1656 \mathrm{E}+05$ \\
\hline 51 & 11.4 & 11.6 & 25.0 & 5.0 & 5.09 & 6.74 & $-.1933 E+04$ & $.7087 E+05$ & $.1681 E+05$ \\
\hline 52 & 11.3 & 11.5 & 25.0 & 0 & 5.17 & 6.74 & $-.1513 E+04$ & $.7234 E+05$ & $.1761 E+05$ \\
\hline 53 & 11.2 & 11.3 & 25.0 & 25.0 & 5.21 & 6.74 & $-.1695 E+04$ & $.7301 E+05$ & $.1784 E+05$ \\
\hline 54 & 11.1 & 11.2 & 25.0 & 5.0 & 5.30 & 6.74 & $-.1680 E+04$ & $.7392 E+05$ & $.1814 E+05$ \\
\hline 55 & .1 & 11.0 & .0 & 5.0 & 5.29 & 6.74 & $-.1572 E+04$ & $.7512 E+05$ & $.1858 E+05$ \\
\hline 56 & .8 & 10.9 & 0 & 5.0 & 5.48 & 6.74 & $-.135 i E+04$ & $.7596 E+05$ & $.1924 E+05$ \\
\hline 7 & 10.7 & 10.7 & 5.0 & 25.0 & 5.53 & 6.74 & $-.1173 E+04$ & $4 E+05$ & $E+05$ \\
\hline 58 & 10.7 & 10.6 & 25.0 & 25.0 & 5.57 & 6.74 & $-.9399 E+03$ & $.7753 E+05$ & $E+05$ \\
\hline 59 & 10.4 & 10.4 & 25.0 & 25.0 & 5.75 & 6.74 & $-.9556 E+03$ & $.7809 E+05$ & $E+05$ \\
\hline 60 & 10.3 & 10.2 & 25.0 & 25.0 & 5.82 & 6.74 & $-.9177 E+03$ & $.7911 E+05$ & $.2105 E+05$ \\
\hline 61 & 10.1 & 10.1 & 25.0 & 25.0 & 5.94 & 6.74 & $-.6625 E+03$ & $.8032 E+05$ & $.2121 E+05$ \\
\hline 62 & 9.9 & 9.9 & 25.0 & 25.0 & 6.08 & 6.74 & $-.7763 E+03$ & $.8056 E+05$ & $.2210 E+05$ \\
\hline 63 & 9.7 & 9.7 & 25.0 & 25.0 & 6.19 & 6.74 & $-.4039 E+03$ & $.8176 E+05$ & $.2238 E+05$ \\
\hline 84 & 9.6 & 9.5 & 25.0 & 25.0 & 6.28 & 5.74 & $-.3394 E+03$ & $.8348 E+05$ & $.2280 E+05$ \\
\hline 65 & 9.5 & 9.3 & 25.0 & 25.0 & 6.37 & 6.74 & $-.2158 E+03$ & $.8437 E+05$ & $.2367 E+05$ \\
\hline 66 & 9.3 & 9.1 & 25.0 & 25.0 & 6.45 & 6.74 & $-.1361 E+03$ & $.8548 E+05$ & $.2406 E+05$ \\
\hline 67 & 8.9 & 8.9 & 25.0 & 25.0 & 7.65 & 6.74 & $-.2383 E+02$ & $8613 E+05$ & $.2459 E+05$ \\
\hline 68 & 8.9 & 8.7 & 25.0 & 25.0 & 7.63 & 6.74 & $1694 E+02$ & $.8636 E+05$ & $.2523 E+05$ \\
\hline 69 & 8.7 & 8.5 & 25.0 & 25.0 & 7.62 & 6.74 & $1294 E+03$ & $.8734 E+05$ & $.2554 E+05$ \\
\hline 70 & 8.3 & 8.3 & 25.0 & 25.0 & 7.66 & 6.74 & $.2164 E+03$ & $.8847 E+05$ & $.2626 E+05$ \\
\hline 71 & 8.2 & 8.1 & 25.0 & 25.0 & 7.64 & 6.74 & $.2852 E+03$ & $.8920 E+05$ & $.2681 E+05$ \\
\hline 2 & 7.8 & 7.8 & $25.0^{\prime}$ & 25.0 & 7.66 & 6.74 & $.3810 E+03$ & $.9018 E+05$ & $.2746 E+05$ \\
\hline 73 & 7.4 & & 25.0 & 25.0 & 7.66 & 6.74 & $.2546 \mathrm{E}+03$ & $.9114 E+05$ & $.2821 E+05$ \\
\hline 74 & 7.3 & & 25.0 & 25.0 & 7.68 & 6.74 & $.4163 E+03$ & $.9091 E+05$ & $.2854 E+05$ \\
\hline 75 & 7.1 & & 25.0 & 25.0 & 7.67 & 6.74 & $.4718 E+03$ & $.9176 E+05$ & $.2857 E+05$ \\
\hline 76 & 6.8 & & 25.0 & 25.0 & 7.65 & 6.74 & $.4534 E+03$ & $.9135 E+05$ & $.2913 E+05$ \\
\hline 77 & 6.4 & & 25.0 & 25.0 & 7.68 & 6.74 & $.4925 E+03$ & $.9151 E+05$ & $.2896 E+05$ \\
\hline 8 & 6.2 & & 25.0 & 25.0 & 7.61 & 6.74 & $.3551 \mathrm{E}+03$ & $.9232 E+05$ & $.2933 E+0$ \\
\hline 79 & 5.9 & 9 & 25.0 & 25.0 & 7.64 & 6.74 & $.3688 E+03$ & $.9203 E+05$ & $.2937 E+0$ \\
\hline 80 & 5.4 & 5 & 5.0 & 25.0 & 7.69 & 6.74 & $6 E+03$ & $9 E+05$ & .2970 \\
\hline & 5.2 & 5.3 & .0 & 25.0 & 7.67 & .74 & $3 E+03$ & $3 E+05$ & $2973 E+0$ \\
\hline 82 & 4.9 & 4.9 & .0 & 25.0 & 7.69 & 6.74 & $.1608 E+03$ & $.9265 E+05$ & $.3006 E+05$ \\
\hline 83 & 4.5 & 4.6 & .0 & .0 & 7.68 & .74 & $5 E+$ & $.9247 E+05$ & $.3030 E+05$ \\
\hline 84 & 4.2 & 4.3 & .0 & .0 & 7.66 & .74 & 2 & $4 E+05$ & $.3009 E+05$ \\
\hline 85 & 4.0 & 4.0 & .0 & .0 & .67 & .74 & 2 & $E+05$ & $3056 E+05$ \\
\hline 86 & 3.6 & 3.7 & .0 & .0 & 7.71 & .74 & $\Sigma+02$ & $1 E+05$ & $.3065 E+05$ \\
\hline 8 & 3.4 & 3,3 & .0 & 25.0 & 7.71 & .74 & $3 E+02$ & $.9406 E+05$ & $3075 E+05$ \\
\hline 88 & 3.2 & 3,0 & 25.0 & 5.0 & 7.69 & .74 & $.1495 E+02$ & $.9403 E+05$ & $.3122 E+05$ \\
\hline 89 & 2.8 & 2.7 & 25.0 & 5.0 & 7.70 & .74 & $.1495 E+02$ & $.9371 E+05$ & $3129 E+05$ \\
\hline 90 & 2.5 & 2.4 & 25.0 & 25.0 & 7.76 & 6.74 & $.1286 \mathrm{E}+02$ & $.9417 E+05$ & $3130 E+05$ \\
\hline 91 & 2.4 & 2.1 & 25.0 & 25.0 & 7.67 & 6.74 & $.1405 E+01$ & $.9456 E+05$ & $3156 E+05$ \\
\hline 92 & 1.1 & 1.8 & 25.0 & 25.0 & 7.72 & 6.74 & $.0000 E+00$ & $9453 E+05$ & $.3194 E+05$ \\
\hline 9 & 1.9 & 1.5 & 25.0 & 25.0 & 7.70 & 6.74 & $.0000 E+00$ & $9460 E+05$ & $3197 E+05$ \\
\hline 9 & 1.0 & 1.2 & 25.0 & 25.0 & 7.73 & 6.74 & $0000 E+00$ & $9484 E+05$ & $3237 E+05$ \\
\hline 95 & 1.0 & 1.0 & 25.0 & 25.0 & 7.74 & 6.74 & $.0000 E+00$ & $9503 E+05$ & $3258 E+05$ \\
\hline 36 & 1.0 & 1.0 & 25.0 & 25.0 & 7.68 & 6.74 & $.0000 E+00$ & $3551 E+05$ & $3262 E+05$ \\
\hline 37 & 1.0 & $? .0$ & 25.0 & 25.0 & 7.66 & 6.74 & $.0000 E+00$ & $9433 E+05$ & $3292 c+05$ \\
\hline
\end{tabular}




\begin{tabular}{|c|c|c|c|c|c|c|c|c|c|}
\hline 98 & 1.0 & 1.0 & 25.0 & 25.1 & 7.60 & 6.74 & $.0000 E+00$ & $.9532 E+05$ & $.3309 E+05$ \\
\hline 99 & 1.0 & 1.0 & 25.0 & 25.1 & 7.54 & 6.74 & $.0000 \varepsilon+00$ & $.9449 E+05$ & $3345 E+05$ \\
\hline 100 & 1.0 & 1.0 & 25.0 & 25.1 & 7.60 & 6.74 & $.0000 E+00$ & $.9419 E+05$ & $3383 E+05$ \\
\hline 101 & 1.0 & 1.0 & 25.0 & 25.1 & 7.47 & 6.74 & $.0000 E+00$ & $.9382 E+05$ & \\
\hline 102 & 1.0 & 1.0 & 25.0 & 25.1 & 7.47 & 6.74 & $.0000 E+00$ & $.9326 E+05$ & $.3406 \varepsilon+0$ \\
\hline 103 & 1.0 & 1.0 & 25.0 & 25.1 & 7.44 & 6.74 & $.0000 E+00$ & $.9053 E+05$ & $3389 E+$ \\
\hline 104 & 1.0 & 1.0 & 25.0 & 25.1 & 7.40 & 6.74 & $.0000 E+00$ & $.8859 E+05$ & $.3419 E+0$ \\
\hline 105 & 1.0 & 1.0 & 25.0 & 25.1 & 7.38 & 6.74 & $.0000 E+00$ & $.8696 E+05$ & $.3403 E+$ \\
\hline 106 & 1.0 & 1.0 & 25.0 & 25.1 & 7.29 & 6.74 & $.0000 E+00$ & $.8525 E+05$ & $.3391 E+$ \\
\hline 107 & 1.0 & 1.0 & 25.0 & 25.1 & 7.35 & 6.74 & $.0000 E+00$ & $.8325 E+05$ & $8 E+$ \\
\hline 108 & 1.0 & 1.0 & 25.0 & 25.1 & 7.28 & 6.74 & $.0000 E+00$ & $.8133 E+05$ & $.3404 E+0$ \\
\hline 109 & 1.0 & 1.0 & 25.0 & 25.0 & 7.27 & 6.74 & $.0000 E+00$ & $.7914 E+05$ & $.3383 E+0$ \\
\hline 110 & 1.0 & 1.0 & 25.0 & 25.0 & 7.18 & 6.74 & $.0000 E+00$ & $.7757 E+05$ & $.3400 E+0$ \\
\hline 111 & 1.0 & 1.0 & 25.0 & 25.0 & 7.22 & 6.74 & $.0000 E+00$ & $.7621 E+05$ & $.3360 E+0$ \\
\hline 112 & 1.0 & 1.0 & 25.0 & 25.0 & 7.12 & 6.74 & $.0000 E+00$ & $.7379 E+05$ & $.3359 E+0$ \\
\hline 113 & 1.0 & 1.0 & 25.0 & 25.0 & 7.17 & 6.74 & $O O E+O O$ & $.7203 E+05$ & $.3359 E+0$ \\
\hline 114 & 1.0 & 1.0 & 25.0 & 25.0 & 7.07 & 6.74 & $O E+O O$ & $.7044 E+05$ & $E+D$ \\
\hline 115 & 1.0 & 1.0 & 25.0 & 25.0 & 7.04 & 6.74 & $.0000 E+00$ & $.6910 E+05$ & $.3374 E+0$ \\
\hline 116 & 1.0 & 1.0 & 25.0 & 25.0 & 7.05 & 6.74 & $O E+00$ & $.6711 E+05$ & $.3335 E+0$ \\
\hline 117 & 1.0 & 1.0 & 25.0 & 25.0 & 6.98 & 6.74 & $O E+0 O$ & $.6609 E+05$ & $.3316 E+0$ \\
\hline 118 & 1.0 & 1.0 & 25.0 & 25.0 & 6.79 & 6.74 & $D E+0 O$ & $.6390 E+05$ & $.3329 E+0$ \\
\hline 119 & 1.0 & 1.0 & 25.0 & 25.0 & 7.02 & 6.74 & $O E+O O$ & $.6188 E+05$ & $.3330 E+0$ \\
\hline 120 & 1.0 & 1.0 & 25.0 & 25.0 & 6.90 & 6.74 & $O E+00$ & $.6067 E+05$ & $.3331 E+0$ \\
\hline 121 & 1.0 & 1.0 & 25.0 & 24.9 & 6.72 & 6.74 & $E+00$ & $.5903 E+05$ & $.3296 E+0$ \\
\hline 122 & 1.0 & 1.0 & 25.0 & 24.9 & 6.69 & 6.74 & $.0000 E+00$ & $.5718 E+05$ & $.3309 E+0$ \\
\hline 123 & 1.0 & 1.0 & 25.0 & 24.9 & 6.80 & 6.74 & $O E+O O$ & $.5580 E+05$ & $.3272 E+05$ \\
\hline 124 & 1.0 & 1.0 & 25.0 & 24.9 & 6.68 & 6.74 & $.0000 E+00$ & $.5451 E+05$ & $.3292 E+05$ \\
\hline 125 & 1.0 & 1.0 & 25.0 & 24.9 & 6.50 & 6.74 & $.0000 E+00$ & $.5307 E+05$ & $.3264 \Sigma+05$ \\
\hline 126 & 1.0 & 1.0 & 25.0 & 24.9 & 6.52 & 6.74 & $.0000 E+00$ & $.5195 E+05$ & $.3266 E+05$ \\
\hline 127 & 1.0 & 1.0 & 25.0 & 24.8 & 6.65 & 6.74 & $.0000 E+00$ & $.5050 E+05$ & $3242 E+05$ \\
\hline 128 & 1.0 & 1.0 & 25.0 & 24.8 & 6.66 & 6.74 & $.0000 E+00$ & $.4926 E+05$ & $.3254 E+05$ \\
\hline 129 & 1.0 & 1.0 & 25.0 & 24.8 & 6.38 & 6.74 & $.0000 E+00$ & $.4793 E+05$ & $.3236 c+05$ \\
\hline 130 & 1.0 & 1.0 & 25.0 & 24.8 & 6.59 & 6.74 & $.0000 E+00$ & $.4672 E+05$ & $.3201 E+05$ \\
\hline 131 & 1.0 & 1.0 & 25.0 & 24.7 & 8.23 & 6.74 & $.0000 E+00$ & $.4398 E+05$ & $.3228 E+0$ \\
\hline 132 & 1.0 & 1.0 & 5.0 & 24.7 & 8.55 & 6.74 & $.0000 E+00$ & $.4258 E+05$ & $.3212 E+0$ \\
\hline 133 & 1.0 & 1.0 & 25.0 & 24.7 & 6.62 & 6.74 & $.0000 E+00$ & $.4087 E+05$ & $.3201 E+0$ \\
\hline 134 & 1.0 & 1.0 & 25.0 & 24.6 & 6.42 & 6.74 & $.0000 E+00$ & $.3981 E+05$ & $.3158 E+C$ \\
\hline 135 & 1.0 & 1.0 & 25.0 & 24.6 & 6.47 & 6.74 & $.0000 E+00$ & $.3871 E+05$ & $.3167 \mathrm{E}+$ \\
\hline 136 & 1.0 & 1.0 & 24.0 & 24.6 & .54 & 6.74 & $E+O O$ & $3764 E+05$ & $.3140 E+$ \\
\hline 137 & 1.0 & 1.0 & 25.0 & 24.5 & 6.10 & 6.74 & $.0000 E+00$ & $3630 E+05$ & $.3148 E+0$ \\
\hline 138 & 1.0 & 1.0 & 24.0 & 24.5 & 5.90 & 6.74 & $0 E+00$ & $3543 E+05$ & $.3129 E+$ \\
\hline 139 & 1.0 & 1.0 & 24.0 & 24.5 & 5.82 & 6.74 & $O E+0 O$ & $3407 E+05$ & $.3109 E+05$ \\
\hline 40 & .0 & .0 & 24.0 & 24.4 & 6.42 & 6.74 & $E+00$ & $3290 E+05$ & $E+05$ \\
\hline 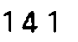 & 1.0 & .0 & 24.0 & 24.4 & 6.22 & 6.74 & $E+00$ & $3154 E+05$ & $.3098 E+05$ \\
\hline 142 & .0 & .0 & 24.0 & 24.3 & 5.87 & 6.74 & $E+00$ & $3071 E+05$ & $3059 E+05$ \\
\hline & .0 & .0 & 24.0 & 24.3 & .96 & 6.74 & $E+00$ & $2925 E+$ & 302 \\
\hline & 0 & 0 & .0 & 24.3 & .85 & .74 & $E+00$ & $2838 E+05$ & .30 \\
\hline 145 & . D & .0 & 25.0 & 24.2 & 5.79 & 6.74 & $.0000 E+00$ & $2749 E+05$ & $.3009 E+0$ \\
\hline & 0 & 0 & 4.0 & 24.2 & 5.70 & 6.74 & $.0000 E+00$ & $2647 E+05$ & .296 \\
\hline 147 & .0 & .0 & 24.0 & 24.1 & 5.45 & 6.74 & $.0000 E+00$ & $2578 \varepsilon+05$ & $.2928 E+05$ \\
\hline 143 & 0 & 0 & 24.0 & 24.1 & 5.47 & 6.74 & OOOOE+0O & $2438 E+05$ & $.2933 E+05$ \\
\hline 149 & .0 & .0 & 24.0 & 24.0 & 5.36 & 6.74 & $.0000 E+00$ & $.2373 E+05$ & $.2913 E+05$ \\
\hline 150 & 1.0 & .0 & 24.0 & 24.0 & 5.31 & 6.74 & $.0000 \varepsilon+00$ & $2269 E+05$ & $.2900 E+05$ \\
\hline 151 & 1.0 & 1.0 & 23.0 & 23.9 & 5.11 & 6.74 & $.0000 E+00$ & $.2183 E+05$ & $.2875 E+05$ \\
\hline 152 & 1.0 & 1.0 & 24.0 & 23.8 & 5.05 & 6.74 & $.0000 E+00$ & $2094 E+05$ & $.2831 E+05$ \\
\hline 153 & 1.0 & 1.0 & 25.0 & 23.8 & 4.85 & 6.74 & $.0000 E+00$ & $.2014 E+05$ & $.2813 E+05$ \\
\hline 154 & 1.0 & 1.0 & 24.0 & 23.7 & 4.54 & 6.74 & $.0000 E+00$ & $.1916 E+05$ & $.276 E E+05$ \\
\hline
\end{tabular}




\begin{tabular}{|c|c|c|c|c|c|c|c|c|c|}
\hline 55 & 1.0 & 1.0 & 24.0 & 23.7 & 4.31 & 6.74 & $.0000 E+00$ & $.1858 E+05$ & $.275 B E+05$ \\
\hline 156 & 1.0 & 1.0 & 23.0 & 23.6 & 4.39 & 6.74 & $.0000 E+00$ & $.1742 E+05$ & $.2741 E+05$ \\
\hline $15 ?$ & 1.0 & 1.0 & 23.0 & 23.5 & 3.98 & 6.74 & $.0000 E+00$ & $.1683 E+05$ & $.2697 E+05$ \\
\hline 58 & 1.0 & 1.0 & 23.0 & 23.5 & 3.76 & 6.74 & $.0000 E+00$ & $.1625 E+05$ & $.2672 E+05$ \\
\hline 159 & 1.0 & 1.0 & 24.0 & 23.4 & 3.50 & 6.74 & $.0000 E+00$ & $.1533 E+05$ & $.2636 E+05$ \\
\hline 160 & 1.0 & 1.0 & 23.0 & 23.3 & 3.19 & 6.74 & $.0000 E+00$ & $.1456 E+05$ & $1 E+05$ \\
\hline 161 & 1.0 & 1.0 & 23.0 & 23.3 & 3.38 & 6.74 & $.0000 E+00$ & $.1375 E+05$ & $.2552 E+05$ \\
\hline 162 & 1.0 & 1.0 & 23,0 & 23.2 & 2.97 & 6.74 & $.0000 E+00$ & $.1300 E+05$ & $.2560 E+05$ \\
\hline 163 & 1.0 & 1.0 & 23.0 & 23.1 & 2.60 & 6.74 & $.0000 E+00$ & $.1259 E+05$ & $.2490 E+05$ \\
\hline 164 & 1.0 & 1.0 & 23.0 & 23.1 & 2.71 & 6.74 & $.0000 E+00$ & $31 E+05$ & $5 E+05$ \\
\hline 165 & 1.0 & 1.0 & 23.0 & 23.0 & 2.40 & 6.74 & $.0000 E+00$ & $.1098 E+05$ & $.2437 E+05$ \\
\hline 166 & 1.0 & 1.0 & 23.0 & 22.9 & 1.99 & 6.74 & $.0000 E+00$ & $.1039 E+05$ & $.2361 E+05$ \\
\hline 167 & 1.0 & 1.0 & 22.0 & 22.8 & 1.93 & 6.74 & $.0000 E+00$ & $.9866 E+04$ & $.2340 E+05$ \\
\hline 168 & 1.0 & 1.0 & 23.0 & 22.8 & 1.84 & 6.74 & $.0000 E+00$ & $5 E+04$ & $.2307 E+05$ \\
\hline 169 & 1.0 & 1.0 & 24.0 & 22.7 & 1.55 & 6.74 & $.0000 E+00$ & $.8499 E+04$ & $.2268 E+05$ \\
\hline 170 & 1.0 & 1.0 & 22.0 & 22.6 & 1.59 & 6.74 & $.0000 E+00$ & $.7941 E+04$ & $2200 E+05$ \\
\hline 171 & 1.0 & 1.0 & 23.0 & 22.5 & 1.44 & 6.74 & $.0000 E+00$ & $.7342 E+04$ & $2156 E+05$ \\
\hline 172 & 1.0 & 1.0 & 23.0. & 22.5 & 1.28 & 6.74 & $.0000 E+00$ & $.7062 E+04$ & $.2109 E+05$ \\
\hline 173 & 1.0 & 1.0 & 22.0 & 22.4 & 1.62 & 6.74 & $.0000 E+00$ & $.6553 E+04$ & $.2064 E+05$ \\
\hline 174 & 1.0 & 1.0 & 23.0 & 22.3 & 1.61 & 6.74 & $. .0000 E+00$ & $.6014 E+04$ & $.2004 E+05$ \\
\hline 175 & 1.0 & 1.0 & 21.0 & 22.2 & 1.28 & 6.74 & $.0000 E+00$ & $.5590 E+04$ & $.1954 E+05$ \\
\hline 176 & 1.0 & 1.0 & 23.0 & 22.1 & 1.21 & 6.74 & $.0000 E+00$ & $.5059 E+04$ & $.1891 E+05$ \\
\hline 177 & 1.0 & 1.0 & 24.0 & 22.1 & 1.08 & 6.74 & $.0000 E+00$ & $.4568 E+04$ & $.1838 E+05$ \\
\hline 178 & 1.0 & 1.0 & 23.0 & 22.0 & 1.09 & 6.74 & $.0000 E+00$ & $.4225 E+04$ & $.1794 E+05$ \\
\hline 179 & 1.0 & 1.0 & 22.0 & 21.9 & 1.52 & 6.74 & $.0000 E+00$ & $.3912 E+04$ & $.1702 E+05$ \\
\hline 180 & 1.0 & 1.0 & 19.0 & 21.8 & 1.33 & 6.74 & $.0000 E+00$ & $.3487 E+04$ & $.1671 E+05$ \\
\hline 181 & 1.0 & 1.0 & 23.0 & 21.7 & 1.75 & 6.74 & $.0000 E+00$ & $.3186 E+04$ & $.1580 E+05$ \\
\hline 182 & 1.0 & 1.0 & 21.0 & 1.7 & 1.50 & 6.74 & $.0000 E+00$ & $.2792 E+04$ & $.1522 E+05$ \\
\hline 83 & 1.0 & 1.0 & 22.0 & 1.6 & .79 & 6.74 & $.0000 E+00$ & $6 E+04$ & $.1474 E+05$ \\
\hline 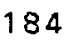 & 1.0 & .0 & 20.0 & 1.5 & 1.89 & 6.74 & $E+00$ & $.2248 E+04$ & $.1380 E+05$ \\
\hline 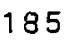 & 1.0 & .0 & 20.0 & 21.4 & 1.92 & 6.74 & $.0000 E+00$ & $E+04$ & $.1319 E+05$ \\
\hline 100 & 1.0 & 1.0 & 22.0 & 21.3 & 2.00 & 6.74 & $.0000 E+00$ & $.1743 E+04$ & $.1231 E+05$ \\
\hline 187 & 1.0 & 1.0 & 21.0 & 21.2 & .83 & 6.74 & $.0000 E+00$ & $.1498 E+04$ & $.1146 E+05$ \\
\hline 188 & 1.0 & 1.0 & 23.0 & 21.1 & 1.40 & 6.74 & $.0000 E+00$ & $.1258 E+04$ & $.1075 E+05$ \\
\hline 189 & 1.0 & 1.0 & 20.0 & 21.1 & .84 & 6.74 & $.0000 E+00$ & $.1106 E+04$ & $1005 E+05$ \\
\hline 190 & 1.0 & 1.0 & 24.0 & 21.0 & 1.75 & 6.74 & $.0000 E+00$ & $.8768 E+03$ & $.9123 E+04$ \\
\hline 191 & 1.0 & 1.0 & 20.0 & 20.9 & 1.61 & 6.74 & $.0000 E+00$ & $.7979 E+03$ & $.8128 E+04$ \\
\hline 192 & 1.0 & 1.0 & 19.0 & 20.8 & 1.17 & 6.74 & $.0000 E+00$ & $.6525 E+03$ & $.7250 E+04$ \\
\hline 193 & 1.0 & 1.0 & 19.0 & 20.7 & .72 & 6.74 & $.0000 E+00$ & $.5166 E+03$ & $.8368 E+04$ \\
\hline 194 & 1.0 & 1.0 & 21.0 & 20.6 & 2.75 & 6.74 & $.0000 E+00$ & $.4112 E+03$ & $.5357 E+04$ \\
\hline 195 & 1.0 & 1.0 & 22.0 & 20.5 & 1.50 & 6.74 & $.0000 E+00$ & $.2968 E+03$ & $.4230 E+04$ \\
\hline
\end{tabular}
INPUT POS TO SAVE ON DISC OR NEG TO DELETE SAVE. 
APPENDIX VI

LISTING OF THE CODE RMPSNS.FOR USED TO DERIVE THE NEUTRON SPECTRUM FROM PROTON RECOIL DATA AND CALIBRATION MEASUREMENTS 
LISTING OF THE CODE RMPSNS. FOR USED TO DERIVE THE NEUTRON SPECTRUM FROM PROTON RECOIL DATA AND CALIBRATION MEASUREMENTS.

\$LARGE

\$NODEBUG

\$NOFLOATCALLS

C RMPSNS.FOR

C VERSION OF PSNS USED WITH THE 8088 COMPAQ AND RAMP VOLTAGE BIASING.

C CONVERT PROTON-RECOIL PULSE HEIGHT SPECTRA TO NEUTRON SPECTRUM.

C

C

C

C

C

C

C

C

C
DIMENSION FLXL(512), ERFL(512), RES(512), RAOS(512), TIME(512), XENRGY ( 512$)$,WHION( 512$)$, WHAMP( 512$), \operatorname{ETR}(512), F R L V(512)$, XEGRF (1024), FLGRF (1024)

CHARACTER FNAME*16, FLNAME*72, IDENT*72, JDENT*72

THE LOG OF ENERGY AT ANY CHANNEL I, ELOG(I), IS RELATED TO I, THE CHANNEL NUMBER, IBS, THE CHANNEL SHIFT FROM RMPRDN, AND THE

CALIBRATION FACTOR, CAL, BY

$$
E L O G(I)=(F L O A T(I+I B S)-1.0) / 64+C A L
$$

WHERE CAL = ALOG( (LVL/GMAX)*FSEXA/4096).

ELOG IS THE "IONIZATION" ENERGY, NOT THE "TRUE" ENERGY.

FSEXA IS THE PRODUCT OF THE FULL-SCALE ENERGY AND MULTIPLICATION A. FSEXA IS FIXED AND MUST BE IDENTICAL FOR ALL A VALUES.

LVL IS THE ADC Y CHAN BIAS AND MAXG IS THE MAXIMUM GAS GAIN.

THE INTRINSIC RESOLUTION(FWHM) OF THE NEUTRON SPECTRUM IS COMPUTED FROM THE ENERGY E AND THE SLOPE TAKING FULL FRACTIONAL WIOTH FW AS FWHM $(E)=S Q R T(F W * F W+0.17 / E)$

1 FORMAT( $37 \mathrm{H}$ IHPUT FILE NAME FOR THE HEADER DATA. )

2 FORMAT (6E12.5)

3 FORMAT ( $8 F 8.0)$

4 FORMAT $(10 F 8.1)$

5 FORMAT $(/ / / 16 \mathrm{H}$ RMPSNS OUTPUT. //)

6 FORMAT ( 4 IH INPUT FLUENCE NORMALIZATION FOR THE RUN.)

7 FORMAT $(10 F 8.0)$

8 FORMAT(//43H INPUT(I5) IGO NEGATIVE TO DELETE DISC SAVE / $X 57 H$ OF THE NEUTRON AND PROTON SPECTRA IN NON-GRAPHER FORMAT. $X)$

9 FORMAT(//9H ENERGY, 10H FLUX,11H ERROR, 10H RESLN: )

10 FORMAT (I5)

11 FORMAT $/ / / 32 \mathrm{H}$ TOTAL POINTS AND STARTING POINT 2 I8/

X17H ADC Y-BIAS LEVEL I $8 /$

$\times 19 H$ MAXIMUM GAS GAIN $=E 12.5 /$

$\times 26 H$ THE RUN TIME IN SECONDS = I $8 /$

$\times 34 \mathrm{H}$ THE CALIBRATION TIME IN SECONDS $=18 / /)$

12 FORMAT (4OH INPUT A 10 CHAR. HEAdER. DATA File NaMe. )

13 FORMAT(A)

14 FORMAT $(7 H \quad M A X=E 11.4)$

15 FORMAT (47H INPUT A 10 CHAR. RECOIL-PROTON DATA FILE NAME. )

16 FORMAT (18H FRST DEC $=1 \mathrm{KEV}$ )

17 FORMAT (51H INPUT(E12.5) THE REFERENCE CALIBRATION ENERGY ERF. / X53H THEN INPUT(D15.8/) THE TOP 5 POLYNOMIAL COEFFICIENTS / X6OH IN AN M=6 LSQPOL FIT TO THE RATIO OF THE OBSERVED VARIATION/ $\times 52 H$ OF NEUTRON SPECTRUM (PER LETHARGY) TO THE ERF VALUE /

$X 36 \mathrm{H}$ AS A FUNCTION OF $X=L O G$ (ENERGY/ERF). 1)

18 FORMAT ( 2 I 8 )

19 FORMAT (F10.3,E11.4,E10.3,F6.3) 
20 FORMAT(45H INPUT A 10 CHARACTER FILE NAME FOR THE SAVED / $\times 24 H$ FINAL NEUTRON SPECTRUM.)

21 FORMAT( ' INPUT THE FILE NAME FOR IHHE CALIBRATION SPECTRUM ' )

22 FORMAT( $/ 51 \mathrm{H}$ LIST ENERGIES AND THEN LIST PROTON SPECTRA $(/ L E T H Y) / / 1)$

23 FORMAT (4D15.8)

24 FORMAT ( $10 F 8.3)$

25 FORMAT ( $8 E 10.4)$

375 FORMAT(53H INPUT POS. TO SAVE A. DAT FILE FOR NEUTRON PLOTTING.)

378 FORMAT (43H INPUT. DAT FILE NAME FOR GRAPHER NEUT SPC. )

381 FORMAT (53H INPUT POS. TO SAVE . DAT FILE OF PROTONS FOR GRAPHER.)

383 FORMAT ( 53 H INPUT A . DAT FILE NAME FOR PROTONS FOR GRAPHER PLOT.)

950 FORMAT(37H INPUT(E12.5) THE ENERGY SCALE FSEXA.)

951 FORMAT (45H INPUT(E12.5) THE HYDROGEN ATOM CONTENT HATM.)

952 FORMAT( 35 H THE LOGGED TEST PULSE COUNTS/SEC $=E 12.5 /$ $\times 284$ INPUT(E12.5) CORRECT VALUE. )

C

953 FORMAT (43H INPUT(E12.5) UPPER ENERGY LIMIT IN OUTPUT. )

C INPUT THE SPECTRUM OF PROTON RECOILS RAPS AND THE TEST PULSER

C SPECTRUM TIME TOGETHER WITH OTHER DATA AS PRODUCED BY THE

C ANALYSIS OF THE RAW DATA IN RMPRDN.

165 PAUSE ' PROGRAM BEGINS HERE OR RETURNS AFTER COMPLETION.

WRITE $(*, 15)$

READ (*,13) FNAME

OPEN $\left(10, F I L E=F N A M E, F O R M={ }^{\prime}\right.$ FORMATTED' ${ }^{\prime}, S^{\prime} T_{A T U S}{ }^{\prime}$ OLD $\left.^{\prime}\right)$

READ $(10,13)$ FNAME

READ $(10.13)$ IDENT

WRITE $(*, 13)$ FNAME

WRITE(*,13) IDENT

C NPT AND IBS ARE THE TOTAL POINTS AND THE STARTING POINT.

READ $(10,18)$ NSEC

$\operatorname{READ}(10,10)$ NPT

READ $(10,10)$ IBS

READ $(10,18)$ LVL

$\operatorname{READ}(10,2)$ GMAX

$\operatorname{READ}(10,2)$ (RAPS (I), I=1,NPT)

$\operatorname{READ}(10,7)(\operatorname{TIME}(I), I=1, N P T)$

CLOSE (10)

C

C

READ THE CALIBRATION SPECTRA. THESE INCLUDE BOTH 'WHITE IONIZATION' WHION, AND 'WHITE AMPLITUDE' WHAMP AS DERIVED FROM THE SPECIAL

C TEST PULSE CALIBRATION RUN OPTION IN RAMPDA.

WRITE $(*, 21)$

READ (*, 13) FLNAME

OPEN ( 10, FILE =FLNAME, FORM = 'FORMATTED', STATUS $\left.={ }^{\circ} O L D^{\prime}\right)$

READ (10,13) FLNAME

$\operatorname{READ}(10,13)$ JDENT

WRITE $(*, 13)$ FLNAME

WRITE $(*, 13)$ JDENT

$\operatorname{READ}(10,18) \mathrm{KSEC}$

$\operatorname{READ}(10,2)$ CPS

$\operatorname{READ}(10,18)$ NNI I

$\operatorname{READ}(10,2)$ GGGG

$\operatorname{READ}(10,2)$ (WHION(I), $I=1,512)$

$\operatorname{READ}(10,3)$ (WHAMP(I), $I=1,512$ )

CLOSE (10) 


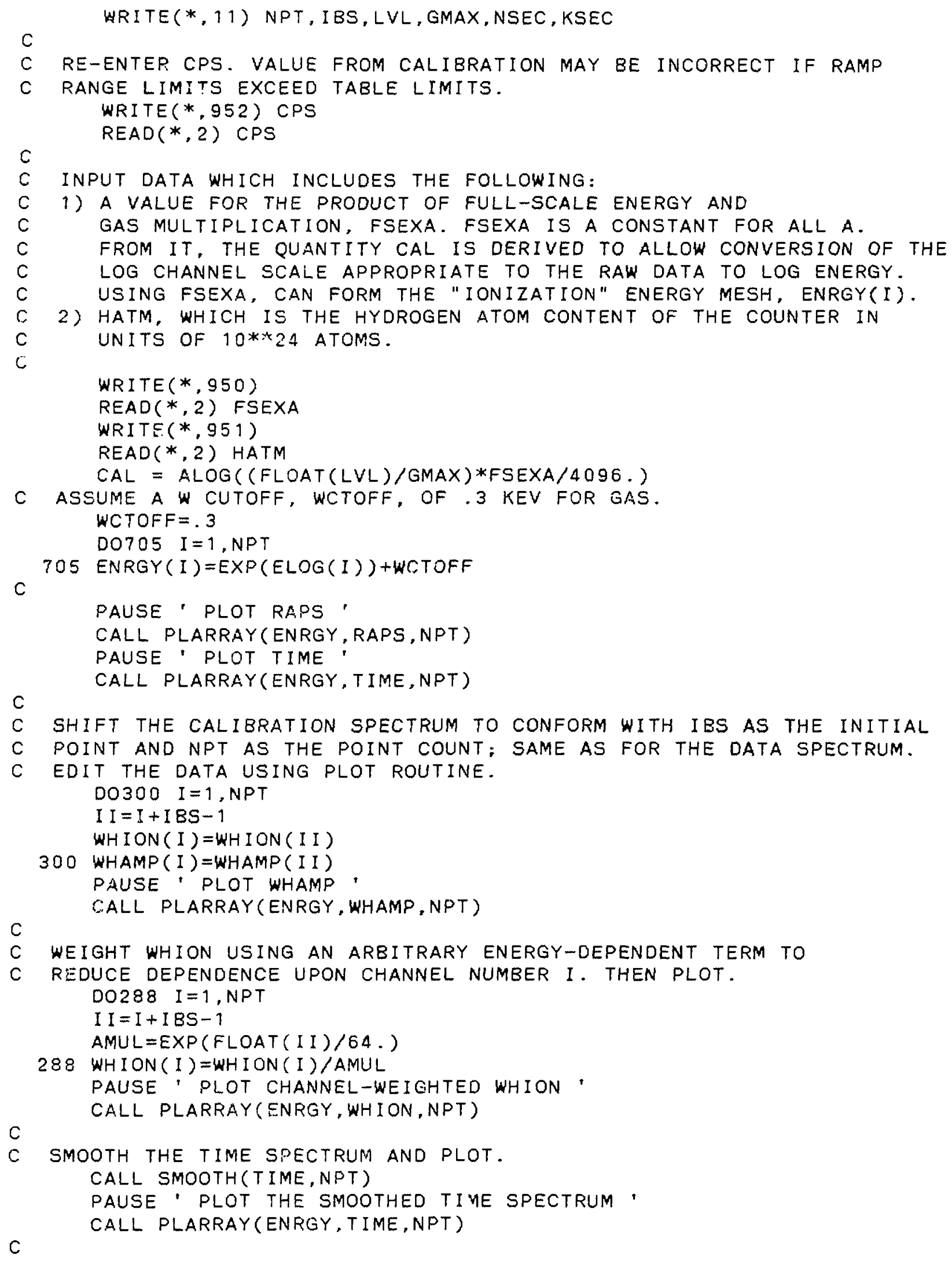

C

$\mathrm{C}$

$\mathrm{C}$

C WEIGHT WHION USING AN ARBITRARY ENERGY-OEPENDENT TERM TO

C REDUCE DEPENDENCE UPON CHANNEL NUMBER I. THEN PLOT.

SHIFT THE CALIBRATION SPECTRUM TO CONFORM WITH IBS AS THE INITIAL POINT AND NPT AS THE POINT COUNT; SAME AS FOR THE DATA SPECTRUM.

EDIT THE DATA USING PLOT ROUTINE. D0300 I=1, NPT

$I I=I+I B S-1$

WHION (I) $=$ WHION (II)

300 WHMP (I ) =WHAMP (II)

PAUSE ' PLOT WHAMP '

CALL PLARRAY (ENRGY, WHAMP, NPT)

DO288 I $=1$, NPT

$I I=I+I B S-1$

$A M U L=E X P(F L O A T(I I) / 64$.

288 WHION (I ) $=$ WH ION (I )/AMUL

PAUSE ' PLOT CHANNEL-WEIGHTED WHION '

CALL PLARRAY (ENRGY, WHION, NPT)

$\mathrm{C}$

C SMOOTH THE TIME SPECTRUM AND PLOT.

CALL SMOOTH(TIME, NPT)

PAUSE ' PLOT THE SMOOTHED TIVE SPECTRUM '

C 


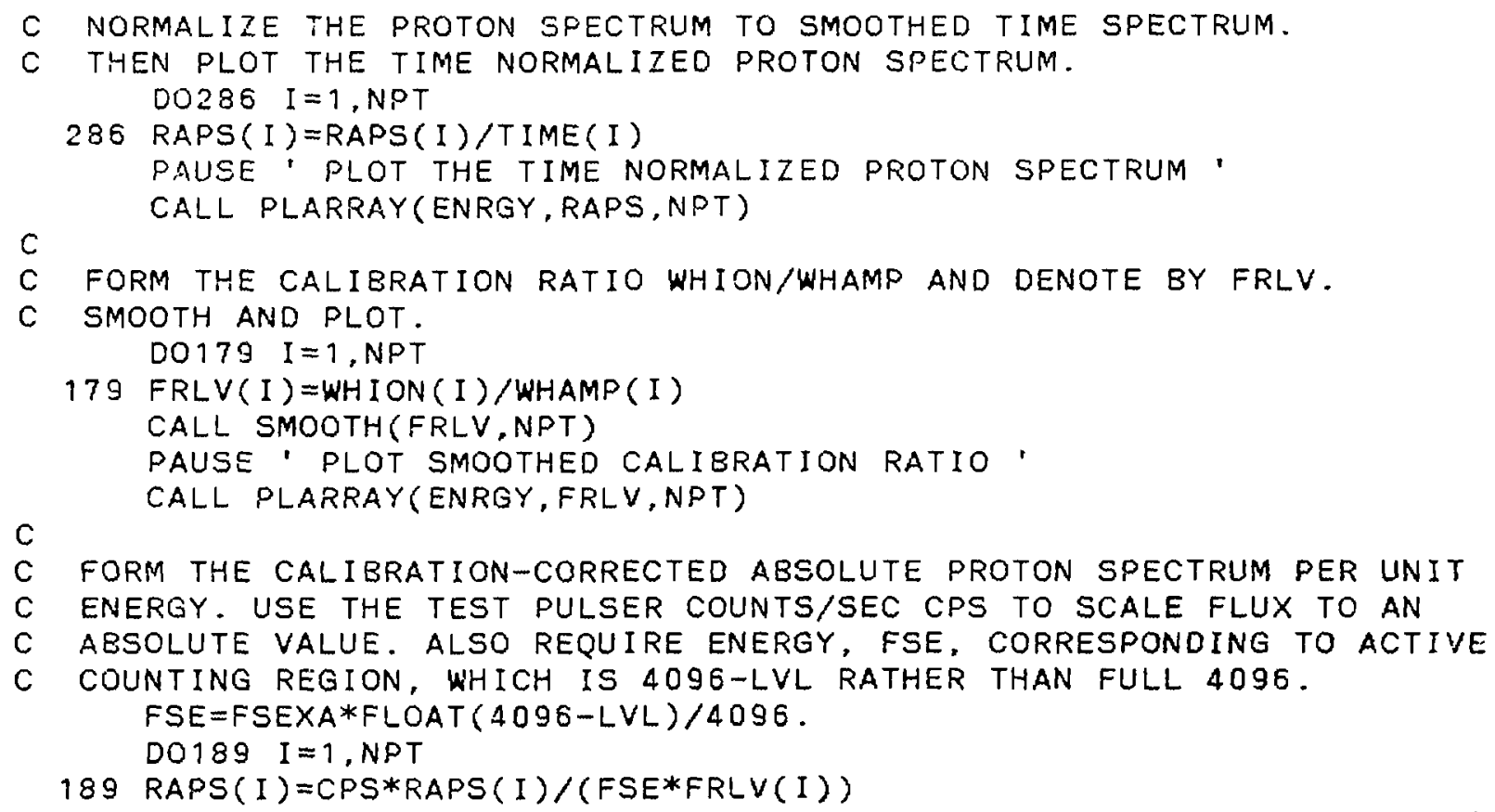

C DETERMINE SLOPES AND ERRORS OVER ABOUT $10 \%$ FWHM.

C ANY OTHER FWHM COULD BE SPECIFIED IF NOT MORE THAN A FEW TIMES

C THE INTRINSIC RESOLUTION OF THE COUNTER.

C LET FW BE THE FRACTIONAL LOG ENEKGY INTERVAL FOR SLOPE TAKING. $F W=.10$

C NSTHW IS THE SLOPE TAKING HALF WIDTH (CHANNELS) DERIVED FROM FW. NSTHW=IFIX(FW*64./2.)

$J=N S T H W$

$97 E O I T=E N R G Y(J)$

I $F(J-N S T H W) 93,93,92$

$93 \quad N 1=1$

N2 $=2 * N S T H W-1$

GO TO 8 :

92 IF (J-NPT+NSTHW-1287.96,89

$98 N 1=N P T-(N S T H W+1)$

$N 2=N P T$

GO TO $8 \&$

$87 N 1=J-N S T H W$

$\mathrm{N} 2=J+N S T H W$

C N1 AND N2 ARE THE LOWER A.ND UPPER SLOPE-TAKING CHANNEL VALUES.

$88 \mathrm{~L}=\mathrm{N1}$

$T 1=0.0$

$\mathrm{T} 2=0.0$ 


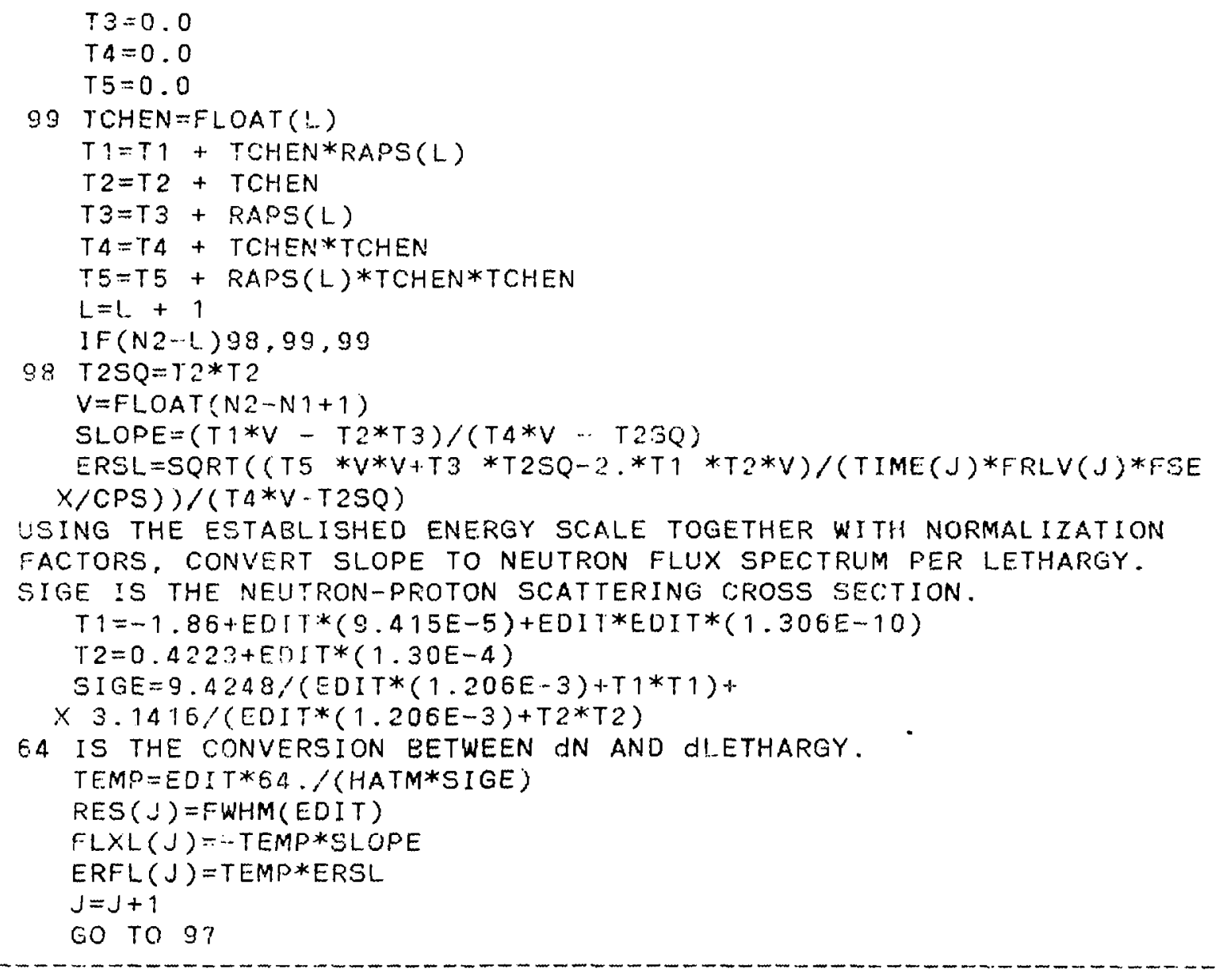

C LET ETR CONIAIN THE ENERGIES APPROPRIATE TO RAPS.

C NORMALIZE RAPS TO THE TOTAL H-ATOM NUMBER IN COUNTER AND $/ L E T H Y$. $8.900730 \quad I=1$, NPT

RAPS (I) =RAPS (I)*ENRGY (I )/HATM

$E T R(I)=E N R G Y(1)$

730 CONTINUE

KPTS $=N P$ ?

c

C AVERAGE THE FLUXEs OVER 3 ADJACENT POINTS.

C REPORT FINAL DATA AT A SPACING OF 3 POINTS (ABOUT .05 LETHARGY). $I=5$

$K=1$

Q4 IMIN $=I-1$

$I$ MAX $=I+?$

IF (IMAX NNPT) $85,85,86$

$85 \quad D M M=0.0$

$0070 J=I M I N, I M A X$

$70 \quad D M M=D M M+F L X L(J)$

$F L X L(K)=D M M / 3$.

ENRGY $(K)=\operatorname{ENRCYY(1)}$

$E R F L(K)=E R F L(I)$

$\operatorname{RES}(K)=\operatorname{RES} S(I)$

$I=I+3$

$K=k+1$ 


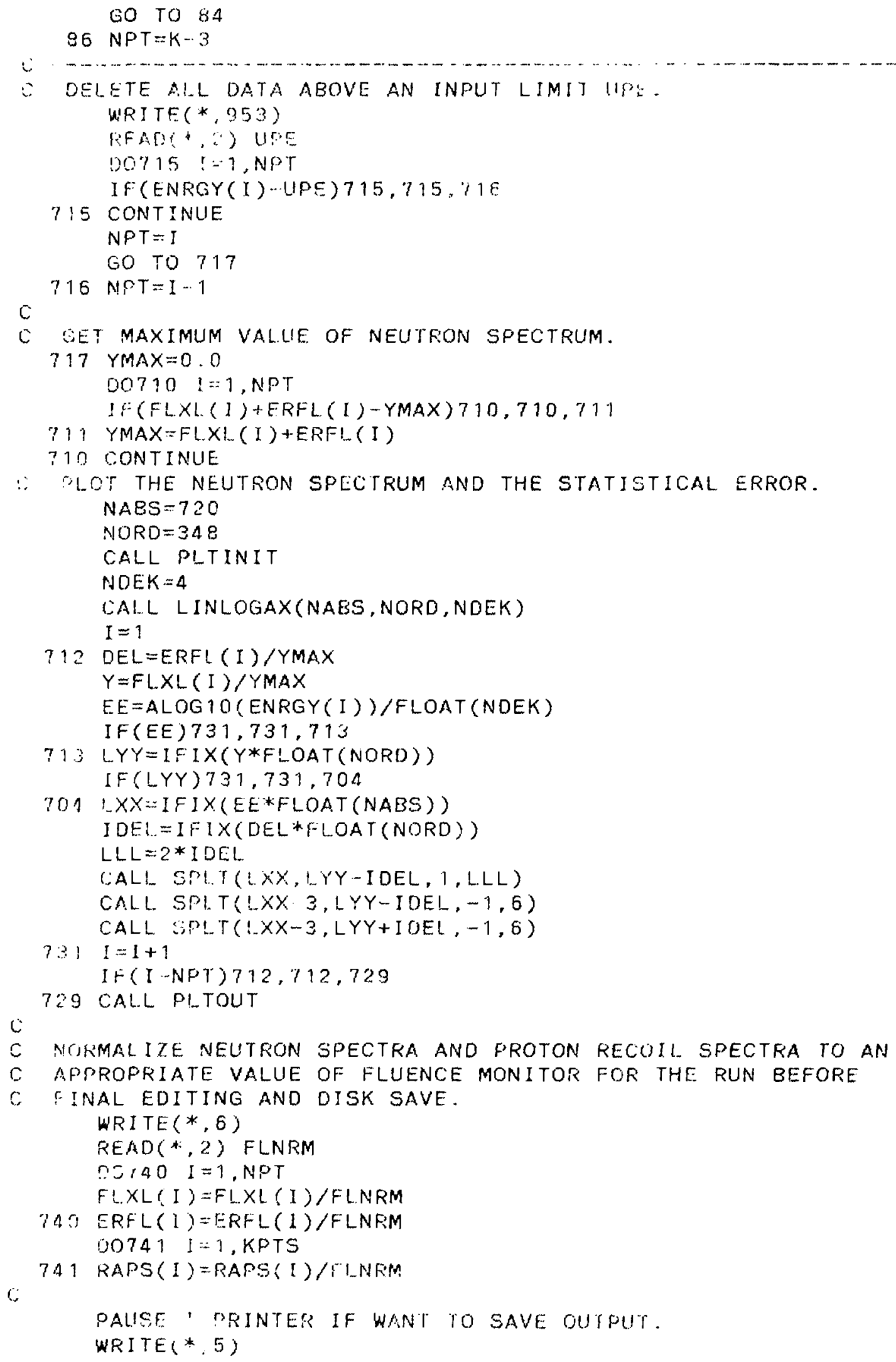




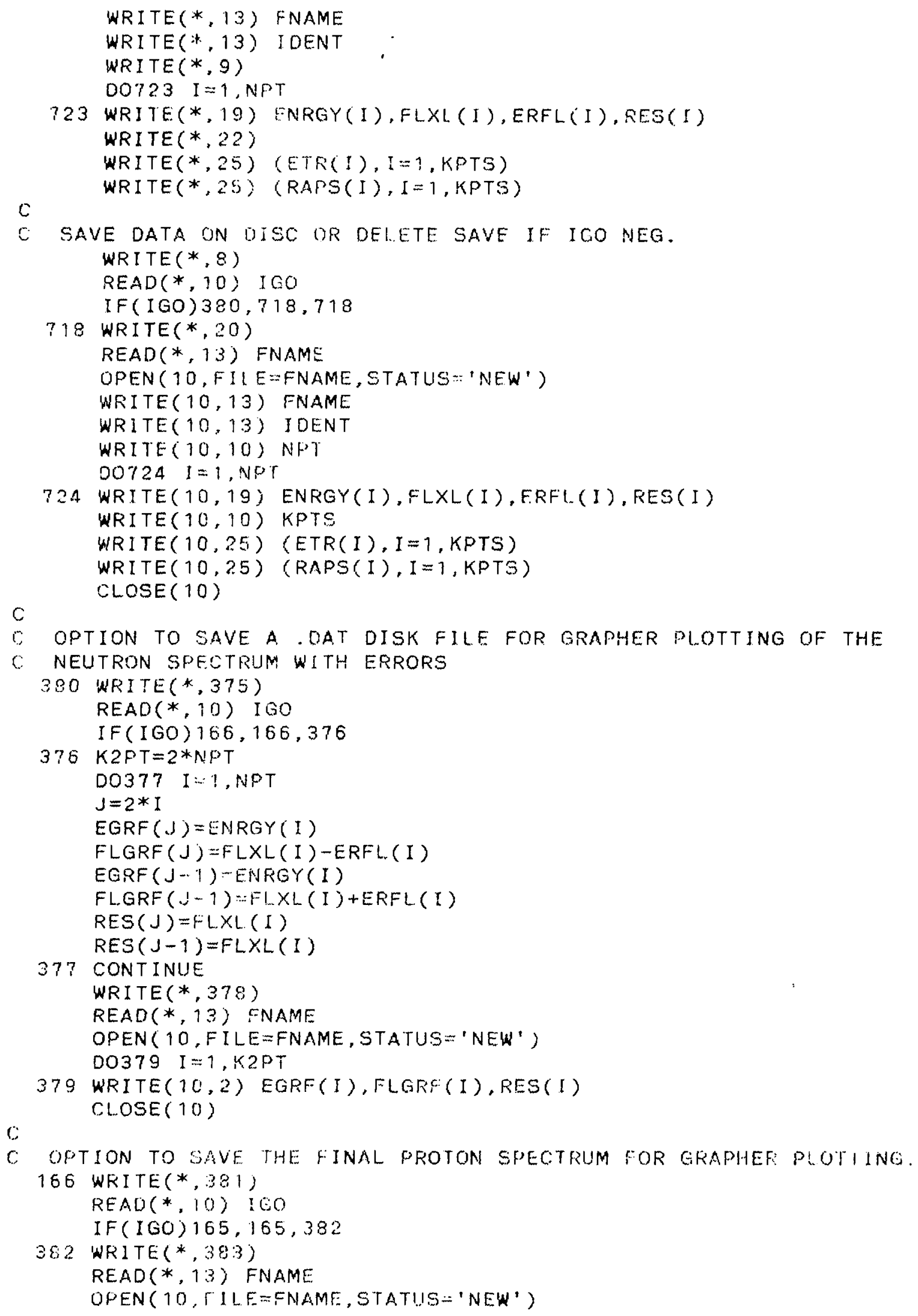




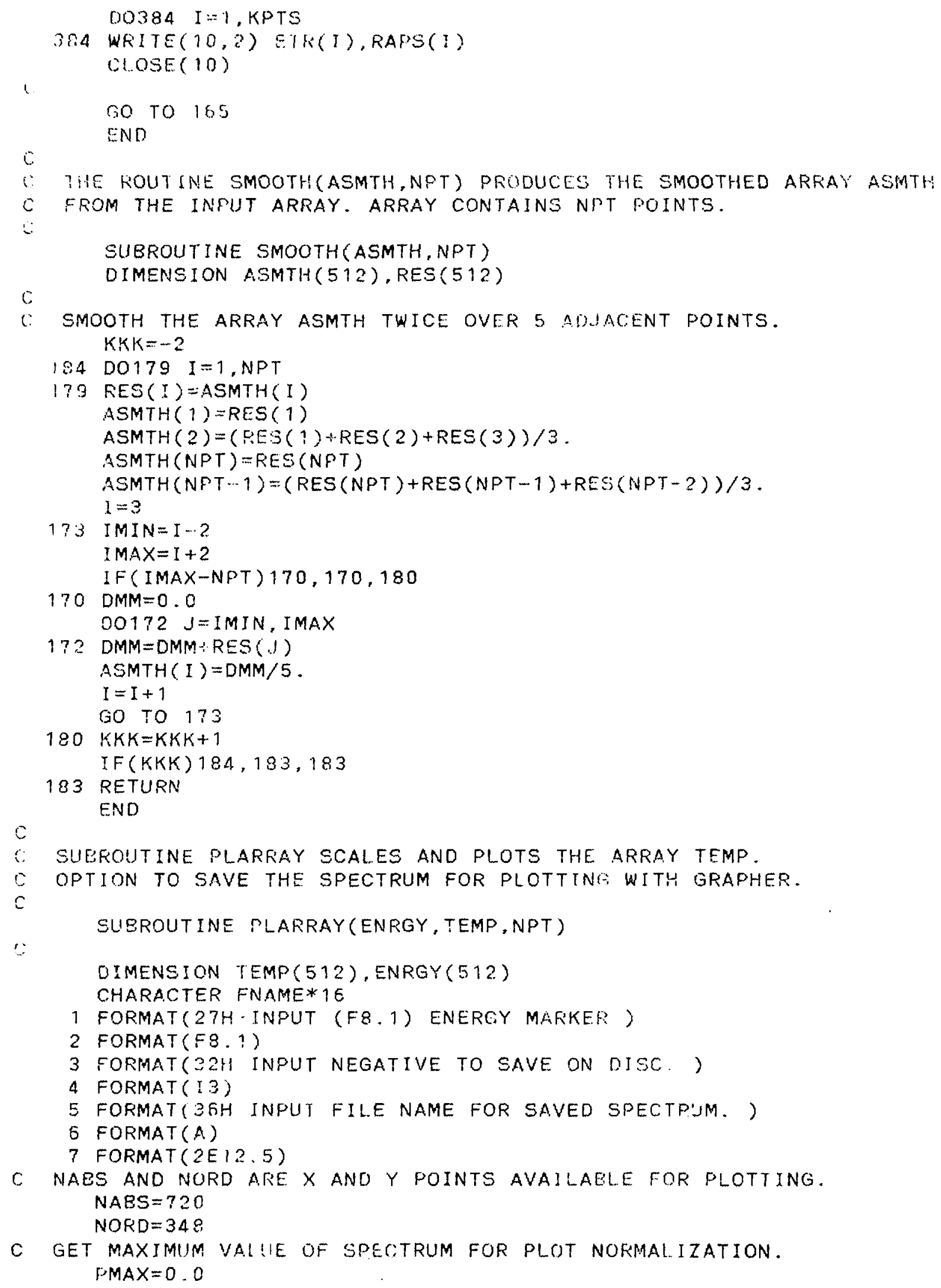




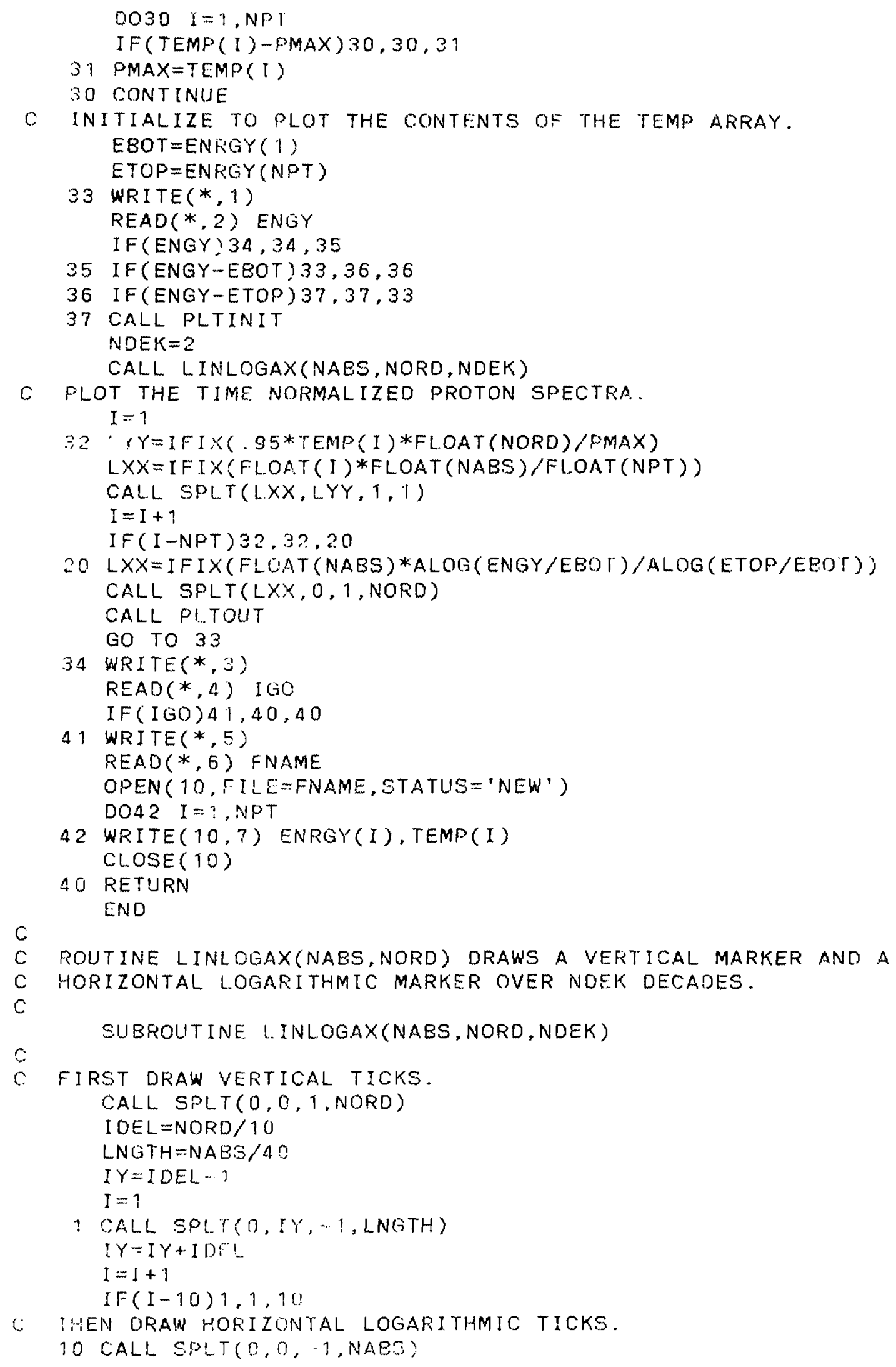

c 


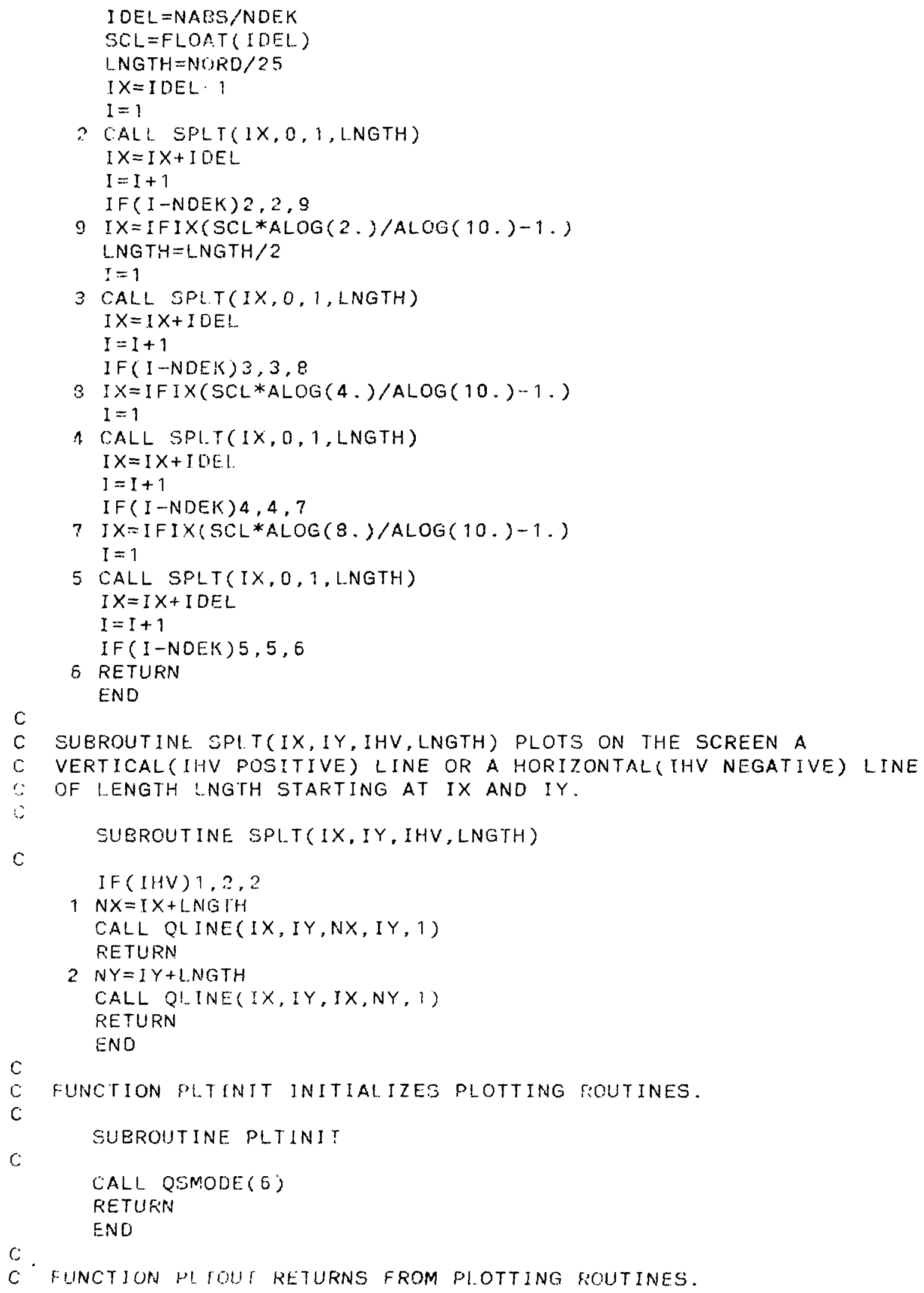


(.

CHARACIIK*! SHAK

OALL QINUHIYHAR.O\}

CALL QSMMOE(2)

RETURN

ENO 


\title{
DISTRIBUTION LIST FOR ANL/FPP-TM-239
}

\section{Internal:}
E. Bennett (15)
C. Baker
Y. Gohar
R. Mattas
R. McKnight
K. Porges

\author{
D. Smith \\ FPP Files (15) \\ ANL Contract File \\ ANL Libraries \\ ANL Patent Dept. \\ TIS Files ( 3 )
}

\section{External:}

DOE-OSTI, for distribution per UC-420 (37)

Manager, DOE-CH

M.A. Abdou, University of California, Los Angeles

T. Alsmiiler, Oak Ridge National Laboratory

E. Arthur, Los Alamos National Laboratory

M. Baht, BNL

J. Barnes, Oak Ridge National Laboratory

S. Berk, US Department of Energy

L. Berry, Oak Ridge National Laboratory

D. Berwald, Grumman

R. Brogli, EIR

F. Carre, Centre D'etudes Nucleaires de Saclay

G. Casini, Joint Research Centre

E. Cheng, GA Technologies

J. Clarke, US Department of Energy

R. Conn, University of California, Los Angeles

W. Davidson, Los Alamos National Laboratory

A. Davies, US Department of Energy

R. Dowling, US Department of Energy

Du Shi-Hua, Southwest Institute of Nuclear Physics and Chemistry

D. Dudziak, Los Alamos National Laboratory

D.V. Efremov, SRIEA

M. Embrechts, Rensselaer Polytechnic Institute

A.M. Epinatiev, IET

U. Fischer, KfK

C. Fu, Oak Ridge National Laboratory

T. Fuketa, JAERI

T. Gabriel, Oak Ridge National Laboratory

L. Green, Westinghouse Hanford Company

E. Greenspan, AEC

C. Gung, University of California, Los Angeles

G. Haas, US Department of Energy

L. Hansen, Lawrence Livermore National Laboratory

P. Hemming, US Department of Energy

N. Hertel, University of Texas

R.J. Howerton, Lawrence Livermore National Laboratory

J.H. Huang, Southwest Institute of Nuclear Physics and Chemistry T. Iguch 1 : University of Tokyo

Y. Ikeda, JAERI 


\section{Y. Ishiguro, JAERI}

Jian Wen-Mian, Southwest Institute of Nuclear Physics and Chemistry

I. Jun, University of California, Los Angeles

Y. Kaneko, JAERI

B.G. Karasev, SRIEA

W. Kastenberg, University of California, Los Angeles

G. Kessler, KfK

I. Kimura, Kyoto University

C. Konno, JAERI

T. Kosako, JAER I

L.P. Ku, Princeton Plasma Physics Laboratory

M. Kuchle, KfK

A. Kumar, University of California, Los Angeles

I.V. Kurchatov, IAE

R. Labauve, Los Alamos National Laboratory

I.V. Lavrent jev, SRIEA

J.D. Lee, Lawrence Livermore National Laboratory

Liu Cheng-An, Southwest Institute of Nuclear Physics and Chemistry

H. Maekawa, JAERI

K. Maki, JAERI

J. Maniscalco, TRW

F. Mann, Hanford Engineering Development Laboratory

D. Matthews, GA Technologies

C. Maynard, University of Wisconsin-Madison

R. McFarlane, Los Alamos National Laboratory

K. Miya, University of Tokyo

R. Moir, Lawrence Livermore National Laboratory

S. Mor $i$, JAERI

T. Mori, JAERI

D. Muir, Los Alamos National Laboratory

M. Nakagawa, JAERI

H. Naka jima, Kyushu University

T. Nakamura, JAERI

M. Nakazawa, University of Tokyo

Y. Oka, University of Tokyo

P.V.V. Orlov, IAE

Y. Oyama, JAERI

S. Pearlstein, BNL

R. Peelle, Oak Ridge National Laboratory

S. Pelloni, EIR

S.T. Perkins, Lawrence Livermore National Laboratory

G. Pomraning, University of California, Los Angeles

C. Ponti, Joint Research Centre

Qiu Li-Jian, Southwest Institute of Nuclear Physics and Chemistry

M. Ragheb, University of Illinois

G. Reffo, Joint Research Centre

M. Roberts, US Department of Energy

R. Roussin, RSIC

R. Santoro, Oak Ridge National Laboratory

M. Sawan, University of Wisconsin-Madison

J. Schifield, Oak Ridge National Laboratory

K. Schultz, GA Technologies

J.P. Schwartz, Centre D'etudes Nucleaires de Saclay

Y. Seki, JAERI 
H. Sekimoto, Tokyo Institute of Technology

G. Shatalov, IAE

Shen Ji-An, Southwest Institute of Nuclear Physics and Chemistry

K. Shin, Kyoto University

M. Song, University of California, Los Angeles

W. Stacey, Georgia Tech

D. Steiner, Rensselaer Polytechnic Institute

J. Stepanek, EIR

Yu. Strebkov, IET

K. Sugiyama, Tohoku University

K. Sumita, Osaka University

A. Takahashi, Osaka University

T. Tone, JAERI

K. Tsuda, JAERI

Y. Watanabe, University of California, Los Angeles

R. White, Oak Ridge National Laboratory

R. Whitley, TRW

G. Woodruff, University of Washington

S. Yamaguch $i$, JAERI

Y. Yamamoto, Osaka University

M. Yoshikanla, JAERI

K. Young, Princeton Plasma Physics Laboratory

P. Young, Los Alamos National Laboratory

M.Z. Youssef, University of California, Los Angeles 